\author{
UNIVERSIDADE DE SÃO PAULO \\ FACULDADE DE ECONOMIA, ADMINISTRAÇÃO E CONTABILIDADE \\ DEPARTAMENTO DE ADMINISTRAÇÃO \\ PROGRAMA DE PÓS-GRADUAÇÃO EM ADMINISTRAÇÃO
}

UM ESTUDO SOBRE A ELABORAÇÃO DE ROADMAPS TECNOLÓGICOS EM EMPRESAS BRASILEIRAS DE SOFTWARE

Adalton Masalu Ozaki

Orientador: Prof. Dr. Eduardo P. G. de Vasconcellos

SÃO PAULO 
Prof. Dr. Marco Antônio Zago Reitor da Universidade de São Paulo

Prof. Dr. Reinaldo Guerreiro

Diretor da Faculdade de Economia, Administração e Contabilidade

Prof. Dr. Roberto Sbragia

Chefe do Departamento de Administração

Prof. Dr. Lindolfo Galvão de Albuquerque Coordenador do Programa de Pós Graduação em Administração 


\section{UM ESTUDO SOBRE A ELABORAÇÃO DE ROADMAPS TECNOLÓGICOS EM EMPRESAS BRASILEIRAS DE SOFTWARE}

Tese apresentada ao Programa de Pós-Graduação em Administração da Faculdade de Economia, Administração e Contabilidade da Universidade de São Paulo como requisito para a obtenção do título de Doutor em Ciências.

Orientador: Prof. Dr. Eduardo P. G. de Vasconcellos

Versão Corrigida

(versão original disponível na Faculdade de Economia, Administração e Contabilidade)

\section{SÃo PAULO}


FICHA CATALOGRÁFICA

Elaborada pela Seção de Processamento Técnico do SBD/FEA/USP

Ozaki, Adalton Masalu

Um estudo sobre a elaboração de roadmaps tecnológicos

em empresas brasileiras de software / Adalton Masalu Ozaki. -- São Paulo, 2014.

$208 p$.

Tese (Doutorado) - Universidade de São Paulo, 2014.

Orientador: Eduardo Pinheiro Gondim de Vasconcellos.

1. Administração de inovações tecnológicas 2. Technological roadmap 3. Estratégia tecnológica 4. Setor de software I. Universidade de São Paulo. Faculdade de Economia, Administração e Contabilidade. II. Título.

CDD - 658.514 
Aos meu pais,

pelo amor e ensinamentos transmitidos.

Agora que tenho filhos, compreendo melhor o quanto se empenharam para me proporcionar o melhor, sem nada querer em troca. 


\section{AGRADECIMENTOS}

Ao prof. Dr. Eduardo Vasconcellos, pela dedicação ao longo de todo o doutorado. Seus ensinamentos vão muito além do conteúdo específico desta tese, pois pude aprender como ser um melhor professor, pesquisador e orientador.

Aos demais funcionários administrativos e professores da FEA-USP, pela dedicação a esta nobre atividade que é a educação.

Agradeço a todos os entrevistados, que deram todo o apoio necessário para pesquisa de campo, e ainda fizeram o favor de revisar os textos relativos às suas respectivas empresas a fim de identificar eventuais incorreções. Não vou citá-los nominalmente para evitar constrangimentos, mas fica aqui meu mais sincero obrigado. Atitudes como a de vocês contribuem em muito para o avanço do conhecimento e para construirmos um país melhor. Não poderia deixar de agradecer também ao Roberto Mayer, vice-presidente da Assespro, pelo apoio a esta e a outras pesquisas que fiz ao longo do doutorado.

Aos colegas, professores, administrativos e alunos, da Federal (IFSP), FIAP e FIA pelo apoio para realização desta pesquisa e pela confiança no meu trabalho. Aos colegas e amigos também alunos da FEA-USP. Muitas idéias aqui contidas foram discutidas e debatidas antes com muitos de vocês.

Por fim, agradeço aos meus familiares, em especial à minha esposa, Adriana, e aos meus filhos, Akio e Yoshio. Vocês são a fonte de minha inspiração e a razão de minha vida. 


\section{RESUMO}

O setor de software é muito dinâmico e competitivo, o que obriga as empresas a constantemente se transformar, seja pela incorporação de novas tecnologias, pela implementação de inovações em produtos e serviços, ou pela exploração de novos modelos de negócio. Neste cenário, empresas de software, para se manterem competitivas, precisam desenvolver rotinas de inteligência tecnológica (IT) que permitam coletar, analisar e tomar decisões sobre oportunidades e ameaças tecnológicas. Empresas de diversos setores têm adotado uma técnica de IT denominada roadmap tecnológico, que sucintamente representa uma visão de futuro que identifica a rota tecnológica, ou seja, as tecnologias a serem adotadas no futuro, associadas aos produtos a serem desenvolvidos e aos mercados a serem explorados. Neste contexto, esta tese procurou responder à questão "Como empresas brasileiras de software realizam atividades de elaboração de roadmap tecnológico?". Com base na literatura sobre roadmaps foi possível elaborar um modelo conceitual com as principais características identificadas em termos de objetivos, fontes de informação, barreiras, processo/conteúdo e benefícios dos roadmaps. Foi adotada a metodologia de estudos de casos múltiplos, com amostragem intencional, sendo selecionadas duas empresas de pequeno, duas de médio e duas de grande porte. $\mathrm{O}$ modelo conceitual elaborado para esta tese se mostrou muito útil, pois permitiu descrever os casos analisando sempre as mesmas dimensões, facilitando a comparação. Foi possível verificar, por exemplo, as características da atividade de elaboração de roadmaps importantes para todas as empresas estudadas, bem como aquelas importantes apenas para empresas de grande porte. Os casos evidenciam que há duas importantes influências do porte da empresa sobre a atividade de elaboração de roadmaps. Primeiro, a complexidade das interações internas e externas durante todo o processo é maior nas grandes empresas. Segundo, a organização do processo também é mais elaborada nas grandes empresas. Adicionalmente, este estudo permitiu identificar particularidades do setor de software com relação à elaboração de roadmaps: a) Foco no curto prazo - as empresas pesquisadas possuem foco no curto prazo, em geral trabalhando nas decisões tecnológicas e de funcionalidades para a próxima versão de seus produtos; e, b) Gestão de códigos do software - a estratégia da empresa sobre códigos ativos (ou seja, vigentes em clientes) a serem mantidos está relacionada ao roadmap e pode limitar o potencial de crescimento da firma. Visando cobrir um hiato existente entre a prática das empresas estudadas (foco em curto prazo) e a literatura (foco em longo prazo), é apresentada nesta tese uma proposta de metodologia para elaboração de roadmap tecnológico de longo prazo para empresas de software. Este estudo traz contribuições práticas e teóricas. Empresas de software, e eventualmente de setores correlatos, podem se beneficiar deste estudo por permitir comparar sua atividade de elaboração de roadmaps com a das empresas estudadas, bem como identificar pontos para aprimoramento à medida que planeja crescer. Do ponto de vista acadêmico, este estudo oferece diversas contribuições. Primeiramente, o modelo conceitual adotado nesta tese pode ser utilizado em outros estudos sobre roadmaps, inclusive em outros setores. Os estudos de caso evidenciam como a atividade de elaboração de roadmaps se diferencia em empresas de diferentes portes. Por fim, foram identificadas particularidades das empresas de software na atividade de elaboração de roadmaps.

Palavras-chave: Administração de inovações tecnológicas. Technological roadmap. Estratégia tecnológica. Setor de software. 


\begin{abstract}
The software industry is highly dynamic and competitive. Companies competing in this industry must continuously transform themselves, through the incorporation of new technologies, innovation in products and services, or the exploration of new business models. Given this scenario, in order to remain competitive, software companies should develop technological intelligence (TI) routines to enable them to collect, analyse and make decisions regarding technological opportunities and threats. Companies from different industries are adopting a TI technique named technological roadmapping, which succinctly presents a future vision that identifies a technological path, that is, the technologies to be adopted in the future, together with the products to be developed and markets to be explored. Against this backdrop, this thesis addresses the question of "How do Brazilian software companies carry out technological roadmapping activities?" Based on the literature on roadmaps it has been possible to develop a conceptual model with the main characteristics in terms of objectives, sources of information, barriers, components and benefits of roadmaps. A multiple case studies methodology was adopted, with an intentional sample. Two small, two medium and two large companies were selected. The conceptual model developed for this thesis proved effective, as it enabled the description of the cases while always analysing the same dimensions, which facilitated the comparison. It was possible to verify, for example, the characteristics of the roadmapping activity important for all the companies studied, as well as those important only for large companies. The cases show that there are two important influences on roadmapping activities stemming from the size of the firm. First, the complexity of internal and external interactions throughout the process is greater for large companies. Second, the organization of the process is also more developed in large companies. Furthermore, this study identified some characteristics unique to the software industry with regards to the development of roadmaps: a) Focus on the short term - the companies surveyed have focused on the short-term, typically working with technology decisions and features for the next version of products; and, $b$ ) Management of software codes - the company's strategy for active codes (i.e. currently used with clients) to be maintained is related to the roadmap and may limit the potential growth of the firm. With a view to bridging a gap that exists between the practice of the companies studied (focus on short-term) and literature on the subject (focus on long-term), a proposed methodology for developing a longterm technological roadmap for software companies is presented in this thesis. This study presents theoretical and practical contributions. Software companies, and possibly related industries, can benefit from this study by comparing their roadmapping activities to those from the companies studied, and identifying points for improvement as they plan to grow. From an academic perspective, this study offers several contributions. First, the conceptual model adopted in this thesis can be used in other roadmap studies, including in other sectors. The case studies show how the roadmapping activities differ in firms of different sizes. Finally, characteristics specifically related to software companies in the roadmapping activity have been identified.
\end{abstract}

Key-words: Technological innovation management. Technological roadmap. Technological strategy. Software industry. 


\section{SUMÁRIO}

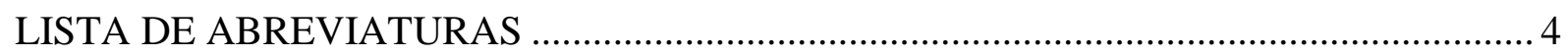

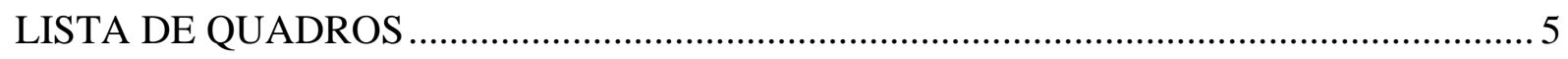

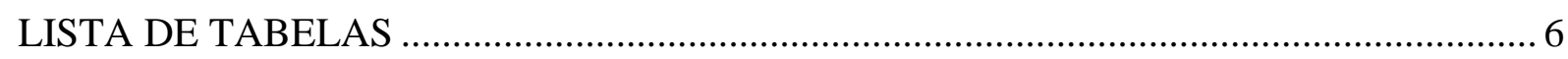

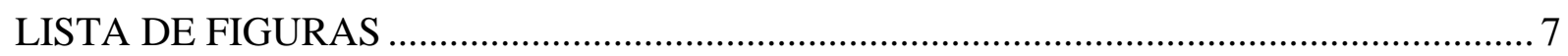

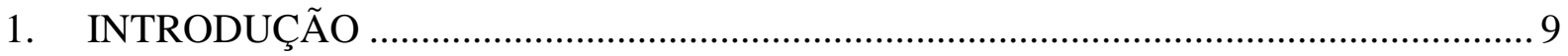

1.1. Contextualização da Situação Problema.................................................................... 9

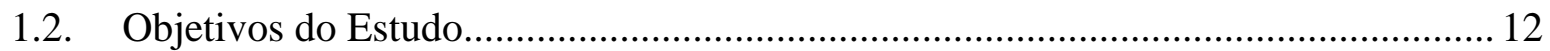

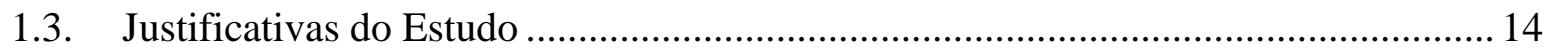

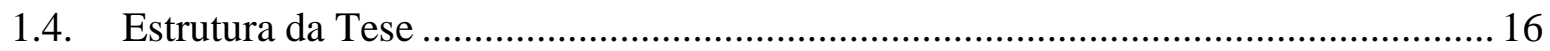

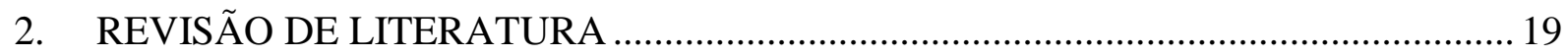

2.1. Visão Estratégica do Escaneamento do Ambiente .................................................. 19

2.1.1. Visão da Firma Baseada em Recursos ........................................................... 19

2.1.2. Capacidades Dinâmicas................................................................................ 22

2.1.3. A Importância do Escaneamento do Ambiente ................................................. 24

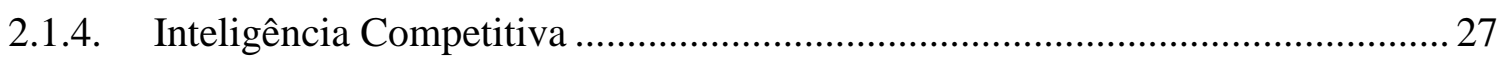

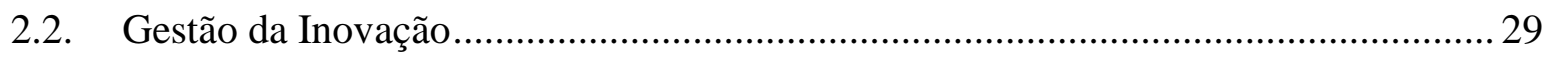

2.2.1. Conceito de Inovação e Seus Diferentes Graus ............................................... 29

2.2.2. A Busca por Oportunidades e Ameaças Tecnológicas....................................... 32

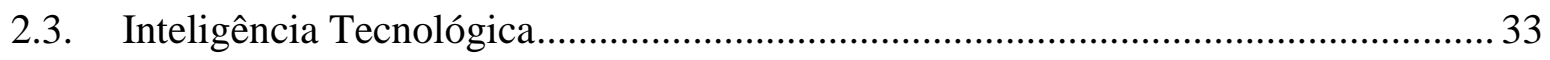

2.3.1. Conceitos e Modelos de Inteligência Tecnológica............................................. 33

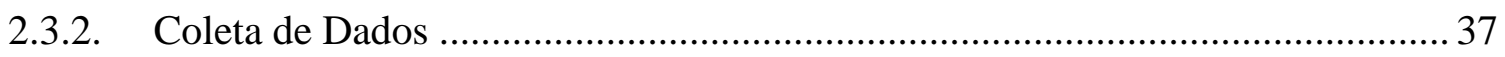

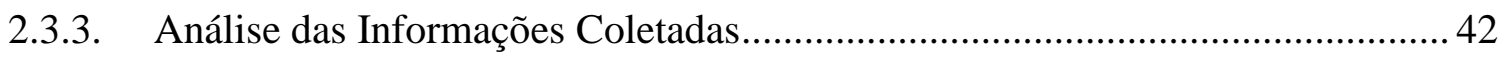

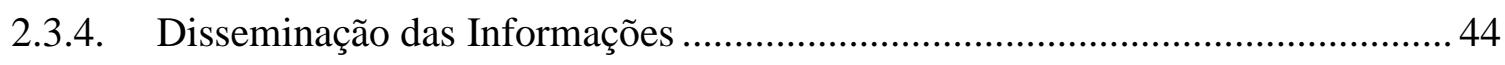

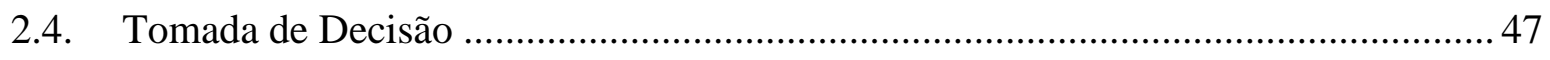

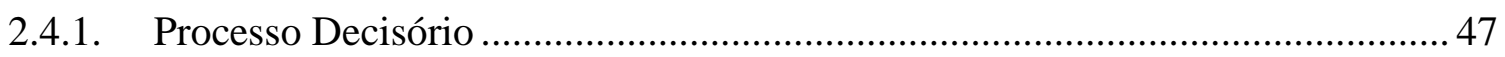

2.4.2. Métodos Multicritério para Tomada de Decisão ............................................. 50

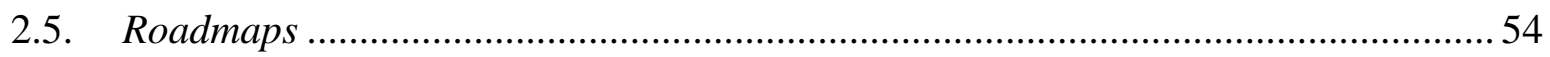

2.5.1. Conceituação e Objetivos do Roadmap ........................................................... 54

2.5.2. Formato e Conteúdo dos Roadmaps................................................................ 57

2.5.3. O Processo de Elaboração de Roadmaps ........................................................... 62

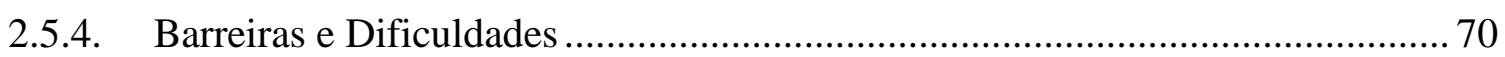

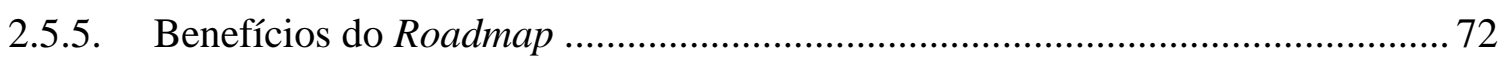

2.6. A Indústria de Software e a Importância das Plataformas ......................................... 73 
2.6.1. Características Competitivas e de Inovação …................................................... 74

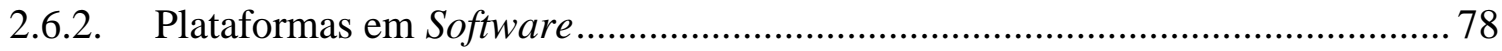

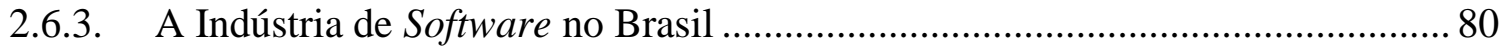

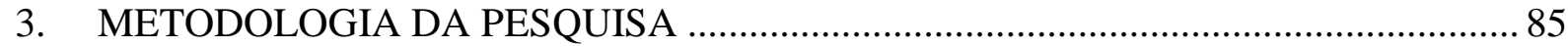

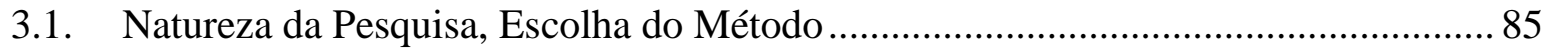

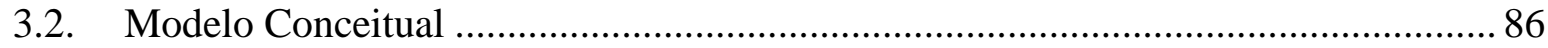

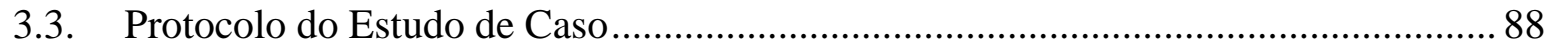

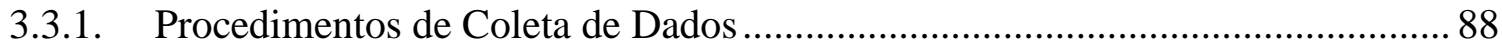

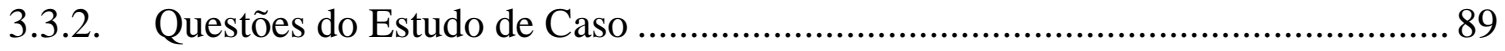

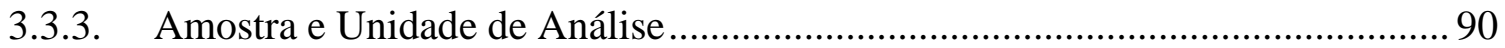

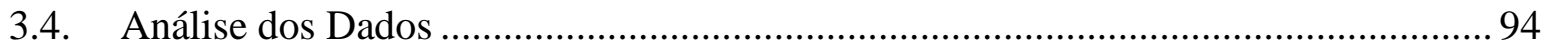

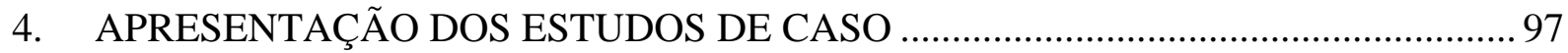

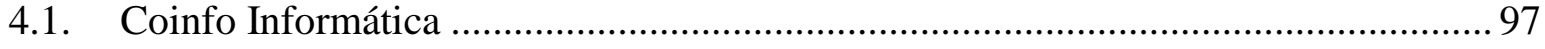

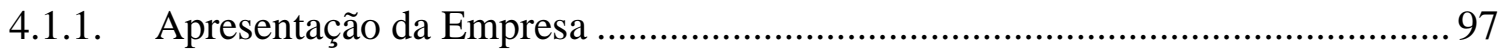

4.1.2. Atividade de Elaboração do Roadmap .................................................................. 98

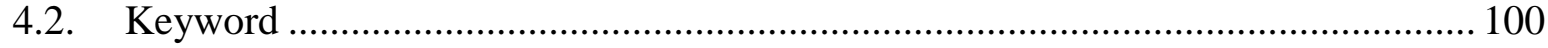

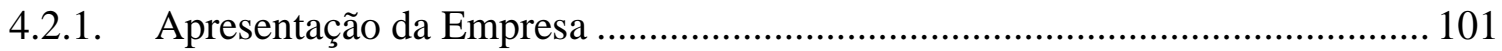

4.2.2. Atividade de Elaboração do Roadmap ............................................................. 101

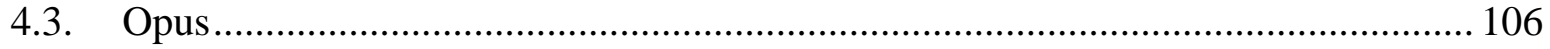

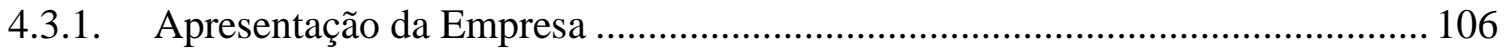

4.3.2. $\quad$ Atividade de Elaboração do Roadmap ............................................................. 108

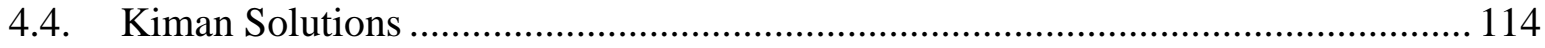

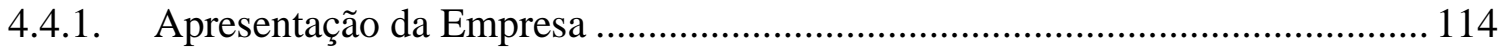

4.4.2. $\quad$ Atividade de Elaboração do Roadmap ............................................................ 115

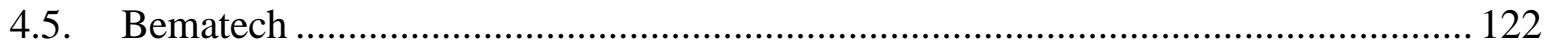

4.5.1. Apresentação da Empresa ............................................................................. 122

4.5.2. Atividade de Elaboração do Roadmap ............................................................ 124

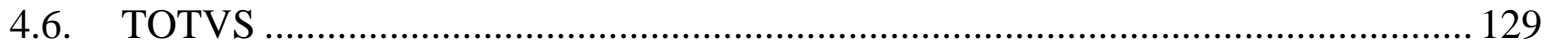

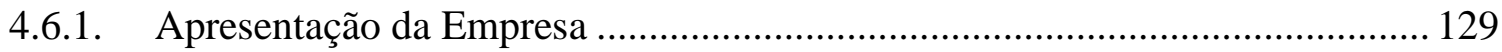

4.6.2. Atividade de Elaboração do Roadmap ............................................................ 131

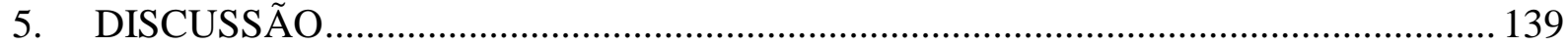

5.1. Influência do Porte da Empresa Sobre a Atividade de Elaboração de Roadmaps

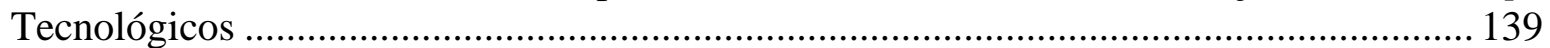

5.1.1. Comparação das Características Encontradas nos Casos ................................. 139

5.1.2. Complexidade das Interações Internas e Externas .......................................... 148 
5.1.3. Organização do Processo ............................................................................. 152

5.2. Particularidades da Elaboração de Roadmap no Setor de Software ........................ 158

5.2.1. Foco no Curto Prazo..................................................................................... 158

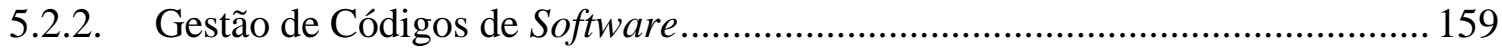

5.3. Proposta de Uma Metodologia Para Elaboração de Roadmap Tecnológico de Longo

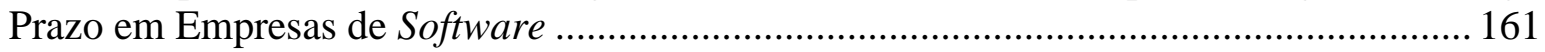

5.3.1. Planejamento do Processo de Elaboração de RLTP........................................... 164

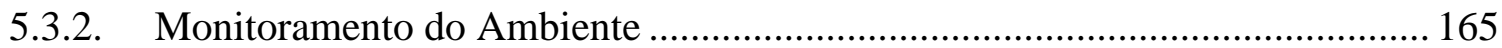

5.3.3. Análise das Tendências Tecnológicas e de Mercado ......................................... 168

5.3.4. Priorização das Tendências Tecnológicas......................................................... 172

5.3.5. Desenho do Roadmap Tecnológico de Longo Prazo ......................................... 174

5.3.6. Avaliação do Processo ................................................................................... 177

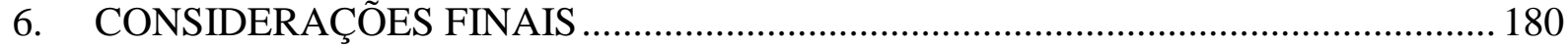

6.1. Limitações do Estudo ……………………………………………………..... 183

6.2. Sugestões para Estudos Futuros ……………………………………………. 185

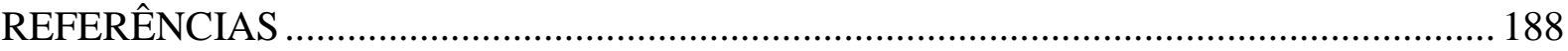

ANEXO A - ROTEIRO DE ENTREVISTA.................................................................. 198 


\section{LISTA DE ABREVIATURAS}

\begin{tabular}{|c|c|}
\hline AHP & Analytical Hyerarchy Process \\
\hline CIS & Community Innovation Survey \\
\hline CMM & Capability Maturity Model \\
\hline CNPJ & Cadastro Nacional de Pessoas Jurídicas \\
\hline ERP & Enterprise Resource Planning \\
\hline EUROSTAT & Statistical Office of the European Communities \\
\hline IBGE & Instituto Brasileiro de Geografia e Estatística \\
\hline IBSS & Indústria Brasileira de Software e Serviços \\
\hline IC & Inteligência Competitiva \\
\hline IT & Inteligência Tecnológica \\
\hline $\mathrm{KBV}$ & Knowledge Based View \\
\hline $\mathrm{P} \& \mathrm{D}$ & Pesquisa e Desenvolvimento \\
\hline PINTEC & Pesquisa de Inovação Tecnológica \\
\hline RBV & Resource-Based View \\
\hline SAAS & Software-as-a-Service \\
\hline SCIP & Strategic and Competitive Intelligence Professionals \\
\hline SMART & Simple Multiattribute Rating Technique \\
\hline SOFTEX & Associação para Promoção da Excelência do Software Brasileiro \\
\hline TDE & Technology Development Envelope \\
\hline TI & Tecnologia da Informação \\
\hline
\end{tabular}




\section{LISTA DE QUADROS}

Quadro 1 - Ambientes para escaneamento/monitoramento ................................................. 39

Quadro 2 - Intensidade de uso de diferentes fontes de informação ....................................... 41

Quadro 3 - Intensidade do uso de métodos de inteligência tecnológica segundo Lichtenthaler (2004) 43

Quadro 4 - Elementos da habilidade de tomada de decisão segundo Keeney ......................... 48

Quadro 5 - Matriz para decisão segundo o método SMART .................................................. 52

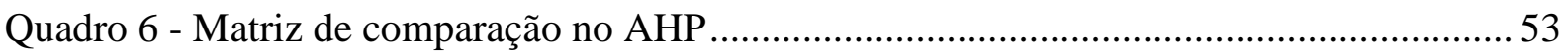

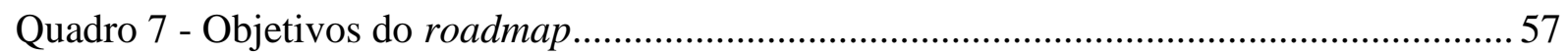

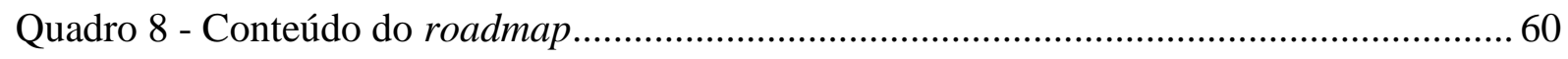

Quadro 9 - Exemplo de matriz de decisão para escolha entre diferentes alternativas

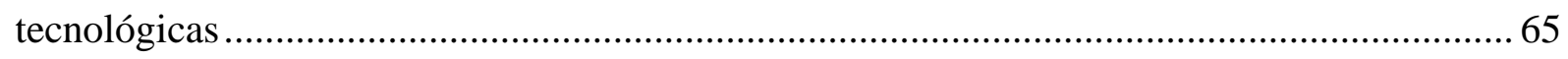

Quadro 10 - Etapas do processo para elaboração de roadmaps .............................................. 69

Quadro 11 - Barreiras e dificuldades da atividade de elaboração de roadmaps ...................... 71

Quadro 12 - Benefícios da elaboração de roadmaps ............................................................... 73

Quadro 13 - Diferenças entre software pacote e software por encomenda............................. 75

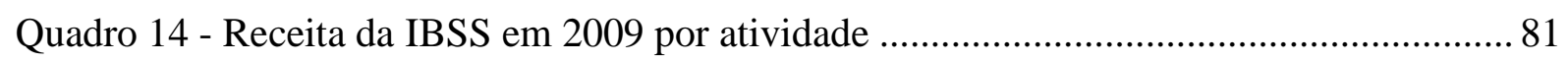

Quadro 15 - Distribuição das empresas da IBSS com 5 ou mais pessoas ocupadas ................. 82

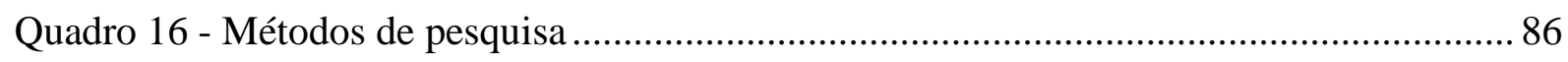

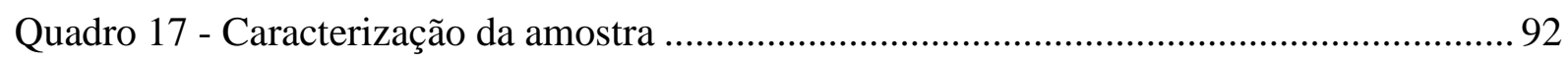

Quadro 18 - Evolução tecnológica dos softwares da Keyword ........................................... 102

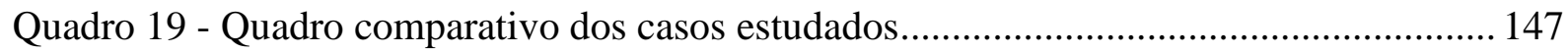




\section{LISTA DE TABELAS}

Tabela 1 - Objetivos do roadmap - comparação entre as empresas ..................................... 140

Tabela 2 - Fontes de informação - comparação entre as empresas ....................................... 141

Tabela 3 - Componentes do roadmap - comparação entre as empresas ............................... 142

Tabela 4 - Barreiras / dificuldades do roadmap - comparação entre as empresas ................. 143

Tabela 5 - Benefícios do roadmap - comparação entre as empresas.................................... 144 


\section{LISTA DE FIGURAS}

Figura 1 - Processo geral de escaneamento, interpretação e aprendizagem............................ 25

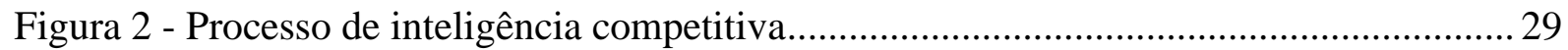

Figura 3 - Funil de desenvolvimento segundo Clark e Weelwright....................................... 32

Figura 4 - Processo de inteligência tecnológica segundo Norling et al. .................................. 34

Figura 5 - Sistema de inteligência tecnológica................................................................... 36

Figura 6 - Inteligência tecnológica segundo Schuh e Grawatsch.......................................... 37

Figura 7 - Modos de busca de informação segundo Kerr et al ................................................ 38

Figura 8 - Modelo para identificar oportunidades e ameaças tecnológicas ............................. 39

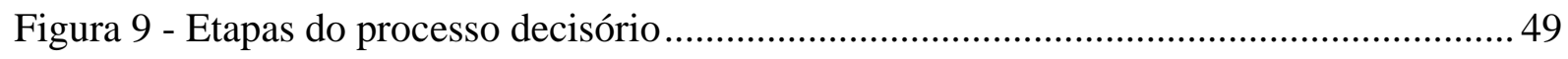

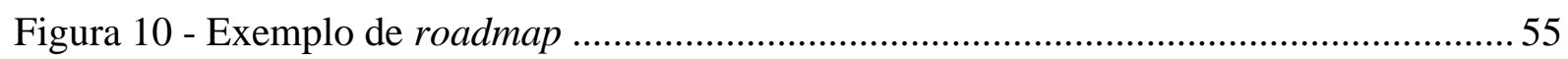

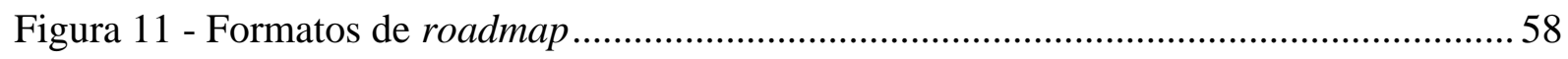

Figura 12 - Modelo de avaliação hierárquica proposta por Gerdsri e Kocaoglu ..................... 66

Figura 13 - Framework para estudo de roadmapping para produto de software ...................... 68

Figura 14 - A diagonal volume-variedade do setor de software …........................................ 74

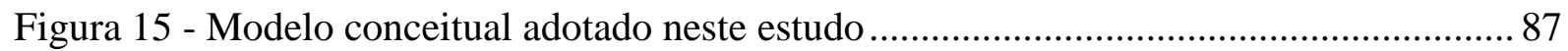

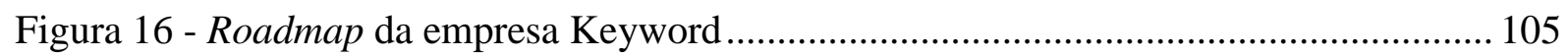

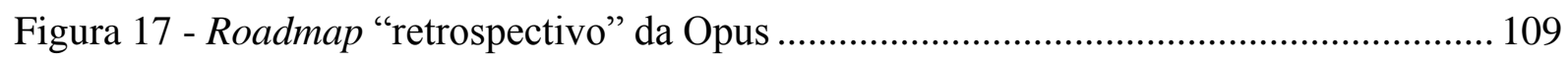

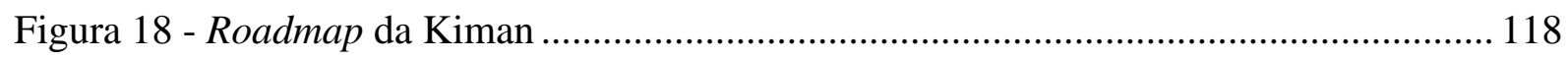

Figura 19 - Roadmap da solução Bematech Chef ............................................................... 125

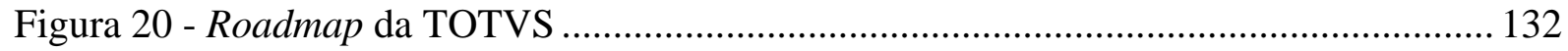

Figura 21 - Características da elaboração do roadmap em empresas de software .................. 145

Figura 22 - Interações para elaboração de roadmaps na Coinfo, Keyword e Opus................ 148

Figura 23 - Interações para elaboração de roadmaps na Kiman .......................................... 150

Figura 24 - Interações para elaboração de roadmaps na Bematech ..................................... 151

Figura 25 - Interações para elaboração do roadmap na TOTVS ........................................ 152

Figura 26 - Processo de elaboração de roadmaps na Bematech .......................................... 154

Figura 27 - Processo de elaboração de roadmap na Kiman................................................. 155

Figura 28 - Processo de elaboração de roadmap da TOTVS ................................................. 156

Figura 29 - Versões ativas de código do software e impacto no roadmap ............................ 160

Figura 30 - Proposta de metodologia para elaboração de RTLP........................................... 163

Figura 31 - Formato final de roadmap tecnológico de longo prazo para software ................. 176 


\section{INTRODUÇÃO}

\subsection{Contextualização da Situação Problema}

Em setores que apresentam rápida e constante mudança, as empresas precisam desenvolver capacidades dinâmicas para se manterem competitivas (TEECE et al, 1997; EISENHARDT; MARTIN, 2000). As capacidades dinâmicas consistem na habilidade que a empresa possui de integrar, criar e reconfigurar competências internas e externas para fazer frente ao ambiente em mudança (TEECE et al, 1997). Esta abordagem tem origens na visão da firma baseada em recursos (BARNEY, 1991; WERNERFELT, 1984) e em conhecimento (KOGUT; ZANDER, 1992; GRANT, 1996). Outro fundamento importante é o reconhecimento de que a capacidade gerencial limita o crescimento da firma (PENROSE, 1959). Neste sentido, as empresas desenvolvem capacidades que precisam evoluir conforme a firma cresce, e o ambiente seleciona as empresas com maior capacidade de adaptação às mudanças (PENROSE, 1959; NELSON; WINTER, 1982). No âmbito organizacional, capacidade pode ser entendida como a habilidade de entregar recursos por meio de processos (AMIT; SCHOEMAKER, 1993). Segundo Davenport (1993) um processo é um conjunto de atividades estruturadas e desenhadas para entregar um resultado a um cliente ou mercado. Na revisão de literatura serão discutidas com mais profundidade as abordagens teóricas da visão da firma baseada em recursos e das capacidades dinâmicas.

O setor de tecnologia da informação (TI) ilustra bem essa necessidade das empresas se transformarem para aproveitarem novas oportunidades e se manterem competitivas. Como exemplo de empresa que fracassou devido às dificuldades em se transformar, podemos citar a PALM, fabricante de PDAs (Personal Data Assistants ou Assistentes de Dados Pessoais). A PALM foi uma companhia muito admirada pela capacidade de inovação e pelo rápido crescimento na década de 1990. Porém, não conseguiu acompanhar o ritmo de evolução tecnológica e lançar telefones inteligentes (smartphones) ou tablets que pudessem ser competitivos ao longo dos anos 2000. Acabou sendo adquirida pela HP em 2010, que chegou a lançar um tablet com base no sistema operacional da PALM, mas que, devido ao insucesso, foi descontinuado em 2011. 
Dentro do setor de TI, o setor de software possui grande importância. Um número cada vez maior de empresas em diversos setores depende intensivamente de software para dar suporte às suas operações (CARMEL, 1995, 1997; EVANS et al, 2005; SAWYER, 2000). Do ponto de vista econômico, é um dos cinco maiores setores exportadores dos EUA (CARMEL, 1995). No Brasil, o setor de software engloba mais de 64 mil empresas com faturamento da ordem de R \$ 56,5 bilhões em 2009, com projeções de atingir mais de R \$ 83 bilhões em 2014 (SOFTEX, 2012). É um setor bastante competitivo e que exige das empresas uma constante capacidade de transformação devido à evolução tecnológica.

Uma característica competitiva importante desta indústria é que recorrentemente surgem tecnologias de ruptura (CHRISTENSEN, 1997) que muitas vezes exigem que uma empresa crie novos softwares, recodifique os existentes, ou até mesmo reveja seu modelo de negócios para aproveitar novas oportunidades (CHESBROUGH; ROSEMBLOOM, 2002; ZOTT; AMIT, 2010). A indústria da computação evoluiu de computadores de grande porte (mainframes) na década de 1960, para computadores de médio porte na década de 1970/80 e computadores pessoais (PCs - personal computers) a partir da década de 90. Os primeiros softwares, voltados para computadores de grande porte, eram desenvolvidos em linguagens como COBOL, sendo muito comum o fato de serem executados em lote (batch) e não em tempo real. Ou seja, os dados só eram atualizados, por exemplo, ao final do dia. Os computadores de médio porte e os PCs trouxeram vantagens como o processamento em tempo real e o processamento dividido entre o servidor e as estações clientes, modelo também conhecido como cliente-servidor. Primeiramente as aplicações eram desenvolvidas no chamado ambiente caracter (ambiente dos sistemas operacionais DOS e Unix, por exemplo, nos quais as informações eram apresentadas apenas em um número limitado de linhas e colunas na tela). Mas com a ascensão do sistema operacional Windows a partir da década de 90, muitas empresas de software precisaram migrar suas aplicações para ambiente gráfico (BRESNAHAN; GREENSTEIN，1999; CHRISTENSEN, 1997). Posteriormente com o advento da Internet, principalmente a partir da segunda metade da década de 90, muitas empresas de software se depararam novamente com a necessidade de reescreverem seus sistemas para serem operados via Web. Mais recentemente está se difundindo o conceito de computação em nuvem (cloud computing), no qual a empresa cliente não paga mais uma licença de software, mas uma taxa de serviço mensal para utilizar aplicações por meio da Internet (BENLIAN et al, 2009; SÄÄKSJÄRVI et al, 2005; VOUK, 2008). O cliente não se 
preocupa mais com a infraestrutura computacional, pois as aplicações são hospedadas e mantidas pelo fornecedor. Na computação em nuvem, as empresas oferecem seu software como serviço (SAAS - software-as-a-service), e o código do software precisa ser desenvolvido para ser utilizado simultaneamente por múltiplos clientes, de diferentes nacionalidades e localidades.

Em várias das mudanças ocorridas no setor, as empresas de software precisaram também decidir sobre sua plataforma de desenvolvimento (MEYER; SELINGER, 1998; CUSUMANO; GAWER, 2002). A plataforma de desenvolvimento corresponde a um conjunto de subsistemas e interfaces que formam uma estrutura comum, sobre a qual a empresa de software desenvolve uma linha de produtos (MEYER; SELIGER, 1998). No setor de software, a maior parte das empresas que desenvolvem aplicações comerciais não desenvolvem suas próprias plataformas, salvo raras exceções (por exemplo, a empresa SAP adota uma plataforma própria de desenvolvimento). Geralmente, as empresas adotam plataformas de desenvolvimento fornecidas por grandes empresas tal como a plataforma .Net (da empresa Microsoft), Java (desenvolvida inicialmente pela empresa Sun, que foi adquirida pela Oracle), entre outras. Além deste primeiro nível básico de plataforma, muitas vezes a empresa agrega tecnologias complementares ou componentes de arquitetura que podem, por exemplo, permitir que outras empresas parceiras ou até mesmo clientes possam modificar várias características no software sem necessidade de programação.

A decisão da adoção/construção de uma plataforma de desenvolvimento é importante, pois pode conferir à empresa vantagens como maior agilidade de desenvolvimento, facilidade de manutenção, confiabilidade e segurança, entre outras características. Normalmente não é uma decisão facilmente reversível. Muitas vezes uma empresa fica anos desenvolvendo aplicações sobre uma determinada plataforma. Porém, devido à natureza dinâmica do setor, de tempos em tempos, as empresas se defrontam novamente com este problema decisório, seja para migrar aplicações já existentes, seja para desenvolver novas aplicações ou até novos mercados.

Em suma, empresas de software que queiram se manter competitivas e atualizadas precisam constantemente reescrever ou criar novas aplicações para aproveitar as oportunidades e evitar que seu portfólio de produtos fique obsoleto. Porém, este é um processo demorado e que 
requer o aprendizado de novas competências, nem sempre dominadas pela equipe existente (PRAHALAD; HAMEL, 1990). Neste contexto, torna-se importante para a empresa desenvolver uma capacidade denominada de inteligência tecnológica (IT). A IT compreende processos de coleta, análise e disseminação de informações tecnológicas para tomada de decisão no momento certo (LICHTENTHALER, 2004; VASCONCELLOS; DINIZ, 2000; NORLING et al, 2000; KERR et al, 2006). Não necessariamente a empresa precisar ter uma área de IT, nem saber conscientemente que as práticas que está adotando correspondem a IT (LICHTENTHALER, 2004). Empresas que desenvolveram melhor sua capacidade de previsão ou criação de visão podem antever consequências e riscos de adotar determinada tecnologia, tendo em vista particularidades de seus recursos internos e do mercado específico de atuação.

Existem inúmeras técnicas de análise relacionadas a IT, e seria inviável estudar em profundidade todas elas. Assim sendo, esta tese irá se concentrar especificamente no estudo da elaboração de roadmaps tecnológicos. Sucintamente, o roadmap tecnológico representa um "mapa de estrada", que procura relacionar a evolução futura da tecnologia, com potenciais produtos que irão adotá-las, e os mercados que serão atingidos (GROENVELD, 1997; PHAAL et al, 2004). Ao longo do texto, adotaremos o termo roadmap como sinônimo de roadmap tecnológico, para fins de simplificação. Mais do que o mapa em si, a própria atividade de elaboração de roadmaps (também chamada de roadmapping) é uma grande oportunidade de aprendizado para a empresa, pois envolve previsão tecnológica e decisões sobre rotas que a empresa pretende seguir. O dinamismo da indústria de software e a constante necessidade de evolução dos produtos e de incorporação de novas tecnologias torna ainda mais importante a atividade de elaboração de roadmaps tecnológicos para empresas deste setor.

Neste contexto, foi realizada uma pesquisa que procurou responder à seguinte questão: Como empresas brasileiras de software realizam atividades de elaboração de roadmap tecnológico?

\subsection{Objetivos do Estudo}


Este estudo teve como objetivo geral identificar como empresas brasileiras de software realizam atividades de elaboração de roadmap tecnológico. Não é uma premissa desta tese que necessariamente as empresas realizem tais atividades, sendo que investigar se a empresa elabora ou não roadmap tecnológico também é um objetivo deste estudo. Como será melhor explorado na seção de Metodologia, foi adotado o método de estudo de casos múltiplos para investigar esta atividade em seis empresas, sendo duas de pequeno porte, duas de médio porte e duas de grande porte.

A fim de nortear o trabalho de pesquisa, foram estabelecidos os seguintes objetivos específicos (OE):

1) Identificar as principais características da atividade de elaboração de roadmaps tecnológicos em empresas brasileiras de software. É parte integrante deste objetivo primeiro verificar se a empresa elabora roadmaps tecnológicos. Com base na revisão de literatura sobre roadmaps foram identificadas cinco dimensões importantes desta atividade. Primeiramente, existem objetivos ao se iniciar a atividade de elaboração de roadmaps. Para tanto, a empresa monitora fontes de informações que fornecem os elementos necessários à decisão sobre evolução da tecnologia, dos produtos e dos mercados almejados. A elaboração de roadmaps em geral segue algum processo, formalizado ou não, que visa elaborar o conteúdo do roadmap propriamente dito. Este processo possui inúmeras barreiras e/ou dificuldades tanto na elaboração quanto na colocação em prática do roadmap. Por fim, existem diversos benefícios que esta atividade proporciona. Identificar as características em termos dos aspectos mais relevantes em cada uma das cinco dimensões (objetivos, fontes de informação, processo/conteúdo, barreiras/dificuldades e benefícios) constitui um dos focos deste estudo. A atividade de elaboração de roadmaps e os atores envolvidos serão descritos em cada um dos casos.

2) Analisar como o porte da empresa influencia as características da atividade de elaboração de roadmaps. Com base em Penrose (1959), adotamos como premissa que a atividade de roadmap é uma importante capacidade que limita o crescimento da firma, e que portanto deve variar conforme aumenta o porte da empresa. Com base nos dados coletados nas empresas pesquisadas, considerando as características estudadas 
no OE 1, procurar-se-á identificar as diferenças na atividade de elaboração de roadmaps entre empresas de diferentes portes.

3) Identificar particularidades da atividade de elaboração de roadmaps no setor de software. O setor de software apresenta diversas diferenças em relação a outros setores. Grande parte dos estudos sobre roadmap se referem à aplicação desta técnica em empresas industriais, tais como o estudo de Barker e Smith (1995) na British Petroleum, Groenveld (1997) na Philips, Albright e Kappel (2003) na Lucent Technologies, Grossman (2004) na GM, entre outros. Assim sendo, para atingir este objetivo específico identificaremos as particularidades da atividade de elaboração de roadmaps nas empresas estudadas em relação aos demais estudos da literatura que abordam o uso desta técnica em outros setores, ou em relação aos poucos estudos encontrados sobre roadmap em empresas de software (SUOMALAINEN et al, 2011; FLEURY et al, 2006).

A natureza deste estudo é exploratória, sendo adotado o método de estudo de caso, indicado para investigar como fenômenos contemporâneos e complexos ocorrem em seu ambiente (YIN, 2003), permitindo assim aprimorar construtos para formulação de teorias (EISENHARDT, 1989).

\subsection{Justificativas do Estudo}

Este estudo pretende trazer contribuições tanto para a teoria quanto para a prática empresarial.

Do ponto de visto teórico, a primeira contribuição deste estudo é a abordagem inédita na qual, por meio de uma extensa revisão de literatura, identificamos cinco importantes dimensões da atividade de elaboração de roadmaps: objetivos, fontes de informação, processo/conteúdo, barreiras/dificuldades e benefícios. Os estudos sobre roadmaps são recentes e em geral eles possuem um caráter muito exploratório (CARVALHO et al, 2013), descrevendo como são elaborados em casos específicos e mostrando o resultado final. Estes estudos não necessariamente buscam olhar os mesmos aspectos da atividade, o que dificulta inclusive a 
comparação entre as pesquisas. Assim, espera-se que o modelo conceitual adotado nesta tese possa servir como referência para futuros estudos.

O estudo de empresas de diferentes portes traz contribuições para a academia e para praticantes. Para a academia, permitirá verificar empiricamente o conceito de que a capacidade gerencial e/ou seus recursos podem limitar o crescimento da firma (PENROSE, 1959). Porém, o que diferencia a atividade de elaboração de roadmaps em pequenas e grandes empresas? Novamente, o modelo conceitual nos permitirá uma base comum para investigação e comparação das diferenças, procurando em cada caso avaliar as mesmas dimensões do fenômeno. Devido à própria natureza do método adotado nesta pesquisa, os resultados não podem ser generalizados (YIN, 2003). Porém, com as devidas análises e adaptações, praticantes poderão se beneficiar deste estudo pois poderão comparar suas práticas de roadmap com a das empresas estudadas de porte semelhante, ou ainda, obter uma visão do que a empresa poderá e/ou precisará modificar em suas capacidades à medida que almeja crescer.

Este estudo também se justifica por identificar particularidades da atividade de elaboração de roadmaps em empresas de software, um setor muito dinâmico e que possui destaque cada vez maior como atividade econômica e geração de riqueza (CARMEL, 1995; EVANS et al, 2005; SAWYER, 2000). Grande parte dos estudos sobre roadmaps mostram que ela é uma importante prática de gestão tecnológica verificada em diversos outros setores industriais (ALBRIGHT; KAPPEL， 2003; BARKER; SMITH， 1995; GROSSMAN， 2004; GROENVELD, 1997; KOSTOFF et al, 2004; PETRICK; ECHOLS, 2004; PHAAL et al, 2004; PROBERT; RADNOR, 2003; WHALEN, 2007). Em nossa revisão de literatura, encontramos poucos estudos sobre roadmap tecnológico específicos sobre empresas de software (SUOMALAINEN et al, 2011; FLEURY et al, 2006). Assim sendo, este estudo permitirá complementar uma literatura muito escassa. Outra contribuição será verificar como a decisão sobre escolha de plataforma de desenvolvimento se relaciona com o roadmap. A importância da plataforma para a competitividade de empresas de software já foi discutida por diversos autores (MEYER; SELINGER, 1998; CUSUMANO; GAWER, 2002; EVANS et al, 2005). A plataforma de desenvolvimento adotada por uma empresa pode restringir ou alavancar suas capacidades dinâmicas (TEECE et al, 1997), facilitando ou dificultando sua capacidade de adaptação às necessidades de mercado. Ela possui características de 
dependência histórica e acumulação do conhecimento (DIERICKX; COOL, 1989), que não são simplesmente compradas no mercado, pois requerem dos colaboradores a capacitação tanto na tecnologia escolhida quanto no conhecimento de negócio relativo ao mercado atendido pela empresa. Porém, mesmo os poucos estudos que abordaram roadmaps em empresas de software não abordaram a questão da plataforma e como ela se relaciona com os roadmaps.

\subsection{Estrutura da Tese}

O capítulo 2 aborda o referencial teórico utilizado nesta pesquisa. O primeiro tópico (2.1) aborda a visão estratégica do escaneamento do ambiente, no qual discutimos primeiramente a visão da firma baseada em recursos (item 2.1.1), que é a âncora teórica para justificar o investimento da empresa em tecnologias que sejam valiosas, raras e de difícil imitação, e a abordagem teórica das capacidades dinâmicas (item 2.1.2), segundo a qual as empresas competitivas em setores dinâmicos como o de software precisam ter a capacidade de se transformar para fazer frente ao ambiente em mudanças. Neste sentido, discutimos a importância do escaneamento do ambiente (item 2.1.3) e da inteligência competitiva (item 2.1.4).

O segundo tópico (2.2) aborda a gestão da inovação, no qual discutimos o conceito de inovação e seus diferentes graus (item 2.2.1) e a busca por oportunidades e ameaças tecnológicas (item 2.2.2). O terceiro tópico (2.3) aborda inteligência tecnológica, discutindo diferentes conceitos e modelos (item 2.3.1), e três de seus importantes processos que são a coleta de dados (item 2.3.2), a análise das informações (2.3.3) e a disseminação das informações (2.3.4).

No tópico 2.4 discutimos tomada de decisão, uma vez que a elaboração de roadmaps envolve decisão sobre adoção de tecnologias. No item 2.4.1. discutimos aspectos gerais sobre processo decisório, e no item 2.4.2. discutimos métodos multicritério para tomada de decisão. Consideramos importante colocar esta discussão antes de roadmaps, pois algumas das metodologias de elaboração de roadmap adotam métodos multicritério de decisão. 
No tópico 2.5 discutimos especificamente roadmaps tecnológicos. São abordados conceitos de roadmap e seus objetivos (item 2.5.1), formato e conteúdo do roadmap (2.5.2), seu processo de elaboração (2.5.3), barreiras e dificuldades (2.5.4) e, por fim, benefícios de sua adoção (2.5.5).

No tópico 2.6 discutimos a indústria de software, com suas características competitivas e de inovação (2.6.1), plataformas em software (2.6.2), e especificamente a indústria de software no Brasil (2.6.3).

No capítulo 3 é discutida a metodologia adotada nesta pesquisa.

No capítulo 4, são apresentados os 6 estudos de caso que fazem parte desta tese (itens 4.1 a 4.6), seguindo-se no capítulo 5 a discussão dos resultados. As considerações finais deste estudo são apresentadas no capítulo 6. Por fim, são citadas as referências bibliográficas utilizadas bem como o Anexo A, com as questões do estudo de caso. 


\section{REVISÃO DE LITERATURA}

\subsection{Visão Estratégica do Escaneamento do Ambiente}

\subsubsection{Visão da Firma Baseada em Recursos}

Iniciamos a revisão de literatura pela visão da firma baseada em recursos ( $R B V$, do inglês Resource-Based View of the Firm) por ser uma corrente teórica importante para o entendimento das capacidades dinâmicas e consequentemente da IT. A RBV é uma abordagem que está enraizada em Penrose (1959) que procura explicar a firma (e a heterogeneidade entre as firmas) a partir de seus recursos internos.

Uma empresa que possua um conjunto de recursos raros, valiosos, difíceis de imitar e insubstituíveis consegue obter vantagem competitiva sustentável (BARNEY, 1991). Recursos (ou a competência em usá-los) que permitam a uma empresa obter vantagem competitiva não são, portanto, comercializáveis e disponíveis no mercado. São construídos ou acumulados pelo investimento de tempo, dinheiro e/ou esforço (DIERICKX; COOL, 1989). Também podem ser herdados (BARNEY, 1991), tanto em decorrência da evolução histórica da própria empresa ou de aquisições/fusões com outras empresas.

Uma das críticas à RBV é que alguns autores incluem na definição de recursos qualquer coisa que uma empresa possa ter, tal como capacidades, processos, informação, conhecimento e outros atributos da firma (BARNEY, 1991; WERNERFELT, 1984). Para fins deste estudo, consideramos mais precisa a definição de Amit e Schoemaker (1993, p. 35), segundo os quais recursos são definidos como "estoques de fatores disponíveis que são possuídos ou controlados pela firma", o que inclui know-how que possa ser comercializado (patentes), ativos físicos e financeiros e capital humano. Já as capacidades se referem à capacidade de usar/entregar um conjunto de recursos por meio de processos, para atingir um fim específico. Penrose (1959) argumenta que não são os recursos, mas os serviços prestados por eles, que importam na análise das entradas (inputs) utilizadas no processo produtivo das empresas. As capacidades são baseadas em informação e específicas da firma, decorrentes de uma evolução 
histórica na forma com que uma empresa realiza suas atividades (AMIT; SCHOEMAKER, 1993).

A RBV “clássica" (ACEDO et al, 2006) entende que uma vez obtida uma vantagem competitiva sustentável somente uma mudança externa, por exemplo na economia, poderia mudar as condições reduzindo o valor, a raridade, ou facilitando a imitação ou substituição de um recurso. Segundo Barney:

[...] uma vantagem competitiva que seja sustentada não implica que ela irá durar para sempre. Isso apenas sugere que ela não será anulada por esforços de duplicação de outras firmas. Mudanças não antecipadas na estrutura econômica de uma indústria pode fazer com que o que foi, em um momento, uma fonte de vantagem competitiva, não seja mais valiosa para a empresa, e portanto não seja fonte de nenhuma vantagem competitiva. (BARNEY, 1991, p. 103).

Assim sendo, para a RBV a mudança é exógena ao setor e o mercado tende ao equilíbrio (BARNEY, 1991). Porém, este parece não ser o caso de setores de alta tecnologia, em que a mudança é constante e muitas vezes gerada por empresas do próprio setor. Além disto, a convergência tecnológica provoca mudanças nos limites entre os setores, fazendo com que empresas que antes atuavam em setores distintos passem a concorrer entre si. A evolução tecnológica que permite esta convergência é, muitas vezes, resultante da inovação gerada pelas próprias empresas atuantes no setor.

A RBV se apresenta como uma contraposição à tradição ECP (estrutura-condutaperformance) da organização industrial, da qual o modelo das cinco forças de Porter (1980) faz parte. De forma simplificada, o modelo de Porter pressupõe certa estabilidade na estrutura da indústria, sendo que uma empresa conseguiria desempenho superior por meio do seu posicionamento e da construção de barreiras. Isto permitiria à empresa obter renda monopolística. Os recursos e capacidades da empresa são facilmente manipuláveis para serem reconfigurados e permitirem à empresa colocar em prática o posicionamento estratégico almejado. Já a RBV argumenta que são recursos internos que geram a vantagem competitiva. Um gestor teria poder limitado para alterar tais recursos. Muitas vezes recursos herdados ou desenvolvidos a partir de uma história única de evolução da empresa é que geram a vantagem competitiva. Existe uma dependência histórica, que faz com que a empresa normalmente 
invista em áreas nas quais já possui conhecimento desenvolvido (KOGUT; ZANDER, 1992; PATEL; PAVITT, 1997) limitando sua capacidade de aproveitar novas oportunidades.

O reconhecimento de que o mercado é dinâmico e que é necessário inovar e se adaptar ao ambiente agrupa um conjunto de trabalhos em uma corrente derivada da RBV, chamada por Acedo et al (2006) de KBV (knowledge based view, ou visão da firma baseada em conhecimento). Essa corrente de pesquisa tem fundamentos na economia evolucionária, segundo a qual as rotinas constituem os blocos de construção de competências que irão gerar a vantagem competitiva (NELSON; WINTER, 1982). O conhecimento e a capacidade de aprendizado constituem o recurso mais importante para as empresas e a mudança é endógena ao setor, provocada pela inovação gerada pelas próprias empresas (PRAHALAD; HAMEL, 1990; KOGUT; ZANDER, 1992).

Kogut e Zander (1992) argumentam que o principal elemento de competitividade das empresas é a forma com que criam e transferem conhecimento dentro do contexto organizacional. Empresas bem sucedidas precisam desenvolver o que os autores chamam de capacidade combinativa, que consiste na capacidade de sintetizar e aplicar o conhecimento corrente e também o adquirido. Os autores diferenciam dois tipos de conhecimento: informação, que é o conhecimento que pode se codificado e transmitido sem perda de conteúdo; e know-how, que é aprendido e acumulado com o tempo permitindo a execução de tarefas de forma eficiente.

O conhecimento pode ser classificado em tácito, que é o conhecimento pessoal e não formalizado, e explícito, que é o conhecimento já documentado ou registrado de maneira formal (NONAKA; TAKEUCHI, 1997; GRANT, 1996). Kogut e Zander (1992) argumentam que existe um paradoxo pois para uma empresa crescer, ela precisa codificar e simplificar o conhecimento a fim de transmití-lo para outros colaboradores. Porém, isto também torna este conhecimento mais fácil de ser replicado, levando a uma possível perda de uma vantagem competitiva. Outra importante implicação dos conceitos apresentados por Kogut e Zander (1992) é que as empresas tendem a investir no desenvolvimento de conhecimentos que combinem as capacidades existentes da empresa e as expectativas sobre futuras oportunidades. Há portanto uma dependência histórica pois as empresas tendem a continuar desenvolvendo conhecimento relacionado ao já existente, dificultando portanto rupturas e o 
aproveitamento de eventuais oportunidades que requerem conhecimentos muito diferentes. A visão de Kogut e Zander (1992) é de que a empresa é formada por um conjunto de capacidades, determinadas pelo conhecimento social embutido nas relações entre os indivíduos.

\subsubsection{Capacidades Dinâmicas}

Segundo Teece et al (1997):

"We define dynamic capabilities as the firm's ability to integrate, build, and reconfigure internal and external competences to address rapidly changing environments" (p. 516).

Mantivemos a definição original em inglês para evitar distorções que pudessem surgir em uma tradução. Por esta definição, possuir capacidades dinâmicas significa não apenas se adaptar de forma passiva ao ambiente, mas também identificar tendências e oportunidades de forma antecipada, desenvolver as competências necessárias e coordenar a mudança tecnológica do setor para a direção desejada (PRAHALAD; HAMEL, 1990; PATEL; PAVITT, 1997). Assim sendo, empresas que atuam em ambientes competitivos e em rápida mudança como o de alta tecnologia precisam ter a capacidade de se adaptar rapidamente às mudanças, sendo fundamental para a companhia a decisão sobre quais tecnologias desenvolver (TEECE et al, 1997; PRAHALAD; HAMEL, 1990). Obviamente mesmo empresas atuantes em setores mais "estáticos" e com menor ritmo de mudança também podem se valer de capacidades dinâmicas para obter vantagem competitiva (HELFAT; WINTER, 2011; EISENHARDT; MARTIN, 2000). Mas é justamente nos setores globalizados, em que mudanças são freqüentes e rápidas, como é o caso do setor de TI, que as capacidades dinâmicas ganham peso e importância (TEECE, 2007).

Eisenhardt e Martin (2000) argumentam que a capacidade dinâmica pode ser entendida não como uma capacidade de alterar capacidades, mas como uma capacidade específica (tal como pesquisa e desenvolvimento) que permite que a empresa altere de forma dinâmica sua posição de recursos. 
Prahalad e Hamel (1990) são classificados por Teece et al (1997) como pertencentes à corrente de pesquisa das capacidades dinâmicas, à medida que reconhecem que o ambiente é dinâmico e que a empresa precisa se adaptar a este ambiente ou até moldá-lo em alguns casos. Porém, Prahalad e Hamel (1990) não atentam para as rotinas ou processos organizacionais, e sim para o que chamam de competências essenciais, definidas como “... o aprendizado coletivo na organização, especialmente como coordenar diversas habilidades de produção e integrar múltiplas correntes de tecnologias" (PRAHALAD; HAMEL, 1990 : 4).

Para Prahalad e Hamel (1990) as competências são estoques de conhecimento, que podem ser recombinados para suportar outras tecnologias, que por sua vez, serão a base para novos produtos e serviços. Assim sendo, uma decisão fundamental da empresa é sobre quais competências devem ser desenvolvidas hoje para dar suporte aos novos produtos e negócios que a empresa irá explorar no futuro.

Cohen e Levinthal (1990) argumentam que empresas bem sucedidas devem desenvolver capacidade absortiva, que consiste na habilidade da firma reconhecer uma nova informação externa valiosa, e aplicá-la em seu processo de inovação. A capacidade absortiva depende do desenvolvimento interno de conhecimentos relacionados à esta informação externa. Assim sendo, de nada adiantará a empresa detectar uma oportunidade no mercado se ela não tem competência interna para aproveitar esta oportunidade no desenvolvimento de novas arquiteturas de produtos ou serviços (PRAHALAD; HAMEL, 1990). O conhecimento é um ativo que demanda tempo e esforço para ser acumulado, apresentando uma natureza de dependência histórica (DIERICKX; COOL, 1989). O aprendizado é pessoal, e portanto a capacidade absortiva da empresa dependerá da capacidade absortiva de seus colaboradores individuais (COHEN; LEVINTHAL, 1990).

Assim sendo, os funcionários precisam dominar não apenas conhecimentos relacionados às tecnologias diretamente utilizadas pela empresa, mas também conhecimentos diferentes, que permitirão à empresa explorar novas tecnologias e se transformar (COHEN; LEVINTHAL, 1990; PRAHALAD; HAMEL, 1990). Conforme já foi discutido, na área de software, muita da concorrência se dá entre diferentes plataformas de desenvolvimento (EVANS et al, 2005; CUSUMANO; GAWER, 2002). TI é um setor dinâmico e competitivo, e constantemente surgem novas plataformas para competição. Empresas que queiram se manter atualizadas 
precisam se adaptar. Neste sentido, não basta treinar seus funcionários apenas quando um design dominante (ANDERSON; TUSHMAN, 1990) tiver emergido e ficar claro o padrão “vencedor". Também não bastará à empresa contratar o desenvolvimento externo caso não possua capacidade absortiva (COHEN; LEVINTHAL, 1990), ou seja, conhecimento interno que permita à empresa absorver a tecnologia contratada externamente. $\mathrm{O}$ conhecimento possui uma característica cumulativa (COHEN; LEVINTHAL, 1990; KOGUT e ZANDER, 1992; GRANT, 1996), o que exige treinamento prévio. Para melhor tomada de decisão, muitas vezes é necessário ter conhecimento sobre plataformas concorrentes para poder decidir, com melhor assertividade, qual a mais adequada para os objetivos estratégicos da empresa.

Porém, a decisão sobre alteração ou manutenção das capacidades (TEECE et al, 1997), da posição de recursos (EISENHARDT; MARTIN, 2000), ou das competências (PRAHALAD; HAMEL, 1990) dependem do que a empresa acredita que será valioso no futuro. Desenvolver uma maior consciência sobre o futuro é então importante para que a empresa não provoque alterações ao acaso em seus processos, recursos ou competências (OZAKI et al, 2013).

\subsubsection{A Importância do Escaneamento do Ambiente}

Apesar do termo escaneamento não ser usual na língua portuguesa, optamos por utilizá-lo como tradução para o termo em inglês scanning, muito comum nos estudos que enfocam a necessidade de obtenção de informações externas. Segundo Daft e Weick (1984), as empresas podem ser entendidas como sistemas interpretativos, nos quais a informação externa precisa ser obtida, filtrada e processada para tomada de decisão. Segundo os autores "interpretação é um elemento crítico que distingue organizações humanas de sistemas de baixo nível” (DAFT; WEICK, 1984). Um pressuposto importante defendido pelos autores é que a empresa possui sistemas cognitivos e memória, que procura reter o aprendizado individual das pessoas. $\mathrm{O}$ processo geral de aprendizagem organizacional compreende funções de escaneamento, interpretação e aprendizado. A figura 1 representa o relacionamento entre estas funções. 


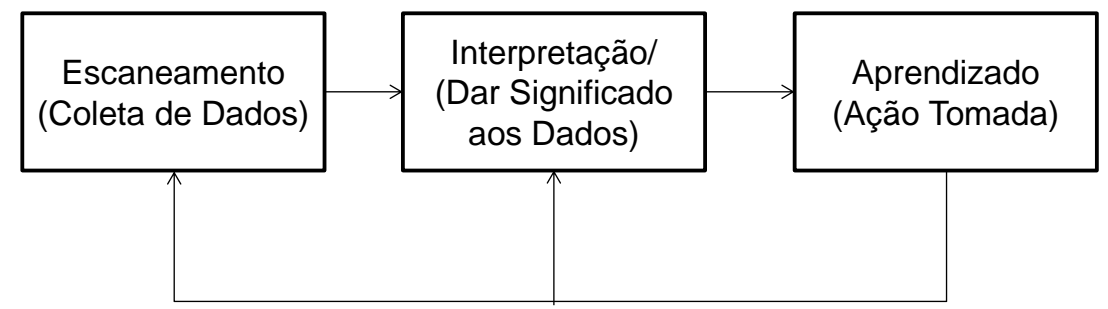

Figura 1 - Processo geral de escaneamento, interpretação e aprendizagem FONTE: DAFT; WEICK, 1984, p. 286

Daft et al (1988) entrevistaram CEOs de 50 empresas manufatureiras para investigar a relação entre o comportamento de escaneamento e a performance organizacional. O comportamento de escaneamento foi avaliado pelos setores (os autores utilizam o termo sectors) escaneados: clientes, competição, tecnológico, regulatório, econômico, sócio-cultural. Foi solicitado ao entrevistado que avaliasse, em cada um dos seis setores, a complexidade, taxa de mudança e importância. Também foi avaliado o uso de fontes de informação: escrita externa, escrita interna, pessoal externa, pessoal interna. A performance da empresa foi avaliada pela taxa de retorno sobre ativos. Para cada fonte de informação, foi pedido ao entrevistado verificar a frequiência com que recebeu informações para cada um dos seis setores. Daft et al (1988) concluem que: (1) executivos tem percepção que os setores cliente, econômico e competição tem maior incerteza que os setores tecnológico, regulatório e sociocultural; (2) o aumento da percepção de risco aumenta o escaneamento em todos os modos, principalmente no modo pessoal comparado com o escrito; (3) o escaneamento nas empresas de maior performance é mais freqüente, e costuma ser mais abrangente quando a percepção de risco é maior.

Dollinger (1984) estudou o comportamento de "ampliação das fronteiras" (boundary spanning) de 82 proprietários de pequenas empresas. Os entrevistados foram solicitados a registrar o número de horas e número de contatos que mantinham em média com nove categorias que o autor chamou de environmental constituencies: clientes, fornecedores, entrevistas com novos empregados, banqueiros/advogados/contadores, associações de negócio/profissionais, reguladores/governo/sindicato, stakeholders externos/credores, competidores, outras atividades relacionadas ao negócio. Suas principais conclusões foram: (1) existe ampliação das fronteiras em pequenos negócios. Os empreendedores estão profundamente envolvidos em interações com o ambiente; e, (2) interações com o ambiente estão fortemente relacionadas com a performance financeira. 
Subramanian et al (1993) analisaram 101 empresas da lista Fortune 500. Como variáveis independentes mediram a função de escaneamento em termos de escopo (medido por "setores" escaneados dentre econômico, político, tecnológico, social e legal), profundidade e foco. Como variáveis dependentes utilizaram a lucratividade, medido pelo retorno sobre ativos, e crescimento, medida relativa entre o crescimento da empresa e da indústria. Concluem que $60 \%$ das empresas apresentavam sistemas de escaneamento avançados. Os dados sustentam que há relacionamento entre performance e sistemas de escaneamento avançados.

Thomas et al (1993) analisaram uma amostra de 156 hospitais. Em sua pesquisa aplicaram dois textos contendo cenários diferentes, e fizeram perguntas relativas a estes cenários para avaliar o estilo cognitivo em termos de percepção de ganho potencial, controlabilidade, escaneamento e interpretação. Os autores chegaram a algumas conclusões interessantes. $\mathrm{O}$ escaneamento está condicionado pela interpretação: a atenção da alta gestão para altos níveis de informação durante o escaneamento está relacionada com sua interpretação de que tópicos estratégicos (strategic issues) são positivos e implicam ganhos potenciais. Também está associado à percepção de que os tópicos estratégicos são controláveis. Relação entre interpretação e ação: existe ligação significativa entre interpretação e ação quando o CEO interpreta tópicos como controláveis. Relação entre ação e performance: hospitais que implementaram mais mudanças de produto ou serviço performaram melhor em todas as métricas de performance. O estudo mostra que a associação entre o comportamento de escaneamento externo e a interpretação de controlabilidade serve como antecedente das ações estratégicas, que por sua vez estão associadas com a performance organizacional.

Estes estudos demonstram que existe relacionamento positivo entre o escaneamento do ambiente e a performance da organização (DAFT et al, 1998; DOLLINGER, 1984; SUBRAMANIAN, 1993). Especificamente o estudo de Thomas et al (1993) mostra que o escaneamento do ambiente está ligado à ação inovativa, uma vez que o lançamento de produtos e serviços está relacionado com a performance da empresa.

Em contraposição, o estudo de Jennings e Lumpkin (1992) não encontraram relação direta entre o escaneamento e a performance da organização. Os autores analisaram 23 empresas com estratégia de custo e 21 com estratégia de diferenciação, para verificar o comportamento 
de escaneamento destas empresas. Concluem que empresas com estratégia de diferenciação adotam mais o escaneamento para busca de oportunidades de crescimento e necessidades de clientes. Por outro lado, empresas com estratégia de liderança de custo monitoram competidores e reguladores, e provavelmente são mais reativas que proativas. Como a estratégia de diferenciação em geral está relacionada com inovação, podemos concluir que o escaneamento de oportunidades também está relacionado com a inovação, corroborando o estudo de Thomas et al (1993).

\subsubsection{Inteligência Competitiva}

A IC tem ganho crescente destaque tanto como prática empresarial quanto em pesquisas acadêmicas (PRESCOTT, 2001; BOSE, 2008). Segundo Dishman e Calof (2008), em 1966, William Fair propôs a criação de uma Agência Central de Inteligência corporativa, fazendo analogia com a agência do governo dos Estados Unidos, a CIA (Central Intelligence Agency), com funções de coletar, triar, organizar, armazenar, recuperar e disseminar informação. Porém foi a partir da década de 90 que sua prática passou a ser mais difundida entre as empresas (PRESCOTT, 2001). Apesar do recente interesse das empresas e academia sobre o tema, Juhari e Stephens (2006) destacam que a IC enquanto conceito já era aplicada para fins militares há mais de 5000 anos na China, e que existem registros com cerca de 1000 anos antes de Cristo de organizações religiosas que utilizaram tais conceitos, espelhados também na prática militar, para tomada de decisão.

Bose (2008) destaca a importância das ferramentas de TI e da Internet como provedora de informação para esta recente ascensão do tema IC. Prescott (2001) complementa que um fator importante, além da globalização e da TI, foi a atuação dos profissionais de inteligência, incluindo a SCIP (Strategic and Competitive Intelligence Professionals) que é uma associação de profissionais e interessados na área de IC.

Alguns autores argumentam que IC se refere tanto ao produto (inteligência) quanto ao processo que o gera (BERNHARDT, 1994; BOSE, 2008). O produto consiste em informação acionável, ou seja, que possa ser utilizada em tomada de decisão. O processo compreende atividades de planejamento, coleta, análise e disseminação/comunicação (BERNHARDT, 
1994; BOSE, 2008; DISHMAN; CALOF, 2008). Existem pequenas variações nas etapas deste processo, sendo alguns um pouco mais detalhados. Por exemplo, Fair apud Dishman e Calof (2008) inclui etapas de armazenamento e recuperação de informação, e Bose (2008) o feedback que deve haver após a disseminação.

Dishman e Calof (2008) fizeram uma pesquisa com 1025 empresas e constaram alguns dados interessantes. Apesar de grande parte das empresas terem cultura e atenção para a IC, apenas $36 \%$ reportaram que os executivos informam seus funcionários sobre suas necessidades de informação, e menos da metade destes relataram que funcionários ligados a IC entrevistam os altos executivos para entender suas necessidades estratégicas. Para suprir esta deficiência, Herring (1999) propõe um método chamado de KITs (Key Intelligence Topics), ou Tópicos de Inteligência Chave para identificar as necessidades dos executivos da empresa. Segundo Herring (1999), as necessidades de informação de uma empresa se dividem em três categorias: (a) decisões estratégicas e ações, que são necessidades imediatas visando uma tomada de decisão; (b) tópicos de sinais antecipativos, que incluem iniciativas de concorrentes, surpresas tecnológicas e ações governamentais, entre outros assuntos que devem ser constantemente acompanhados para identificar oportunidades e ameaças; (c) descrições de participantes chave no mercado da empresa, incluindo competidores, clientes, fornecedores, reguladores e parceiros.

Dishman e Calof (2008) concluem em sua pesquisa que grande parte das empresas possuem infraestrutura formal e envolvimento dos funcionários, bem como a cultura e atenção para IC. Porém, os funcionários executam suas atividades sem saber exatamente quais as necessidades dos altos executivos. O modelo de Dishman e Calof (2008) é representado na figura 2. 


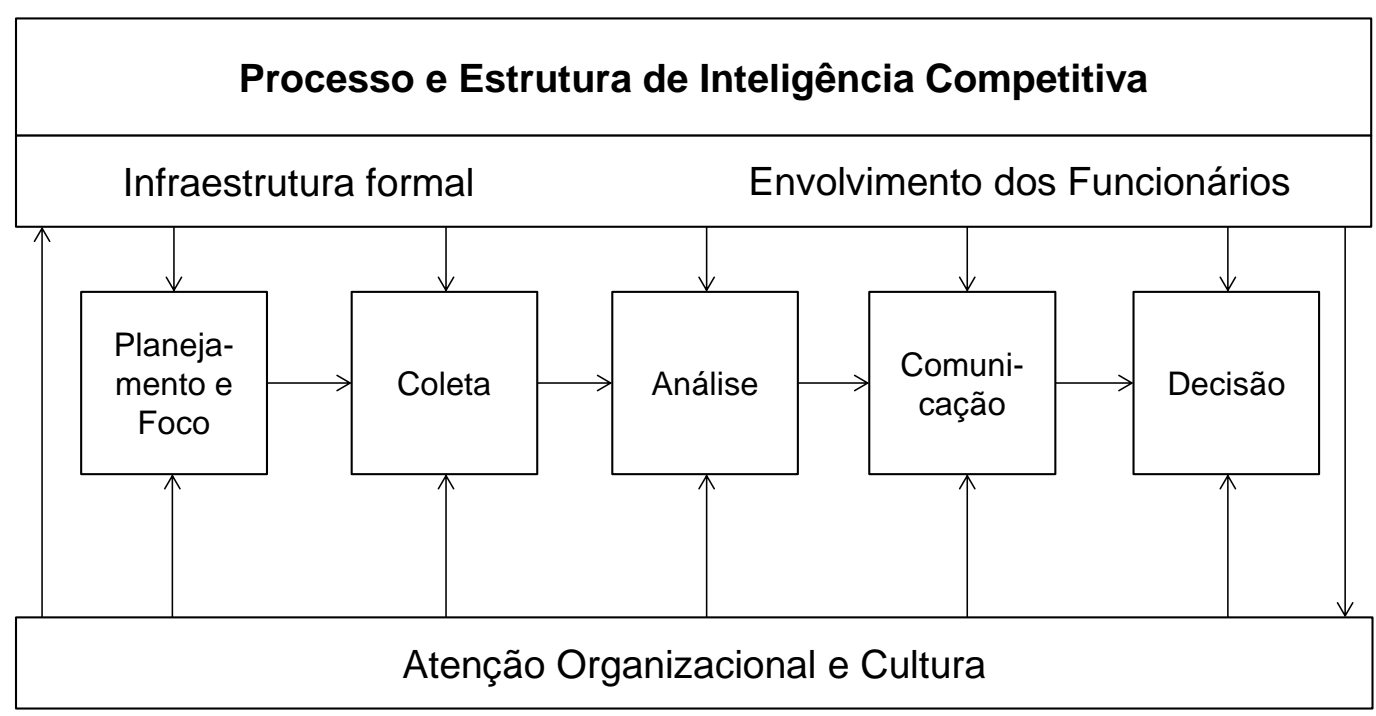

Figura 2 - Processo de inteligência competitiva

FONTE: Adaptado de DISHMAN; CALOF, 2008, p.779

Saayman et al (2008) utilizaram este mesmo modelo da figura 2 para pesquisar a prática de atividades de IC em empresas sul-africanas e belgas e verificaram que as etapas de coleta e análise são construtos que podem ser agrupados. Uma possível explicação é que são atividades conduzidas simultaneamente de forma muito interativa. Outro aspecto importante destacado na pesquisa de Saayman et al (2008) é que o tamanho da empresa influencia a prática de IC, sendo que empresas de maior porte possuem atividades melhor estruturadas. Esta conclusão tem respaldo na literatura sobre capacidades e evolucionismo das empresas (PENROSE, 1959; NELSON; WINTER, 1982; TEECE et al, 1997) e é um dos argumentos para adotarmos o porte como critério para seleção dos casos que serão estudados nesta tese.

\subsection{Gestão da Inovação}

\subsubsection{Conceito de Inovação e Seus Diferentes Graus}

Inovação não é um tema recente, mas até hoje há dificuldade em se definir precisamente o que é inovação. Segundo Schumpeter (1961), inovação é a aplicação comercial ou industrial de algo novo, podendo ser um novo produto, processo, método de produção, mercado ou fonte de suprimento, nova forma comercial, de negócio ou até financeira. Tidd, Bessant e Pavit 
(2005) exploram quatro tipos de inovação. Além da inovação de produto e de processo, eles definem a inovação de posição, que implica mudanças na forma com que produtos e serviços são introduzidos, e inovação de paradigma, que implica mudanças nos modelos mentais que moldam o que a empresa faz. O Manual de Oslo (OECD, 2005) define que inovação é a implementação de um produto (bem ou serviço), processo, método de marketing, ou um método organizacional novo ou significativamente melhorado.

Em ambientes em constante mudança, a inovação de produto ou processo é muito importante para as empresas se manterem competitivas (NEMOTO et al, 2010).

A inovação pode ter diferentes graus. Segundo Clark e Wheelwright (1993) há 4 categorias principais de inovação. A primeira categoria é a pesquisa e desenvolvimento avançado, que normalmente é realizada pela academia ou por centros avançados de P\&D e sem interesse de aplicação comercial imediata. A segunda é a inovação radical, que corresponde à introdução de um novo produto ou um novo processo. O sistema de gestão empresarial ERP (enterprise resource planning), quando surgiu, é um exemplo de uma inovação radical. O terceiro grau de inovação é o que Clark e Wheelwright (1993) chamam de plataforma ou nova geração. O produto ou processo em si é o mesmo, mas há uma reformulação significativa. Como exemplo, podemos citar quando um ERP inicialmente desenvolvido para operar em plataforma cliente-servidor em rede local - com um servidor central e várias estações de trabalho como clientes - é reescrito para operar pela Internet, usando uma nova plataforma de desenvolvimento. O quarto e último grau é o de melhoria incremental, que por exemplo equivale às melhorias periódicas de pequeno porte que as empresas de software fazem em seus sistemas.

Christensen (1997) destaca ainda a inovação disruptiva para caracterizar um outro tipo de inovação, que muda as bases de competição da indústria porque normalmente adota uma outra tecnologia, é mais barata e oferece inicialmente menos funcionalidades do que a tecnologia em uso.

Segundo Archibugi e Pianta (1996) é possível se medir a mudança tecnológica por meio de patentes ou pesquisas, sendo esta última sub-dividida em pesquisas objetivas, nas quais o objeto de análise são inovações específicas introduzidas pelas empresas, ou subjetivas nas 
quais as empresas são convidadas a responder um questionário com várias questões ligadas a diversos indicadores. Seguindo esta linha subjetiva, o Manual de Oslo (OCDE, 2005) se tornou um método padrão para coletar informações gerais sobre a atividade inovativa nas empresas (ALEGRE et al, 2006; ARCHIBUGI; PIANTA, 1996). Exemplos de pesquisas que utilizam o Manual de Oslo como referência são a CIS (Community Innovation Survey) realizada pela EUROSTAT (Statistical Office of the European Communities), e a PINTEC (Pesquisa de Inovação Tecnológica), realizada a cada três anos pelo Instituto Brasileiro de Geografia e Estatística (IBGE, 2010).

Laursen e Salter (2006) utilizaram dados da pesquisa sobre inovação realizada na Inglaterra, que segue o mesmo padrão do Manual de Oslo, para investigar a relação entre a inovação aberta e a performance inovativa das empresas. Como variável dependente (performance inovativa) eles adotaram três métricas: se a empresa lançou no período um produto ou serviço novo para o mundo, se a empresa lançou no período um produto ou serviço novo para a empresa, e o percentual de faturamento oriundo de produtos significativamente melhorados. Lançar um produto novo apenas para a empresa ou um produto melhorado requer principalmente capacidades operacionais. Porém, identificar oportunidades que sejam novas para o mundo exigirá das empresas uma alta maturidade das capacidades dinâmicas devido a alguns fatores. Primeiramente, requer da empresa uma capacidade de monitoramento do ambiente, identificação de mercados, bem como de seleção do projeto para desenvolver a tecnologia em questão. Segundo, requer da empresa também a capacidade de aproveitar a oportunidade (TEECE, 2007). Empresas de software estão a todo momento desenvolvendo inovações e portanto, se for uma tecnologia simples, provavelmente será fácil encontrar uma outra empresa que já tenha desenvolvido um software semelhante. Oportunidades novas para o mundo provavelmente venham a requerer da empresa o domínio de tecnologias complexas e complementares, nem sempre presentes na maior parte das empresas que estão preocupadas apenas com o mercado atual e as tecnologias atuais. Por fim, em muitos casos poderá exigir da empresa também capacidade de transformação. Por exemplo, a computação em nuvem oferece inúmeras oportunidades para que a empresa explore novos serviços (BENLIAN et al, 2009; SÄÄKSJÄRVI et al, 2005; VOUK, 2008). 


\subsubsection{A Busca por Oportunidades e Ameaças Tecnológicas}

Uma das formas de uma empresa gerar inovação envolve processos de pesquisa e desenvolvimento (P\&D). Segundo Clark e Wheelwright (1993) a estratégia de desenvolvimento de novos produtos e processos envolve a avaliação e previsão tecnológica, bem como a avaliação e previsão de mercado. A partir destas duas avaliações, são estabelecidos os objetivos e metas de desenvolvimento. Logo após, é elaborado um plano agregado de projetos, os quais são executados até o lançamento do produto no mercado, gerando aprendizado para melhorias. A figura 3 ilustra o processo também conhecimento como funil de desenvolvimento de novos produtos e serviços.

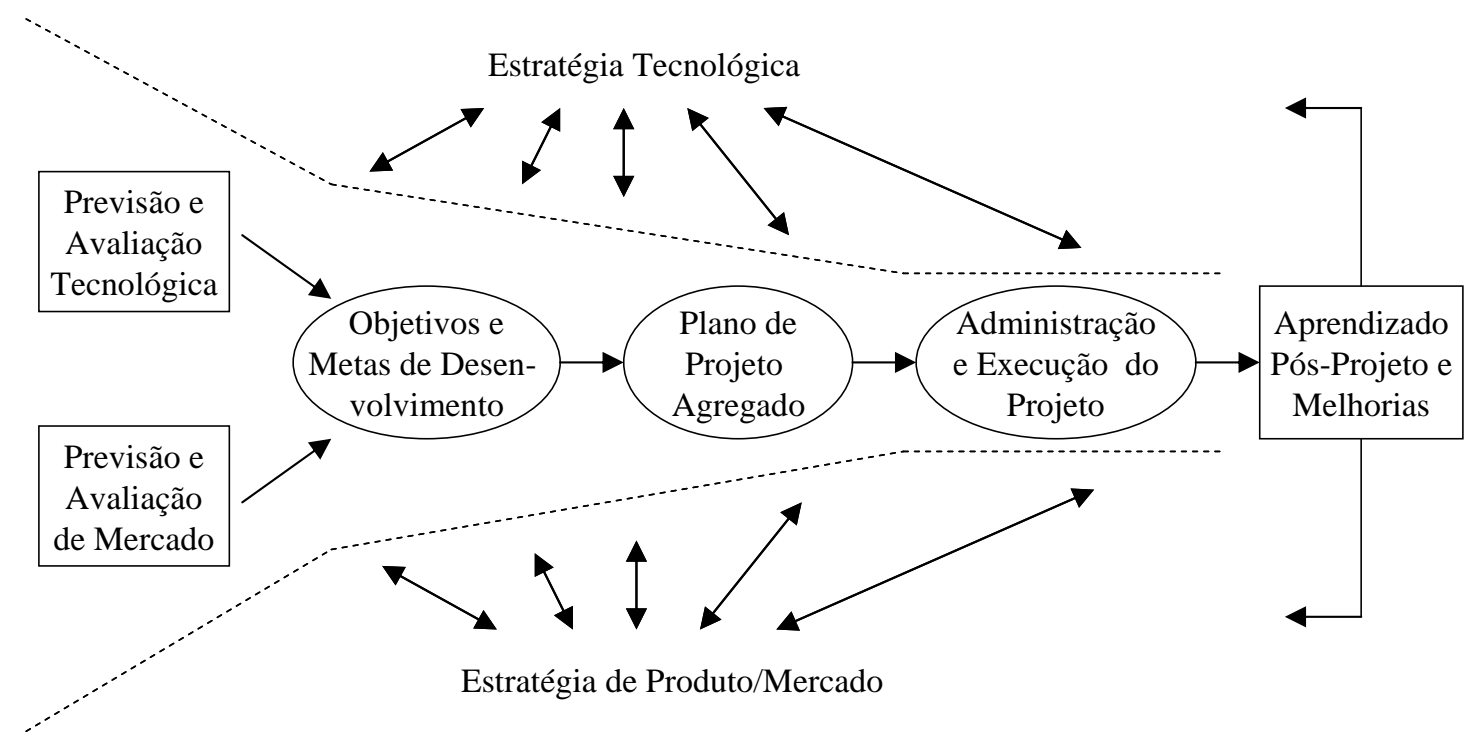

Figura 3 - Funil de desenvolvimento segundo Clark e Weelwright

FONTE: CLARK; WEELWRIGHT, 1993, p. 90

Este funil transmite a impressão de que o processo de inovação é "fechado", ou seja, primordialmente conduzido internamente pela empresa. No passado, predominou a idéia de que seria melhor controlar todo o processo de inovação e muitas etapas eram conduzidas internamente pelas empresas, em departamentos de $\mathrm{P} \& \mathrm{D}$ pouco alinhados com as estratégias de negócio (ROUSSELL et al, 1991; CHESBROUGH, 2003, 2006). Segundo Chesbrough (2003, 2006) estamos atualmente na era da inovação aberta (open innovation), sendo que o modelo fechado de inovação, que dependia basicamente da equipe interna da empresa para $\mathrm{P} \& \mathrm{D}$, pode não ser mais adequado. Inovação aberta corresponde ao uso de fluxos de 
conhecimento interno e externo para acelerar a inovação da empresa, e expandir os mercados para uso externo da inovação (CHESBROUGH, 2006). A abertura pode ocorrer em várias etapas do funil de desenvolvimento, tal como na geração de idéias, no desenvolvimento da inovação ou de partes dela, no licenciamento de tecnologia externa para ser incorporada no produto, ou mesmo na comercialização posterior da inovação gerada pela empresa (CHESBROUGH, 2003, 2006). Para ser competitiva, a empresa precisa criar mecanismos e instrumentos para aproveitar e explorar idéias e soluções geradas no ambiente externo. Mesmo assim, a empresa não pode simplesmente depender destas fontes externas para geração de inovações, sendo muito importante um esforço deliberado e contínuo de monitoramento da evolução tecnológica.

Cooper $(1990,2008)$ adiciona ao conceito de funil de desenvolvimento os chamados stagegates. O funil é divido em várias etapas, como por exemplo Geração de Idéia, Escopo, Construção do Caso de Negócios, Desenvolvimento, Teste e Validação, e Lançamento. Entre cada uma destas fases (stages) haveria um "portão" (gate) com a decisão de continuar ou matar o projeto (também chamada de go-kill).

Clark e Weelwright (1993), Chesbrough (2003) e Cooper (1990, 2008) discorrem sobre o processo de desenvolvimento de novos produtos, mas não abordam em profundidade o processo de análise de oportunidades e ameaças tecnológicas. Com este objetivo existem processos e técnicas de IT que a empresa pode adotar e que serão discutidas a seguir.

\subsection{Inteligência Tecnológica}

\subsubsection{Conceitos e Modelos de Inteligência Tecnológica}

O termo inteligência tecnológica (IT) é bastante abrangente, e muitas empresas aplicam técnicas e métodos de IT sem sequer saber que o estão fazendo. É uma atividade difusa entre vários departamentos, mesmo em empresas que possuem um grupo dedicado para IT (LICHTENTHALER, 2004). Em alguns estudos, o termo previsão tecnológica - forecast ou 
foresight - é utilizado para designar o uso de muitas das técnicas e métodos de IT (PORTER et al, 2011; ROHRBACK, 2011).

Segundo Norling et al (2000) a IT é um importante instrumento para suportar a atividade de $\mathrm{P} \& \mathrm{D}$, podendo ser definida como "a informação sensitiva sobre os desenvolvimentos científicos ou tecnológicos externos que podem afetar a posição competitiva da empresa”, compreendendo processos de planejamento, coleta, análise e disseminação representados na figura 4 .

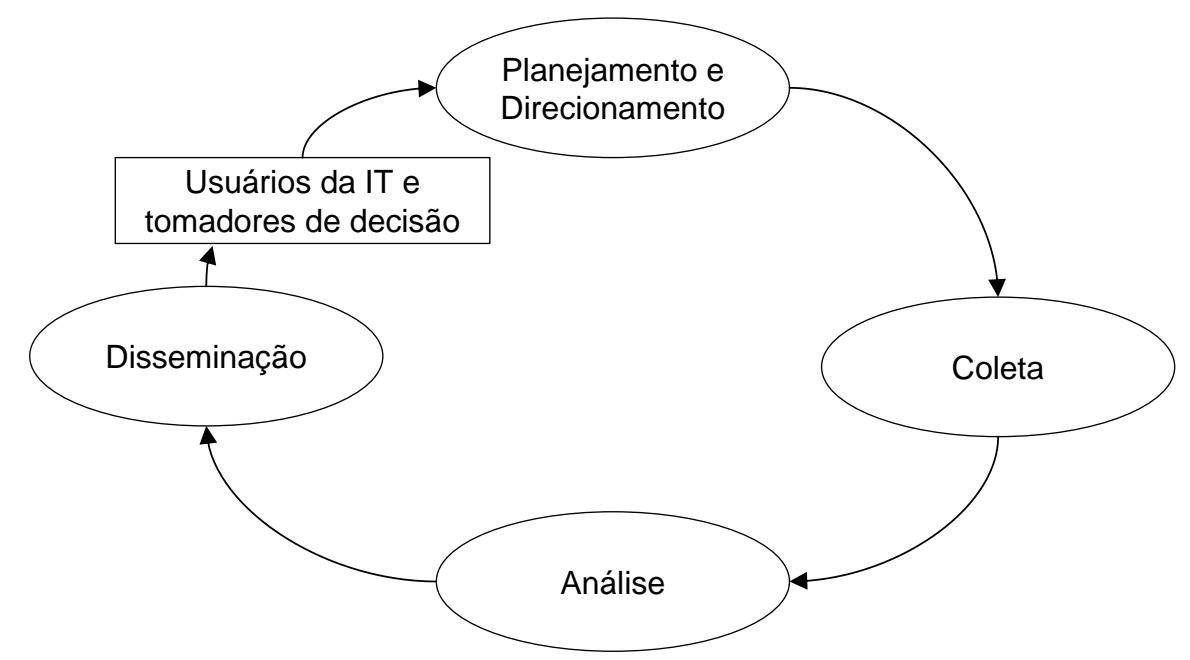

Figura 4 - Processo de inteligência tecnológica segundo Norling et al. FONTE: Adaptado de NORLING et al, 2000, p. 24

Kerr et al (2006) definem que IT "é a captura e entrega de informação tecnológica como parte do processo pelo qual uma organização desenvolve a consciência sobre oportunidades e ameaças tecnológicas". Por esta definição, IT está inserida em um processo maior. Assim, não basta as análises de IT acusarem uma oportunidade ou ameaças que efetivamente se mostre acertada com o tempo, se ela não conseguir sensibilizar no tempo adequado a alta gestão e os diretores, despertando neles a consciência sobre a necessidade de ação.

Vasconcellos e Diniz (2000) definem a IT como sendo parte do sistema de IC, compreendendo o "monitoramento de tendências tecnológicas que possam vir a se transformar em oportunidades e/ou ameaças para a empresa". 
Um dos primeiros artigos a utilizar o termo IT foi o de Brockhoff (1991), que discute a importância do uso de sistemas para monitorar a tecnologia dos concorrentes. $\mathrm{O}$ autor cita que a empresa Bayer já analisava sistematicamente as atividades de patenteamento de seus concorrentes em 1886, apenas nove anos depois do escritório de patentes alemão ser aberto.

Lichtenthaler (2003) realizou uma pesquisa com objetivo de investigar a evolução da atividade de inteligência tecnológica. Descobriu que algumas empresas já possuíam iniciativas entre 1960 e 1970, mesmo sem a utilização do termo IT dentro das empresas. Em seu estudo, identificou três principais gerações de inteligência tecnológica. A primeira geração era caracterizada pela falta de ligação entre a estratégia corporativa e a estratégia tecnológica, sendo o principal objetivo a realização de previsões (forecasting) tecnológicas. Na segunda geração encontra-se uma maior interligação entre o P\&D e a gestão da empresa, mas ainda sem uma orientação estratégica de longo prazo. A terceira geração ocorre no contexto da terceira geração da gestão tecnológica, termo popularizado por Roussell et al (1991). É caracterizada pela integração das estratégias tecnológica e de P\&D com a estratégia corporativa ou da unidade de negócios. A habilidade de aprendizado é fortalecida pela descentralização do processo de planejamento tecnológico e alocação de recursos. Atividades de P\&D são integradas globalmente e os sites internacionais são vistos como ferramenta para aprendizado de tecnologia e mercado globais. A descentralização muda a forma de disseminação. A alta administração recebe menos informação, que é distribuída de forma mais ampla dentro das corporações.

Segundo Vasconcellos e Diniz (2000) um modelo de sistema de inteligência tecnológica é constituído de dois componentes principais: um processo contínuo de coleta e disseminação de informações e projetos específicos voltados para os temas prioritários. 


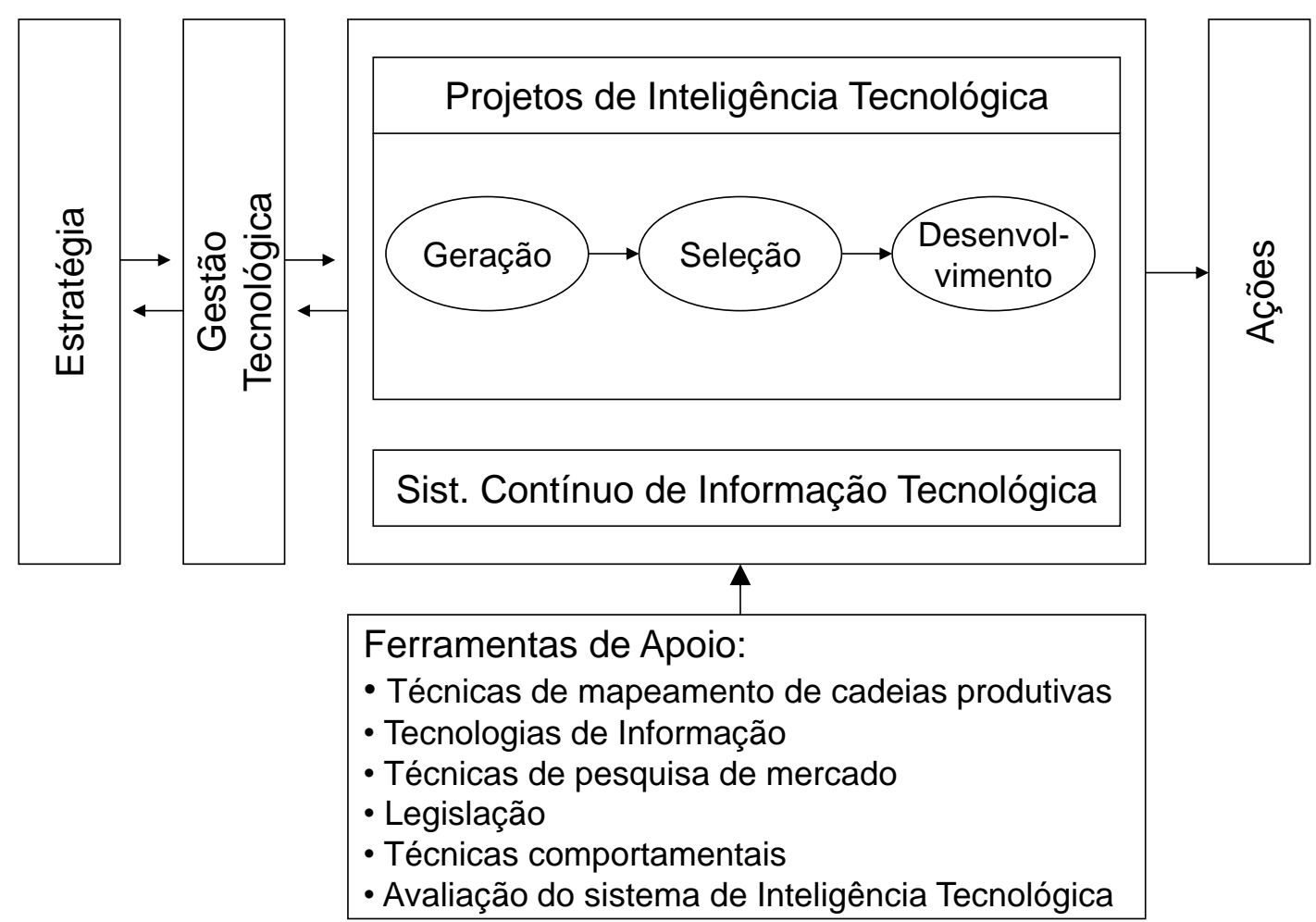

Figura 5 - Sistema de inteligência tecnológica

FONTE: VASCONCELLOS; DINIZ, 2000

Schuh e Grawatsch (2004) discorrem sobre o uso do modelo das cinco forças de Porter (PORTER, 1980) para avaliação de oportunidades e ameaças tecnológicas. Segundo estes autores, a questão central que este método irá responder é "como o potencial de diferentes tecnologias de produto que atendem a mesma função primária pode ser avaliada a partir da perspectiva da empresa" (SCHUH e GRAWATSCH, 2004). O resultado deste processo pode ser um roadmap tecnológico exploratório descrevendo o desenvolvimento de uma tecnologia e seu entorno. A partir deste resultado, caberia à empresa analisar as oportunidades e ameaças para desenvolver o roadmap tecnológico específico da companhia. A figura 6 ilustra o modelo de inteligência tecnológica proposto por Schuh e Grawatsch. 


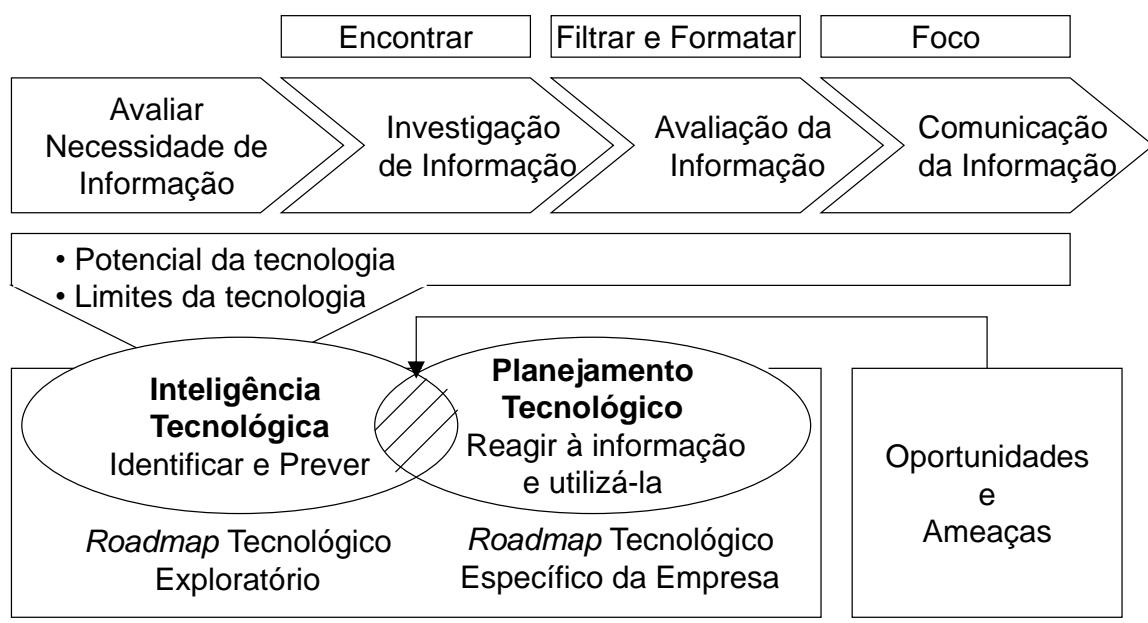

Figura 6 - Inteligência tecnológica segundo Schuh e Grawatsch

FONTE: Adaptado de SCHUH; GRAWATSCH, 2004

O tema IT e especificamente técnicas para avaliar ameaças e oportunidades tecnológicas são assuntos ainda muito recentes na academia, representando uma grande oportunidade como campo de estudo.

A seguir, discutiremos os processos de coleta, análise e disseminação das informações.

\subsubsection{Coleta de Dados}

Segundo Kerr et al (2006) existem quatro modos de busca de informação para a IT, representados na figura 8: Passar a Rede (Trawl), no qual a empresa não sabe o que ela sabe; Minerar (Mine), no qual a empresa sabe o que ela sabe; Escanear (Scan), no qual a empresa não sabe o que ela não sabe; Mirar (Target), no qual a empresa sabe o que ela não sabe. 


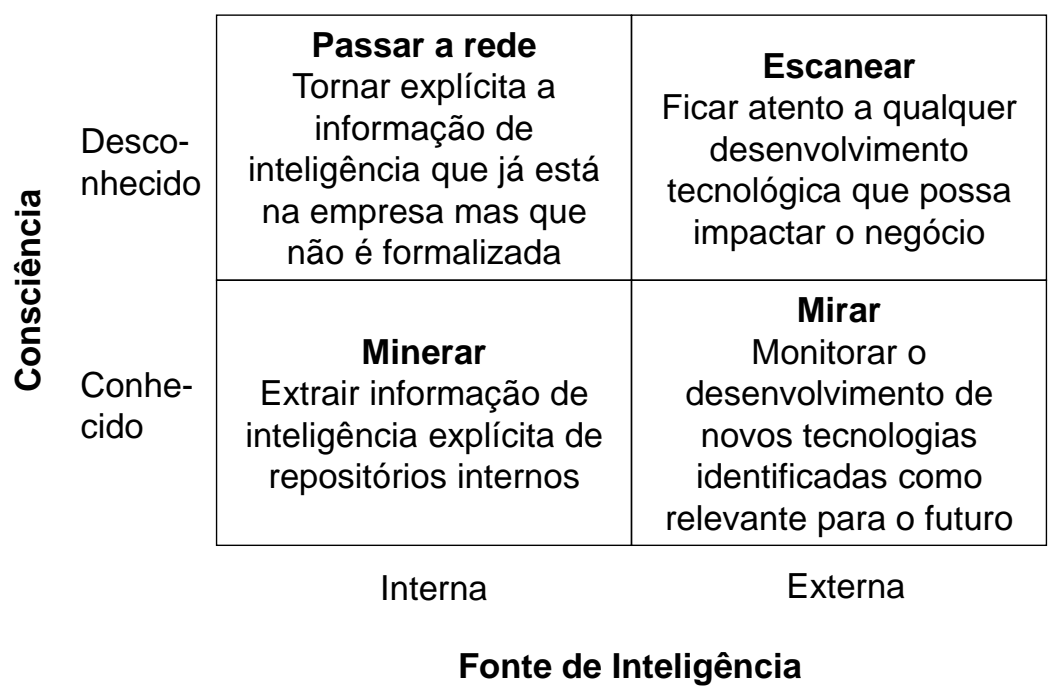

\section{Figura 7 - Modos de busca de informação segundo Kerr et al}

FONTE: Adaptado de KERR et al, 2006, p. 81

Existem vários estudos apontando a importância de se coletar dados do ambiente externo a fim de se identificar potenciais oportunidades ou ameaças no campo tecnológico. Não necessariamente estas oportunidades e ameaças são oriundas do ambiente tecnologia. Por exemplo, Bright (1970), já em 1970, salientava a importância de se antecipar mudanças tecnológicas, sendo que as oportunidades e ameaças poderiam ser oriundas do ambiente político, econômico, tecnológico propriamente dito, e social. Subramanian et al (1993) adicionam a estes 4 ambientes os aspectos legais. Daft et al (1988) salientam, adicionalmente, a importância dos clientes e da concorrência. Ozaki et al (2011) realizaram uma revisão da literatura sobre monitoramento do ambiente e propõem uma ferramenta denominada radar de monitoramento tecnológico.

Vasconcellos et al (2007) realizaram uma pesquisa aplicando o modelo das forças competitivas de Porter (1980) para acompanhar e planejar o avanço e a evolução tecnológica no ambiente competitivo. Adaptaram o modelo retirando a força "Produtos Substitutos" e incluindo-a nas demais forças, uma vez que produtos substitutos podem surgir de concorrentes, novos entrantes, fornecedores, ou até mesmo serem adotados pelos clientes. Também incluíram uma categoria denominada "Outras Forças" para avaliar, por exemplo, o impacto das regulamentações governamentais. A figura 7 representa o modelo conceitual desse estudo. 


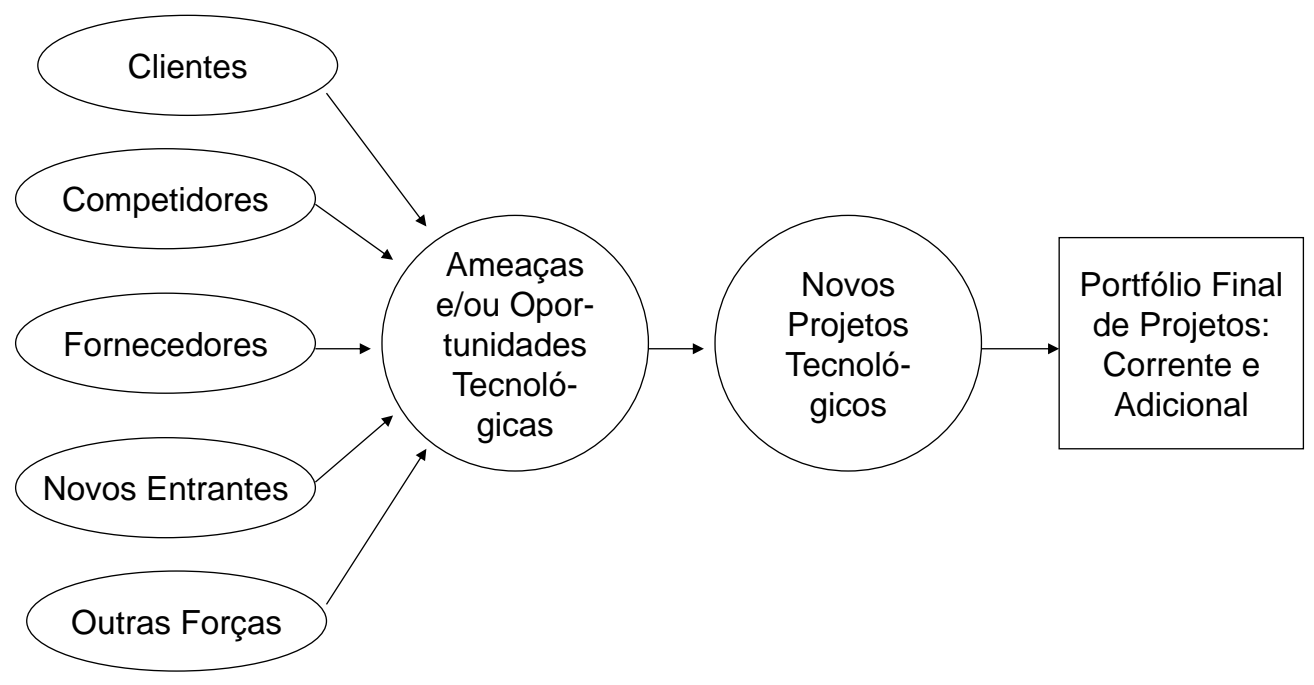

Figura 8 - Modelo para identificar oportunidades e ameaças tecnológicas FONTE: VASCONCELLOS et al, 2007, p.5

Segundo Brockhoff (1991), a coleta e o uso da informação deve ser descentralizado, mas a análise centralizada, e que quando os processos de IT são institucionalizados, a empresa se beneficia pela capacidade de identificar alertas mesmo antes dos competidores introduzirem novos produtos no mercado.

No quadro 1 sintetizamos a nomenclatura e os ambientes que, segundo os autores pesquisados, devem ser escaneados/monitorados.

\section{Quadro 1 - Ambientes para escaneamento/monitoramento}

\begin{tabular}{|c|c|c|c|c|c|}
\hline & \multicolumn{5}{|c|}{ Autor } \\
\hline & \begin{tabular}{|ll} 
Vasconcellos & $e t$ \\
al (2006) &
\end{tabular} & $\begin{array}{lll}\text { Daft } & \text { et } & \text { al } \\
(1988) & & \end{array}$ & $\begin{array}{l}\text { Subramanian } \\
\text { et al (1993) }\end{array}$ & Bright (1970) & $\begin{array}{l}\text { Ozaki, Del Rey e } \\
\text { Almeida (2011) }\end{array}$ \\
\hline $\begin{array}{l}\text { Nomenclatura } \\
\text { utilizada }\end{array}$ & Forças & Setores & Setores & Ambiente & Ambiente \\
\hline $\begin{array}{l}\text { Ambiente } \\
\text { escaneado/ } \\
\text { monitorado }\end{array}$ & \begin{tabular}{|l} 
Clientes \\
Competidores \\
Fornecedores \\
Novos Entrantes \\
Outras Forças
\end{tabular} & \begin{tabular}{|l|} 
Clientes \\
Competição \\
Tecnológico \\
Regulatório \\
Econômico \\
Sócio-cultural
\end{tabular} & \begin{tabular}{|l|} 
Econômico \\
Político \\
Tecnológico \\
Social \\
Legal
\end{tabular} & $\begin{array}{l}\text { Político } \\
\text { Econômico } \\
\text { Social } \\
\text { Tecnológico }\end{array}$ & \begin{tabular}{|l|} 
Político \\
Econômico \\
Social \\
Tecnológico \\
Concorrencial
\end{tabular} \\
\hline
\end{tabular}


Para cada uma destas categorias, existem fontes de informações específicas que uma empresa pode utilizar para buscar informações. A mesma fonte pode inclusive fornecer informações sobre mais de um ambiente. Por exemplo, ao monitorar bancos de patentes como fonte de informação, a empresa pode obter informações sobre o desenvolvimento do ambiente Tecnológico em si, que ocorre em universidades e centros de pesquisa independentes, mas também resultados da atividade de P\&D de Concorrentes e Clientes. Um cliente específico pode ser fonte de informação do ambiente Clientes, mas também do ambiente Concorrentes ao informar propostas que tenha recebido de outras empresas, por exemplo.

A literatura faz distinção entre os termos escaneamento (scanning) e monitoramento (monitoring). O escaneamento é uma busca não direcionada de informações no ambiente, enquanto que o monitoramento é uma busca mais direcionada a ambientes ou fontes específicas (LICHTENTHALER, 2004; ASHTON et al, 1991). Ashton et al (1991) inclui ainda no monitoramento as atividades de análise e disseminação de informações. O mesmo autor explora uma metodologia para se monitorar o avanço científico e tecnológico. A busca não direcionada de informações, mesmo sendo apenas indícios de possíveis oportunidades e ameaças, já foi explorada por outros autores. Por exemplo, Ansoff (1975) destacou a importância de se identificar e acompanhar sinais fracos (weak signals) de eventos/fatos que possam impactar a organização a fim de permitir à empresa tomar decisões de forma antecipada para aproveitar oportunidades ou mitigar ameaças.

Lichtenthaler (2004) analisou o processo de IT em grandes empresas européia e norteamericanas. Um dos aspectos estudados foi a intensidade de uso de diferentes fontes de informação nos setores estudados. O quadro 2 sumariza as descobertas do autor. 
Quadro 2 - Intensidade de uso de diferentes fontes de informação

\begin{tabular}{|c|c|c|c|}
\hline & $\begin{array}{l}\text { Farmacêu- } \\
\text { ticas }\end{array}$ & Eletrônicos & $\begin{array}{l}\text { Auto/ } \\
\text { Maquinários }\end{array}$ \\
\hline Publicações Científicas & $* * *$ & $* * *$ & $* *$ \\
\hline Patentes & $* *$ & $* * *$ & $* * *$ \\
\hline Fundos de capital de risco & $* * *$ & $* *$ & $*$ \\
\hline Feiras de start ups & $* * *$ & $* *$ & $*$ \\
\hline Contatos universitários & $* * *$ & $* * *$ & $* *$ \\
\hline Consultores e especialistas externos & $* * *$ & $* *$ & $* *$ \\
\hline Conferências científicas & $* * *$ & $* * *$ & $* * *$ \\
\hline Feiras de produtos & - & $*$ & $* *$ \\
\hline Conferências comerciais & $* *$ & $* * *$ & $* * *$ \\
\hline Cooperações & $* * *$ & $* * *$ & $* * *$ \\
\hline Fornecedores & - & $* *$ & $* * *$ \\
\hline Provedores de informação & $* * *$ & **** & $* * *$ \\
\hline Relatórios de bolsa de valores & $* * *$ & $*$ & $*$ \\
\hline Estudos de previsões governamentais & $*$ & $*$ & $* *$ \\
\hline Comitês industriais/de padronização & $*$ & $* * *$ & $* *$ \\
\hline Comitês de pesquisa nacionais & $* * *$ & $* * *$ & $* * *$ \\
\hline Financiamento de teses de doutorado & $* * *$ & $* *$ & $*$ \\
\hline Período sabático & $* * *$ & $*$ & - \\
\hline Emprego temporário de pós-docs & $* * *$ & $* *$ & $*$ \\
\hline Entrevistas com clientes & - & $* * *$ & $* * *$ \\
\hline
\end{tabular}

$* * *=$ usado frequentemente; $* *=$ usados às vezes; $*=$ raramente usado; - = não usado

FONTE: LICHTENTHALER, 2004, p. 130

Ao longo dos últimos anos tem ganho destaque tanto nas empresas quanto nas pesquisas acadêmicas o conceito de inovação aberta (open innovation), termo popularizado por Chesbrough (2003), mas que reflete um fenômeno existente já há muitos anos. Por este conceito, a inovação não é conduzida apenas internamente pela empresa, mas pode existir o envolvimento de agentes externos nas diversas etapas da inovação. Uma das formas de abrir o processo de inovação é justamente ampliar o leque de fontes de inovação e estabelecer parcerias que permitam desenvolver inovações de forma conjunta. Uma importante fonte de 
informações em indústrias altamente inovadoras são as universidades e institutos de pesquisa (TEECE, 2007; CASTELLACCI, 2008).

\subsubsection{Análise das Informações Coletadas}

O processo de coleta tem pouca valia se a empresa não possuir processos de criação de sentido (sensemaking) (WEICK, 1995; ALMEIDA et al, 2007). Enquanto a interpretação está associada ao produto (um entendimento passivo de um fato, por exemplo), a criação de sentido está associada a um processo no qual o agente (empresa) é também autor, ou seja, envolve não apenas o processo reflexivo, mas também a criação e descoberta do objeto que está sendo analisado (WEICK, 1995). Processos que estimulem a criatividade são fundamentais para a criação de sentido (ALMEIDA et al, 2007).

Lichtenthaler (2004), ao estudar empresas multinacionais européias e norte-americanas, além de pesquisar o uso de fontes de informações apresentado previamente no quadro 2, também verificou a intensidade no uso de métodos de inteligência tecnológica, conforme pode ser verificado no quadro 3. 
Quadro 3 - Intensidade do uso de métodos de inteligência tecnológica segundo Lichtenthaler (2004)

\begin{tabular}{|c|c|c|c|}
\hline & $\begin{array}{l}\text { Farmacêu- } \\
\text { ticas }\end{array}$ & Eletrônicos & $\begin{array}{l}\text { Auto/ } \\
\text { Maquinários }\end{array}$ \\
\hline Análise de freqüência de publicações & $* * *$ & $* *$ & * \\
\hline Análise de citação de publicações & $* * *$ & - & - \\
\hline Análise quantitativa de conferências & $* *$ & $* * *$ & * \\
\hline Análise de freqüência de patentes & $* *$ & $* * *$ & $* * *$ \\
\hline Análise de citação de patentes & - & - & $*$ \\
\hline Análise de curva-S & - & - & - \\
\hline Estudos de benchmarking & $* * *$ & $* * *$ & $* * *$ \\
\hline Portfólios & $* * *$ & $* * *$ & $* * *$ \\
\hline Estudos Delphi & - & - & - \\
\hline Painéis de especialistas & $* * *$ & $*$ & $* *$ \\
\hline Entrevistas flexíveis com especialistas & $* * *$ & $* * *$ & $* * *$ \\
\hline Roadmaps de tecnologia & $* *$ & $* * *$ & - \\
\hline Roadmaps de tecnologia de produtos & - & $* * *$ & * \\
\hline Roadmaps de produto & $* * *$ & - & - \\
\hline Curvas de experiência & $*$ & $* * *$ & $* *$ \\
\hline Simulações & $* *$ & - & - \\
\hline Modelos de precificação de opções & $* *$ & - & - \\
\hline Análise de cenários & $* * *$ & $* * *$ & $* * *$ \\
\hline Análise de usuários chave (lead users) & - & $* * *$ & $* *$ \\
\hline $\begin{array}{l}\text { Desdobramento da função qualidade } \\
\text { (QFD) }\end{array}$ & - & $* *$ & $* * *$ \\
\hline
\end{tabular}

$* * *=$ usado frequentemente; $* *=$ usados às vezes; * = raramente usado; - = não usado

FONTE: LICHTENTHALER, 2004, p. 130

Foge ao escopo deste trabalho detalhar cada uma das técnicas deste quadro, porém, algumas destas técnicas têm maior adoção por empresas de TI. Fonseca et al (2011) realizaram uma pesquisa sobre uso de 4 técnicas de análise em 57 empresas de TI brasileiras. Identificaram que, em ordem decrescente, as técnicas mais utilizadas são cenários (usada por 38,6\% das empresas), roadmaps $(35,1 \%)$, extrapolação de tendências $(26,3 \%)$ e pesquisa Delphi $(8,8 \%)$. 
Os autores identificaram também um alto grau de desconhecimento por parte das empresas com relação à pesquisa Delphi (28\%). Planejamento de cenários corresponde a um método disciplinado para imaginar possíveis futuros (SCHOEMAKER, 1995). Segundo Wright e Spers (2006), cenários não tem como objetivo a predição, e consiste em um esforço para criar descrições plausíveis e consistentes de situações futuras possíveis. Teve origem militar, sendo aplicado no instituto Rand, mas foi rapidamente incorporado por grandes corporações que precisavam melhorar seu sistema de planejamento a fim de se preparar para o futuro (DREW, 2006). O método Delphi corresponde a um questionário interativo, que é respondido repetidas vezes por um grupo de especialistas (WRIGHT; GIOVINAZZO, 2000). A cada rodada, os respondentes recebem informações sobre as respostas da rodada anterior, sendo o ciclo repetido diversas vezes até se obter convergência nos resultados.

Devido à necessidade de se atribuir um foco mais específico, nesta pesquisa iremos estudar o uso de roadmaps, que será melhor explorado no item 2.4.

A seguir, discutimos o processo de disseminação das informações.

\subsubsection{Disseminação das Informações}

A informação também precisa ser disseminada para a organização (NORLING et al, 2001; DISHMAN; CALOF, 2008), a fim de que os colaboradores possam utilizá-la e identificar a necessidade de ação. Esta ação pode ser a decisão imediata de alguma transformação na empresa, ou apenas o despertar da consciência da necessidade de aprendizado de alguma tecnologia, possibilitando assim o acúmulo de um estoque de conhecimento que possa ser utilizado posteriormente.

Lichtenthaler (2004) identificou duas principais formas de integração entre as atividades de IT e a estratégia da empresa que são a integração de IT nos processo de planejamento e decisão e a comunicação por parte de IT aos executivos de descontinuidades tecnológicas que possam representar oportunidades ou ameaças. A primeira situação permite a IT tanto expor as análises realizadas, quanto identificar novas necessidades de informação. Lichtenthaler (2004) cita como exemplo a indústria farmacêutica, cujas empresas normalmente possuem um funil 
de desenvolvimento de produtos bem definido, sendo que no estágio inicial geralmente fazem um planejamento integrado entre marketing e tecnologia para analisar e considerar as informações existentes, ao mesmo tempo que geram novas necessidades de informação para a tomada de decisão sobre início de novos projetos de desenvolvimento de produtos. As empresas podem também criar rotinas para avaliar e comunicar as tendências de descontinuidade tecnológica, o que pode gerar a conscientização dos executivos sobre uma necessidade de decisão (por exemplo, descontinuar um produto), demandando novas informações por parte da IT para tomada de decisão.

Segundo Nonaka e Takeuchi (1997) existem quatro modos de conversão do conhecimento: (a) internalização: corresponde à conversão do conhecimento explícito em tácito, que ocorre quando uma pessoa apreende conhecimentos através de manuais ou vídeos, por exemplo; (b) socialização: é o processo pelo qual o conhecimento tácito é compartilhado pelas pessoas; (c) externalização: é processo pelo qual o conhecimento tácito é formalizado e tornado explícito; (d) combinação: que são mecanismos para combinar conhecimentos explícitos, por meio, por exemplo, de sistemas inteligentes que possam gerar inferências a partir de informações de diferentes fontes.

Segundo Lichtenthaler (2004) as empresas utilizam uma ampla variedade de ferramentas para comunicação das informações e análises de IT, que vão do e-mail, fax, telefonema ou intranets. Cita o exemplo da Novartis, que possui um time global de cerca de 180 pessoas relacionadas com IT direta ou indiretamente, e que na maior parte do ano postam e discutem suas informações e análises por meio de uma intranet. Adicionalmente, três ou quatro vezes ao ano se reúnem fisicamente para socialização do conhecimento. Lichtenthaler (2004) discute 3 formas principais de coordenação, que podem ser utilizadas ou não de forma simultânea pelas empresas:

- Coordenação hierárquica, na qual as tarefas são atribuídas por meio da hierarquia entre posições e departamentos. Muitas das empresas pesquisadas por Lichtenthaler (2004) possuíam uma unidade central de IT e unidades de IT também nas unidades de negócio, formando uma rede de especialistas que trocam informações coletadas periodicamente; 
- Coordenação híbrida, na qual os times de IT muitas vezes são formados para projetos de duração limitada, para atender a problemas ou necessidades específicas de informação. Pode estar ligada ao processo de planejamento tecnológico, que devido à necessidade de realizar o roadmap ou análise de cenários, monta um time responsável para estas atividades;

- Coordenação informal: na qual a área de IT procura direcionar a coleta de informação autônoma por meio da facilitação da comunicação, cultura e estratégias de comunicação.

Além de processos para adquirir conhecimento novo, empresas bem sucedidas precisam se preocupar em socializar (NONAKA; TAKEUCHI, 1997) e integrar (GRANT, 1996) seus conhecimentos. A socialização do conhecimento permite à empresa criar uma base comum sobre a qual as pessoas possam operar rotinas e minimizar a perda natural da tentativa de transmissão de conhecimento tácito (GRANT, 1996). Esta prática também minimiza a perda de conhecimento decorrente da rotatividade de pessoal, bem como amplia a base de conhecimento sobre a qual a empresa conseguirá posteriormente explorar novas oportunidades criando capacidade absortiva (COHEN; LEVINTHAL, 1990). As capacidades podem ser divididas em vários níveis hierárquicos (GRANT, 1996). Na base, estão os conhecimentos individuais especializados, que podem ser utilizados em capacidades de tarefaespecífica (ex: inserção manual de componentes), que por sua vez são usados em capacidades de níveis cada vez mais amplas e interfuncionais dentro da empresa. Designar um time multifuncional para desenvolvimento de um novo produto não é difícil. A grande dificuldade reside em integrar a amplitude e profundidade do conhecimento dos vários indivíduos da organização para que a inovação seja bem sucedida (GRANT, 1991).

Kerr et al (2006) discutem métricas de qualidade para avaliar os processos de IT. Sugerem o uso de quatro dimensões:

- Intrínseca, que avalia se a informação tem valor em si. Considera acurácia, credibilidade, objetividade, confiabilidade e verificabilidade.

- Contextual, que avalia a informação no contexto de uso. Considera se é completa, importante, informativa, relevante, no tempo certo, única, volátil. 
- Representacional, que se refere à facilidade de interpretação pelo decisor. Considera a clareza, granularidade, interpretabilidade, integridade semântica e facilidade de entendimento.

- Acessibilidade, que considera a facilidade de acesso e manipulação da informação.

A atividade de IT não pode, portanto, ter um fim em si mesma. Ela tem por objetivo gerar informação útil à tomada decisão (NORLING et al, 2001; VASCONCELLOS; DINIZ, 2000; KERR et al, 2006). Por este motivo, modelos de processo decisório serão discutidos no próximo tópico.

\subsection{Tomada de Decisão}

\subsubsection{Processo Decisório}

A atividade de elaboração do roadmaps envolve uma série de decisões, desde a própria decisão de iniciar o planejamento de um novo roadmap, passando por decisões específicas sobre as funcionalidades a serem incluídas, até decisões sobre mudança de plataforma tecnológica (SUOMALAINEN et al, 2010; PHAAL et al, 2004). Algumas metodologias adotam métodos multicritério para decisão entre alternativas tecnológicas e elaboração do roadmap (GERDSRI; KOCAOGLU, 2007; SILVEIRA JR, 2013). Assim sendo, antes de discutir especificamente o processo de elaboração de roadmaps, é necessário discutir teorias sobre o processo decisório.

Não há um consenso na literatura sobre um processo único de tomada de decisão. Segundo Keeney (2004), grande parte das decisões empresariais são tomadas de forma inadequada, sem o devido rigor de análise. No quadro 4, Keeney discute os elementos de tomada de decisão que deveriam ser adotados pelas empresas. 


\section{Quadro 4 - Elementos da habilidade de tomada de decisão segundo Keeney}

1. Problema: Definir o problema de decisão para que se resolva o problema certo

2. Objetivos: Especificar o que realmente se está querendo atingir com a decisão

3. Alternativas: Criar melhores alternativas para se escolher

4. Conseqüências: Descrever o quão bem cada alternativa atinge os objetivos

5. Escolhas: Balancear prós e contras de diferentes alternativas para atingir os objetivos

6. Incerteza: Identificar e quantificar as maiores incertezas que afetam a decisão

7. Tolerância ao risco: Avaliar a pré-disposição de aceitar riscos

8. Decisões ligadas: Planejar pela efetiva coordenação de decisões correntes e futuras

FONTE: Adaptado de KEENEY, 2004, p. 197

Os três primeiros elementos do quadro 4 se referem ao processo de estruturar a decisão, que segundo Keeney (2004) é uma etapa fundamental do processo.

Segundo Mintzberg et al (1976), o processo decisório estratégico envolve três fases com alguns processos principais:

- Fase de identificação, que compreende duas rotinas: (a) o reconhecimento da decisão, rotina na qual oportunidades e problemas são reconhecidos e se reconhece a necessidade de uma decisão; e (b) o diagnóstico, na qual os gestores tentam compreender as relações de causa e efeito relativas à situação de decisão.

- Fase de desenvolvimento, que é a fase mais importante, demandando normalmente mais recursos. Envolve duas rotinas: (a) busca, que consiste em procurar uma solução pronta; e, (b) desenho, que consiste em desenvolver uma solução específica para a empresa ou adaptar uma solução pré-existente. Desenvolver não significa implementar a solução, mas desenhar os componentes da solução de forma a clarificar a tomada de decisão.

- Fase de seleção, que muitas vezes é executada de forma concomitante com a fase de desenvolvimento. A empresa vai desenvolvendo alternativas de solução específicas, comparando-as e decidindo qual manter e avançar em seu desenvolvimento. Envolve uma investigação progressiva e aprofundada sobre as 
alternativas. Mintzberg et al (1976) discutem três rotinas nesta fase: (a) triagem, é a rotina que interage com a busca de alternativas, para triar e definir quais alternativas merecem um desenvolvimento mais aprofundado; (b) avaliação e escolha: rotina que, segundo Mintzberg et al (1976), recebe ênfase em muitos estudos e métodos decisórios mas que, porém, sua pesquisa empírica mostrou que geralmente apenas ratifica a alternativa que avançou mais durante a rotina de desenho e que de certa forma já estava pré-concebida na rotina de diagnóstico. Segundo a pesquisa de Mintzberg et al (1976) a escolha pode envolver três modos: julgamento, no qual um executivo julga e toma a decisão sem conseguir explicar bem os motivos da escolha; barganha, na qual um grupo de executivos discutem e tentam convencer os demais de que a sua alternativa favorita é a melhor; e análise, na qual tecnocratas elaboram análises detalhadas e depois há a tomada de decisão efetiva pelo modo julgamento ou barganha. A terceira e última rotina consiste na (c) autorização, que é necessária quando a(s) pessoa(s) que tomou a decisão não tem autonomia para direcionar a empresa rumo à alternativa escolhida.

Cabe destacar que as rotinas citadas por Mintzberg et al (1976) não precisam necessariamente ser formalmente definidas e nem são executadas por todas as organizações e em todas as decisões. Este modelo, representado na figura 9, foi elaborado com base na análise de 25 processos de decisão estratégica.

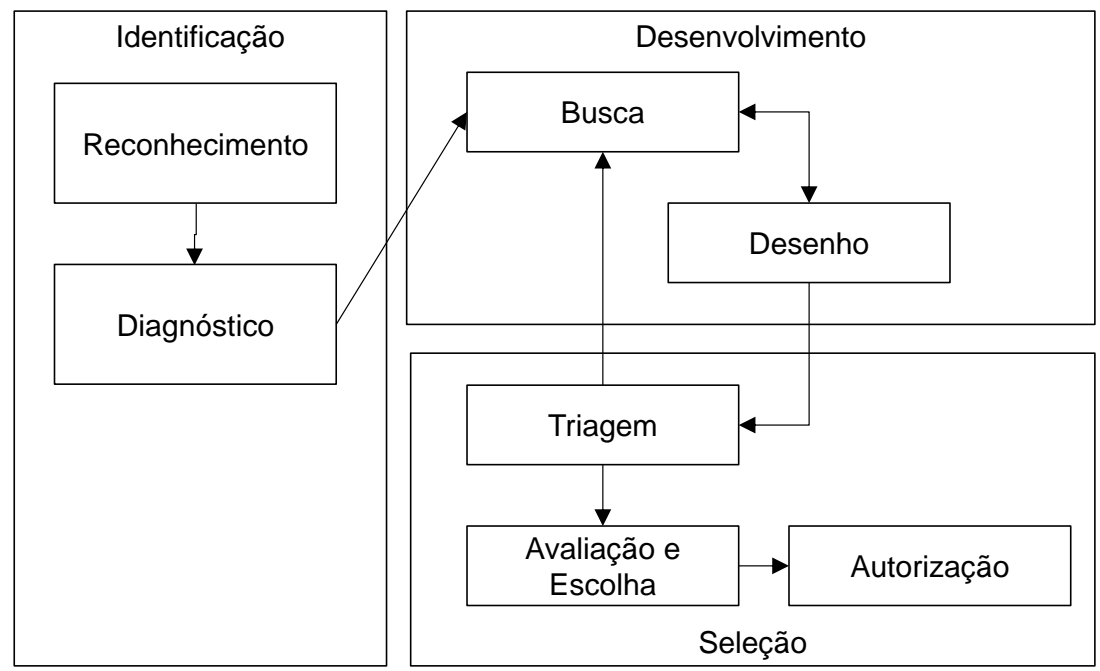

Figura 9 - Etapas do processo decisório

FONTE: Adaptado de MINTZBERG et al, 1976 
As três formas de avaliação e escolha identificadas por Mintzberg et al (1976) - julgamento, barganha e análise - correspondem justamente a três grandes correntes teóricas dos estudos sobre o processo decisório segundo Elbanna (2006):

- Racionalidade: na qual existe um processo formal de decisão que pretende ser racional. Esta corrente reconhece que há subjetividade e limitações cognitivas dos gestores que geram vieses de decisão. Porém, tenta-se criar processos para minimizar os efeitos destas limitações.

- Comportamento político: segundo esta corrente, a alternativa escolhida não é necessariamente a que apresenta melhor avaliação técnica, mas a que atende aos interesses dos gestores que politicamente possuem mais poder dentro da organização.

- Intuição: segundo esta corrente, o gestor adota uma abordagem holística e não consegue racionalmente explicar porque tomou uma determinada decisão.

Desta forma, as pesquisas buscam aperfeiçoar processos de tomada de decisão que permitam tornar mais claro um problema "opaco", por meio da formulação e entendimento da situação, busca de alternativas, identificação das informações necessárias para a tomada de decisão em geral expressas por meio de critérios, culminando com a análise das preferências em termos de valor, tempo e risco (HOWARD, 1988). Os passos podem variar, porém, o ponto central é o estabelecimento de alternativas e critérios para a tomada de decisão. Devido ao uso de diversos critérios para análise, são também chamados de métodos multicritério de tomada de decisão (MMTD) (HOBBS; MEIER, 1994; SALO et al, 2003).

\subsubsection{Métodos Multicritério para Tomada de Decisão}

Segundo Hobbs e Meier (1994), os MMTD possuem dois objetivos principais. O primeiro é descrever as vantagens e desvantagens das alternativas segundo diferentes objetivos. $\mathrm{O}$ segundo é auxiliar os decisores a articular seus valores, de forma racional e consistente, documentando o resultado. Desta forma, um dos grandes benefícios da aplicação dos MMTD 
é clarificar melhor as vantagens e desvantagens de cada alternativa, e obter insights para a tomada de decisão.

Existem diversos MMTD. Porém, nesta tese nos concentraremos em explicar dois métodos, o SMART (sigla para simple multiattribute rating technique) e o AHP (sigla para analytic hierarchy process), pois são os métodos que possuem relação com os estudos sobre elaboração de roadmaps que abordam processo decisório.

Poucas pesquisas sobre roadmap tecnológico abordam como a empresa decide entre tecnologias alternativas. Silveira Jr. (2013) descreve um método que se aproxima do método SMART, e Gerdsri e Kocaoglu (2007) propõe um método que faz uma adaptação do AHP. Ambas as metodologias, de Silveira Jr. (2013) e Gerdsri e Kocaoglu (2007) serão explicadas no próximo tópico. Porém, cabe aqui uma explicação sobre os métodos SMART e AHP para que as metodologias de roadmap possam ser plenamente entendidas posteriormente.

O método SMART se baseia na identificação de alternativas de decisão (chamadas pelos autores de entities) e critérios de avaliação (chamados pelos autores de dimensions). Para atribuição dos pesos dos critérios, Edwards (1977) recomenda ordená-los em ordem crescente de importância, atribuindo para o critério menos importante o peso 10. Para o segundo critério menos importante, se pergunta o quanto ele é mais importante que o primeiro. Uma nota 20 significa que ele é duas vezes mais importante que o primeiro. Executa-se este procedimento para todos os critérios. Depois, divide-se o peso de cada critério pela somatória dos pesos, para que eles sejam expressos em forma de percentual. $\mathrm{O}$ quadro 5 ilustra a aplicação do método, considerando critérios $\left(\mathrm{C}_{1}\right.$ a $\left.\mathrm{C}_{\mathrm{n}}\right)$, os seus respectivos pesos $\left(\mathrm{W}_{1}\right.$ a $\left.\mathrm{W}_{\mathrm{n}}\right)$, e alternativas consideradas na decisão $\left(\mathrm{A}_{1}\right.$ a $\left.\mathrm{A}_{\mathrm{k}}\right)$. Para cada critério, pede-se para o decisor atribuir um valor de utilidade para a alternativa, segundo o critério $\left(\mathrm{U}_{\mathrm{ij}}\right.$, sendo que $\mathrm{i}$ varia de 1 a $\mathrm{k}$ alternativas de decisão, e j varia de 1 a n critérios). 
Quadro 5 - Matriz para decisão segundo o método SMART

\begin{tabular}{|l|c|c|c|c|}
\hline \multirow{2}{*}{ Critério } & \multirow{2}{*}{\begin{tabular}{c} 
Peso do \\
\multirow{2}{*}{ Critério }
\end{tabular}} & \multicolumn{3}{|c|}{ Alternativas a serem analisadas na decisão } \\
\cline { 3 - 5 } & $\mathrm{W}_{1}$ & $\mathrm{~A}_{11}$ & $\mathrm{~A}_{2}$ & $\mathrm{~A}_{\mathrm{k}}$ \\
\hline $\mathrm{C}_{1}$ & $\mathrm{~W}_{2}$ & $\mathrm{U}_{12}$ & $\mathrm{U}_{21}$ & $\mathrm{U}_{\mathrm{k} 1}$ \\
\hline $\mathrm{C}_{2}$ & $\cdots$ & $\cdots$ & $\mathrm{U}_{22}$ & $\mathrm{U}_{\mathrm{k} 2}$ \\
\hline$\cdots$ & $\mathrm{W}_{\mathrm{n}}$ & $\mathrm{U}_{1 \mathrm{n}}$ & $\mathrm{U}_{2 \mathrm{n}}$ & $\cdots$ \\
\hline $\mathrm{C}_{\mathrm{n}}$ & & & $\mathrm{U}_{\mathrm{kn}}$ \\
\hline
\end{tabular}

Por fim, para cada alternativa de decisão $\mathrm{A}_{\mathrm{i}}$, (i variando de $1 \mathrm{a} \mathrm{k}$ ) é calculada a sua Utilidade $\left(\mathrm{U}_{\mathrm{i}}\right)$, que corresponde à somatória da multiplicação da nota atribuída para a utilidade da alternativa pelo peso do respectivo critério.

$$
U_{i}=\sum_{j=1}^{n} W_{j} \cdot U_{i j}
$$

A alternativa com maior utilidade total é a que maximiza os benefícios de acordo com os critérios analisados (EDWARDS, 1977). A vantagem deste método é a facilidade de aplicação e compreensão por parte dos gestores, além de exigir menos tempo para a sua aplicação.

O AHP é um método que tem como preocupação principal a mensuração e a escala na comparação de diversas alternativas (SAATY, 1990; SALO et al, 2003). De acordo com este método, cria-se uma estrutura, partindo-se de um grande objetivo geral, decomposto em critérios, que podem ser divididos em sub-critérios, e assim por diante, em tantos níveis quanto forem necessários. A hierarquia deve representar as dimensões necessárias para avaliação, mas ao mesmo tempo deve contemplar apenas os elementos mais importantes, sendo que os menos importantes (os que geram pouco impacto no objetivo geral), devem ser eliminados do modelo (SAATY, 1990). A partir do estabelecimento da hierarquia, para cada nível, faz-se uma comparação dois a dois entre os diferentes critérios, por meio de uma escala verbal que varia de 1 a 9, sendo 1 - igual importância, 3 - importância moderada de um sobre o outro, 5 - importância forte ou essencial, 7 - importância muito forte, 9 - extremamente importante, e os valores 2, 4, 6 e 8 representando valores intermediários. O quadro 6 ilustra esta matriz comparativa. Comparando dois critérios $\mathrm{C}_{1}$ e $\mathrm{C}_{2}$, digamos que o $\mathrm{C}_{1}$ tenha uma 
importância entre forte e muito forte em relação a $C_{2}$, recebendo nota 6 (w1/w2). A nota de $C_{2}$ em relação a $\mathrm{C}_{1}$ será o inverso, 1/6.

\section{Quadro 6 - Matriz de comparação no AHP}

\begin{tabular}{|l|l|l|l|l|}
\cline { 2 - 5 } \multicolumn{1}{c|}{} & $\mathrm{C}_{1}$ & $\mathrm{C}_{2}$ & $\cdots$ & $\mathrm{C}_{\mathrm{n}}$ \\
\hline $\mathrm{C}_{1}$ & w1/w1 & w1/w2 & & w1/wn \\
\hline $\mathrm{C}_{2}$ & w2/w1 & w2/w2 & & w2/wn \\
\hline$\cdots$ & & & & \\
\hline $\mathrm{C}_{\mathrm{n}}$ & wn/w1 & wn/w2 & & wn/wn \\
\hline
\end{tabular}

O peso do critério, também chamado eigenvalue, corresponde à enézima raiz do produto dos pesos relativos constantes da linha da matriz correspondente, que por sua vez deve ser normalizada dividindo-a pela soma dos pesos (SAATY, 1990).

Sendo $\mathrm{a}_{\mathrm{ij}}=\mathrm{w}_{\mathrm{i}} / \mathrm{w}_{\mathrm{j}}$, o peso $\mathrm{W}_{\mathrm{i}}$ do critério $\mathrm{C}_{\mathrm{i}}$ é dado por:

$$
W_{i}=\sqrt[n]{\sum_{j=1}^{n} a_{i j}}
$$

E o peso normalizado dado por:

$$
W_{i} / \sum_{j=1}^{n} W_{j}
$$

O mesmo procedimento é aplicado para se comparar as alternativas de decisão, dois a dois, segundo cada um dos critérios. Ao final, a somatória da multiplicação das notas de cada alternativa pelo peso do critério resultará na prioridade final de cada alternativa (SAATY, 1990).

Existem diversos outros métodos para tomada de decisão, porém, seria inviável explorar todos eles nesta tese. Assim sendo, procuramos nos concentrar nestes dois métodos, por serem 
adotados em outras pesquisas relacionando elaboração de roadmaps com métodos de tomada de decisão (SILVEIRA JR., 2013; GERDSRI; KOCAOGLU, 2007).

\subsection{Roadmaps}

\subsubsection{Conceituação e Objetivos do Roadmap}

Para aproveitar de forma competitiva os avanços tecnológicos, as empresas precisam de informações sobre o momento em que novas tecnologias estarão disponíveis, os recursos necessários para desenvolvê-las, uma visão sobre as diversas formas com que tais tecnologias podem ser incorporadas a quais produtos, bem como os mercados que se pretende atingir (PETRICK; ECHOLS, 2004).

Roadmapping é o termo utilizado para se referir ao processo que contribui para a integração entre mercado, produto e tecnologia, auxiliando na elaboração da estratégia tecnológica da empresa, integrando a tecnologia ao negócio da empresa (GROENVELD, 1997; PETRICK; ECHOLS, 2004). O resultado deste processo é o roadmap.

O roadmap genérico é uma representação gráfica com base no tempo, que normalmente inclui as perspectivas tecnológicas (tanto de desenvolvimento de produtos quanto de tecnologias importantes a serem utilizadas) e de mercado (PHAAL et al, 2004; ALBRIGHT; KAPPEL, 2003). Segundo Kostoff e Schaller apud Suomalainen et al (2011) roadmap é um layout de caminhos e rotas existentes, que é usado para decidir entre direções alternativas rumo a um objetivo desejado. Porém, o roadmap pode assumir diferentes formatos, podendo, por exemplo, ser uma lista dos futuros desenvolvimentos tecnológicos a serem realizados (PHAAL et al, 2004).

O roadmap pode ser elaborado para analisar tanto uma indústria/setor (industry roadmap) quanto uma empresa específica (corporate roadmap) (PROBERT; RADNOR, 2003). De acordo com Kappel (2001), existem diversas categorias de roadmaps, tais como os de ciência e tecnologia, geralmente elaborados por órgãos governamentais, os de indústria, geralmente 
elaborados por empresas de pesquisa ou associações setoriais, e os de produto, elaborados pela empresa para mostrar a evolução futura de seus produtos.

De acordo com Probert e Radnor (2003), o uso de roadmaps teve início na indústria automobilística, mas foi aprimorado ao longo da década de 70 pelas empresas Motorola e Corning, em um esforço para encorajar os executivos a dar a atenção devida ao futuro tecnológico. É portanto, uma técnica recente, e que passou a ser estudada pela academia apenas nos últimos anos. Um dos primeiros artigos acadêmicos a tratar deste assunto foi o de Willyard e McClees, publicado em 1987 na Research Technology Management (PROBERT; RADNOR, 2003) sobre o uso do roadmap na Motorola.

A figura 10 ilustra um roadmap. Nele, são identificadas as tecnologias a serem adotadas pela empresa, relacionando-as com os respectivos produtos e os mercados-alvo que a empresa pretende atingir.

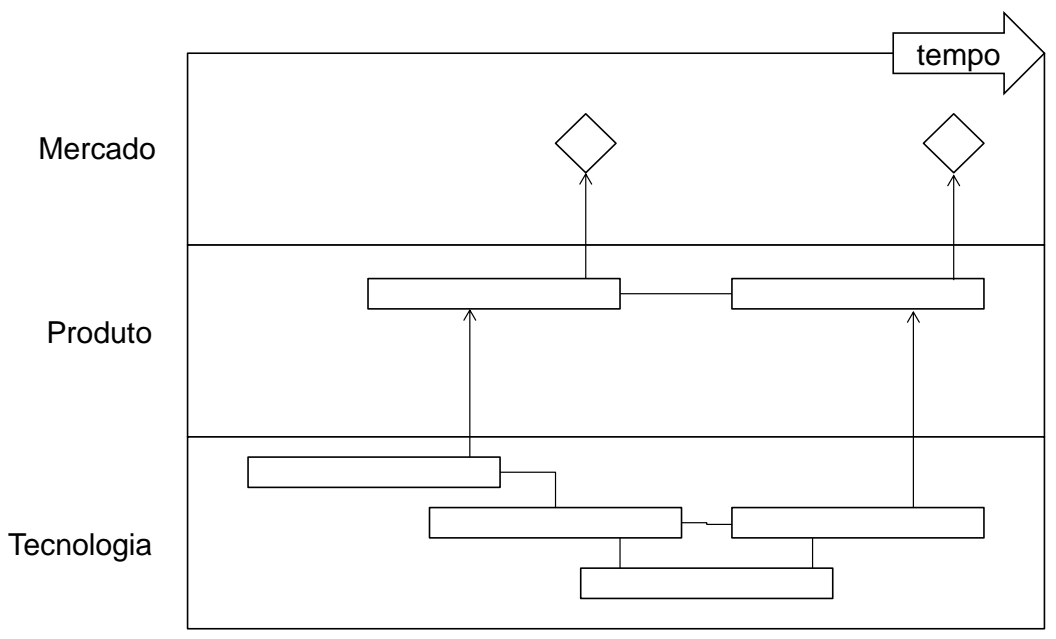

Figura 10 - Exemplo de roadmap

FONTE: Adaptado de PHAAL et al, 2004

Carvalho et al (2013) realizaram uma revisão bibliográfica das publicações sobre o tema entre 1997 e 2011. Localizaram 79 artigos, sendo que as duas revistas que mais têm publicado sobre o tema são a Technological Forecasting and Social Change e a Research-Technology Management. 
Segundo Whalen (2007), o roadmap provê um framework pelo qual as estratégias de negócio ao longo do tempo podem ser alinhadas de uma forma contínua para suportar os objetivos de negócios. Por retratar tecnologia, produto e mercado, permite uma abordagem estratégica tanto puxada pelo mercado (market-pull) quando de empurrar o produto (product-push) (Phaal et al, 2004). Porém, Fleury et al (2006) destacam que a indústria de software possui algumas características peculiares e que a visão de demanda de mercado deveria ser a mais importante, tendo em vista planejar os produtos e tecnologias a serem desenvolvidos.

A adoção de roadmaps tem diversos objetivos, sendo uma ferramenta de apoio ao planejamento estratégico da empresa, permitindo a integração entre diversas áreas e funções e melhorando a comunicação (ALBRIGHT; KAPPEL, 2003; PHAAL et al, 2004; PROBERT; RADNOR, 2003; WHALEN, 2007; BARKER; SMITH, 1995). O roadmap é utilizado também com objetivo de planejamento de programas de $\mathrm{P} \& \mathrm{D}$ e processos, bem como no planejamento de capacidade da empresa (PHAAL et al, 2004; PHAAL et al, 2007; PROBERT; RADNOR, 2003). Kostoff et al (2004) destacam ainda que esta técnica pode ser utilizada para identificar tecnologias de ruptura. Empresas com múltiplas unidades de negócio podem também utilizar esta ferramenta para fazer análises cruzadas entre os roadmaps das diferentes unidades de forma a identificar sinergia e potenciais projetos duplicados que possam ser desenvolvidos conjuntamente (PROBERT; RADNOR, 2003). Adicionalmente, empresas podem adotar também os roadmaps como uma forma de persuadir a alta gestão sobre a importância de seus projetos de desenvolvimento de tecnologia ou produtos e também como ferramenta para treinamento de novos funcionários, transmitindo conhecimentos sobre os projetos em andamento e os futuros mercados e produtos a serem lançados pela empresa (BARKER; SMITH, 1995). O quadro 7 sintetiza os objetivos do roadmap segundo a literatura pesquisada. 
Quadro 7 - Objetivos do roadmap

\begin{tabular}{|c|c|c|c|c|c|c|c|}
\hline & 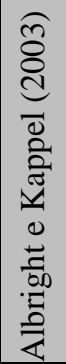 & 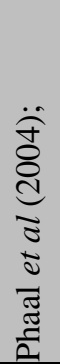 & 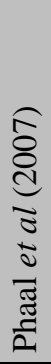 & 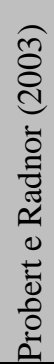 & 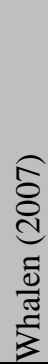 & 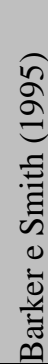 & 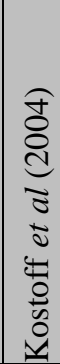 \\
\hline \multicolumn{8}{|l|}{ Objetivos / Aplicações Corporativas } \\
\hline Planejamento de produto & & $\mathrm{x}$ & & $\mathrm{x}$ & $\mathrm{x}$ & & \\
\hline Planejamento de capacidade & & $\mathrm{x}$ & & $\mathrm{x}$ & & & \\
\hline Planejamento estratégico & $\mathrm{x}$ & $\mathrm{x}$ & & $\mathrm{x}$ & $\mathrm{x}$ & $\mathrm{x}$ & \\
\hline Planejamento futuro a longo prazo & $\mathrm{x}$ & $\mathrm{x}$ & & $\mathrm{x}$ & & $\mathrm{x}$ & $\mathrm{x}$ \\
\hline Identificar tecnologias de ruptura & & & & & & & $\mathrm{X}$ \\
\hline $\begin{array}{l}\text { Planejamento dos ativos de } \\
\text { conhecimento }\end{array}$ & & $\mathrm{X}$ & & & & & \\
\hline Planejamento de programas de P\&D & & $\mathrm{x}$ & & $\mathrm{x}$ & $\mathrm{x}$ & $\mathrm{x}$ & \\
\hline Planejamento de processos & & $\mathrm{x}$ & & $\mathrm{x}$ & & & \\
\hline $\begin{array}{l}\text { Integração entre diversas áreas/funções } \\
\text { (produto/tecnologia/mercado) }\end{array}$ & $\mathrm{x}$ & $\mathrm{X}$ & & $\mathrm{x}$ & $\mathrm{X}$ & $x$ & \\
\hline Melhoria da comunicação & $\mathrm{x}$ & & & & $\mathrm{X}$ & $\mathrm{X}$ & \\
\hline Integração com processos de qualidade & & & & & $\mathrm{x}$ & & \\
\hline $\begin{array}{l}\text { Análise cruzada de roadmaps entre } \\
\text { diferentes unidades de negócio }\end{array}$ & & & & $\mathrm{x}$ & & & \\
\hline Persuadir alta gestão & & & & & & $\mathrm{x}$ & \\
\hline Treinamento de novos funcionários & & & & & & $\mathrm{x}$ & \\
\hline
\end{tabular}

\subsubsection{Formato e Conteúdo dos Roadmaps}

Apesar de parecer bastante simples, Phaal et al (2004) realizaram uma pesquisa empírica que mostrou uma grande variedade e flexibilidade na aplicação de roadmaps. Analisando 40 diferentes roadmaps, identificaram que eles podem servir tanto para o planejamento estratégico quanto tecnológico, para curto e longo prazos, para produtos, serviços ou processos. 
Phaal et al (2004) destacaram em sua pesquisa 6 tipos principais de formatos de apresentação de roadmaps representados na figura 11, a saber: a) camadas múltiplas, b) barras, c) tabular, d) gráfico, e) figurativo, f) fluxograma. O formado de barras foi explorado no artigo de Grossman (2004), que explora a abordagem de roadmap da GM. Mas a grande maioria dos artigos encontrados explora casos que utilizam o formato de múltiplas camadas (ALBRIGHT; KAPPEL, 2003; GROENVELD, 1997; PETRICK; ECHOLS, 2004; WHALEN, 2007; KOSTOFF et al, 2004).

a)

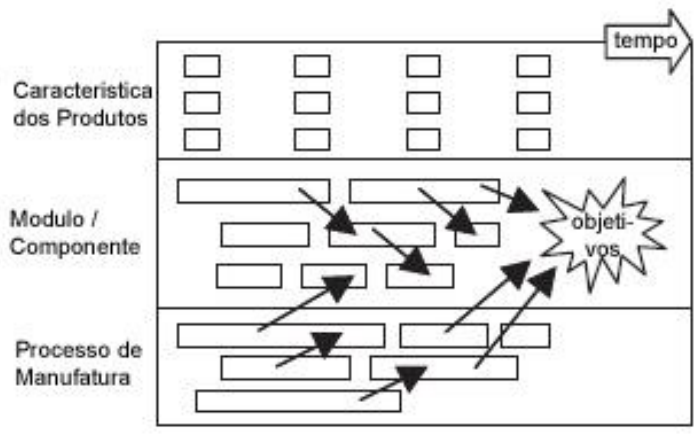

c)

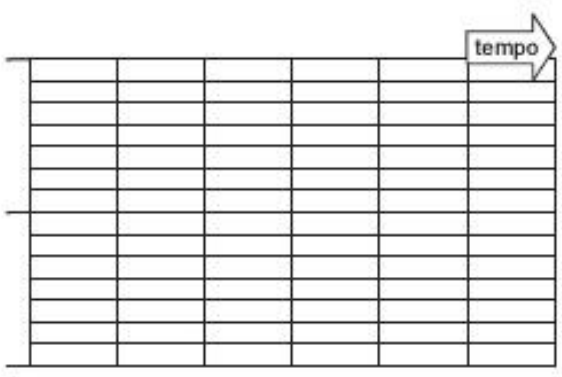

e)

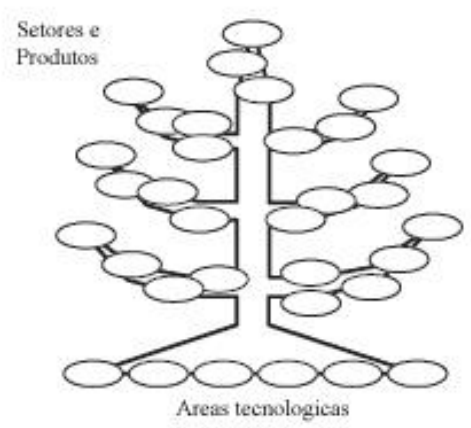

b)

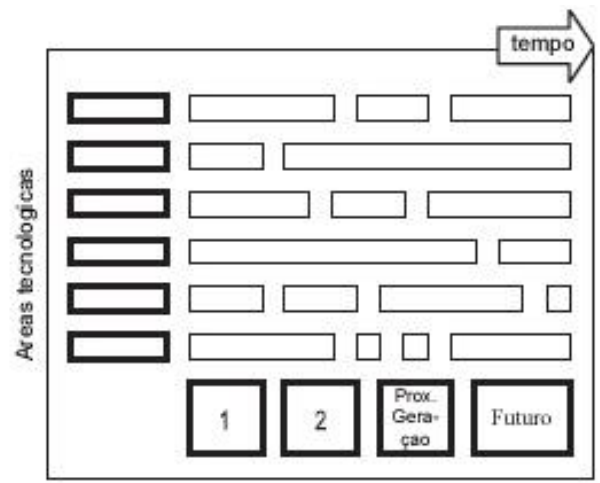

d)

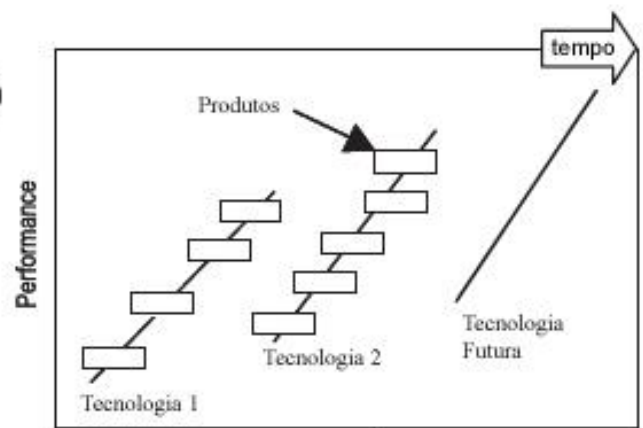

f)

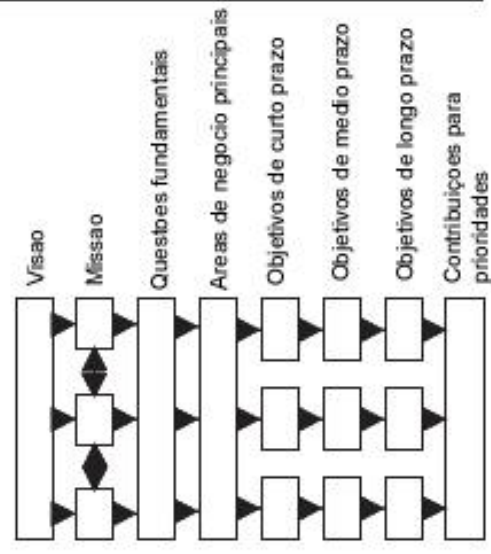

Figura 11 - Formatos de roadmap

FONTE: PHAAL et al, 2004 
Com relação ao conteúdo do roadmap, a maior parte dos artigos que explora este aspecto contempla a tríade mercado, produto e tecnologia (ALBRIGHT; KAPPEL, 2003; PETRICK; ECHOLS, 2004; WHALEN, 2007; BARKER; SMITH, 1995; KOSTOFF et al, 2004).

Segundo Barker e Smith (1995) o roadmap deve também conter uma seção sobre a estratégia de negócios da empresa. Kostoff et al (2004) argumentam que o roadmap também deve abordar aspectos de capacitação sobre competências necessárias para desenvolvimento das tecnologias e produtos planejados. Albright e Kappel (2003) destacam ainda que ao final, deve-se apresentar um plano de ação, identificando os potenciais riscos para cumprimento do roadmap.

Especificamente sobre as três seções mais importantes (tecnologia-produto-mercado), alguns autores detalham aspectos que devem ser contemplados. Na seção mercado, deve-se abordar as tendências de mercado e análise dos competidores (ALBRIGHT; KAPPEL, 2003; WHALEN, 2007), a definição dos segmentos de mercado (ALBRIGHT; KAPPEL, 2003), podendo também ser abordado roadmap da indústria ou de padrões, ações governamentais/regulatórias, bem como a necessidade dos consumidores (WHALEN, 2007). $\mathrm{Na}$ seção produto, pode-se detalhar aspectos como os direcionadores do produto, ou seja, aspectos importantes que podem contribuir para seu desenvolvimento, curva de experiência com previsão de preços (ALBRIGHT; KAPPEL, 2003), além de aspectos do projeto de P\&D (PETRICK; ECHOLS, 2004; GROSSMAN, 2004), tais como datas de início e término de desenvolvimento dos produtos, data de lançamento e retirada de mercado, atributos chave específicos do produto, bem como o roadmap de fornecedores ou parceiros críticos para o produto (WHALEN, 2007). A seção tecnologia pode abordar custos futuros (ALBRIGHT; KAPPEL, 2003), início e fim do desenvolvimento da tecnologia, pontos de decisão sobre tecnologias alternativas, início e término da disponibilidade da tecnologia no mercado, e especificação ou metas de performance para cada esforço de desenvolvimento de tecnologia (WHALEN, 2007).

O quadro 8 sintetiza o conteúdo contemplado no roadmap segundo a literatura pesquisada. 
Quadro 8 - Conteúdo do roadmap

\begin{tabular}{|c|c|c|c|c|c|c|}
\hline & 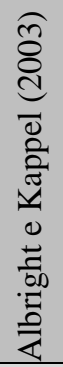 & 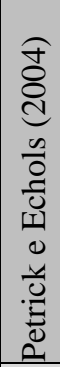 & 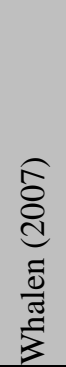 & 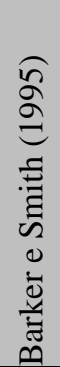 & 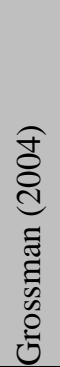 & 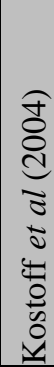 \\
\hline \multicolumn{7}{|l|}{ Conteúdo do roadmap } \\
\hline Estratégia de negócios & & & & $\mathrm{x}$ & & \\
\hline Seção Mercado / Ambiente & $\mathrm{x}$ & $\mathrm{x}$ & $\mathrm{x}$ & $\mathrm{x}$ & & $\mathrm{x}$ \\
\hline Definição dos segmentos de mercado & $\mathrm{x}$ & & & & & \\
\hline Análise dos competidores & $\mathrm{x}$ & & $\mathrm{x}$ & & & \\
\hline Tendências de mercado & $\mathrm{x}$ & & $\mathrm{x}$ & & & \\
\hline Roadmaps da indústria / padrões de mercado & & & $\mathrm{x}$ & & & \\
\hline Ações governamentais, regulatórias & & & $\mathrm{x}$ & & & \\
\hline Necessidades dos consumidores & & & $\mathrm{x}$ & & & \\
\hline Seção Produto & $\mathrm{x}$ & $\mathrm{x}$ & & $\mathrm{x}$ & & $\mathrm{x}$ \\
\hline Direcionadores do produto & $\mathrm{x}$ & & & & & \\
\hline Curva de experiência (previsão de preços) & $\mathrm{x}$ & & & & & \\
\hline Roadmap de produto & $\mathrm{x}$ & & & & & \\
\hline Desenvolvimento do produto com data de início e término & & & $\mathrm{x}$ & & & \\
\hline Data de lançamento e retirada de mercado & & & $\mathrm{x}$ & & & \\
\hline Atributos chave específicos do produto & & & $\mathrm{x}$ & & & \\
\hline Roadmap de fornecedores / parceiros críticos para o produto & & & $\mathrm{x}$ & & & \\
\hline Projetos de P\&D & & $\mathrm{x}$ & & & $\mathrm{x}$ & \\
\hline Seção Tecnologia & $\mathrm{x}$ & $\mathrm{x}$ & & $\mathrm{x}$ & & $\mathrm{x}$ \\
\hline Custo futuro & $\mathrm{x}$ & & & & & \\
\hline Roadmap de tecnologia & $\mathrm{x}$ & & & & & \\
\hline Início e fim do desenvolvimento da tecnologia & & & $\mathrm{x}$ & & & \\
\hline Pontos de decisão sobre tecnologias alternativas & & & $\mathrm{X}$ & & & \\
\hline Início e término da disponibilidade da tecn. no mercado & & & $\mathrm{x}$ & & & \\
\hline Metas de performance para as tecnologias & & & $\mathrm{x}$ & & & \\
\hline Roadmaps tecnológicos de fornecedores/parceiros críticos & & & $\mathrm{x}$ & & & \\
\hline Capacitação & & & & & & $\mathrm{x}$ \\
\hline Plano de ação & $\mathrm{x}$ & & & & & \\
\hline Análise de riscos & $\mathrm{x}$ & & & & & \\
\hline
\end{tabular}


Fleury et al (2006) discutem em seu artigo a customização do roadmap para o setor de software e argumentam que a camada de tecnologia deveria ser substituída pelas seguintes camadas na representação gráfica:

a) Camadas relativas ao processo de desenvolvimento

- Requisitos: onde seria representada a evolução dos desejos e necessidades dos clientes;

- Projeto e arquitetura: onde seriam representadas as evoluções de métodos, ferramentas e técnicas;

- Programação: representando a evolução nos métodos e técnicas para transformar o projeto em códigos;

- Testes: representando os métodos, ferramentas e técnicas para verificar e validar o software.

b) Aspectos gerenciais

- Gestão de projetos: que incluiria atividades de gestão de projetos;

- Gestão de risco: envolvendo processos para identificar, analisar e desenvolver formas de mitigar os riscos;

- Gestão da qualidade de software: abordagem para avaliar a qualidade do software;

- Gestão de configuração: que abordaria os problemas de gerir a evolução do software;

- Integração de sistemas: que envolve atividades necessárias para que dois ou mais sistemas independentes possam trocar informações e atuar como um único sistema.

Fleury et al (2006) aplicou esta "customização" do roadmap para software em uma Universidade e em uma empresa de software pequena, reconhecendo que uma grande dificuldade foi desenhar o roadmap incluindo todos os aspectos relevantes. Neste sentido, fica o questionamento se realmente seria importante incluir todos os elementos propostos por Fleury et al (2006) no desenho do roadmap, uma vez que muitos deles são etapas específicas do processo de desenvolvimento, não tendo relação direta com o planejamento da evolução futura do produto/tecnologia. Estudos realizados em outras indústrias normalmente não 
incluem o processo ou metodologia praticada pela empresa para desenvolvimento de seus produtos no desenho final do roadmap.

\subsubsection{O Processo de Elaboração de Roadmaps}

O processo de elaboração de roadmaps varia muito de empresa para empresa (GROENVELD, 1997). Em geral, envolve a análise de três aspectos comumente presentes no diagrama que são mercado, tecnologia e produto (PHAAL et al, 2007; ALBRIGHT; KAPPEL, 2003):

- Análise de Mercado: envolve a definição de segmentos de mercado que a empresa pretende atingir, análise de competidores, pontos fortes e fracos.

- Análise dos Produtos: envolve a análise das necessidades de mercado, análise da evolução dos produtos concorrentes, a análise da evolução dos produtos da empresa e o plano de evolução dos produtos.

- Análise das Tecnologias: segundo Albright e Kappel (2003) esta é a parte mais importante dos roadmaps de produto-tecnologia, sendo normalmente muito densa em informação. Envolve analisar a evolução das diversas tecnologias utilizadas pela empresa, ou mesmo as que possam vir a substituí-las. Tais tecnologias são representadas ao longo do tempo, e normalmente são ligadas aos produtos que as utilizam. Pelo entendimento de Albright e Kappel (2003) nesta etapa já se consolida as informações dos três aspectos do roadmap. Phaal et al (2007) propõem um método rápido no qual estas três análises são conduzidas em sessões de workshops, havendo uma quarta sessão para consolidar o plano.

Como em alguns estudos as fases do processo de elaboração do roadmap se confundem com os três elementos principais que compõem o conteúdo (tecnologia-produto-mercado), optamos por representar processo e conteúdo juntos no modelo conceitual.

Groenveld (1997) descreve a atividade de elaboração de roadmaps na Philips. A primeira atividade consiste no estabelecimento dos objetivos e na obtenção de informação. Segue-se um primeiro workshop, com objetivo de compartilhar a informação, construir uma visão 
comum e os blocos principais para o roadmap. Depois, selecionam-se cenários para o roadmap, bem como seus fundamentos. Segue-se um segundo workshop, com objetivo de gerar o roadmap por meio de compartilhamento de informação, criando-se esboços para o roadmap e as realizando-se as avaliações tecnológicas necessárias. Por fim, formula-se o desenho do roadmap final e se organiza o acompanhamento.

Phaal et al (2007) discutem a aplicação de um método rápido para desenho de roadmaps, denominado T-Plan, com base em 4 workshops. Antes dos workshops, deve-se realizar o planejamento, no qual se definem o foco, escopo e objetivo do roadmap. Também fazem parte do planejamento a definição dos participantes, a definição da agenda, a logística e a preparação. O primeiro workshop tem por objetivo analisar o mercado, com discussão sobre como avaliar a performance da empresa, os direcionadores de negócio e do mercado, priorização de mercados, realização de análise SWOT (análise de oportunidades, ameaças, pontos fortes e fracos) e identificação de gaps. O segundo workshop tem como foco a análise dos produtos, com discussão sobre os conceitos e características dos produtos, e análise da estratégia de produtos. O terceiro workshop tem como foco a análise da tecnologia, discutindo-se soluções tecnológicas. Por fim, o último workshop tem por objetivo ligar os recursos de tecnologia com as oportunidades de mercado futuras.

Silveira Jr (2013) fez uma pesquisa-ação para elaborar um roadmap para amortecedores estruturais com objetivo principal de redução de peso. Um primeiro passo foi realizar uma análise morfológica. Segundo Silveira Jr (2013), “a análise morfológica é uma técnica nãoquantitativa de estruturação e avaliação do conjunto de relações inerentes a um complexo problema multidimensional". Desta forma, procurou-se decompor o objeto de estudo, e chegou-se a cinco componentes principais. Com base em cinco componentes de um amortecedor estrutural, identificou diferentes materiais e tecnologias que poderiam ser adotadas em cada um. Em seguida, realizou uma pesquisa Delphi para identificar diversas tendências, entre as quais os materiais mais promissores para redução de peso, bem como a visão dos entrevistados sobre quando estes materiais estariam disponíveis. Kanama et al (2008) também defendem que tanto as empresas quanto as agências nacionais de tecnologia podem se beneficiar ao adotarem conjuntamente as técnicas Delphi e de roadmap. A técnica Delphi auxilia principalmente com dados quantitativos, sobre o tempo de realização das tecnologias e seu grau de importância. 
Após a aplicação da pesquisa Delphi, Silveira Jr (2013) adotou um método multicritério semelhante ao método SMART (EDWARDS, 1977) para decidir o material mais adequado. Primeiramente, identificou critérios importantes para que a empresa analisasse a adoção ou não de diferentes materiais identificados na pesquisa, bem como seus respectivos pesos na decisão. Os critérios apontados por Silveira Jr (2013) e aplicados a um fabricante de amortecedores estavam associados a fatores de competitividade, ou seja, fatores que permitiram à empresa uma maior competitividade, seja por agregar valor ao cliente, seja por representar um custo menor de fabricação.

Com base nos critérios e nas possíveis tecnologias, Silveira Jr. (2013) criou uma matriz para tomada de decisão, semelhante ao quadro 9. Depois, para cada critério, atribuiu notas para os materiais. Multiplicando-se a nota pelo peso do critério, obtém-se um total, que somado ao final, permite identificar as tecnologias prioritárias.

No exemplo apresentado no quadro 9, a tecnologia prioritária seria a tecnologia 1, que obteve maior pontuação geral (total de 112 pontos). Posteriormente Silveira Jr. (2013) realizou entrevistas qualitativas com clientes e fornecedores para verificar a plausibilidade do roadmap. 


\section{Quadro 9 - Exemplo de matriz de decisão para escolha entre diferentes alternativas} tecnológicas

\begin{tabular}{|c|c|c|c|c|c|c|c|c|c|c|c|}
\hline \multirow[b]{2}{*}{ Peso } & \multirow[b]{2}{*}{ Critério } & \multicolumn{2}{|c|}{$\begin{array}{c}\text { Tecnologia } \\
1\end{array}$} & \multicolumn{2}{|c|}{$\begin{array}{c}\text { Tecnologia } \\
2\end{array}$} & \multicolumn{2}{|c|}{$\begin{array}{c}\text { Tecnologia } \\
3\end{array}$} & \multicolumn{2}{|c|}{$\begin{array}{c}\text { Tecnologia } \\
4\end{array}$} & \multicolumn{2}{|c|}{$\begin{array}{c}\text { Tecnologia } \\
5\end{array}$} \\
\hline & & Nota & Total & Nota & Total & Nota & Total & Nota & Total & Nota & Total \\
\hline 4 & Estado da técnica & 5 & 20 & 3 & 12 & 2 & 8 & 4 & 16 & 1 & 4 \\
\hline 1 & Lead time implantação & 5 & 5 & 5 & 5 & 3 & 3 & 5 & 5 & 1 & 1 \\
\hline 2 & Custo matéria-prima & 4 & 8 & 2 & 4 & 2 & 4 & 3 & 6 & 1 & 2 \\
\hline 1 & $\begin{array}{l}\text { Despesa de } \\
\text { desenvolvimento }\end{array}$ & 5 & 5 & 3 & 3 & 2 & 2 & 4 & 4 & 1 & 1 \\
\hline 3 & Investimento em produto & 5 & 15 & 3 & 9 & 2 & 6 & 4 & 12 & 1 & 3 \\
\hline 3 & Investimento em processo & 4 & 12 & 2 & 6 & 2 & 6 & 3 & 9 & 1 & 3 \\
\hline 5 & Confiabilidade & 5 & 25 & 4 & 20 & 3 & 15 & 5 & 25 & 3 & 15 \\
\hline 4 & $\begin{array}{l}\text { Potencial de redução de } \\
\text { peso }\end{array}$ & 2 & 8 & 4 & 16 & 4 & 16 & 2 & 8 & 5 & 20 \\
\hline 2 & Sustentabilidade & 4 & 8 & 3 & 6 & 2 & 4 & 4 & 8 & 2 & 4 \\
\hline 3 & Imagem & 2 & 6 & 4 & 12 & 4 & 12 & 3 & 9 & 5 & 15 \\
\hline & & Total & 112 & Total & 93 & Total & 76 & Total & 102 & Total & 68 \\
\hline
\end{tabular}

FONTE: SILVEIRA JR., 2013

Gerdsri e Kocaoglu (2007) propõem um conceito chamado Envelope de Desenvolvimento de Tecnologia (TDE, de Technology Development Envelope), no qual adotam tanto o método Delphi quanto o AHP. O principal motivador para elaboração deste método é a dificuldade de manter o roadmap vivo e atualizado quando existem várias tecnologias concorrentes que estão em rápida evolução. Pelo método AHP tradicional, a cada alteração nas tecnologias, seria necessário reavaliá-las par a par para se refazer o modelo, e depois reelaborar o roadmap. Assim sendo, o TDE foi elaborado tendo como premissa a possibilidade de apenas inserir medidas de efetividade em um modelo que permitirá recalcular os valores, apontando a melhor alternativa tecnológica. Neste método mantém-se o princípio do AHP em decompor um objetivo estratégico em critérios, e estes últimos em fatores. A figura 12 ilustra esta hierarquia para avaliação tecnológica proposta pelos autores. 


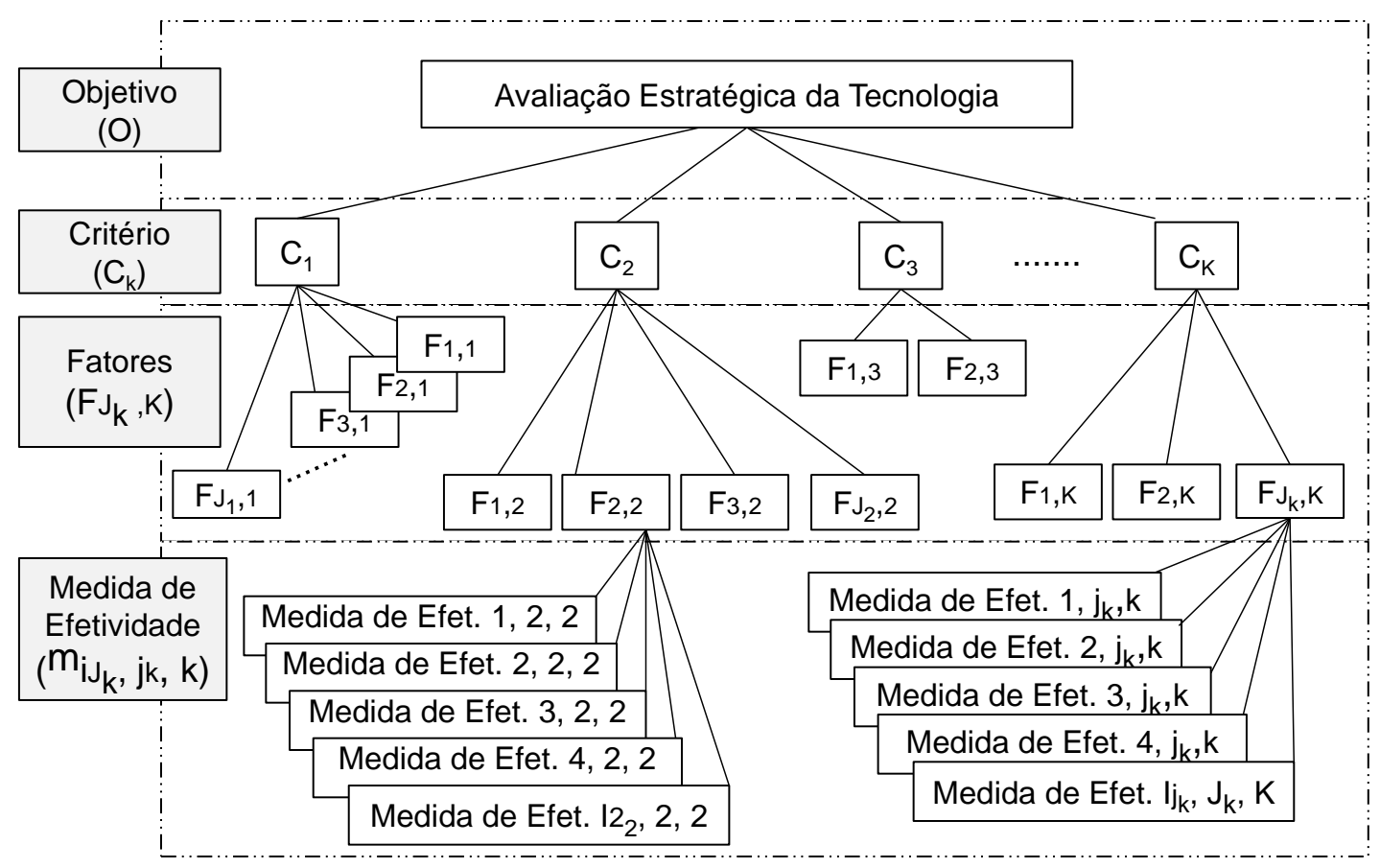

Figura 12 - Modelo de avaliação hierárquica proposta por Gerdsri e Kocaoglu FONTE: Adaptado de GERDSRI; KOCAOGLU, 2007

Da mesma forma que no AHP, os critérios são avaliados aos pares, para verificar a importância relativa entre eles, bem como os fatores, obtendo-se ao final os pesos relativos de cada um. Porém, ao invés de comparar as diversas tecnologias diretamente em relação aos fatores, Gerdsri e Kocaoglu (2007) propõem que sejam estabelecidas métricas de efetividade para os fatores. Para cada métrica, estabelece-se uma função que expressa a curva de desejabilidade (desirability curve) da empresa em relação à métrica, variando de 0 a 100 . Esta curva pode ser estabelecida mesmo para variáveis que são avaliadas em escala estilo Likert, atribuindo-se por exemplo 100 para Excelente, 80 para Muito Bom, e assim por diante até 0 para Inaceitável.

Assim sendo, uma vez construído o modelo, basta inserir as previsões sobre a performance de cada tecnologia para as diversas métricas, para que o modelo permita obter o Valor Tecnológico. Gerdsri e Kocaoglu (2007) aplicaram seu método em uma empresa fabricante de servidores computacionais, tendo como objetivo obter competitividade tecnológica por meio de uma nova plataforma de resfriamento. Este objetivo foi decomposto em sete critérios: performance, geometria, confiabilidade, economia, compatibilidade ambiental, serviços e 
manutenção, flexibilidade. Cada critério foi decomposto em fatores. Por exemplo, o critério performance foi decomposto em 3 fatores: fluxo de remoção de calor, resistência térmica, controlabilidade da temperatura. Para avaliar o primeiro fator, fluxo de remoção de calor, foi adotada uma métrica com o mesmo nome, medida em Watts por centímetro quadrado $\left(\mathrm{W} / \mathrm{cm}^{2}\right)$. Para cada um dos fatores foi então identificada uma ou mais métricas, bem como sua curva de desejabilidade.

Em sua pesquisa, Gerdsri e Kocaoglu (2007) identificaram 16 tecnologias alternativas que poderiam ser utilizadas para resfriamento de temperatura em servidores. Cada tecnologia foi avaliada pelas métricas estabelecidas, para 5 períodos (2003, 2004-5, 2006-7, 2008-9, 2010). Não fica claro no artigo, mas provavelmente a técnica Delphi tenha sido adotada para se realizar a previsão de evolução das tecnologias para estes cinco períodos. Ao final, obtiveram a um gráfico que expressa o Valor Tecnológico (variando de 0 a 100) ao longo do tempo. As tecnologias que se situam no topo em cada ano constituem o TDE, que é a curva ótima de adoção de tecnologias.

Suomalainen et al (2011) propôs um framework para estudo da atividade de roadmap em empresas de software no qual investiga a importância de diversos stakeholders e fases da atividade de roadmap (Figura 13). Os autores destacam que o roadmap se diferencia da engenharia de requisitos porque é um processo que visa prever atividades futuras em longo prazo, e que portanto somente características de alto nível seriam apresentadas dentro de um quadro temporal com as datas de lançamento. Segundo Suomalainen et al (2011), as principais fases do processo de roadmap em uma empresa de software são:

- Captura de características: nesta fase, a empresa busca um alinhamento com a estratégia sobre sua visão de futuro. Segundo Suomalainen et al (2011), um dos aspectos mais importantes é encontrar problemas que precisam de soluções, e identificar os limites do software (qual o seu propósito, para qual mercado, com quais potenciais clientes).

- Análise de características: nesta fase, a empresa procura eliminar incertezas, analisando com maior profundidade as funcionalidades, o que permite analisar a viabilidade e elaborar uma estimativa de custos. 
- Priorização de características: segundo Suomalainen et al (2011), esta é uma etapa difícil, pois muitas características são inter-relacionadas, e a empresa precisa decidir quais são as mais importantes. As empresas podem adotar diferentes métodos para esta priorização.

- Validação do roadmap e acordo: após a priorização, é preciso validar o escopo do roadmap. Nesta fase, deve ser verificado o quanto o roadmap está de acordo com a visão da empresa. Suomalainen et al (2011) argumentam que nesta etapa a empresa chega a um acordo sobre diferentes funcionalidades que as novas versões deverão conter nos próximos três ou quatro anos.

- Gestão da mudança do roadmap: a gestão da mudança afeta o roadmap, pois inúmeras mudanças no ambiente, nas necessidades dos stakeholders, ou mesmo internas podem gerar mudanças nas funcionalidades que o software deverá incorporar para as próximas versões.

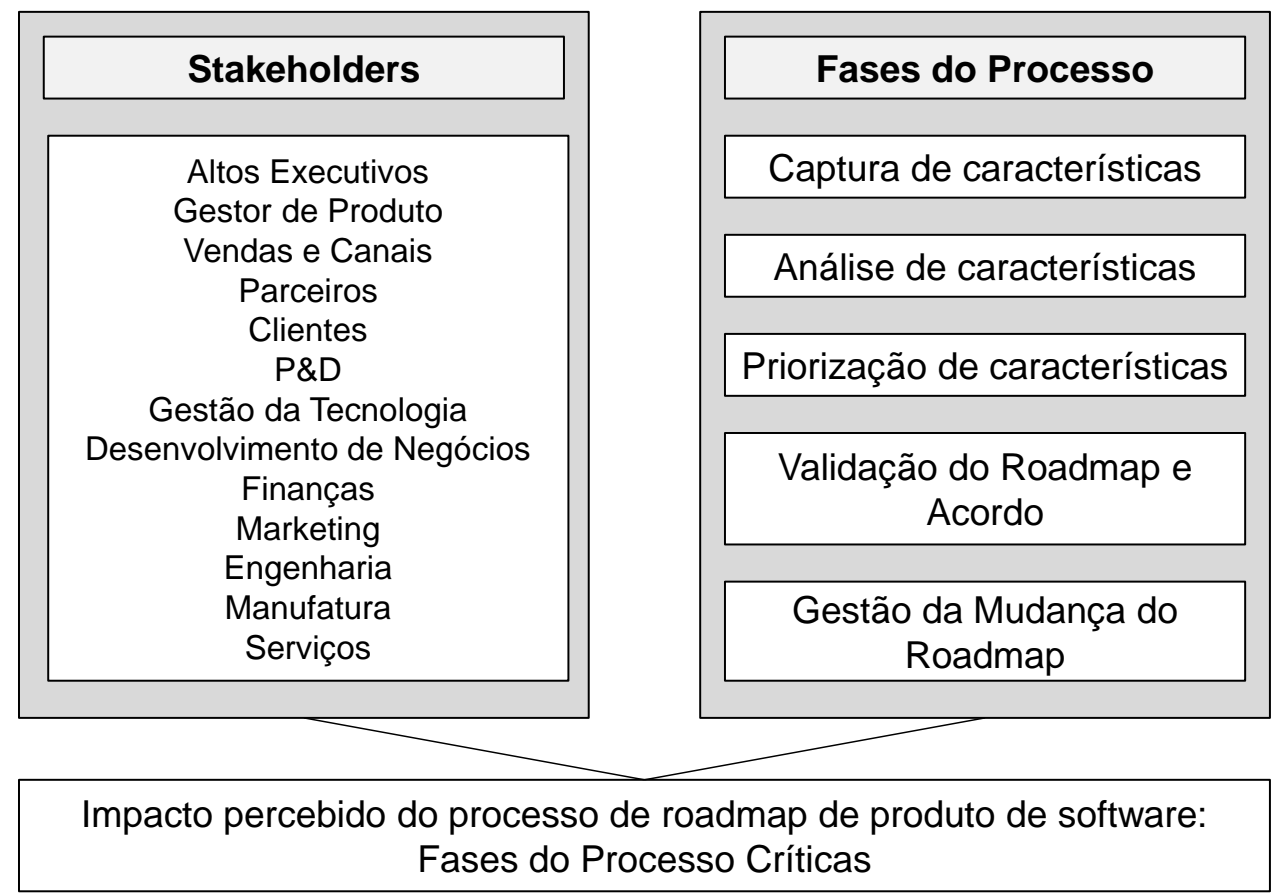

Figura 13 - Framework para estudo de roadmapping para produto de software FONTE: SUOMALAINEN et al, 2011

O quadro 10 apresenta um resumo com as etapas do processo de elaboração de roadmaps segundo a bibliografia pesquisada. 


\section{Quadro 10 - Etapas do processo para elaboração de roadmaps}

\begin{tabular}{|c|c|}
\hline Autor & Principais Etapas \\
\hline Groenveld (1997) & $\begin{array}{l}\text { 1) Estabelecimento de objetivos e coleta de informações } \\
\text { 2) Workshop } 1 \text { - Compartilhamento de informações e construção de uma visão } \\
\text { comum } \\
\text { 3) Seleção de cenários de roadmap, criação de fundamentos do roadmap } \\
\text { 4) Workshop } 2 \text { - Geração dos roadmaps por: compartilhamento de informação, } \\
\text { rascunhos e avaliação } \\
\text { 5) Formulação, organização e acompanhamento }\end{array}$ \\
\hline $\begin{array}{l}\text { Phaal et al (2004) e } \\
\text { Phaal et al (2007) }\end{array}$ & $\begin{array}{l}\text { 1) Planejamento } \\
\text { 2) Elaboração do roadmap, por meio de } 4 \text { workshops } \\
\text {-Workshop 1: Mercado } \\
\text { Dimensões de performance, direcionadores de mercado/negócios, priorização, } \\
\text { análise SWOT, análise de gaps } \\
\text {-Workshop 2: Produto } \\
\text { Conceitos de características de produto, agrupamento, ranking de impacto, } \\
\text { estratégia de produto, análise de gaps } \\
\text {-Workshop 3: Tecnologia } \\
\text { Soluções tecnológicas, Grupamento, ranking de impacto, análise de gaps } \\
\text {-Workshop 4: Desenho do roadmap } \\
\text { Ligar tecnologia a mercados futuros, análise de gaps } \\
\text { 3) Revisão }\end{array}$ \\
\hline Silveira Jr. (2013) & $\begin{array}{l}\text { a) Análise morfológica para identificar os componentes importantes do } \\
\text { objeto de estudo } \\
\text { b) Pesquisa Delphi para identificar quando as tecnologias estarão disponíveis } \\
\text { c) Matriz de decisão para decidir entre as tecnologias alternativas } \\
\text { d) Entrevista com fornecedores e clientes para verificar plausibilidade } \\
\text { e) Elaboração do roadmap final }\end{array}$ \\
\hline $\begin{array}{l}\text { Gerdsri e Kocaoglu } \\
\text { (2007) }\end{array}$ & $\begin{array}{l}\text { Propõe o método TDE (Techonological Development Envelop): } \\
\text { a) Monitoramento contínuo de alternativas tecnológicas } \\
\text { b) Caracterização tecnológica: partindo de um objetivo estratégico, identificar } \\
\text { critérios, depois fatores para cada critérios, e métricas para cada fator. } \\
\text { c) Modelagem hierárquica: como recomendado pelo AHP, fazer o } \\
\text { julgamento comparative para cada par de critérios e fatores. Estabelecer a } \\
\text { curva de desejabilidade da empresa para cada métrica. } \\
\text { d) Avaliação tecnológica: avaliar a evolução tecnológica dentro do período } \\
\text { pretendido. } \\
\text { e) Formação do TDE }\end{array}$ \\
\hline $\begin{array}{l}\text { Suomalainen } \text { et al } \\
\text { (2011) }\end{array}$ & $\begin{array}{l}\text { Explora um modelo específico para empresas de Software com as fases: } \\
\text { a) Captura de características (features) } \\
\text { b) Análise de características } \\
\text { c) Priorização de características } \\
\text { d) Validação e acordo sobre o roadmap } \\
\text { e) Gestão de mudanças do roadmap }\end{array}$ \\
\hline
\end{tabular}


Enfim, o roadmap contribui para a integração entre a estratégia de negócios e a estratégia tecnológica. Muito mais do que a representação gráfica da evolução dos produtos e das tecnologias utilizadas pela empresa ao longo do tempo, seu processo é interativo e multidisciplinar, propiciando aprendizado e uma maior integração entre as áreas da empresa (GROENVELD, 1997; PHAAL et al, 2007).

Segundo Gerdsri et al (2010), a implementação do roadmap tecnológico envolve três grandes estágios: (a) iniciação, que introduz a técnica para a organização; (b) desenvolvimento, que lança o roadmap em uma maior escala de adoção; e (c) integração, que visa manter o uso roadmap como um processo contínuo. Existem inúmeras barreiras que dificultam sua adoção, sendo que Gerdsri et al (2010) propõem o uso de técnicas de gestão de mudanças para implementar de forma mais efetiva os processos de elaboração de roadmaps.

A seguir, discutimos barreiras e dificuldades da atividade de elaboração de roadmaps.

\subsubsection{Barreiras e Dificuldades}

A literatura também aborda dificuldades e barreiras encontradas pelas empresas na elaboração dos roadmaps, as quais estão sintetizadas no quadro 11. Existe uma dificuldade inicial em começar a atividade ou estruturar o processo (FLEURY et al, 2006; SUOMALAINEN et al, 2011). Muitas empresas carecem de uma visão de futuro e têm dificuldade em prever a evolução tecnológica, e assim identificar as funcionalidades de seus produtos que serão importantes no futuro (GROSSMAN, 2004; SUOMALAINEN et al, 2011). A cultura existente na empresa e a resistência de algumas áreas também pode ser uma barreira, pois o roadmap obriga a empresa a alinhar a visão de mercado, produto e tecnologia (GROENVELD, 1997; GROSSMAN, 2004; PETRICK; ECHOLS, 2004). Em algumas situações, pode também ser difícil obter as informações para elaborar o roadmap (WHALEN, 2007; GROSSMAN, 2004; SUOMALAINEN et al, 2011). Manter o roadmap atualizado ou mesmo colocá-lo em prática também é outro desafio, uma vez que há inúmeras pressões para que, após aprovado, haja alteração no roadmap (PHAAL et al, 2004; PHAAL et al, 2007; WHALEN, 2007; SUOMALAINEN et al, 2011). 


\section{Quadro 11 - Barreiras e dificuldades da atividade de elaboração de roadmaps}

\begin{tabular}{|c|c|c|c|c|c|c|c|}
\hline & 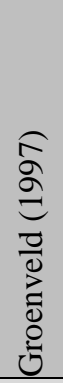 & 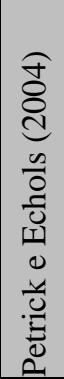 & 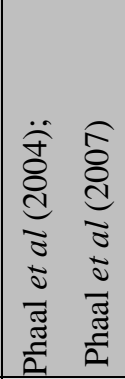 & 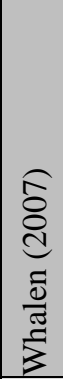 & 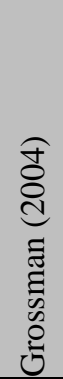 & 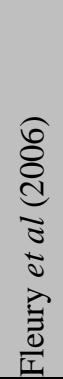 & 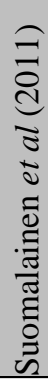 \\
\hline \multicolumn{8}{|l|}{ Barreiras / Dificuldades } \\
\hline $\begin{array}{l}\text { Dificuldade em começar a atividade } \\
\text { de roadmap }\end{array}$ & & & & & & $\mathrm{x}$ & \\
\hline Dificuldade em estruturar o processo & & & & & & $\mathrm{x}$ & $\mathrm{x}$ \\
\hline Cultura funcional & $\mathrm{x}$ & & & & $\mathrm{x}$ & & \\
\hline $\begin{array}{l}\text { Falta de comprometimento dos } \\
\text { executivos }\end{array}$ & $\mathrm{x}$ & & & & & & \\
\hline $\begin{array}{l}\text { Esforço e carga de trabalho } \\
\text { subestimados }\end{array}$ & $\mathrm{x}$ & & & & $\mathrm{x}$ & & \\
\hline Vazamento de informação & & $\mathrm{x}$ & & & & & \\
\hline Resistência por parte de algumas áreas & & $\mathrm{x}$ & & & $\mathrm{x}$ & & \\
\hline Falta de visão de futuro & & & & & $\mathrm{x}$ & & \\
\hline $\begin{array}{l}\text { Dificuldade de obtenção de } \\
\text { informações }\end{array}$ & & & & $\mathrm{x}$ & $\mathrm{x}$ & & $\mathrm{x}$ \\
\hline Manter o roadmap atualizado & & & $\mathrm{x}$ & $\mathrm{x}$ & & $\mathrm{x}$ & \\
\hline $\begin{array}{l}\text { Dificuldade de colocar em prática o } \\
\text { roadmap }\end{array}$ & & & $\mathrm{x}$ & $\mathrm{x}$ & & & \\
\hline Chegar a um acordo sobre prioridades & & & & & & & $\mathrm{x}$ \\
\hline $\begin{array}{l}\text { Gerenciar mudanças após o roadmap } \\
\text { ser aprovado }\end{array}$ & & & & & & & $\mathrm{x}$ \\
\hline $\begin{array}{l}\text { Dificuldade de prever a evolução } \\
\text { tecnológica }\end{array}$ & & & & & $\mathrm{x}$ & & \\
\hline $\begin{array}{l}\text { Dificuldade de identificar as } \\
\text { funcionalidades do produto que serão } \\
\text { importantes no futuro }\end{array}$ & & & & & & & $\mathrm{X}$ \\
\hline
\end{tabular}

Outras dificuldades apontadas pela literatura são a cultura funcional e a mudança de cultura, uma vez que elaborar o roadmap torna necessário o trabalho conjunto entre diferentes áreas da empresa (GROENVELD, 1997; GROSSMAN, 2004; PETRICK; ECHOLS, 2004), o comprometimento dos executivos (GROENVELD, 1997) para que o processo de roadmap 
não seja um esforço de um único tiro, mas um esforço contínuo e atualizado, a falta de visão de futuro (GROSSMAN, 2004), uma vez que um dos grandes benefícios do roadmap é justamente o planejamento futuro e identificação de futuras tecnologias a serem adotadas, além do esforço e carga de trabalho (GROENVELD, 1997; GROSSMAN, 2004) que não podem ser subestimados. A empresa também precisa se assegurar sobre os procedimentos adotados para que não haja vazamento de informação (PETRICK; ECHOLS, 2004). O quadro 11 relaciona as principais barreiras e dificuldades da atividade de elaboração de roadmaps e os respectivos autores que as mencionaram.

\subsubsection{Benefícios do Roadmap}

Diferentes autores destacam vários possíveis benefícios do uso de roadmaps. Muitos destes benefícios não são apenas decorrentes do roadmap pronto, mas do próprio processo de elaboração do roadmap. O uso da técnica permite ligar a estratégia aos planos de produto e tecnologia, possibilitando a construção de planos corporativos com visão de longo prazo, melhorando a comunicação entre os departamentos e estimulando o aprendizado interfuncional (ALBRIGHT; KAPPEL, 2003; GROENVELD, 1997; PHAAL et al, 2004; WHALEN, 2007) ou mesmo facilitando a transferência de conhecimento dentro da cadeia de suprimentos (PETRICK; ECHOLS, 2004; WHALEN, 2007; GOSSMAN, 2004). Desta forma, melhora o planejamento sobre as prioridades da empresa (ALBRIGHT; KAPPEL, 2003; PHAAL et al, 2004; PHAAL et al, 2007; WHALEN, 2007), repercutindo em melhoria no tempo de disponibilização dos produtos ao mercado (time-to-market) e na redução do tempo necessário para rentabilizar os investimentos (GROENVELD, 1997). Adicionalmente facilita a gestão de riscos e o reuso da tecnologia de forma a reduzir a duplicidade de esforços (ALBRIGHT; KAPPEL, 2003; PETRICK; ECHOLS, 2004; GOSSMAN, 2004).

Segundo Barker e Smith (1995), a ênfase nos aspectos gráficos oferece vários benefícios, tal como a facilidade de entendimento, capacidade de condensar informações complexas e extensas, facilidade de checar a consistência dos dados, além de facilitar a comunicação dos aspectos abordados (tecnologia, produto e mercado) a um público variado, envolvendo não apenas pessoas técnicas. O quadro 12 sumariza os benefícios aqui discutidos decorrentes da atividade de elaboração de roadmaps. 
Quadro 12 - Benefícios da elaboração de roadmaps

\begin{tabular}{|c|c|c|c|c|c|c|c|c|c|}
\hline & 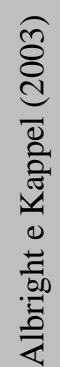 & 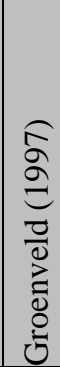 & 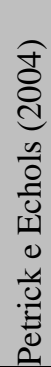 & 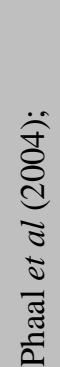 & 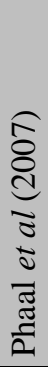 & 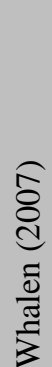 & 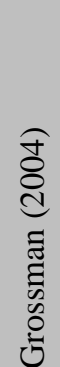 & 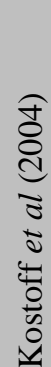 & 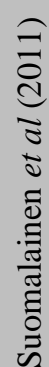 \\
\hline \multicolumn{10}{|l|}{ Benefícios } \\
\hline $\begin{array}{l}\text { Ligar a estratégia a planos de produto e } \\
\text { tecnologia }\end{array}$ & $\mathrm{x}$ & $\mathrm{x}$ & & $\mathrm{x}$ & & $\mathrm{x}$ & & & $\mathrm{x}$ \\
\hline Possibilitar planos de tecnologia corporativos & $\mathrm{x}$ & & & & & $\mathrm{x}$ & & & \\
\hline $\begin{array}{l}\text { Construção de visão de longo prazo ligando } \\
\text { produto e tecnologia }\end{array}$ & $\mathrm{x}$ & $\mathrm{X}$ & & $\mathrm{x}$ & & $\mathrm{x}$ & $\mathrm{x}$ & $\mathrm{x}$ & $\mathrm{X}$ \\
\hline Estímulo ao aprendizado inter-funcional & & $\mathrm{x}$ & & $\mathrm{x}$ & & $\mathrm{x}$ & & & $\mathrm{X}$ \\
\hline Melhora da comunicação & $\mathrm{x}$ & & & $\mathrm{x}$ & & $\mathrm{x}$ & $\mathrm{x}$ & & $\mathrm{x}$ \\
\hline Melhoria do time-to-market & & $\mathrm{x}$ & & & & & & & \\
\hline $\begin{array}{l}\text { Melhoria do tempo necessário para rentabilizar } \\
\text { o investimento }\end{array}$ & & $\mathrm{x}$ & & & & & & & \\
\hline $\begin{array}{l}\text { Melhora o planejamento sobre prioridades da } \\
\text { empresa }\end{array}$ & $\mathrm{x}$ & & & $\mathrm{x}$ & & $\mathrm{x}$ & & & \\
\hline $\begin{array}{l}\text { Transferência de conhecimento na cadeia de } \\
\text { suprimentos }\end{array}$ & & & $\mathrm{x}$ & & & $\mathrm{x}$ & $\mathrm{x}$ & & \\
\hline Gestão de riscos & $\mathrm{x}$ & & $\mathrm{x}$ & & & & & & \\
\hline $\begin{array}{l}\text { Reuso de tecnologia / reduzir duplicidades de } \\
\text { esforços }\end{array}$ & $\mathrm{x}$ & & $\mathrm{x}$ & & & & $\mathrm{x}$ & & \\
\hline
\end{tabular}

A seguir, discutimos a indústria de software, abordando conceitos importantes sobre a competição no setor, a importância das plataformas de desenvolvimento e especificamente algumas de suas características no Brasil.

\subsection{A Indústria de Software e a Importância das Plataformas}




\subsubsection{Características Competitivas e de Inovação}

A indústria de software não é uniforme, e existem diferenças bastante significativas entre pelo menos dois tipos empresas: empresas de software pacote (packaged software) e serviços de software (SAWYER, 2000; CUSUMANO, 2004; CARMEL, 1997). Softwares pacote são sistemas prontos, tratados como produtos comercializáveis. Tipicamente são licenciados e não vendidos, o que significa que o direito autoral continua sendo da empresa fabricante, que concede o direito de uso para a empresa licenciada. Serviços de software compreendem a integração de sistemas, consultoria, bem como desenvolvimento de software por encomenda para um cliente específico. Fleury et al (2006) subdividem os serviços de software em softwares pacote (orientado ao produto), software customizados (orientados ao cliente) e serviços de software (orientado ao serviço, normalmente implantando ou customizando pacotes), e classificam os três segmentos segundo os eixos de volume-variedade conforme a figura 14.

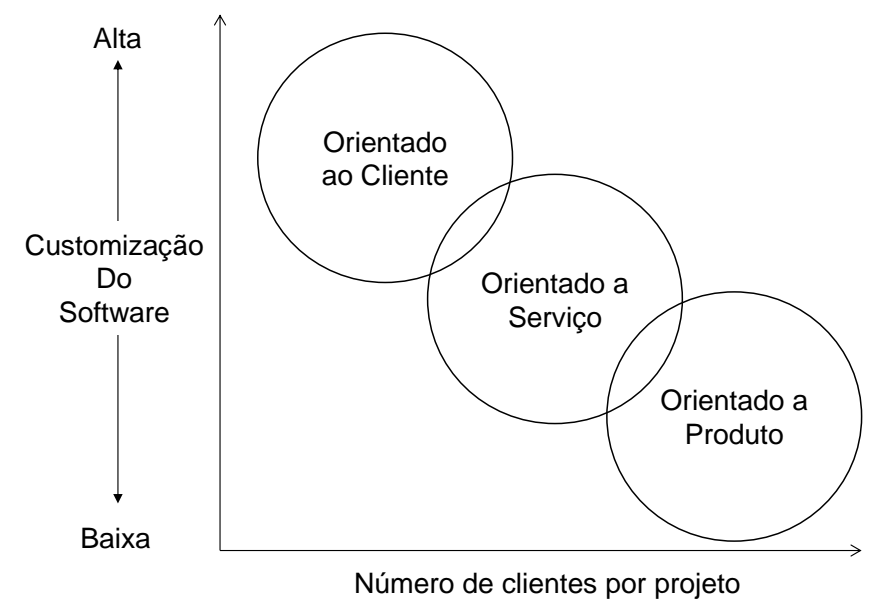

Figura 14 - A diagonal volume-variedade do setor de software FONTE: FLEURY et al, 2006, p. 1534

O quadro 13 apresenta a visão de Sawyer (2000) sobre as diferenças entre software pacote e software por encomenda, que é uma das áreas de serviços de software. 
Quadro 13 - Diferenças entre software pacote e software por encomenda

\begin{tabular}{|c|c|c|}
\hline & Software Pacote & Software por Encomenda \\
\hline Indústria & $\begin{array}{l}\text { Pressões de tempo de chegada } \\
\text { ao mercado } \\
\text { Métricas de sucesso: } \\
\text { lucratividade, participação de } \\
\text { mercado, lembrança da marca }\end{array}$ & $\begin{array}{l}\text { Pressões de custo } \\
\text { Métricas de sucesso: satisfação, } \\
\text { aceitação do usuário, retorno sobre } \\
\text { o investimento }\end{array}$ \\
\hline $\begin{array}{l}\text { Abordagem de } \\
\text { desenvolvi- } \\
\text { mento }\end{array}$ & $\begin{array}{l}\text { Talento do desenvolvedor } \\
\text { Usuário distante e menos } \\
\text { envolvido } \\
\text { Processo é imaturo } \\
\text { Design e desenvolvimento } \\
\text { integrado } \\
\text { Controle do projeto por } \\
\text { coordenação }\end{array}$ & $\begin{array}{l}\text { Parte de uma equipe corporativa } \\
\text { Usuário perto e mais envolvido } \\
\text { Processo é mais maduro } \\
\text { Design e desenvolvimento } \\
\text { separados } \\
\text { Controle do projeto via construção } \\
\text { de consenso }\end{array}$ \\
\hline $\begin{array}{l}\text { Aspectos } \\
\text { culturais }\end{array}$ & $\begin{array}{l}\text { Empreendedorismo } \\
\text { Individualismo }\end{array}$ & $\begin{array}{l}\text { Burocracia } \\
\text { Menos individualista }\end{array}$ \\
\hline Times & $\begin{array}{l}\text { Menos propenso a ter estrutura } \\
\text { de projeto ou matricial, mais } \\
\text { propenso a ser auto-gerido } \\
\text { Envolvimento em todo o ciclo } \\
\text { de desenvolvimento } \\
\text { Time mais coeso, motivado } \\
\text { Oportunidades para grandes } \\
\text { retornos financeiros } \\
\text { Empresas menores } \\
\text { Tarefas orientadas pela visão } \\
\text { compartilhada do produto }\end{array}$ & $\begin{array}{l}\text { Gestão matricial e focado em } \\
\text { projeto } \\
\text { Pessoas designadas a partes de } \\
\text { múltiplos projetos } \\
\text { Equipes formadas conforme } \\
\text { necessidade } \\
\text { Remuneração em forma de salário } \\
\text { Crescimento ao longo do tempo, } \\
\text { com tendência a dispersar a equipe } \\
\text { Tarefas baseadas em especificações } \\
\text { e documentação formal }\end{array}$ \\
\hline
\end{tabular}

FONTE: Adaptado de SAWYER, 2000, p. 50

Segundo Sawyer (2000), um dos mercados mais significativos e de maior crescimento em software pacote são os sistemas integrados de gestão empresarial, também chamados de ERP (Enterprise Resource Planning). Implementações de sistemas ERP costumam ser demoradas 
e demandam muitos serviços de consultoria de implantação. Segundo Souza e Zwicker (2003), sistemas ERP são "sistemas informatizados integrados adquiridos na forma de pacotes comerciais de software com a finalidade de dar suporte à maioria das operações de uma empresa". A implementação pode ser feita pela própria empresa fornecedora, mas grandes projetos em geral demandam empresas especializadas, pois a implementação envolve o mapeamento e reestruturação de processos, configuração do sistema, desenvolvimento específico de customizações necessárias, treinamento e gestão da mudança, entre outras atividades. São empresas que possuem, portanto, competências tanto no negócio do cliente quanto em software.

Segundo Carmel (1997), a indústria de pacotes de software tem suas raízes na decisão do departamento de justiça dos Estados Unidos que, em 1968, obrigou a IBM a separar as vendas de hardware e software. Ao longo dos anos, as empresas aprenderam a reduzir a dependência do desenvolvimento por encomenda, em geral caro e sujeito a problemas de prazo e qualidade. Mas foi a difusão dos microcomputadores nos anos 1980 que levou a um grande crescimento desta indústria. Apesar do grande crescimento de empresas estrangeiras, principalmente as indianas, no fornecimento de software por encomenda, existe ainda uma hegemonia das empresas americanas no setor de software pacote devido a alguns fatores (CARMEL, 1997): mão-de-obra qualificada, condições favoráveis de financiamento, clientes sofisticados, associação próxima aos fabricantes de hardware, mercado competitivo, concentração geográfica, vantagem de ser o primeiro a lançar produtos (first mover advantage), forte regime de propriedade intelectual, e a vantagem da língua inglesa ser o padrão na área de negócios, e especificamente na indústria de TI e de direitos autorais.

Outra característica competitiva desta indústria é o efeito das externalidades de rede (BRYNJOLFSSON e KEMERER, 1996; EVANS et al, 2005), que pode ser definida como o aumento no valor de um produto devido ao aumento no número de usuários. Para ter aceitação, o software não precisa apenas ter qualidade técnica e ser inovador. Também contribuem para sua aceitação a base instalada e a conformidade com os padrões da indústria. Brynjolfsson e Kemerer (1996) analisaram dados do mercado de planilhas eletrônicas e chegaram a algumas conclusões interessantes. Primeiro, existe relação positiva e direta entre as externalidades de rede, medida pela base instalada do produto, e o preço do produto. Segundo, produtos que aderiram a um padrão dominante, no caso uma interface específica de 
menu adotada pela empresa líder na época, cobravam preços em média $46 \%$ maiores que os outros concorrentes. Para a estratégia competitiva da empresa, uma importante implicação do estudo é que a empresa precisa rapidamente aumentar sua base instalada de usuários a fim de aumentar o valor percebido do cliente devido às externalidades de rede. De certa forma, os primeiros usuários subsidiam os usuários posteriores, pois estes têm o benefício das externalidades de rede. Isto implica em vantagem teórica para as empresas que lançarem primeiro os produtos "certos" e conseguirem conquistar uma grande base de usuários. Vantagem teórica porque sabe-se que é muito difícil lançar o produto "certo", e muitas vezes as empresas pioneiras passam por um aprendizado que é aproveitado pelas empresas seguidoras que lançam posteriormente produtos mais adequados às necessidades do mercado (CHRISTENSEN, 1997). É importante também salientar que a vantagem gerada pela externalidade de rede não é permanente. Caso haja uma tecnologia de ruptura (CHRISTENSEN, 1997) ou mudança de plataforma tecnológica gerada por outra empresa que tenha antecipado necessidades não atendidas dos consumidores, rapidamente esta nova empresa pode captar clientes e gerar externalidades de rede a seu favor, fazendo com que antigos líderes percam mercado (BRYNJOLFSSON; KEMERER, 1996).

Segundo Smith e Mann (2004), empresas de software podem sofrer dois principais tipos de ameaças no que tange sua propriedade intelectual. A primeira é a cópia ilegal de seu software, ou seja, a pirataria. A segunda se refere a seguidores de mercado que conseguem reproduzir parte das funcionalidades do software original criando similares no mercado.

Uma outra peculiaridade da indústria de software é a existência de produtos de código aberto (open source). Von Hippel e Von Krogh (2003) propõe a existência de um modelo de inovação privado-coletivo, que mescla características dos modelos privado e coletivo. No modelo privado, o inventor explora sua inovação protegido por leis de propriedade intelectual. No modelo coletivo, há um investimento coletivo na criação de um bem público, e todos podem usufruir dele. Por exemplo, uma comunidade pode investir na construção de uma ponte que une dois lados de um córrego. No caso dos softwares de código aberto, Von Hippel e Von Krogh (2003) argumentam que existem elementos dos dois tipos de modelo. Por um lado, existe uma comunidade colaborando com a construção, melhoria ou suporte a um software, sendo que cada colaborador despende esforço em inovação e depois a disponibiliza gratuitamente para comunidade. Por outro lado, existem outros tipos de recompensas, como 
por exemplo o reconhecimento e a satisfação de trabalhar em um projeto de seu interesse, o que nem sempre ocorre em um emprego formal na indústria. Von Hippel e Von Krogh (2003) observam ainda que grande parte dos colaboradores não são empresas de software, mas pessoas físicas ou usuários finais. E mesmo no caso das empresas de software que participam, elas geralmente obtém benefícios pela externalidade de rede, devido à adoção mais rápida do software, bem como por produtos complementares, devidamente protegidos. Este é o caso da IBM, citado por Von Hippel e Von Krogh (2003), que incentiva a comunidade do sistema operacional aberto Linux, beneficiando-se por sua adoção mais rápida e pela colaboração da comunidade em aperfeiçoar o sistema e eliminar seus erros. Por outro lado, a IBM vende softwares proprietários que podem ser utilizados nesse sistema operacional.

\subsubsection{Plataformas em Software}

$\mathrm{Na}$ área de tecnologia da informação, o termo plataforma é utilizado com diferentes significados. Basicamente, uma plataforma provê infraestrutura e serviços para desenvolvedores de aplicação, fabricantes de hardware e usuários finais (EVANS et al, 2005). Por este motivo é um mercado chamado de multi-lados (multi-sided platform markets). Evans et al (2005) cita o exemplo do Windows, que é uma plataforma de três-lados porque provê serviços para fabricantes de hardware, desenvolvedores de software e clientes. Antes do desenvolvedor final, podem existir múltiplas camadas de plataforma, ou seja, ela não é a única camada entre o hardware e o desenvolvedor de aplicativo. Por exemplo, o Java é uma plataforma que provê bibliotecas e máquinas virtuais para que um mesmo aplicativo possa ser executado em diferentes sistemas operacionais e diferentes hardwares (EVANS et al, 2005). As plataformas podem diferir em diversos aspectos: produtividade de desenvolvimento, disponibilidade de mão de obra, nível de aceitação maior ou menor conforme nichos específicos de mercado, entre outros fatores (EVANS et al, 2005; CUSUMANO; GAWER, 2002).

Cusumano e Gawer (2002) argumentam que empresas que competem no mercado de plataformas enfrentam três grandes desafios: (a) evoluir e inovar a plataforma mantendo a integridade e compatibilidade com tecnologias complementares, (b) garantir a compatibilidade com versões passadas, e (c) competir pela liderança. Com exceção de poucas 
grandes empresas que optam por desenvolver e manter sua própria plataforma de desenvolvimento, normalmente as empresas de software adotam uma ou mais plataformas para desenvolver seus produtos. E com a evolução tecnológica, muitas vezes a empresa precisa se defrontar com o desafio de trocar sua plataforma e/ou agregar novas plataformas de desenvolvimento.

O estudo de Evans et al (2005) permite ilustrar perfeitamente o quanto a indústria é dinâmica e se renova em pouco tempo. Os autores exploram cinco plataformas: computadores pessoais, vídeo games, PDAs, telefones móveis inteligentes e dispositivos de conteúdo. Apesar do estudo ser relativamente recente, o mercado de PDAs praticamente acabou. A empresa citada pelos autores como líder do setor, a Palm, foi comprada pela HP que descontinuou os produtos. $\mathrm{Na}$ área de telefones móveis inteligentes, eles citam como líder a Nokia, com a plataforma Symbian. Atualmente, as plataformas de software líderes neste mercado são o Android, do Google, e o iOS, da Apple. A Nokia, para fazer frente à concorrência, tomou decisão de descontinuar o uso do Symbian nos seus celulares inteligentes e passou a adotar o sistema operacional Windows Mobile da Microsoft. Isto mostra o quão crítico é a decisão sobre escolha de plataforma para empresas de software. Empresas que eventualmente optaram por se especializar em desenvolver software para estas plataformas descontinuadas tiveram que se transformar para sobreviver.

Para fins deste estudo, consideramos mais adequada a definição de Meyer e Seliger (1998) que definem plataforma de produto como "um conjunto de subsistemas e interfaces que formam uma estrutura comum, sobre a qual uma corrente de produtos derivados podem ser eficientemente desenvolvidos e produzidos". Uma plataforma de software bem desenvolvida confere à empresa produtividade em seu P\&D (MEYER; SELINGER, 1998). Contribui para decisões mais acertadas, pois devido à produtividade, requer da empresa menos tempo/esforço para desenvolver uma solução permitindo a ela desenvolver rapidamente soluções que o mercado necessita. Desta forma, contribui também como barreira à entrada de concorrentes que não tenham tal agilidade (MEYER; SELINGER, 1998). Uma empresa, ao adotar uma plataforma de desenvolvimento, pode optar por desenvolver o mínimo possível de complementos e utilizar em grande parte as funções padronizadas oferecidas pelo fornecedor, bem como pode optar por customizar, incluindo outras funções de terceiros ou desenvolvidas pela própria empresa para agilizar futuramente o desenvolvimento das aplicações de software 
que a empresa comercializa. Por exemplo, empresas que usam a plataforma de desenvolvimento .NET da Microsoft podem simplesmente utilizar as funções prontas já fornecidas pelo fabricante para desenvolver um ERP por exemplo, ou criar uma arquitetura na qual a plataforma é complementada com uma série de funções e frameworks. Não necessariamente isso acelera o desenvolvimento imediato de uma tela específica, mas pode gerar produtividade pelo reaproveitamento de códigos e pela facilidade de se fazer alterações futuras, por exemplo. Outra grande vantagem de uma plataforma é que ela pode, dependendo da forma como foi desenvolvida, servir de base para que terceiros desenvolvam produtos complementares, tornando-a um padrão para inovação em larga escala (MEYER; SELINGER, 1998).

De tempos em tempos surgem novas tecnologias ou conceitos na área de software que, para serem aproveitadas, exigem da empresa novas competências e a disposição para rever seu modelo de negócios. Atualmente existe uma grande tendência rumo à computação em nuvem, na qual o software é oferecido como serviço (SAAS - software-as-a-service), o que requer da empresa não apenas reescrever o software mas, muitas vezes, repensar seu modelo de negócios (BENLIAN et al, 2009; SÄÄKSJÄRVI et al, 2005; VOUK, 2008). Imagine por exemplo, uma empresa que tipicamente gera receitas por meio de licenciamento e manutenção de softwares, tendo uma equipe formada principalmente de programadores. Ao optar por oferecer suas soluções no modelo SAAS, terá que investir em servidores e equipe de operação (antes responsabilidade de seus clientes), além de abdicar das receitas de licença de uso, pois na computação em nuvem as empresas geralmente cobram um taxa mensal pelo serviço (BENLIAN et al, 2009; SÄÄKSJÄRVI et al, 2005; VOUK, 2008).

A seguir, discutimos características da indústria brasileira de software.

\subsubsection{A Indústria de Software no Brasil}

A Associação para Promoção da Excelência do Software Brasileiro (SOFTEX) é a organização que gerencia o Programa SOFTEX do Ministério da Ciência, Tecnologia e Inovação (MCTI) com objetivo de desenvolver a Indústria Brasileira de Software e Serviços de TI (IBSS). O SOFTEX publicou dois estudos (2009 e 2012) sobre a IBSS no Brasil, tendo 
como ponto de partida a Classificação Nacional de Atividades Econômicas (CNAE) do Instituto Brasileiro de Geografia e Estatística (IBGE).

Quadro 14 - Receita da IBSS em 2009 por atividade

\begin{tabular}{|l|r|c|}
\hline Atividade principal & $\begin{array}{r}\text { Receitas em } \\
2009-\mathrm{R} \$ \text { mil }\end{array}$ & \multicolumn{1}{c|}{} \\
\hline Desenv. de SW sob encomenda & 6.928 .381 & $16,0 \%$ \\
\hline Desenv. e licenciamento de SW customizável & 14.142 .776 & $32,7 \%$ \\
\hline Desenv. e licenciamento de SW não customizável & 2.799 .670 & $6,5 \%$ \\
\hline Consultoria em TI & 7.114 .399 & $16,4 \%$ \\
\hline Suporte técnico, manutenção e outros serviços em TI & 4.194 .550 & $9,7 \%$ \\
\hline $\begin{array}{l}\text { Tratamento de dados, provedores de serviços e } \\
\text { hospedagem na Internet }\end{array}$ & 1.966 .324 & $11,5 \%$ \\
\hline $\begin{array}{l}\text { Portais, provedores de conteúdo e outros serviços de } \\
\text { informação na Internet }\end{array}$ & 1.917 .583 & $4,4 \%$ \\
\hline $\begin{array}{l}\text { Reparação e manutenção de computadores e equipamentos } \\
\text { periféricos }\end{array}$ & & $2,5 \%$ \\
\hline Reparação e manutenção de equipamentos de comunicação & 152.814 & $0,4 \%$ \\
\hline Total & 43.285 .370 & $100,0 \%$ \\
\hline
\end{tabular}

FONTE: Adaptado de SOFTEX, 2012, p. 33

O quadro 14 apresenta estes sub-segmentos segundo o CNAE e a respectiva receita líquida auferida em 2009, considerando empresas com 20 ou mais pessoas ocupadas. Em termos gerais, entre 2003 e 2009 o setor vem crescendo cerca de 4,3\% por ano em número de empresas, tendo atingido um total de 64.345 empresas em 2009 (Softex, 2012).

Cabe destacar que $90 \%$ são pequenas empresas (até 19 pessoas ocupadas). Um grande número destas empresas (cerca de 53 mil) possuem menos de 4 pessoas ocupadas. Porém, como apontado pelo próprio Softex, "muitas existem como forma de contratação de pessoal fora do regime da Consolidação das Leis Trabalhistas (CLT)”, ou seja, muitas vezes são empresas de um ou dois sócios, registradas apenas para emissão de nota fiscal para um cliente específico, ao invés dos sócios serem contratados como funcionários registrados pelo regime CLT. Devido a este motivo, o estudo do Softex apresenta também a distribuição das empresas por 
pessoas ocupadas considerando-se apenas aquelas com 5 ou mais funcionários. Segundo este critério, existem 11 mil empresas distribuídas conforme o quadro 15.

\section{Quadro 15 - Distribuição das empresas da IBSS com 5 ou mais pessoas ocupadas}

\begin{tabular}{|l|r|c|}
\hline \multicolumn{1}{|c|}{ Faixa de Pessoal Ocupado } & \multicolumn{2}{|c|}{$\begin{array}{c}\text { Quantidade de } \\
\text { empresas }\end{array}$} \\
\hline Até 19 & 8.690 & $79,0 \%$ \\
\hline De 20 a 49 & 1.430 & $13,0 \%$ \\
\hline De 50 a 99 & 550 & $5,0 \%$ \\
\hline 100 ou mais & 330 & $3,0 \%$ \\
\hline Total & 11.000 & $100,0 \%$ \\
\hline
\end{tabular}

FONTE: SOFTEX, 2012

Neste trabalho, optamos por analisar empresas pertencentes à atividade de Desenvolvimento de Software Pacote (PROD). Embora seja o segundo segmento em número de empresas, perdendo para o de software por encomenda, o segmento de PROD envolve atividades de alto valor agregado e geralmente envolvem significativo esforço em P\&D.

Apesar do tamanho atual da indústria de software brasileira ser muito semelhante à indiana, 90\% da produção brasileira é orientada para atender à demanda interna, diferentemente da Índia em que grande parte da produção corresponde às exportações (GOUVEA, 2007).

A indústria de software no Brasil se desenvolveu até os anos 1990 em parte protegida por barreiras à importação (GOUVEA, 2007; CASSIOLATO; BAPTISTA, 1996). Apesar das barreiras terem sido impostas para o setor de hardware, muitas empresas de software também acabaram se desenvolvendo (CASSIOLATO; BAPTISTA, 1996). Muitas das empresas brasileiras de software nasceram para automatizar ou fornecer software para grandes instituições financeiras, para o governo ou para grandes grupos que se formaram decorrentes da chamada política de substituição de importações, na qual se estimulou a criação e crescimento de indústrias brasileiras (GOUVEA, 2007).

Segundo Cassiolato e Baptista (1996), o principal objetivo das barreiras à importação foi o desenvolvimento de capacidades nas empresas locais, sejam brasileiras ou filiais de 
multinacionais. Porém, o aprendizado foi prejudicado porque seria necessário um contínuo investimento em $\mathrm{P} \& \mathrm{D}$, que não ocorreu, a fim de poderem tanto absorver tecnologia externa, quanto evoluí-la posteriormente. Com exceção de poucas empresas, em geral vinculadas a grandes grupos como por exemplo a Itautec que era pertencente ao banco Itaú, as empresas de TI nacionais eram pequenas e independentes, e não viam estímulo para realizar investimentos de longo prazo em P\&D.

Até mesmo os processos operacionais das empresas brasileiras, ligados ao desenvolvimento de software, são imaturos relativamente a outros países do mundo. Até 2003, nenhuma empresa brasileira possuía certificação CMM nível 5, contra 32 empresas indianas certificadas (VELOSO et al apud MONTONI et al, 2009). O CMM é a sigla para Capability Maturity Model, ou Modelo de Capacidade de Maturidade, que avalia o nível de capacitação dos processos de desenvolvimento de uma empresa entre 1 (processos imaturos) e 5 (processos otimizados). A preocupação em capacitar as empresas brasileiras levou a um esforço conjunto da SOFTEX, da indústria de software, do governo brasileiro e instituições de pesquisa em criar e disseminar um modelo de melhoria dos processos de desenvolvimento cuja implementação fosse viável para pequenas e médias empresas (MONTONI et al, 2009). Em 2003, teve início um programa para melhoria das capacidades de software das empresas brasileiras chamado MPS.BR - Melhoria do Processo do Software Brasileiro. Segundo Montoni et al (2009), até dezembro de 2008, 123 empresas foram bem sucedidas na avaliação MPS.BR em diferentes níveis de maturidade.

Recentemente o Brasil tem ganho destaque no setor de software mundial com algumas empresas intensificando seu processo de internacionalização (GOUVEA, 2007). Este processo teve como motivador principal a abertura do mercado, que acirrou a competição interna obrigando as empresas a aumentarem sua competitividade tanto gerencial quanto operacional. A saturação do mercado interno, o fato de empresas nacionais já prestarem serviços para filiais de multinacionais estrangeiras, bem como a proximidade comercial com países latino-americanos e da Península Ibérica gerou condições propícias para algumas empresas brasileiras comprarem empresas já estabelecidas ou montarem suas operações no exterior (GOUVEA, 2007).

No próximo tópico, passamos à discussão da metodologia da pesquisa. 


\section{METODOLOGIA DA PESQUISA}

\subsection{Natureza da Pesquisa, Escolha do Método}

A ciência é um empreendimento preocupado com o entendimento de fenômenos naturais, ou sociais no caso da administração, tendo como propósito a teoria, ou seja, uma exposição sistemática das relações entre um conjunto de variáveis (KERLINGER, 1980). A metodologia científica é extremamente importante para se garantir que a pesquisa permita obter informações relevantes para o problema proposto, de forma precisa e não viesada (SELLTIZ et al, 1974).

Conforme já foi apresentado, este estudo pretende investigar a seguinte questão de pesquisa: Como empresas brasileiras de software realizam atividades de elaboração de roadmap tecnológico?

Neste sentido, esta pesquisa pode ser classificada como de natureza aplicada sendo do tipo tanto exploratória quanto descritiva (SELLTIZ et al, 1974). É aplicada pois visa identificar como uma atividade (elaboração de roadmap tecnológico) ocorre e pode ser aplicada na prática. É descritiva, à medida que, à luz da teoria, foi elaborado um modelo conceitual, que serviu de guia para identificar as características importantes desta atividade, visando a descrição de como ela ocorre nas empresas pesquisadas. Porém, é também exploratória, à medida que existem poucos estudos sobre roadmap em empresas de software. A maior parte dos estudos foi realizada em grandes empresas multinacionais de setores industriais, e também não foi encontrado na revisão de literatura estudos que procurassem comparar a atividade de roadmap em empresas de diferentes portes.

De acordo com Yin (2003) existem três condições para se determinar qual método deve ser utilizado para a pesquisa: (a) o tipo de questão de pesquisa; (b) a extensão do controle do investigador sobre os eventos comportamentais; (c) o grau de foco em eventos contemporâneos, em oposição a eventos históricos. O quadro 16 apresenta as situações mais adequadas para cada estratégia de pesquisa. 
Quadro 16 - Métodos de pesquisa

\begin{tabular}{|c|c|c|c|}
\hline Estratégia & $\begin{array}{l}\text { Forma da questão da } \\
\text { pesquisa }\end{array}$ & $\begin{array}{l}\text { Requer controle sobre } \\
\text { eventos } \\
\text { comportamentais? }\end{array}$ & $\begin{array}{l}\text { Foca em eventos } \\
\text { contemporâneos? }\end{array}$ \\
\hline Experimento & Como, por que & Sim & Sim \\
\hline Pesquisa de campo & $\begin{array}{l}\text { Quem, o que *, onde, } \\
\text { quantos }\end{array}$ & Não & Sim \\
\hline $\begin{array}{l}\text { Análise de arquivos (ex. } \\
\text { estudos econômicos) }\end{array}$ & $\begin{array}{l}\text { Quem, o que *, onde, } \\
\text { quantos }\end{array}$ & Não & Sim/Não \\
\hline Histórico & Como, por que & Não & Não \\
\hline Estudo de Caso & Como, por que & Não & Sim \\
\hline
\end{tabular}

FONTE: YIN, 2003, p. 5

Pelo fato deste estudo focar eventos contemporâneos, sobre os quais não se exige controle sobre os eventos comportamentais, tendo como principal questão de pesquisa o "como", a estratégia de pesquisa mais indicada é a de estudo de caso.

\subsection{Modelo Conceitual}

Segundo Dul e Hak (2008), o modelo conceitual é uma representação gráfica que estabelece como os conceitos teóricos se relacionam entre si. Jonker e Pennik (2010) argumentam que o modelo conceitual é uma abstração, representando a forma que o pesquisador escolhe para perceber uma parte, função, propriedade ou aspecto da realidade. $\mathrm{O}$ modelo conceitual serve como base para elaborar um roteiro de entrevista. Em estudos de casos múltiplos, ele auxilia o pesquisador a buscar olhar as mesmas dimensões do fenômeno nos diversos casos, propiciando assim a comparação entre eles.

Com base na revisão de literatura, identificamos que a atividade de roadmap possui 5 importantes dimensões. Uma delas se refere aos objetivos que motivam a empresa e dão início à atividade de elaboração de roadmaps. Para atingir tais objetivos, a empresa realiza uma série de etapas em um processo de elaboração de roadmap tecnológico. A literatura aborda também o conteúdo do roadmap, ou seja, aspectos que são analisados e formalizados. Considerando que o roadmap é uma técnica de inteligência tecnológica, podemos adotar 
como pressuposto que a empresa realiza atividades de monitoramento e busca contínua de informações junto a diferentes fontes de informacão para tomar decisões sobre o roadmap. Outro aspecto relevante que impacta o processo são barreiras e dificuldades. Por fim, a literatura também aborda benefícios que a atividade de elaboração de roadmaps pode trazer para as empresas. Com base nestes elementos, elaboramos o modelo conceitual da figura 15 .

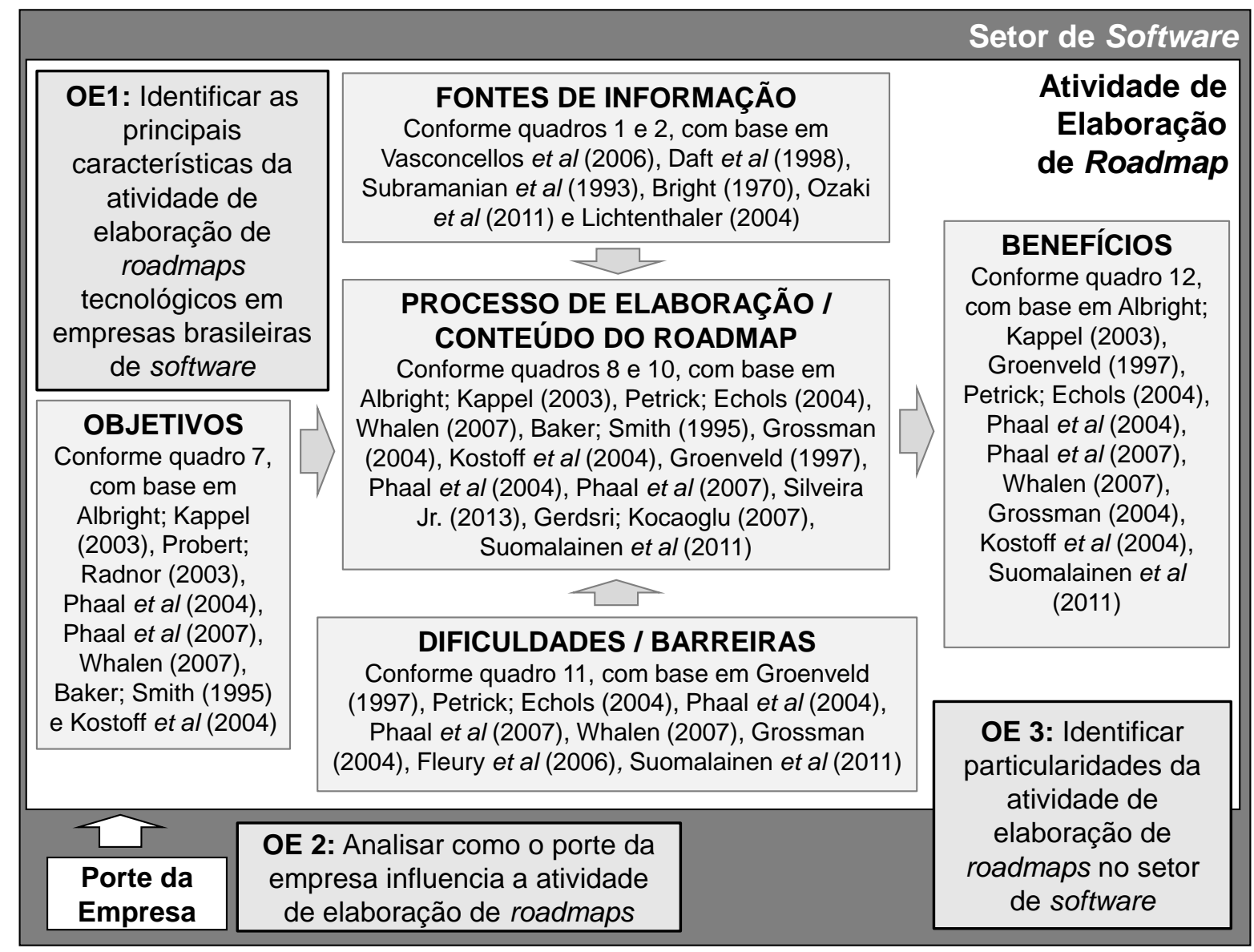

Figura 15 - Modelo conceitual adotado neste estudo

Cada um destes elementos foi devidamente explorado e apresentado na forma de um quadro com o detalhamento dos aspectos já identificados pela literatura existente sobre o tema.

Estamos assumindo como premissa que empresas de software atuam em um ambiente competitivo e em constante mudança, o que impõe a necessidade das empresas desenvolverem capacidades dinâmicas para serem competitivas (CARMEL, 1995; EVANS et al, 2005; SAWYER, 2000; TEECE et al, 1997, EISENHARDT; MARTIN, 2000). Neste sentido, a plataforma de desenvolvimento adotada por uma empresa de software é um 
importante elemento para sua competitividade (MEYER; SELINGER, 1998; CUSUMANO; GAWER, 2002), permitindo à empresa obter benefícios como agilidade, menor esforço de desenvolvimento, maior qualidade, entre outros aspectos.

\subsection{Protocolo do Estudo de Caso}

Seguindo orientações propostas por Yin (2003), foi elaborado um protocolo para o estudo de caso, instrumento muito útil para garantir a confiabilidade da pesquisa. A seguir, discutimos os detalhes do protocolo adotado nesta pesquisa.

\subsubsection{Procedimentos de Coleta de Dados}

Yin (2003) destaca alguns pontos importantes sobre os procedimentos de coleta de dados:

a) Obter acesso às organizações e aos respondentes

Foi realizado primeiramente um convite por e-mail, individual e nominal, a uma relação de executivos que o autor desta tese possui, decorrentes de sua atividade como exempreendedor do setor e como docente/pesquisador. $\mathrm{O}$ objetivo inicial foi conseguir acesso a duas empresas pequenas, duas empresas médias, e uma empresa grande conforme constava do projeto de qualificação desta tese. Conseguimos acesso a oito empresas, sendo que duas foram descartadas por não ter sido possível obter todas as informações relevantes para o estudo, seguindo o protocolo elaborado. A pesquisa se concentrou portanto no estudo de seis estudos de caso, um a mais do que o pretendido na qualificação, sendo duas empresas pequenas, duas médias e duas grandes, que serão melhor caracterizadas ao discutir a amostra.

b) Recursos de campo

A cada entrevista foi levado: cópia impressa do protocolo de pesquisa, um notebook para anotações, uma câmera fotográfica para eventualmente fotografar materiais impressos 
com autorização do entrevistado, um pen-drive para copiar relatórios e materiais que o entrevistado pudesse fornecer. Também foi levada uma cópia do projeto de qualificação bem como da apresentação, para eventuais esclarecimentos caso seja de interesse do entrevistado entender conceitualmente os fundamentos que nortearam a pesquisa.

Nas primeiras entrevistas ficou evidente um desconforto dos entrevistados em permitir a gravação, uma vez que o assunto tratado é altamente estratégico. Neste sentido, optamos por não gravar as entrevistas, mas em anotar detalhadamente todas as respostas e falas dos entrevistados.

Segundo Yin (2003 : 85) existem seis fontes de evidência que devem ser o foco da coleta de dados para os estudos de caso: (1) documentação, (2) registros de arquivos, (3) entrevistas, (4) observação direta, (5) observação participativa e (6) artefatos físicos. Não foi adotada a observação direta, devido a restrições de tempo para realização da pesquisa e acessibilidade nas dependências da empresa. Com relação às outras fontes (documentação, registros de arquivos e artefatos físicos) foram solicitadas pelo pesquisador durante a entrevista, com objetivo de aumentar a riqueza de detalhes sobre o caso.

\subsubsection{Questões do Estudo de Caso}

As questões em estudos de caso não têm por objetivo serem auto-respondidas pelo entrevistado (YIN, 2003). O objetivo é servirem como um roteiro de pesquisa para que o entrevistador aborde todos os conceitos e questões centrais do estudo.

As entrevistas foram baseadas em um roteiro de entrevista com algumas questões estruturadas e outras semi-estruturadas, conforme roteiro reproduzido no Anexo A desta tese. As questões estruturadas se referem justamente às dimensões da atividade de elaboração de roadmaps que foram identificadas na revisão de literatura. Neste caso, para cada item identificado na literatura, foi solicitado ao respondente que atribuísse o grau de importancia em uma escala Likert que variava de 1 a 7. O objetivo da adoção de um formato mais estruturado para estas questões foi permitir uma melhor comparação dos casos, e não realizar análises estatísticas. Nos itens de alto grau de importância, sempre foi solicitado que o entrevistado justificasse a 
resposta, a fim de se obter um melhor entendimento sobre a atividade de elaboração de roadmaps na empresa.

Antes da condução dos estudos de caso da tese, foram realizados dois pré-testes com outras empresas para assegurar que as questões estavam claras e foram suficientes para atingir os objetivos propostos neste estudo. Pequenos ajustes foram realizados no questionário, cuja versão final está reproduzida no Anexo A.

\subsubsection{Amostra e Unidade de Análise}

O critério de amostragem foi teórico (EISENHARDT, 1989), pois foram escolhidas empresas de software que atendessem a alguns requisitos:

a) Porte: a tese buscou inicialmente analisar duas empresas de pequeno porte (até 19 funcionários), duas empresas de médio porte (entre 20 e 99 funcionários) e uma empresa de grande porte (acima de 100 funcionários). O critério adotado para definir o porte conforme o número de funcionários é o mesmo utilizado pelo Softex (2009). Consideramos o tamanho uma importante variável nesta pesquisa com base na teoria do crescimento da firma (PENROSE, 1956) e na economia evolucionária (NELSON; WINTER, 1982), segundo as quais as empresas desenvolvem diferentes capacidades conforme cresce, e o ambiente seleciona as empresas mais capacitadas a se adaptarem às mudanças. Saayman et al (2008) também descobriram em sua pesquisa empírica que empresas maiores tendem a ter práticas de inteligência competitiva mais avançadas. Conforme comentamos, obtivemos acesso a 8 empresas, sendo que duas foram descartadas por não ter sido possível obter todas as informações do roteiro de entrevistas. A amostra final contempla duas empresas de pequeno, duas de médio e duas de grande porte.

b) Segmento de atuação no setor de software: buscamos apenas empresas que atuassem no segmento de pacotes de softwares de gestão empresarial. Descartamos empresas que atuassem como fábricas de software ou software por encomenda porque, por atuar com demandas específicas, possivelmente elas não teriam atividade de elaboração de 
roadmap. Já em empresas de software produto, é esperado que haja uma atividade de estruturar a evolução e a incorporação de novas tecnologias no produto, mesmo que a empresa não adote o termo roadmap para esta atividade.

c) Nacionalidade da empresa e local em que é elaborado o roadmap: foram escolhidas empresas cuja sede está localizada no Brasil, ou seja, com origem de capital nacional, e que realizam no país atividade de elaboração de roadmaps. O setor de software de gestão é um setor competitivo, no qual existem empresas de porte bastante expressivo no Brasil, e que competem com grandes concorrentes internacionais. Excluímos empresas multinacionais de capital estrangeiro pela dificuldade de interação com a matriz, no sentido de entrevistar pessoas-chave envolvidas com a elaboração de roadmaps.

Consideramos pertinente a inclusão de empresas pequenas no estudo porque $96 \%$ das empresas de IBSS no Brasil possuem até 19 funcionários (SOFTEX, 2012). As empresas grandes, por sua vez, respondem por apenas $0,6 \%$ das empresas, mas são as que potencialmente devem possuir maior domínio na aplicação das técnicas de IT. As empresas médias correspondem a $3,4 \%$ do total das empresas e acreditamos serem igualmente importantes de serem incluídas na pesquisa porque já possuem uma estrutura maior que as empresas pequenas. Potencialmente executivos contratados e não mais os donos executam parte das tarefas de inteligência tecnológica, mas por outro lado não dispõem dos recursos que uma grande empresa possui.

A unidade de análise corresponde à atividade de elaboração de roadmaps. Assim, sendo, se a empresa executa de forma diferente a atividade de elaboração de roadmaps em diversos produtos, nesta tese iremos focalizar em um produto específico para esta análise. O quadro 17 apresenta as empresas que fizeram parte da amostra, a unidade de análise e os entrevistados.

Em cada empresa, foi escolhido um entrevistado principal, para o qual foi aplicado o roteiro de entrevista completo, constante do Anexo A desta tese. A duração das entrevistas variou de uma a duas horas, conforme o domínio do entrevistado sobre as questões apresentadas. Para complementar as informações, foram identificadas as pessoas com perfil mais relevante para entrevistas complementares. 


\section{Quadro 17 - Caracterização da amostra}

\begin{tabular}{|c|c|c|c|}
\hline Empresa & \begin{tabular}{|}
$\mathbf{N}^{\mathbf{o}}$ \\
$\begin{array}{c}\text { Funcionários } / \\
\text { Porte }\end{array}$
\end{tabular} & Unidade de Análise & Entrevistados \\
\hline TOTVS & $\begin{array}{l}5500 \\
\text { Grande Porte }\end{array}$ & $\begin{array}{l}\text { Roadmap na área } \\
\text { Software e } \\
\text { Segmentos }\end{array}$ & $\begin{array}{l}\text { Analista de Roadmap*, Gestor } \\
\text { de Mercados Internacionais }\end{array}$ \\
\hline BEMATECH & $\begin{array}{l}1095 \\
\text { Grande Porte }\end{array}$ & $\begin{array}{l}\text { Roadmap na vertical } \\
\text { Restaurantes, da } \\
\text { Diretoria de Software }\end{array}$ & $\begin{array}{l}\text { Gestor da Vertical*, Diretor de } \\
\text { Software, Gerente de } \\
\text { Desenvolvimento }\end{array}$ \\
\hline KIMAN & $\begin{array}{c}80 \\
\text { Médio Porte }\end{array}$ & $\begin{array}{l}\text { Roadmap do KiPrev - } \\
\text { produto principal da } \\
\text { empresa }\end{array}$ & $\begin{array}{l}\text { Diretor de Negócios*, Diretor } \\
\text { de Desenvolvimento }\end{array}$ \\
\hline OPUS & $\begin{array}{c}90 \\
\text { Médio Porte }\end{array}$ & $\begin{array}{l}\text { Roadmap na área de } \\
\text { Franquias }\end{array}$ & $\begin{array}{l}\text { Sócio Diretor*, Gerente } \\
\text { Comercial, Gerente de Projetos }\end{array}$ \\
\hline COINFO & $\begin{array}{c}17 \\
\text { Pequeno Porte }\end{array}$ & $\begin{array}{l}\text { Roadmap do Sigot e } \\
\text { SICA, produtos } \\
\text { principais }\end{array}$ & $\begin{array}{l}\text { Sócio Diretor*, Consultor de } \\
\text { Negócios }\end{array}$ \\
\hline KEYWORD & $\begin{array}{c}20 \\
\text { Pequeno Porte }\end{array}$ & $\begin{array}{c}\text { Roadmap do software } \\
\text { de BI - produto } \\
\text { principal }\end{array}$ & Diretor de Tecnologia* \\
\hline
\end{tabular}

* Entrevistado Principal

Para os demais entrevistados, o roteiro de entrevista foi aplicado de forma parcial, principalmente no sentido de complementar as informações e obter um ponto de vista diferente sobre a atividade de elaboração de roadmaps, a fim de se fazer a triangulação das informações e aumentar a confiabilidade da pesquisa (YIN, 2003).

A empresa TOTVS, é uma empresa de grande porte listada na Bolsa de Valores de São Paulo, com 5.500 funcionários aproximadamente. As soluções de gestão empresarial (ERP) estão sob a Vice-Presidência de Software e Segmentos, sendo a única empresa da amostra que apresentou uma área específica para a atividade de elaboração de roadmaps, denominada departamento de roadmap. A unidade de análise foi a atividade de elaboração de roadmaps nesta Vice-Presidência. O entrevistado principal foi o Analista de Roadmaps da empresa. Devido à forte atuação internacional da TOTVS, e a fim de se verificar os impactos da 
internacionalização sobre esta atividade, foi também entrevistado o Gestor de Mercados Internacionais.

A empresa Bematech é também uma empresa de grande porte listada na Bolsa de Valores de São Paulo, com 1095 funcionários aproximadamente. Possui quatro verticais na diretoria de software, sendo que a unidade de análise foi a atividade de elaboração de roadmap na vertical de Restaurantes, bastante significativa e que possuía um processo melhor estruturado para evolução dos produtos. Entrevistado principal foi o gestor da vertical. As informações foram complementadas com entrevistas com o Diretor de Software e o Gerente de Desenvolvimento. Algumas informações foram complementadas consultando-se o Gerente de Projetos da empresa diversas vezes por $e$-mail.

A empresa Kiman é uma empresa de médio porte, com 80 funcionários. Possui uma solução principal, voltada ao mercado de previdência. A atividade de elaboração de roadmap desta solução foi a unidade de análise. O entrevistado principal foi o Diretor de Negócios, principal responsável pelas decisões de evolução dos produtos, e informações complementares foram obtidas com o Diretor de Desenvolvimento.

A Opus é uma empresa de médio porte, com cerca de 90 funcionários à época em que as entrevistas foram realizadas. A unidade de análise foi a elaboração de roadmap na unidade Franquias, que possuía uma solução que mais se aproximava de um pacote. O entrevistado principal foi o Sócio-Diretor da empresa, sendo que informações complementares foram obtidas com uma entrevista em que participaram o Gerente Comercial e o Gerente de Projetos.

A Coinfo é uma empresa de pequeno porte, com cerca de 17 funcionários, mas que possui uma atuação muito forte no setor de turismo. A unidade de análise foi a forma como evolui os dois produtos principais, denominados SICA e SIGOT, que serão melhor explicados na apresentação do caso. O entrevistado principal foi o Sócio-Diretor da empresa, sendo que informações complementares foram obtidas com um consultor de negócios da empresa.

A Keyword é uma empresa de pequeno porte, com cerca de 20 funcionários, que possui um produto principal voltado para inteligência de negócios, ou BI (business intelligence). A 
atividade de evolução deste produto foi a unidade de análise. Nesta empresa foi entrevistado o sócio diretor, responsável pela área de tecnologia da empresa.

\subsection{Análise dos Dados}

Nesta tese, procurou-se adotar, dentro das limitações existentes, a análise de conteúdo.

Segundo Bardin (2011), a análise de conteúdo corresponde a

[...] um conjunto de técnicas de análise das comunicações visando obter por procedimentos sistemáticos e objetivos de descrição do conteúdo das mensagens indicadores (quantitativos ou não) que permitam a inferência de conhecimentos relativos às condições de produção/recepção (variáveis inferidas) dessas mensagens. (BARDIN, 2011, p. 48).

Krippendorff (2004) define a análise de conteúdo como uma técnica de pesquisa para tornar as inferências dos textos válidas e replicáveis para os contextos de seu uso. Uma preocupação importante nesta visão é a replicabilidade, ou seja, permitir que, a partir dos mesmos dados, outros pesquisadores possam chegar às mesmas conclusões.

Como não realizamos a gravação das entrevistas, não procedemos com a categorização e tabulação das palavras citadas pelos entrevistados, conforme recomendado por Bardin (2011).

Porém, para reduzir o risco de esquecimento, logo após a realização das entrevistas foi redigido o estudo de caso individual, contendo todas as informações relevantes de acordo com o modelo conceitual adotado neste estudo. As informações das questões objetivas foram devidamente tabuladas a fim de se gerar os quadros comparativos. A análise recaiu sobre os aspectos que receberam maior avaliação.

Segundo Krippendorff (2004) a literatura de análise de conteúdo provê essencialmente três tipos de diferentes definições: (a) o conteúdo é inerente ao texto; (b) o conteúdo é uma propriedade da fonte do texto; (c) o conteúdo emerge do processo da análise feita pelo pesquisador, relacionado a um determinado contexto. Krippendorff (2004) defende que a terceira definição é a mais adequada. Neste sentido, procurou-se nesta tese entender não 
apenas a palavra específica mencionada, mas o conteúdo que o entrevistado procurou transmitir (BARDIN, 2011), analisado dentro de seu contexto.

Para os casos que possuíssem processos organizados de roadmap, procedeu-se com o desenho das fases do processo, de forma semelhante à representação feita por Suomalainen et al (2011) para representar as principais etapas na elaboração de roadmap em empresas de software (figura 13).

Mesmo com estes procedimentos, existem limitações, as quais serão devidamente exploradas nas considerações finais desta tese.

A seguir, passamos à apresentação dos estudos de caso. 


\section{APRESENTAÇÃO DOS ESTUDOS DE CASO}

Os seis casos estudados nesta tese são apresentados a seguir em ordem crescente de porte por número de funcionários. Dois estudos foram realizados em empresas de pequeno porte (Coinfo e Keyword), dois em empresas de médio porte (Opus e Kiman) e dois em empresas de grande porte (Bematech e TOTVS).

\subsection{Coinfo Informática}

\subsubsection{Apresentação da Empresa}

A Coinfo Informática foi fundada em 1989, e tem como principais produtos dois sistemas voltados ao segmento de turismo. O SIGOT (Sistema Integrado de Gestão de Operadoras Turísticas) tem como público alvo as operadoras de turismo. Na cadeia de valor, as operadoras são responsáveis pela criação dos pacotes turísticos que são vendidos pelas agências de viagens. O SICA (Sistema Integrado de Gestão de Consolidadoras Aéreas) tem como público alvo as chamadas consolidadoras aéreas, que são as empresas que intermediam as vendas dos bilhetes entre as companhias aéreas e as agências. Quando as entrevistas foram realizadas, a empresa contava com 17 funcionários, atendendo a 13 operadoras e 8 consolidadoras.

Um dos maiores desafios da empresa reside em padronizar os dois softwares, permitindo que cada um mantenha seu núcleo comum, mas permitindo também manter as customizações de cada cliente. Como será explicado, a empresa replica o código para cada cliente novo e passa a evoluí-lo de forma independente.

A plataforma tecnológica adotada pela empresa foi citada com sua principal ameaça tecnológica pois o sistema ainda permanece em ambiente caracter (termo utilizado para sistemas que exibem apenas informações em forma de texto, tais como as telas do sistema DOS ou terminais de mainframe, que predominavam antes dos ambientes gráficos do 
Windows e Macintosh). Algumas funcionalidades pontuais, relacionadas a portais na Internet para os clientes, foram desenvolvidos em Java a partir de 2006.

\subsubsection{Atividade de Elaboração do Roadmap}

A Coinfo não adota roadmaps da forma como a literatura propõe. Porém, realiza atividades para evolução dos produtos, que foram entendidas, juntamente com os entrevistados, como sendo a atividade de roadmap da empresa.

No momento em que as entrevistas foram realizadas, cada cliente, ao contratar o software, recebia um "núcleo comum", mas que passava a ser customizado de acordo com suas solicitações. Desta forma, cada cliente possui códigos que em parte possuem um mesmo núcleo, uma vez que tiveram a mesma origem, e em parte são diferentes devido a uma evolução própria e independente conforme a solicitação de cada cliente.

Este modelo possui vantagens, uma vez que há total possibilidade de adaptação do software às necessidades específicas do cliente. Porém, isto limita a possibilidade de expansão da empresa. Foi citada como uma grande ameaça o fato do sistema ainda estar em plataforma caracter, ou seja, ainda não opera em interface gráfica (janelas no estilo Windows). A atualização é muito dispendiosa, justamente porque demandaria um enorme esforço de desenvolvimento e customização do software para as características individuais de cada cliente.

Isto dificulta disponibilizar funcionalidades para todos os clientes. Por exemplo, a empresa trabalhava, no momento em que as entrevistas foram realizadas, em uma implementação de cunho legal e que, portanto, deverá ser replicada para todos os clientes sem custo adicional para eles. Consiste em uma exportação de dados para um sistema do governo denominado Siscoserv, que tem por objetivo discriminar para qual país a empresa de turismo remete cada parte do valor do pacote vendido.

O processo de evolução dos produtos da Coinfo envolve as seguintes etapas: 
a) Solicitações dos clientes: as solicitações dos clientes são inseridas em um portal de relacionamento, alimentando a ferramenta de help desk Kayako, adotada pela Coinfo. Isto dispara automaticamente um e-mail para a diretoria da empresa.

b) Análise: os próprios sócios-diretores da empresa analisam a solicitação. Quando necessário fazem reuniões com o cliente ou entrevistas com usuários-chave para melhor entendimento da necessidade do cliente. Geram um documento de especificação e um lay-out de telas que é então passado aos desenvolvedores, para estimar as horas necessárias para desenvolvimento. Após a estimativa de horas, os sócios diretores formalizam uma proposta e encaminham para o cliente.

c) Aceite: o não-aceite implica no encerramento da pendência no sistema. Quando o cliente aceita, a pendência é designada para um desenvolvedor, com uma atribuição de prazo para término.

d) Desenvolvimento: A diretoria utiliza o próprio sistema de help desk para verificar o acompanhamento da execução da solicitação. O próprio desenvolvedor é responsável pelo desenvolvimento e teste. Apenas funcionalidades de complexidade alta são testadas pelos sócios da empresa. Após o teste interno, a implementação é disponibilizada para ser homologada no ambiente de testes do cliente. Existe uma fase de interação em que a nova funcionalidade pode ir e voltar para ajustes até que o cliente homologue o novo desenvolvimento.

e) Instalação: A instalação é agendada de comum acordo com o cliente, e normalmente é realizada por acesso remoto. A equipe da Coinfo disponibiliza a funcionalidade no ambiente chamado de produção (termo usado em TI para designar o ambiente oficial das aplicações) e o cliente então faz uma nova checagem apenas para verificar se a instalação foi feita corretamente.

As principais fontes de informação utilizadas pela Coinfo são os altos executivos da empresa e os clientes e usuários. Em segundo lugar, os funcionários de TI também são grande fonte de idéias, bem como parceiros tecnológicos, auxiliando na definição de novas tecnologias a serem incorporadas nos produtos. Em um grau menor, foram também citados como fonte de 
informação os fornecedores de tecnologia, governo no caso de alterações legais no software e associações do setor de turismo que é o mercado alvo da companhia.

Com relação ao objetivo do roadmap foi apontado como os mais importantes a integração entre diversas áreas da empresa e o planejamento/definição de processos. Em segundo lugar, foi apontado a identificação de oportunidades e ameaças tecnológicas, o planejamento do projeto e de capacitação dos funcionários.

Como componente do roadmap, o que a empresa possui é uma relação de funcionalidades a serem implementadas no curto prazo. A análise de mercado, apesar de ser reconhecida por um dos entrevistados como um elemento importante, não é realizada pela empresa de forma ativa para explorar novos mercados. O próprio ingresso da empresa no mercado de consolidadoras aéreas aconteceu em 1999, por solicitação de uma empresa que já era cliente da Coinfo com o sistema de operadoras (SIGOT). O crescimento ocorreu em função das indicações de clientes ou ex-funcionários que saíram para trabalhar em outras empresas do mesmo setor.

Entre as barreiras mais importantes foram relatadas pelos funcionários a cultura da empresa, bastante familiar e orientada para atender a cada cliente de forma particularizada, a falta de visão de futuro o que também está associado à dificuldade de identificar as características do produto mais importantes no futuro. Foi salientado que o próprio modelo de negócios atual está em análise e é uma barreira muito relevante. $\mathrm{O}$ fato de a empresa possuir um produto que não é único, mas que evolui de forma independente em cada cliente em que é instalado é uma barreira para o crescimento da empresa. Um dos entrevistados relatou que com o modelo de negócios atual, as possibilidades de crescimento futuro da empresa são muito limitadas. Em contrapartida, a satisfação dos clientes foi citada como sendo um ponto forte da empresa, pois ela consegue atender a todos plenamente, sem a restrição dos softwares pacotes de manter o código base inalterado.

\subsection{Keyword}




\subsubsection{Apresentação da Empresa}

A empresa Keyword foi fundada em 1997 e atua no mercado de Business Intelligence (BI), ou inteligência de negócios. A empresa conta com cerca de 20 colaboradores, dos quais 4 atuam de alguma forma relacionados com desenvolvimento. Foi entrevistado o diretor de tecnologia da empresa. Seu portfólio inclui duas versões de um produto de BI, sendo uma versão clienteservidor e outra versão Web. Este produto consolida informações de outros sistemas que a empresa possua, tais como sistemas ERP, permitindo extrair diversas visões gerenciais (por exemplo, consolidar resultados por filial, categoria de produtos, confrontar realizado com estimado, etc). Possui em sua carteira grandes clientes nos setores de varejo, telecomunicações e comércio, entre outros.

Entre os maiores desafios que a empresa enfrenta com relação à evolução dos produtos está o desenvolvimento de versões para acesso via dispositivos móveis (tablets e smartphones). Entre as principais ameaças foi citado pelo diretor de tecnologia um receio quanto a "caducar a plataforma tecnológica". Apesar de a empresa ter hoje uma versão Web, ela não é utilizada em larga escala. A maior parte dos clientes utiliza a versão cliente-servidor, havendo ainda o risco de substituição do software por outros com maior participação de mercado.

\subsubsection{Atividade de Elaboração do Roadmap}

Em sua trajetória, a empresa passou por diversas transições de plataforma tecnológica, sempre optando por utilizar plataformas da Microsoft. A primeira versão da ferramenta foi lançada em 1997 com a criação da empresa, tendo sido adotada a plataforma de desenvolvimento Visual Basic (VB) 3.0. Posteriormente houve evoluções tanto das versões do produto da empresa quanto da ferramenta de desenvolvimento adotada (VB 4.0 e 5.0). Mas uma mudança significativa aconteceu com a versão 6.0, quando a empresa adotou o VB 6 e passou a disponibilizar uma interface para o usuário semelhante a uma planilha em Excel. Posteriormente houve evolução para a versão 7 e 8, ambas adotando ainda o VB 6 como ferramenta. Em 2009, a empresa decidiu que desenvolveria uma versão Web de seu produto, utilizando a plataforma .NET. Essa versão, lançada em 2010, é conhecida apenas como sendo a versão Web da solução de BI, não havendo uma numeração específica para ela. A empresa 
também optou por adotar uma ferramenta complementar à plataforma .Net, chamada Visual Web Gui, da empresa israelense Gizmox, que oferece benefícios em termos de funcionalidade, recursos de interface e produtividade. $\mathrm{O}$ quadro 18 sintetiza a evolução tecnológica dos softwares da Keyword.

\section{Quadro 18 - Evolução tecnológica dos softwares da Keyword}

\begin{tabular}{|l|l|l|l|}
\hline Ano & Versão & Plataforma & Principais funcionalidades adicionadas \\
\hline 2001 & 6 & VB 6.0 & $\begin{array}{l}\text { Mudança de plataforma (antes era VB 5). } \\
\text { Interface semelhante ao Excel }\end{array}$ \\
\hline 2005 & 7 & VB 6.0 & $\begin{array}{l}\text { Agendamento para rodar consultas, gravar } \\
\text { consultas em vários formatos }\end{array}$ \\
\hline 2008 & 8 & VB 6.0 & $\begin{array}{l}\text { Criação de framework para desenvolvimento, } \\
\text { facilitando assim criar novas funções para o } \\
\text { cliente sem precisar alterar o código do } \\
\text { software e portanto sem necessidade de } \\
\text { distribuir novas versões. }\end{array}$ \\
\hline 2010 & Web & VB.NET + Visual & $\begin{array}{l}\text { Criação de versão para Internet. Adoção do } \\
\text { Visual Web GUI para desenvolver a interface. }\end{array}$ \\
\hline
\end{tabular}

As mudanças ocorridas até 2009 não foram mudanças de plataforma, mas apenas de incorporação de novas funcionalidades.

Em 2010 ocorreu uma mudança de plataforma muito significativa, com criação da versão Web do software, adotando a plataforma .NET da Microsoft. O diretor de tecnologia chegou a instalar a plataforma Java para testes, porém, não com objetivo de estudar a plataforma como possível alternativa de migração, mas sim para conhecer e verificar as vantagens e desvantagens. Apesar de a linguagem de programação adotada ser também o VB, há uma grande mudança no VB.NET em relação ao VB 6.0, desde a arquitetura da solução até a forma como ela é efetivamente codificada.

A Keyword possui roadmap para apenas um produto, que é o correspondente à versão Web. A versão anterior, cliente-servidor, ainda é comercializada e está instalada na maior parte da base de clientes. Porém, a empresa pretende parar com novas implementações nessa versão e 
evoluir apenas a versão Web. Na época da entrevista a versão cliente-servidor estava sofrendo diversas alterações, mas por demanda de dois clientes que precisavam integrar a ferramenta aos seus novos sistemas ERP.

Não há uma ferramenta de apoio para registrar as idéias de novas funcionalidades para o roadmap. De forma geral, o diretor de tecnologia utiliza o próprio e-mail para organizar estas idéias que chegam de diversas fontes (clientes, colaboradores internos, sócio). O entrevistado chegou a comentar que em algumas situações, ele envia um e-mail para ele mesmo, a fim de que fique registrada a idéia para uma futura implementação.

As principais etapas para elaboração do roadmap consistem em primeiramente uma etapa de análise geral (de mercado e tecnológica), para depois fazer análises específicas sobre as funcionalidades visando sua priorização, o desenho do roadmap propriamente dito e, por fim, a divulgação do roadmap.

A etapa de análise geral não é uma atividade específica com início e término determinado, mas uma atividade de monitoramento constante. Envolve:

a) Monitoramento de concorrentes: não é feita de forma estruturada. Foi citado como exemplo o estudo de ferramentas concorrentes de mercado no momento em que a Keyword tentou firmar uma parceria com uma empresa parceira da IBM. O objetivo era implementar a ferramenta Cognos que a IBM havia adquirido. Neste momento, foi realizada uma boa análise da ferramenta, incluindo treinamento, uma vez que ela estava sendo pensada como uma alternativa de novo negócio para a Keyword. Porém, a parceria foi descontinuada. De forma esporádica a empresa baixa versões de demonstração de outras soluções de BI, seja para avaliar a possibilidade de atuar implementado estas soluções, seja porque descobriram que uma ferramenta possui determinadas funcionalidades novas (normalmente oriundas de informações de cliente ou de notícias);

b) Monitoramento de tecnologias: o diretor de tecnologia acompanha de forma constante notícias principalmente por meio de newletters e sites especializados. $\mathrm{O}$ entrevistado citou que é importante saber como está a evolução de diversas 
tecnologias porque junto aos clientes e funcionários ele é a pessoa que mais deve entender de tecnologia, explicando por que motivo estão adotando uma determinada plataforma e não outra. Em grande parte, este acompanhamento é feito não apenas por necessidade da empresa, mas também por interesse e gosto pessoal do diretor em acompanhar a evolução tecnológica. A empresa precisa saber as vantagens e desvantagens de sua tecnologia em relação aos concorrentes, até para poder defender a plataforma tecnológica adotada junto a clientes e às prospecções. Entre as tecnologias monitoradas pela empresa e que potencialmente podem trazer impactos para o roadmap de seu produto, foram citados o big data, plataformas móveis, ambientes de desenvolvimento, sistemas operacionais e tecnologias ou soluções de BI.

c) Demandas do mercado: as demandas de mercado são também monitoradas de forma constante, seja por meio do diretor comercial que faz as prospecções de novos clientes, seja pelo diretor de tecnologia, consultores ou o gerente que cuidam da implementação do software e do atendimento dos clientes. Muitas solicitações que chegam são transcritas para uma planilha, que contém uma relação de funcionalidades que serão depois analisadas e priorizadas pela empresa.

A etapa de análise/priorização é realizada de forma intuitiva e não estruturada. Existem dois grandes processos de priorização de novos desenvolvimentos:

a) Os erros tem máxima prioridade. Foi relatado que o fluxo normal é os erros chegarem por meio de e-mail para o gerente de consultoria, que usa o próprio e-mail para encaminhar para um funcionário (no caso de customizações) ou para o diretor de tecnologia (produto "base") para providenciar a correção de eventuais erros. Existe um back-log (termo usado para lista de pendências) de aproximadamente 15 dias a um mês de trabalho de erros a serem sanados.

b) As novas implementações geralmente tem origem nas solicitações de clientes, análises de concorrentes, ou em idéias próprias geradas pelos diretores da empresa. Foi relatado pelo diretor de tecnologia que é feita uma análise de custo-benefício. O custo é mensurado em termos de dificuldade de implementação (alta, média e baixa), e o 
benefício em função da satisfação do cliente e da evolução do produto de modo a permitir um aumento no poder da ferramenta e algum diferencial em relação aos concorrentes do mercado. A análise não é formal nem estruturada, sendo baseada na intuição do diretor de tecnologia, responsável por tomar a decisão sobre a maior parte das novas funcionalidades.

A elaboração do desenho do roadmap consiste em transcrever para um quadro no Power Point uma visão das futuras implementações. A figura 16 ilustra o último roadmap elaborado pela Keyword, há cerca de 5 anos. Após este desenho, a empresa não realizou novos esforços de formalizar uma visão de futuro para suas soluções.

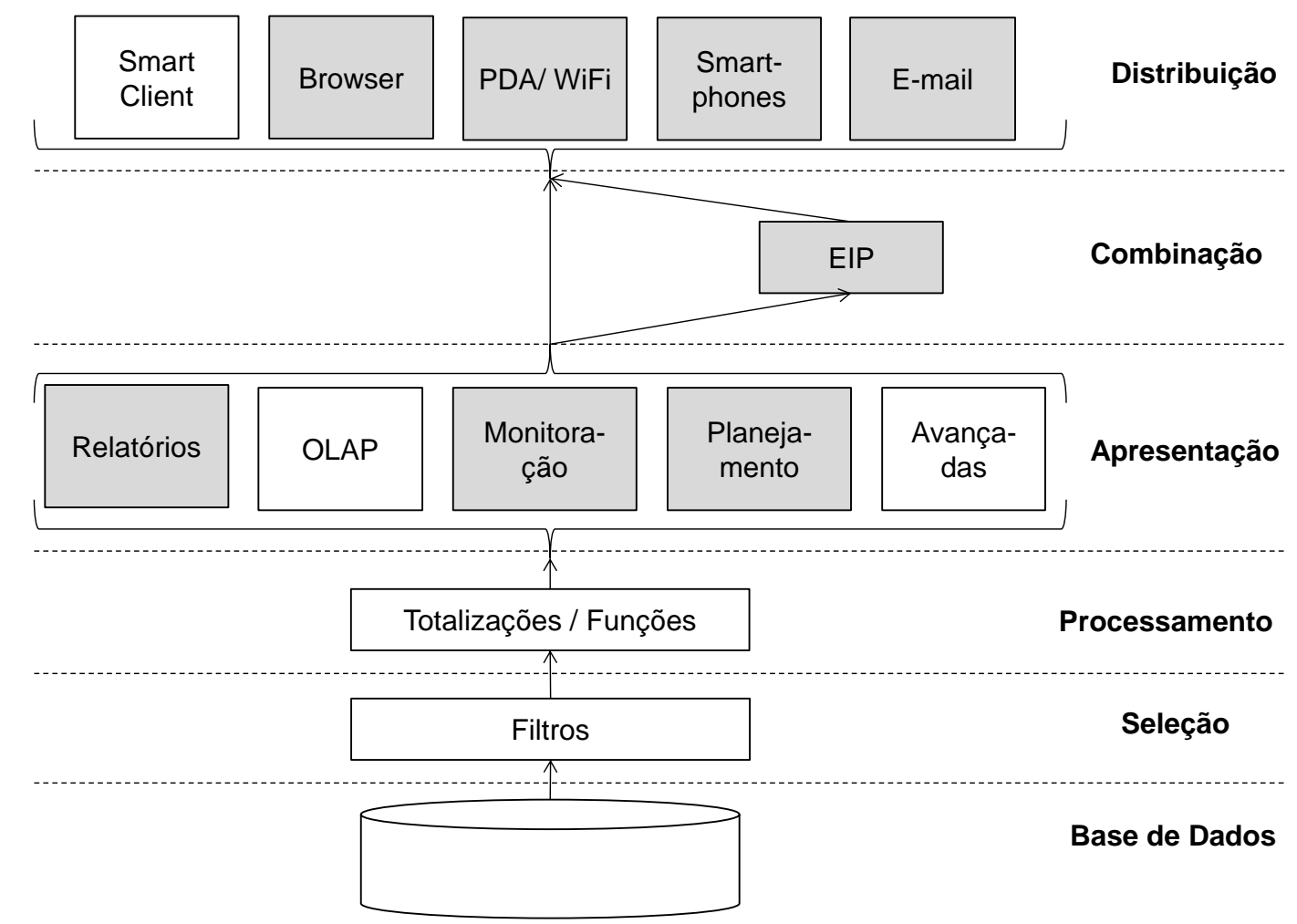

Figura 16 - Roadmap da empresa Keyword

Na figura 16, as funcionalidades dos quadros em branco já estão implementadas, e as pintadas em cinza representam as funcionalidades que seriam desenvolvidas no futuro. Cabe uma explicação sobre algumas funcionalidades previstas neste roadmap. O termo OLAP é utilizado para designar Processamento Analítico On-Line, ou seja, a possibilidade de analisar informações em tempo real. EIP (Enterprise Internet Portal) corresponde à possibilidade de 
combinar suas consultas com portais de internet da empresa. Após a elaboração o roadmap, foram feitas reuniões com a equipe para divulgar o planejamento realizado. Eventualmente este roadmap era mostrado para algum cliente ou prospecção, mostrando que uma solicitação já estava planejada para ser desenvolvida.

Porém, conforme comentado, este processo não é estruturado e também não tem uma periodicidade definida. Por exemplo, após o desenvolvimento da versão Web, a estratégia original seria não evoluir mais a versão cliente-servidor e focar na evolução da nova versão. Porém, por demanda de dois clientes que estão migrando de sistema ERP e possuem a versão cliente-servidor, a empresa estava no momento da entrevista totalmente focada para atender a estes clientes e implementar as funcionalidades por eles requisitadas.

Dentre as principais barreiras para a elaboração do roadmap foram mencionadas a dificuldade de manter o roadmap atualizado, e o tempo necessário para atualizá-lo. Também foi destacada a dificuldade de colocar em prática o roadmap.

O principal benefício do roadmap é ligar a estratégia aos planos de produto e tecnologia. Permite assim que a visão da empresa seja traduzida em uma oferta futura de produtos. Com menor grau de importância, foram citados como benefícios a construção de uma visão de longo prazo e a melhoria do planejamento sobre as prioridades da empresa. Também foi citado o reuso da tecnologia, pois o planejamento permite desenvolver funcionalidades que possam ser aproveitadas futuramente em novos módulos, com redução do esforço de desenvolvimento.

\subsection{Opus}

\subsubsection{Apresentação da Empresa}

A Opus é uma empresa fundada em 1987, com mais de 250 casos de projetos de sucesso no momento em que as entrevistas foram realizadas. Há três anos consecutivos, a Opus é 
considerada, segundo a revista Computerworld, uma das 100 melhores empresas de TI e Telecom para se trabalhar. Possui cerca de 90 funcionários no total.

À época em que as entrevistas foram realizadas, sua atuação estava divida em três áreas de negócios:

- Projetos e terceirização de aplicações: área responsável por projetos específicos de desenvolvimento de software (que não tenham relação com as outras duas áreas) e terceirização de manutenção de aplicações.

- Automação Bancária: área responsável pelo software de automação de agências e correspondentes bancários, tendo como clientes a Caixa Econômica Federal, o Bradesco e a Alelo (que incorporou o banco IBI). Esta área não apenas se preocupa com a evolução do software padrão, mas também é responsável pelos projetos de customização e pela terceirização da operação no caso de alguns clientes. O software foi desenvolvido em linguagem Java com banco de dados Oracle.

- Franquias: área responsável pelo software de gestão de franquias. Alguns clientes, segundo o site da empresa, são as redes de franquias Yázigi, Minds, Onodera, Eurodata, Microcamp e Fotótica. Na época em que foram realizadas as entrevistas, sua solução era adotada por 25 redes de franquias, em mais de 2.300 pontos em 400 cidades do Brasil. O software foi desenvolvido em plataforma .NET, com acesso a banco de dados SQL Server. O software é também oferecido na modalidade SAAS, adotando o conceito de computação em nuvem.

Nesta pesquisa, concentramos as análises sobre a unidade de Franquias, que é a unidade que possui uma solução relativamente padronizada. Nesta unidade, atuam cerca de 10 pessoas relacionadas ao desenvolvimento de software.

Entre os grandes desafios que a empresa enfrenta atualmente com relação à evolução de seus produtos destaca-se a necessidade de acompanhar as tendências de mercado, pois a forma de utilização e os aspectos relevantes da solução para o cliente evoluem constantemente. Uma das mudanças é a crescente importância da mobilidade, o que gera necessidade de 
compatibilidade e/ou de aplicações específicas para aparelhos móveis. Porém, conforme relatado por um dos entrevistados, não há ainda um padrão definido, havendo uma disputa entre iOS (Apple), Android (Google) e agora Windows (Microsoft). Isto torna qualquer decisão mais arriscada, pois a opção por uma plataforma que eventualmente não se mostre vencedora pode comprometer o investimento. Outra mudança é a crescente importância das redes sociais. Também foi destacado como desafio a evolução da plataforma tecnológica utilizada em seus softwares e a necessidade de acompanhar a evolução que tais plataformas sofrem ao longo do tempo.

\subsubsection{Atividade de Elaboração do Roadmap}

Foi citado por um dos entrevistados que é difícil falar em um roadmap unificado na Opus, porque cada cliente possui uma solução específica. Pode-se dizer que cada cliente usa uma versão diferente do produto. Contudo, todas as versões surgiram a partir de um mesmo "tronco", que teve origem no primeiro cliente. A referência a "tronco" é bastante apropriada, pois um dos entrevistados desenhou uma figura em formato de árvore com a evolução do produto ao longo do tempo.

A figura 17, à qual chamamos de roadmap "retrospectivo", representa esta evolução do produto da Opus. Os nomes dos clientes foram omitidos por questão de sigilo. A primeira versão surgiu há cerca de 10 anos, quando uma franquia do setor de ensino encomendou a solução (cliente 1). Logo depois, a Opus fechou contrato com uma franquia de idiomas (cliente 2). Esta segunda versão do sistema serviu de base para outras "ramificações" do produto. Por exemplo, existe uma versão específica para escolas de futebol, outra específica para cursos de informática, e foi criado um novo "ramo" específico para clínicas de estética. Para cada novo cliente a empresa verifica qual a versão mais parecida com o negócio deste novo cliente, e cria uma nova instância da solução que passa a ter "vida própria", evoluindo dentro de um roadmap específico, acordado juntamente com cada cliente. Ao todo, o software é adotado por 25 redes de franquias em mais de 2.300 pontos espalhados pelo Brasil. 


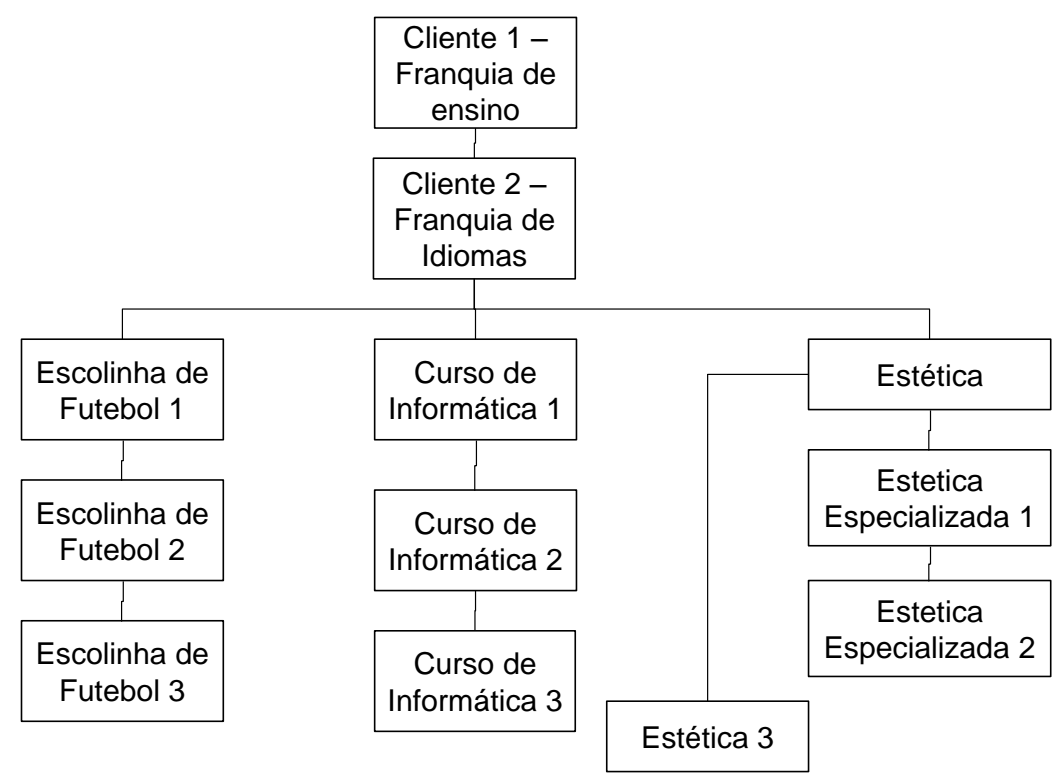

Figura 17 - Roadmap "retrospectivo" da Opus

Assim sendo, empresa não adota um processo de roadmap formal. Porém, existem três processos de planejamento tecnológico importantes que estão relacionados com a atividade de roadmap: Decisão sobre Plataforma Tecnológica, Planejamento de Evolução da Plataforma de Produto e Roadmap de Planejamento de Customizações.

a) Decisão sobre Plataforma Tecnológica

Existe um monitoramento constante sobre a evolução das plataformas tecnológicas.

Os itens mais importantes monitorados pela empresa são a plataforma de desenvolvimento (versão do Java ou do .NET), do banco de dados (são utilizados os bancos de dados Oracle, da empresa de mesmo nome, e SQL Server, da Microsoft) e sistemas operacionais.

Ao ser lançada uma nova versão destas tecnologias, a empresa acompanha avaliações feitas por mídia especializada e comentários em fóruns de usuários. Além disto, também adota novas tecnologias em pequenos desenvolvimentos específicos, para testá-las e verificar se há vantagens em uma migração de plataforma das suas soluções.

A decisão efetiva de migrar ou não a plataforma acontece durante o planejamento anual da empresa, realizado no início do ano, e que abrange um ciclo que vai de março de um ano a fevereiro do ano seguinte. Neste momento, é feita uma análise de custo 
envolvido (principalmente em termos de horas necessárias para a migração) em relação ao benefício em termos de produtividade no desenvolvimento, redução no custo de manutenção (ou eventualmente até acréscimo neste custo por ter que conviver com diversas plataformas), recursos disponíveis na nova plataforma, demanda e relevância para os clientes e ganho de imagem por utilizar uma plataforma mais atualizada. Foi citado o exemplo de um cliente que deseja que seu software seja compatível com todos os browsers de mercado e que deseja sempre ter um software atualizado. Um outro aspecto que pode determinar a migração é o término do suporte por parte do fornecedor da plataforma.

A decisão de mudança de plataforma é uma decisão de diretoria. Ela surge nas discussões da área, mas isto é levado para decisão conjunta com outros diretores da empresa. Atualmente não há previsão de mudanças de plataforma em seus produtos.

Como cada cliente possui uma versão diferente do software, a decisão de migrar para uma nova versão também dependerá de aspectos como a relevância do cliente em termos de faturamento e número de lojas, a necessidade do cliente estar atualizado, entre outros fatores. Foi citado o exemplo do cliente 2 (figura 17) já estar na versão 4.0 da plataforma .NET, enquanto que outros clientes recém implementados ainda estão utilizando a versão 1.1, que foi a originalmente utilizada há 10 anos. No fundo, como a empresa oferece sua solução na modalidade SAAS, para a maioria dos clientes é indiferente a versão da plataforma, porque o que mais interessa são as funcionalidades, se elas atendem às necessidades de negócio dos clientes, bem como a disponibilidade de velocidade do acesso.

b) Planejamento de Evolução do Produto

A empresa possui uma lista de sugestões fornecidas por clientes ou geradas internamente pelos funcionários. Ao se analisar o orçamento anual da empresa, além da análise de investimento em eventual evolução da plataforma, também se analisa a possibilidade de investimento de um número de horas na evolução do produto. As sugestões são então priorizadas, e um conjunto delas é destacado para ser 
implementado ao longo do ano. Existem revisões trimestrais para revisão das prioridades.

O principal critério para priorização das funcionalidades é a possibilidade de ampliação de receita e o aumento da aderência do software às necessidades do mercado. Foi citado como exemplo o desenvolvimento de uma funcionalidade para envio de mensagens por SMS. Quando a empresa percebeu que haveria potencial de cobrança adicional por esta funcionalidade, ela se tornou prioridade e foi desenvolvida. De início, não havia interesse por parte dos clientes, mas hoje, é uma funcionalidade bastante requisitada. Esta funcionalidade foi desenvolvida à parte do software principal, e a empresa trabalhava no momento da entrevista para integrar os diferentes clientes a esta nova funcionalidade.

Foi relatado por um dos entrevistados que este desenvolvimento está associado ao uso de equipe ociosa. Portanto, estes desenvolvimentos possuem menos prioridade. A exceção é quando a funcionalidade já está contratada pelo cliente e, portanto, há um compromisso com data de entrega o que torna o desenvolvimento prioritário.

Geralmente estas decisões de melhoria de produto envolvem o desenvolvimento de novos módulos, correspondendo a um investimento da empresa para melhorar o produto. O principal decisor é o diretor da área. Mas também são envolvidos o gerente de desenvolvimento, os gerentes de contas e o de marketing, pois um elemento essencial na decisão é a possibilidade de geração de receita, e o quanto a empresa pode se beneficiar por sair na frente dos concorrentes.

c) Planejamento de Customizações

Alguns clientes menores utilizam o software com suas funcionalidades básicas. Mas os clientes maiores possuem um contrato de manutenção que prevê o desenvolvimento de funcionalidades específicas. 
A empresa faz reuniões trimestrais com os clientes, em que se planeja o roadmap de implementação das funcionalidades específicas do cliente. Neste caso, são funcionalidades mais específicas, pontuais.

A decisão final por desenvolver ou não determinada funcionalidade, neste caso, é sempre do cliente.

A OPUS adota o método de desenvolvimento de software Scrum. O Scrum é uma metodologia de desenvolvimento de sistemas classificada como metodologia ágil, sendo que o termo é derivado de uma atividade que ocorre durante um jogo de rugby (PRESSMAN, 2005). O Scrum se contrapõe ao ciclo tradicional de desenvolvimento chamado de "cascata", no qual se passa semanas ou até meses fazendo análise, especificação, para depois fazer desenvolvimento, testes e implementação do sistema "completo". O método em cascata possui limitações, tais como a demora em se obter resultados, implementações de grande impacto com grandes riscos, dificuldade de se manter o escopo fechado por período longo de tempo sendo que ao implementar um sistema, muitas vezes a necessidade já mudou. Comumente, mesmo na versão final, o sistema não atende a todas as necessidades dos usuários. Outro problema é que durante o desenvolvimento surgem novas prioridades, fazendo com que a equipe deixe tarefas incompletas, gerando a sensação de que a produtividade é baixa. No método Scrum o desenvolvimento é feito de forma incremental por meio de sucessivos ciclos de curto prazo chamados de sprints (na Opus por exemplo estes ciclos são de um mês). Os times são pequenos, e os testes conduzidos durante o processo de desenvolvimento, que objetiva sempre entregar o software funcionando a cada ciclo de desenvolvimento. O escopo da sprint é fechado pelo cliente, não sofrendo alterações durante este período (PRESSMAN, 2005; SCHWABER; SUTHERLAND, 2013). Prefirmos não abordar conceitualmente o Scrum na revisão bibliográfica porque o foco da tese não é sobre metodologias de desenvolvimento. Porém, como as atividades de elaboração de roadmaps da Opus, e como será visto posteriormente da Bematech, estão intimamente ligadas ao método Scrum de desenvolvimento, julgamos pertinente fazer esta explicação conceitual.

A principal fonte de informação da Opus são os próprios clientes, seja a franqueadora, sejam os franqueados. Qualquer usuário pode inserir solicitações ou apontar erros em um sistema denominado GAT, Gestão de Atendimento inTeligente. Porém, em cada cliente, há apenas um 
ponto focal, que é ponto de contato da Opus com o cliente. Geralmente, ele é um gestor de TI. Outras fontes de informação importantes para o roadmap são os altos executivos, funcionários de marketing e fornecedores, e em terceiro lugar funcionários de TI, concorrentes e a Internet de forma geral.

A empresa utiliza-se de planilha Excel para listar as sugestões recebidas para melhoria. Além dos usuários, diversos profissionais contribuem com este processo: gerentes de conta, gerente de projetos (perfil importante porque lida com a implementação no cliente), e analistas de suporte que captam informação no atendimento.

Esta lista é enviada ao ponto focal no cliente, que retira da lista as funcionalidades que considera que não são pertinentes, e ordena as demais por prioridade.

A avaliação do custo envolve a especificação da funcionalidade, e o custo é avaliado por um método chamado "poker", no qual se decompõe a tarefa em tarefas menores, e os desenvolvedores discutem o esforço necessário para cada tarefa. Cada desenvolvedor apresenta o número de horas que acredita ser necessário para realizar a tarefa, justificando sua opinião. Na primeira rodada geralmente existem divergências, mas o grupo caminha para uma convergência após algumas rodadas.

A estimativa de custo é passada ao cliente, que então seleciona aquelas que efetivamente serão desenvolvidas no sprint do mês. As demais ficam armazenadas para serem discutidas no próximo mês, juntamente com as novas demandas que surgirem. Foi citado por um dos entrevistados que alguns clientes têm tantas demandas que possuem uma lista para mais de 6 meses de horizonte de desenvolvimento. Porém, segundo a metodologia Scrum, fecha-se o escopo apenas para o período do sprint que é mensal.

Depois de analisadas e aprovadas, estas sugestões são então inseridas em um software que gerencia a lista de pendências. Neste software a empresa organiza: a) lista de correções em andamento; b) novas funcionalidades em desenvolvimento (que corresponde à evolução do produto); c) back-log que são as sugestões já analisadas, mas que não foram elencadas como prioridade para desenvolvimento. 
Foi destacado como principal objetivo da atividade de roadmap o planejamento com o cliente. O roadmap é uma forma de alinhar com o cliente quais serão as prioridades e quais funcionalidades serão implementadas em cada nova atualização do sistema.

Com importância um pouco menor foram destacados como objetivos: identificar oportunidades e ameaças tecnológicas, planejamento do produto, planejamento da capacitação dos funcionários, identificação de tecnologias importantes, melhoria da comunicação com clientes e o treinamento de novos funcionários.

\subsection{Kiman Solutions}

\subsubsection{Apresentação da Empresa}

A Kiman é uma empresa nacional, fundada em 2004, provedora de solução de TI para os mercados de seguros e previdência. Possui cerca de 80 funcionários no total. Seu principal produto é a suíte KiPrev, um sistema de gestão de produtos de vida e previdência instalado em 6 seguradoras para o segmento de previdência aberta, e em 1 cliente para o segmento de previdência fechada.

Apesar de ter um menor número de clientes em relação a outras empresas entrevistadas nesta tese, o KiPrev é um sistema bastante complexo. Apenas o manual de parametrização do sistema possui aproximadamente mil páginas, devido à complexidade das regras de negócio do setor de seguros. Atuam com desenvolvimento aproximadamente 40 profissionais entre gerentes, analistas, desenvolvedores e equipe de suporte.

Entre os grandes desafios da empresa foram citados: a) diversificação de atuação, partindo para outros negócios como seguro de vida e capitalização; b) conciliar a expectativa de diferentes clientes em um produto único, pois cerca de $90 \%$ do produto consiste em um núcleo comum; c) legislação do setor, que é muito complicada e em alguns casos pode permitir diferentes interpretações. 
Outro grande desafio é a evolução da plataforma tecnológica. Apesar de muitos dos novos desenvolvimentos serem feitos em Java, grande parte do sistema foi desenvolvido com a tecnologia Oracle Forms, considerada uma plataforma defasada em relação a outras de mercado.

Entre as principais oportunidades foram destacados o fato de sua solução poder ser instalada em forma de private cloud, ou seja, uma nuvem privada no centro de dados da própria empresa, servindo a seus funcionários e colaboradores.

\subsubsection{Atividade de Elaboração do Roadmap}

A empresa não adota formalmente a denominação roadmap, mas realiza uma série de atividades de planejamento sobre a evolução de seus produtos que se enquadram como atividades de roadmap.

A empresa atualmente adota 4 níveis de modificações em seus produtos:

- Versão: contemplam as grandes evoluções do produto. Geralmente envolve atualização da versão do banco de dados Oracle e/ou do servidor de aplicação, bem como o desenvolvimento de um grande conjunto de novas funcionalidades que ajudarão a atender melhor aos clientes.

- Release: envolvem melhorias evolutivas maiores, na maior parte das vezes para atender a demandas de mudanças na legislação.

- Patch: são correções não emergenciais, ou melhorias evolutivas pequenas ou com prazos curtos definidos pela legislação, disponibilizadas quinzenalmente para os clientes.

- Hot fix: são correções que precisam ser disponibilizadas para estabilizar a versão. Não há periodicidade definida, pois precisa ser feita emergencialmente. Pode envolver situações em que os clientes estão parados e não conseguem utilizar o sistema.

Os três últimos níveis de alterações geralmente são de pequeno porte e não exigem grande esforço de planejamento. Porém, a alteração de versão exige da empresa um processo mais 
estruturado, correspondendo a atividades de elaboração de roadmap. As etapas deste processo compreendem:

- Captura de novas funcionalidades: é realizada de forma contínua e tem duas origens principais, as mudanças de legislação, e demandas de clientes. A empresa também participa de fóruns de mercado, tal como a da Fenaprev, bem como de eventos diversos de tecnologia.

- Planejamento: nesta etapa, existe participação do Diretor Executivo, Diretor de Negócios e do Diretor de Tecnologia. O Diretor de Negócio apresenta grandes necessidades funcionais novas no sistema. O Diretor de Tecnologia apresenta necessidades de atualização tecnológica. E o Diretor Executivo é quem decide grandes premissas ou parâmetros do desenvolvimento. Por exemplo, ele aprova as mudanças tecnológicas de grande impacto em termos de custo e risco, bem como define o término do desenvolvimento, tendo em vista uma data que seja estratégica para lançamento da nova versão.

- Análise: nesta etapa, a área de negócios define e especifica melhor o que precisa ser desenvolvido para atender à demanda do cliente ou de alteração legal. Posteriormente, a área de engenharia avalia o custo em termos de homem-hora não apenas para desenvolvimento, mas também para testes. Em conjunto, avalia-se o risco de desestabilização do sistema, verificando-se os potenciais riscos envolvidos com a alteração.

- Priorização: a priorização leva em consideração os interesses dos clientes. Com base na lista de possíveis implementações, a empresa pede para os clientes priorizarem as implementações, para avaliar aquelas que terão maior impacto positivo caso sejam desenvolvidas.

- Características da nova versão: foi citado que a empresa faz uma conta "de trás para frente". Ou seja, define-se uma data de lançamento desejada. Verifica-se então quantas horas será possível disponibilizar para o desenvolvimento da nova versão. Estabelecese, com base neste número de horas disponíveis, um "corte" na lista de prioridades contemplando aquelas que são viáveis de serem desenvolvidas com o orçamento disponível.

- Formalização do roadmap: a empresa elabora então uma documentação contendo a especificação das funcionalidades que serão adicionadas ao sistema, e isto é 
distribuído tanto internamente para os funcionários quanto externamente para os clientes.

A empresa já chegou a lançar novas versões a cada 6 ou 8 meses, mas percebeu que o impacto causado aos clientes é muito grande. Atualmente, a empresa trabalha com roadmaps de aproximadamente um ano e meio.

A partir do momento que se dá o início do projeto de desenvolvimento, a empresa precisa replicar o código e, qualquer alteração que é feita na versão vigente, precisa também ser implementada na nova versão, o que gera portanto uma sobrecarga de trabalho.

O ciclo de desenvolvimento envolve aproximadamente 9 meses, sendo 1 mês de planejamento, 2 meses de especificação detalhada (nesta fase já se duplica o código do sistema), 3 a 4 meses de desenvolvimento, 2 meses de testes para controle de qualidade.

A empresa trabalha sempre com o planejamento da versão imediatamente posterior, não havendo um esforço de identificar tecnologias que serão incorporadas em suas soluções em prazos maiores. Na figura 18 é apresentado o roadmap do software KiPrev. 


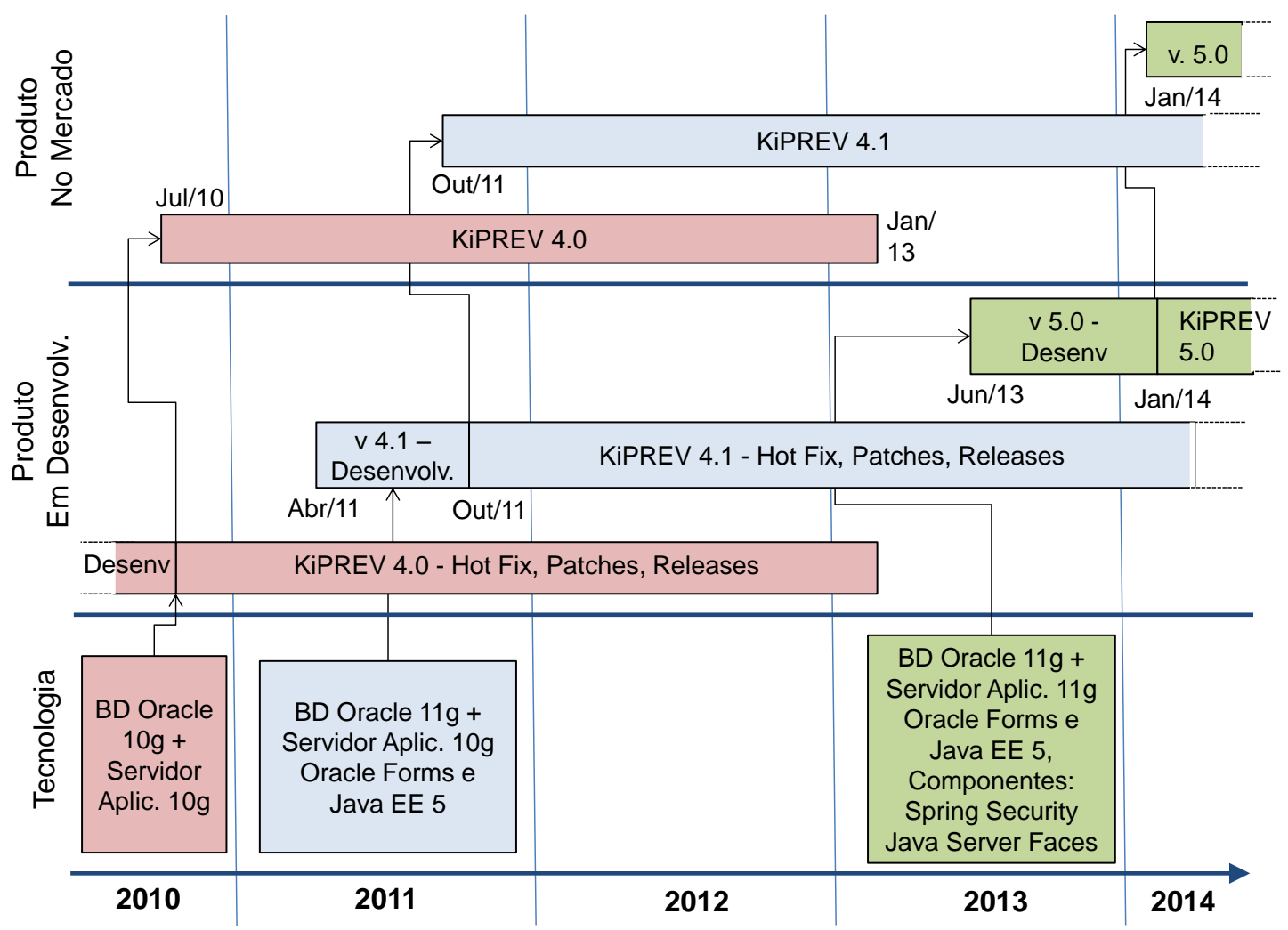

Figura 18 - Roadmap da Kiman

Como a empresa não possui um desenho de roadmap, esta figura foi elaborada pelo autor desta tese com base nas informações fornecidas pela empresa. Porém, mesmo sem ter o desenho, a empresa possui processos para planejar a evolução tecnológica de seu software. Procuramos representar também as versões passadas, para permitir a visualização da evolução tecnológica promovida pela empresa. Ela representa na camada de baixo as tecnologias utilizadas. No caso da versão 4.0, foi adotado o banco de dados Oracle $10 \mathrm{~g}$ e o servidor de aplicação versão 10. Na versão 4.1, houve migração da versão do banco de dados para $11 \mathrm{~g}$, mas o servidor de aplicação permaneceu o mesmo. Na versão 5, existem duas grandes mudanças tecnológicas. Uma é a conversão do SysEstudo, um software para cálculo atuarial desenvolvido em outra plataforma tecnológica, de Visual Basic 6.0 para Java, e que de um software separado passa agora a integrar o mesmo pacote de solução. O servidor de aplicação também foi migrado para a versão 11. Apenas para estudar esta migração foram gastas cerca de 200 horas, para identificar os custos, riscos e melhorias com esta migração. Estas decisões de evolução tecnológica, por serem de grande porte, foram aprovadas na fase de planejamento pelo Diretor Executivo da empresa, que precisava estar ciente do custo, benefícios e riscos 
envolvidos. Outras decisões tecnológicas de implementação, tal como a adoção de um novo framework de segurança chamado Spring Security e novos componentes do framework Java Server Faces, foram adotados por decisão apenas da área de Tecnologia no momento em que o desenvolvimento já estava em andamento. Outra inovação citada por um dos entrevistados foi o próprio processo de desenvolvimento, pois a partir do desenvolvimento da versão 5 do KiPrev, passou-se a adotar o Scrum como metodologia de desenvolvimento. Como grande benefício da adoção desta metodologia foi citado a maior aproximação da área de negócios com a área de tecnologia, para que se evite chegar ao final de um longo ciclo de desenvolvimento com erros conceituais ou de entendimento, o que poderia gerar retrabalho e atraso na disponibilização do produto ao mercado.

Na camada de produtos, é possível verificar que a versão 4.1 teve seu planejamento iniciado em abril/2011, com lançamento em outubro do mesmo ano. A partir daí, houve um esforço muito grande da empresa em migrar todos os clientes para nova versão, e estabilizá-la, corrigindo eventuais falhas, e desenvolvendo funcionalidades que os clientes consideram necessárias. A empresa começou a discutir uma nova versão no início de 2013, mas estava aguardando primeiro estabilizar a versão já que o último cliente foi convertido apenas em janeiro, o que permitiu descontinuar a versão 4.0. Já era certo de que um novo processo de planejamento de roadmap seria iniciado, mas uma negociação em andamento com um potencial cliente atrasou este início. Em junho de 2013 deu início ao planejamento da nova versão.

Os entrevistados destacaram a complexidade de se administrar duas versões de código ativas do sistema, pois precisam receber alterações legais e conviver simultaneamente até que o último cliente da versão antiga migre para a nova versão. Também é necessário manter na equipe pessoas que conheçam as duas tecnologias utilizadas, o que no caso da Kiman não é um fator complicador pelo fato delas serem bastante compatíveis. Mas em uma situação de mudança de plataforma que envolva uma linguagem totalmente diferente, isto poderia representar um custo muito grande a ser mantido pela empresa.

A empresa não planeja o que será implementado tecnologicamente a longo prazo, ou seja, além da próxima versão. Mas existe o monitoramento constante da evolução de algumas tecnologias que podem impactar de alguma forma a empresa. Nas palavras de um 
entrevistado, existem tecnologias que entram no "radar" e que poderão ser adotadas futuramente. As tecnologias importantes monitoradas pela empresa são: banco de dados Oracle, sendo citado inclusive que a empresa acaba adotando o roadmap da Oracle, uma vez que utiliza intensivamente os recursos do banco de dados; Servidor de aplicação, a linguagem Forms e a linguagem de programação Java, pois existe uma preocupação de migração não apenas do passado desenvolvido em Forms, como da própria versão de Java, da versão 5 para uma nova versão (já está para ser lançada a 8); Segurança, pois o público alvo, composto por seguradoras, em geral pertencentes a grandes bancos, são muito exigentes neste quesito; Navegadores de Internet (browsers), uma vez que parte do sistema é Web, mudanças nas versões de navegadores pode fazer com que determinadas páginas do sistema deixem de funcionar ou não exibam corretamente as informações.

Diferentemente das outras empresas pesquisadas, o hardware foi citado também como sendo importante devido ao grande volume de dados que são processados pelo software. Porém, a empresa não monitora detalhes específicos de evolução de equipamentos, pois o gerenciamento do uso das características de equipamento é feito pelo Banco de Dados Oracle, adotado pela empresa. Por exemplo, foi citado que em alguns clientes existe a possibilidade de se utilizar memória flash para os dados mais comumente acessados. Mas o gerenciamento sobre este acesso é feito pelo gerenciador de Banco de Dados, o que poupou a Kiman de desenvolver componentes sofisticados para uso desta tecnologia. Foi citado que o fato da Oracle ter adquirido a empresa Sun e ter ajustado os servidores para terem melhor performance com o banco de dados Oracle tem contribuído para a empresa conseguir oferecer aos clientes uma solução integrada, com excelente performance. A análise de novas tecnologias é feita por meio da participação em fóruns e eventos (enviam representantes para o Oracle Open World em São Francisco), certificação dos desenvolvedores nas tecnologias utilizadas e acompanhamento de notícias na mídia e fóruns de discussão.

Adicionalmente a empresa também monitora a evolução das plataformas móveis. Hoje não existe programado nenhum desenvolvimento voltado para tablets ou celulares, mas existe um potencial para esta adoção, principalmente dependendo do mercado que a empresa pretende ingressar no futuro. 
Sobre a plataforma tecnológica, existem dois aspectos. A empresa procura sempre adotar a última versão do banco de dados Oracle. Quando se faz o roadmap de uma nova versão, geralmente já se contempla esta atualização. Porém, sobre a plataforma de desenvolvimento, a empresa entende que este é um desafio grande e importante, pois a tecnologia adotada em grande parte do sistema, Oracle Forms, já é considerada ultrapassada. Chegaram a avaliar a possibilidade de migração para Java, porém, a análise de alguns fatores indicaram que ainda não seria o momento para esta migração:

- Produtividade: a plataforma adotada é muito mais produtiva do que o desenvolvimento em Java;

- Custo de migração: haveria um custo muito grande para migrar tudo o que já foi desenvolvido para esta nova plataforma;

- Estabilidade: atualmente o sistema está bastante estável. Sempre há risco de desestabilização ao se migrar a plataforma tecnológica, o que pode gerar conflitos com clientes e prejudicar a imagem da empresa;

- Custo do profissional: o custo do profissional Java, até pela complexidade do desenvolvimento, é maior do que em Oracle Forms.

Assim sendo, o passado é mantido em Oracle Forms e a maior parte dos novos desenvolvimentos já são feitos utilizando-se uma plataforma em Java.

As fontes de informação mais importantes para o processo de roadmap são os altos executivos da empresa, clientes/usuários, e o governo, uma vez que o software precisa estar de acordo com a legislação que regula o setor. Foi relatado que existem analistas na equipe responsáveis por monitorar a legislação do setor, a fim de identificar necessidades de mudança no produto.

Os objetivos mais importantes com o roadmap são: identificar oportunidades e ameaças tecnológicas, planejamento do produto, melhorar a comunicação externa (com clientes e parceiros).

Os componentes mais importantes do roadmap são: as ações governamentais e regulatórias, tendências de mercado, necessidades de consumidores, especificações ou metas de 
performance para os novos desenvolvimentos e análise sobre a estratégia de negócio da empresa.

Entre as maiores barreiras e dificuldades para elaboração do roadmap, foram citadas a cultura da empresa, a dificuldade de manter o roadmap atualizado e o desconhecimento da ferramenta. Também foram citados como importantes, mas em um nível menor: subestimar o esforço para fazer o roadmap, a falta de visão de futuro e a dificuldade de identificar as características do produto importantes no futuro.

Dentre os principais benefícios foram destacados a melhora do planejamento sobre as prioridades da empresa, o reuso da tecnologia para reduzir a duplicidade de esforços, bem como a construção de uma visão compartilhada das próximas implementações.

\subsection{Bematech}

\subsubsection{Apresentação da Empresa}

A Bematech é uma empresa provedora de soluções de tecnologia para o varejo, oferecendo uma plataforma integrada composta por sistemas de gestão, equipamentos, serviços e treinamento. A empresa foi constituída em 1990 para fabricação de impressoras matriciais, com grande destaque para impressoras para automação bancária. A partir da obrigatoriedade dos estabelecimentos comerciais emitirem cupom fiscal, entre 1999 e 2000, a Bematech obteve um grande crescimento oferecendo suas impressoras para atender a esta demanda. Em 2003 foi criada a Universidade Bematech visando capacitar melhor parceiros e clientes em suas tecnologias. Em 2005 mudou seu foco para soluções completas em automação comercial, envolvendo a distribuição de equipamentos completos para pontos de venda, com assistência técnica e sistemas de gestão.

Após o lançamento de ações em bolsa, em 2007, tem crescido significativamente, apresentando-se como uma empresa líder de soluções de tecnologia para o varejo e hotelaria. Comprou nos últimos anos seis empresas de software, tais como a Gemco, MisterChef, 
CMNet, com foco respectivamente em Varejo, Restaurantes e Hotéis. Está presente em mais de 500 mil pontos de venda, e encerrou 2012 com 1095 colaboradores, distribuídos nas unidades localizadas no Brasil e também na China, Taiwan, EUA, Argentina, Chile e Portugal.

Sua receita líquida alcançou $\mathrm{R} \$ 328,4$ milhões em 2012, sendo que a área de software responde por $\mathrm{R} \$ 89,3$ milhões, com crescimento de 26,2\% em relação a 2011. A área de software está estruturada em 4 verticais de atuação: varejo, lojas, restaurantes e hotéis.

Além das 4 verticais, o desenvolvimento de software é considerada uma unidade horizontal, que atende às verticais. Grande parte dos softwares da Bematech foram originalmente desenvolvidos pelas empresas adquiridas, o que resulta diferentes plataformas tecnológicas sendo adotadas pela empresa. Quando as entrevistas foram realizadas, possuía cerca de 230 colabores na área de desenvolvimento, formando times específicos para atender a cada vertical, além de alguns grupos comuns às verticais, tais como mobilidade, arquitetura e processos.

Cada vertical possui características muito diferentes. Seja por trazerem parte dos processos e práticas da empresa adquirida, seja pela grande diferença nos negócios de seus clientes. Aliase a estes fatores o fato de cada vertical ter autonomia para decidir o roadmap de seus produtos. Por este motivo, optou-se nesta tese por aprofundar o estudo na vertical de restaurantes. Esta vertical atende desde padarias e bares até grandes cadeias do ramo de alimentos. Conta com cerca de setenta revendas para garantir sua distribuição em nível nacional, e mais de nove mil clientes instalados. Parte destes clientes pertencem a grandes redes, como é o caso da rede de sanduíches Subway, por exemplo. Em alguns casos de grandes redes de franquias clientes, cada loja possui um CNPJ próprio e a Bematech ou seus parceiros são responsáveis tanto pela manutenção quanto pelo suporte em cada loja. Conforme o gerente da vertical de restaurantes comentou, diferente de outros negócios que possuem área de TI, muitas redes de fast-food não possuem uma área de TI grande, cabendo a Bematech desempenhar esta atividade. Além do PDV (sistema para Ponto de Venda) para apoio ao caixa, seu software também permite a gestão do delivery, atendimento às mesas (inclusive com tablet) ou self-service, a produção na cozinha, além da gestão da retaguarda (backoffice) com funções típicas de um ERP. A principal solução desta vertical é o Bematech 
Chef, mas possui outros produtos como o GDI (solução de BI), Live (para vendas on-line), painel fiscal (para nota fiscal eletrônica), TEF (que envolve soluções para pagamento por meios eletrônicos), além de fornecer serviços de instalação, treinamento e consultoria fiscal.

Dentre os principais desafios internos apontados pelos entrevistados encontra-se implantar uma cultura de software em uma empresa que se originou na área de hardware. Mesmo as pessoas que já atuavam com software, em parte são oriundas de empresas adquiridas, em geral pequenas e muito dependentes dos antigos sócios, ou em parte são contratações recentes que muitas vezes não possuem profundo conhecimento dos negócios de atuação da Bematech.

Do ponto de vista externo, há a concorrência, muito acirrada atualmente, e também a dificuldade de se adequar à legislação. A legislação existente regula fortemente os chamados PAF-ECF (Programa Aplicativo Fiscal - Emissor de Cupom Fiscal), chegando até a transferir para o fornecedor de tecnologia a co-responsabilidade em eventuais irregularidades fiscais do estabelecimento de varejo.

\subsubsection{Atividade de Elaboração do Roadmap}

A numeração de versões dos softwares da Bematech seguem diferentes padrões, dependendo da vertical e da solução. Especificamente no caso do Bematech Chef, atualmente a última solução lançada em julho de 2013 é a 1.59. Desde a incorporação da empresa MisterChef, com a versão 1.40, a solução adotava como plataforma tecnológica o .NET framework 1.1 em arquitetura cliente-servidor. Na versão 1.59 houve uma evolução de plataforma, adotando-se o .NET framework 4.0, sendo o software já desenvolvido para Web. A figura 19 ilustra o roadmap da solução Chef. 


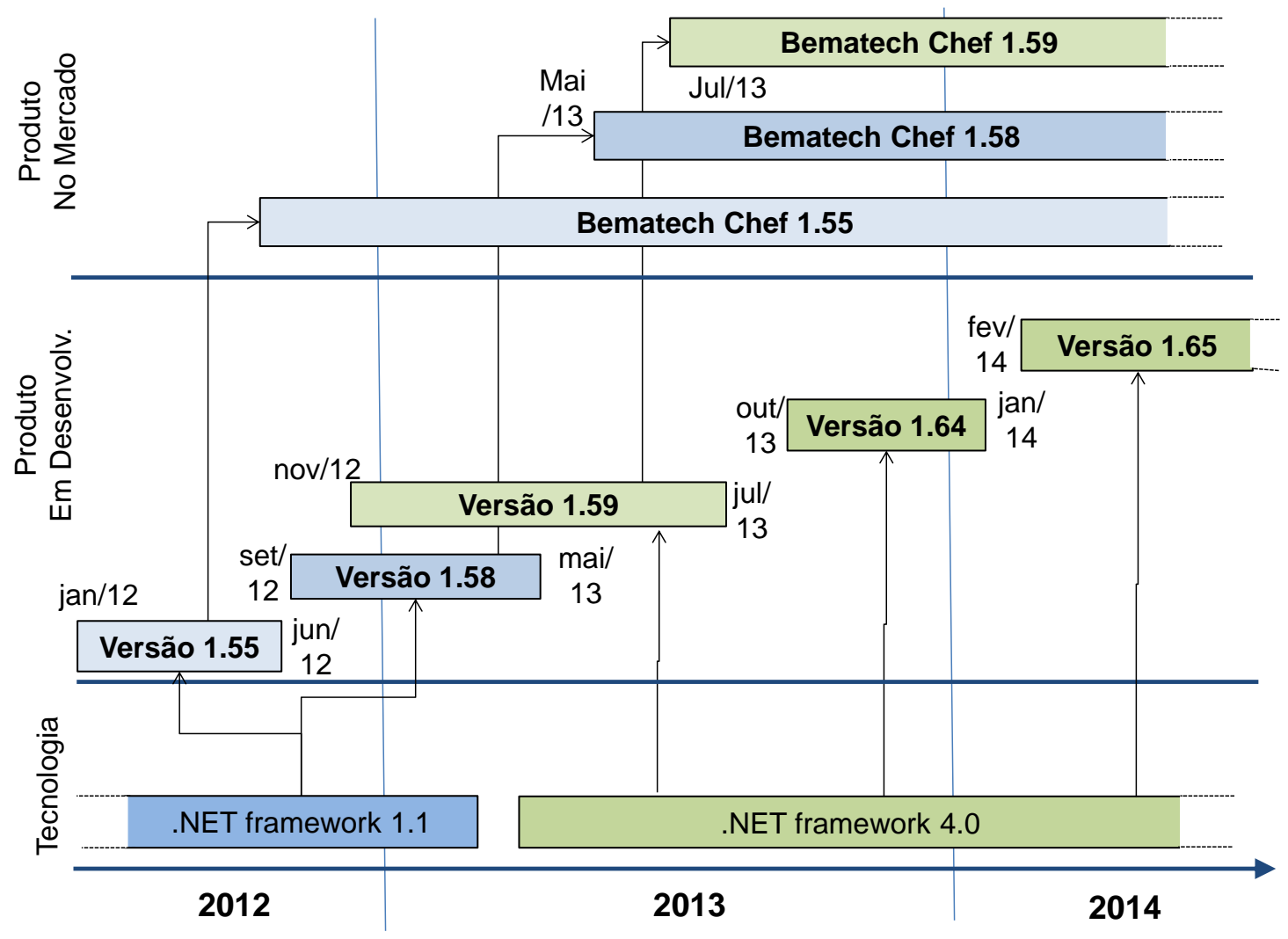

Figura 19 - Roadmap da solução Bematech Chef

Além das versões já comentadas, pela figura 19 é possível verificar ainda a existência da versão 1.55 , que é a versão mais antiga ainda vigente. A Bematech não adota a prática de descontinuar versões, sendo que o fator que invalida uma versão é a evolução da legislação, que eventualmente implica em alterações que fazem com que versões antigas deixem de ser válidas. Em grande parte a versão 1.58 surgiu para aprimoramentos da versão 1.55, sendo que a versão 1.59 sim, representa verdadeiramente uma versão que incorpora inovações, com interface e arquitetura remodeladas. Iniciou-se em junho de 2013 o esforço de planejamento do roadmap de uma nova versão 1.64, que teve seu desenvolvimento iniciado em outubro, com término previsto para janeiro de 2014. Está no roadmap da empresa, iniciar o desenvolvimento da versão 1.65 já no mês seguinte, em fevereiro. A empresa pretende lançar duas versões por ano e ter dois ciclos de discussão e planejamento de roadmap. Pode-se questionar porque o quadro abrange somente até o início de 2014, mas o fato é que, como se trata de um setor muito dinâmico, a empresa se planeja para cumprir lançamentos em ciclos de 6 meses. Isto não significa que a empresa esteja navegando a esmo. Existe uma visão do que se pretende da solução para pelo menos um ano a frente. Porém, esta visão está muito sujeita a mudanças e somente haverá uma certeza maior quando o ciclo de 6 meses atual se 
encerrar e se iniciar o planejamento da próxima versão. Assim sendo, esta figura não significa que a evolução do produto acabe no início de 2014. Certamente, assim que a versão 1.65 for lançada, começará o ciclo de rodmap da versão 1.66 visando 2015 e assim por diante. Porém, a empresa iniciará seu planejamento somente após o lançamento da versão 1.65.

Cada vez que se inicia o desenvolvimento de uma nova versão, a versão anterior não é mais alterada. Cada nova versão do software, depois de pronta, precisa ser devidamente registrada e homologada junto à secretaria da fazenda de cada Estado, sendo que em alguns estados este processo pode demorar até 6 meses. Esta homologação "congela" a versão, e qualquer alteração precisa ser incorporada em uma nova versão, que também deverá ser homologada junto aos órgãos competentes. As constantes mudanças na legislação, que além de complexa é também em muitos casos dúbia, geram uma grande sobrecarga de trabalho para a Bematech.

O processo de roadmap está sendo reformulado junto com a mudança na estrutura da Bematech, com sua divisão em 4 verticais e na horizontal de desenvolvimento.

Não há uma fase de planejamento formal. De forma contínua, o diretor da vertical, que também exerce a função de PO (product owner, ou dono do produto), recebe inúmeras informações e vai constituindo uma visão de evolução para os softwares sob sua gestão. É organizada uma lista de prioridades, tendo em vista a visão do que se imagina de funcionalidades para o produto para daqui a 1 ano. Partindo desta visão, a área deverá priorizar a cada mês as funcionalidades que serão desenvolvidas no prazo do sprint (que varia de 15 dias a 1 mês), tendo em vista a metodologia Scrum utilizada pela empresa.

Com objetivo de contribuir na discussão sobre a evolução futura de seus produtos, a empresa possui alguns comitês:

- Comitê de produto/fiscal: que discute a evolução do produto, principalmente no que se refere aos aspectos fiscais e é formado por gestores da vertical mais o diretor de desenvolvimento. Este comitê possibilita o compartilhamento do conhecimento e eventual aproveitamento de sinergias ao desenvolver demandas comuns a mais de uma área. 
- Comitê de tecnologia: que discute evolução tecnológica e aspectos estratégicos sobre arquitetura. Envolve o líder da vertical, o diretor de tecnologia e de desenvolvimento.

Estes comitês auxiliam a formar uma visão compartilhada entre as verticais sobre a evolução tecnológica dos produtos da empresa.

A adoção da metodologia Scrum trouxe grandes benefícios para a Bematech. Antes havia um grande volume de queixas e reclamações de várias partes. Por parte dos desenvolvedores, havia a queixa de não haver foco e ter que mudar de atividade antes de completar a anterior. Por parte das verticais, a queixa de que não se resolvia o mais importante e de que se demorava muito para implementar novas funcionalidades. Com o Scrum, é definido um conjunto de funcionalidades a serem desenvolvidas no sprint, que tem duração de 15 dias a um mês, e neste período ninguém altera as prioridades. Isto trouxe maior foco para os desenvolvedores, organização para o processo, e visibilidade para as entregas, pois fica claro ao longo do tempo a quantidade de entregas de novas funcionalidades que foram feitas a cada sprint.

As fontes de informação mais importantes para o processo de roadmap na Bematech são os clientes e usuários, parceiros (revendas) de negócio, concorrentes, Internet, a legislação e associações. A Bematech atende diretamente as chamadas contas corporativas, que são grandes redes de fast-food, sendo os demais clientes atendidos pelas revendas. Ambos, clientes e revendas estão constantemente trazendo novas demandas de alteração e evolução no software. Associações setoriais também são importantes, pois congregam clientes e potenciais clientes, permitindo identificar demandas comuns a várias empresas.

As mudanças em legislação são tão frequentes que a empresa está se estruturando para atender ao que ela chama de três tipos diferentes de roadmap: fiscal, corretivo e evolutivo. Sempre os desenvolvimentos irão convergir para uma mesma versão que se pretende lançar, mas a separação tem por objetivo separar os times a fim de que cada um tenha seu respectivo foco de atuação.

Com relação aos objetivos, foi destacado a identificação de tecnologias importantes. Neste setor, é importante trazer inovação, pois seus clientes, as redes de fast-food, também 
enfrentam grande concorrência e consequentemente têm necessidade de se diferenciar. Também foi destacado como importante a identificação de oportunidades e ameaças tecnológicas, a melhoria da comunicação externa com clientes/parceiros e a análise cruzada de roadmaps entre as diferentes unidades de negócio. Esta é uma prática recente, implementada por meio do comitê de produto/fiscal, no qual se discutem necessidades que podem ser comuns a duas ou mais verticais.

Dentre os componentes mais importantes no aspecto de mercado estão a identificação de segmentos de mercado e as ações governamentais e regulatórias. Também tem destaque a análise de competidores e o acompanhamento das tendências de mercado. Com relação ao produto, é muito importante a definição da data de lançamento e retirada de produto, até pelo fato da Bematech, devido à legislação, responder por eventuais irregularidades dos seus clientes. Eles possuem uma ferramenta pela qual se sabe exatamente qual versão está instalada em cada cliente, podendo em medida extrema bloqueá-lo até que seja atualizada a versão. Do ponto de vista tecnológico, é importante a decisão sobre tecnologias alternativas, o início e fim do desenvolvimento de tecnologias adotadas, bem como o roadmap de alguns fornecedores críticos. Neste aspecto foi citada a importância de se acompanhar a evolução dos bancos de dados. Recentemente também a empresa fez uma migração da plataforma tecnológica, passado da versão 1.1 para a 4.0 do .NET. Outros aspectos destacados como importantes são os planos de ação, visando a disseminação da nova versão, bem como a análise de riscos, uma vez que, dada a lentidão na aprovação das versões junto aos órgãos governamentais, não é fácil disponibilizar rapidamente correções para eventuais erros no software.

Dentre as principais barreiras estão a dificuldade de se colocar em prática o roadmap, bem como o tempo disponível para se dedicar a ele. A empresa tem uma capacidade produtiva limitada. O setor de TI está muito aquecido atualmente no Brasil, gerando alta rotatividade e sendo difícil encontrar mão-de-obra qualificada. Isto faz com que, não apenas a Bematech, mas também outras empresas, sofram com a falta de funcionários qualificados nos seus respectivos ramos de atuação. Aliado a isto, a constante demanda por alterações legais e eventuais necessidades de ajustes no software, acaba por deixar um tempo muito limitado para evolução do produto. Este é um dos motivos pelos quais a empresa deseja separar o 
roadmap e a equipe desenvolvimento em três, conforme comentado anteriormente: fiscal, corretivo e evolutivo, todos convergindo para o lançamento de uma nova versão.

Dentre os benefícios mais importantes do roadmap, foram destacados o aspecto de ligar a estratégia a planos de produto e tecnologia, a melhoria no planejamento do investimento, e o reuso de tecnologia para reduzir a duplicidade nos esforços de desenvolvimento. Com grau menor, mas também importantes, foram citados como benefícios o estímulo ao aprendizado interfuncional, a melhora na comunicação, a melhoria do time-to-market, a melhoria no planejamento sobre as prioridades da empresa, e a criação de uma visão compartilhada das próximas implementações.

\subsection{TOTVS}

\subsubsection{Apresentação da Empresa}

A TOTVS é uma empresa que atua com software, tecnologia e serviços. A TOTVS é líder do setor de softwares de gestão não apenas no Brasil, mas também na América Latina, estando presente em 23 países. Possui mais de 26 mil clientes ativos e mais de 5.500 funcionários, dos quais cerca de 1300 ligados a desenvolvimento de software. Foi a primeira empresa de TI da América Latina a ingressar no mercado de capitais (ano de 2006), tendo faturado $\mathrm{R} \$ 1,4$ bilhões em 2012.

Foram entrevistados na TOTVS um analista da área de roadmap de software e o gestor de Negócios Internacionais.

A empresa divide sua história em cinco grandes fases. A primeira fase corresponde à sua fundação. Sua origem remonta à fundação da Siga em 1973, e depois da Microsiga em 1983. A Microsiga foi criada a partir da visão de que os computadores pessoais (PCs) passariam a ter cada vez mais relevância para as empresas. Esta fase se estendeu até aproximadamente 1995. A segunda fase corresponde ao fortalecimento, entre 1996 e 2000, na qual a empresa recebeu aportes de investidores, preparando-se para ser a primeira empresa de TI da América 
Latina a fazer o lançamento de ações em bolsa. A terceira fase corresponde ao que a empresa chama de estabelecer seu "Genoma Empresarial", ou DNA, definindo "uma identidade para crescer, sem se perder”. A quarta fase, entre 2002 e 2011, corresponde à Liderança, na qual houve um rápido e grande crescimento com a aquisição de mais de 26 empresas, sendo as principais a Logocenter, RM Sistemas e Datasul, consolidando assim as principais fornecedoras brasileiras de software de gestão. A marca TOTVS foi adotada em 2005. A quinta e atual fase da empresa se iniciou em 2011, buscando transformar a TOTVS em uma referência global, fortalecendo a marca, com foco em internacionalização e uma nova estrutura baseada em segmentos.

O foco de estudo nesta pesquisa recai sobre as soluções de software de gestão empresarial, sob responsabilidade da Vice-Presidência de Sistemas e Segmentos. A empresa está estruturada em 10 verticais, procurando atender aos clientes de cada vertical com o melhor conjunto de soluções de software para cada segmento: Agroindústria, Manufatura, Distribuição e Logística, Varejo, Construção e Projetos, Educação, Saúde, Serviços, Jurídico, Saúde e Financial Services. Cada uma destas verticais possui três áreas ligadas ao ciclo de vida do produto. De forma resumida, são elas: (a) inovação, responsável por desenvolver as novas funcionalidades; (b) engenharia, responsável pela documentação, testes sistêmicos e integrados, qualidade e expedição do produto; (c) manutenção, responsável pelas correções de bugs e suporte de segundo nível aos sistemas. Outro perfil importante no ciclo de vida do produto é o Gestor da Oferta, ou Evangelizador, que é o responsável por captar as tendências tecnológicas, necessidades do mercado e de clientes junto a diversas fontes e trazê-las para a TOTVS. Além das 10 verticais, a VP de Sistemas e Segmentos possui ainda uma área de staff denominada Central Estratégica de Segmentos, em que uma de suas responsabilidades é coordenar e acompanhar o processo de elaboração do roadmap de software da empresa. Além dos softwares de gestão empresarial, a empresa também possui outras aplicações, que são desenvolvidas em outras áreas da empresa, tais como o Fluig (uma plataforma de integração e colaboração para gestão de processos, documentos e identidades em único local), rede social corporativa, que é utilizada tanto internamente pela TOTVS quanto no relacionamento TOTVS-clientes, podendo ainda ser licenciada para uso interno dentro dos clientes. Também é possível citar produtos e soluções de software para TV Digital. 
Entre os maiores desafios enfrentados pela empresa se destacam a falta de mão-de-obra qualificada disponível para contratação, o constante alinhamento com as necessidades do mercado, e a entrega de inovações no prazo certo (time-to-market). Dentre as principais oportunidades da empresa foram destacados pelos entrevistados o aproveitamento do knowhow das diversas empresas adquiridas ao longo dos últimos anos e parcerias com empresas especializadas nos segmentos em que atuam. Entre as ameaças foram destacadas as convergências por conta das diversas fusões e aquisições da TOTVS realizadas recentemente. Porém as convergências fazem parte da estratégia de evolução tecnológica e funcional dos produtos, para que a empresa foque investimentos em novas funcionalidades, trazendo retorno positivo para seus clientes.

\subsubsection{Atividade de Elaboração do Roadmap}

A TOTVS tem como meta encurtar o ciclo de lançamento de novos produtos a fim de melhorar seu time-to-market. Para tanto, o planejamento e execução do desenvolvimento do roadmap é fundamental.

Possui quatro linhas principais de produtos, oriundas das empresas que formam a TOTVS: Protheus, RM, Datasul e Logix. Contudo, a empresa se reestruturou em 10 verticais focadas em mercados específicos de atuação, e pretende gradativamente desvincular suas soluções da imagem dos produtos originais e passar a tratar de soluções por vertical. Um desafio da empresa, porém, é justamente lidar com diferentes plataformas tecnológicas, uma vez que cada produto possui sua plataforma de desenvolvimento. Possui 4 níveis de lançamento/disponibilização dos softwares para os clientes:

- Versão: corresponde a inovações de grande impacto lançadas no término de um roadmap.

- Release: corresponde a inovações de baixo impacto. Mesmo assim, contempla todo o processo de roadmap praticado para uma nova versão.

- Updates: são pacotes de manutenção, contemplando correções não urgentes e pequenas inovações. Sua periodicidade é bimestral. 
- Patches: são correções emergenciais. Não há periodicidade definida, sendo disponibilizada dependendo de chamados urgentes de clientes que eventualmente não conseguem operar alguma funcionalidade do sistema.

Atualmente seus softwares estão na versão 11, sendo que a versão 12 está em fase de desenvolvimento. A figura 20 apresenta de forma resumida o roadmap da TOTVS.

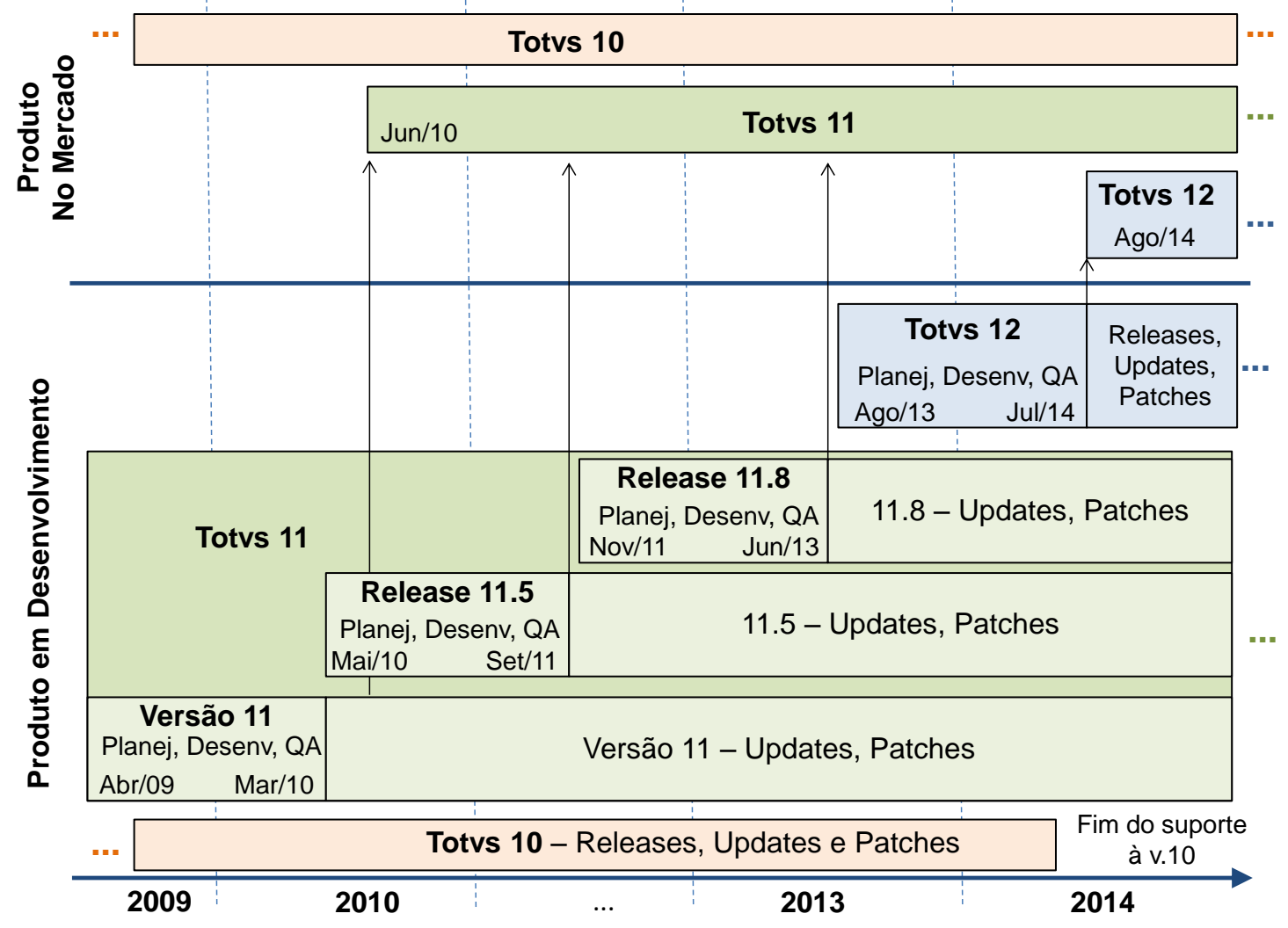

Figura 20 - Roadmap da TOTVS

O período em que a empresa mantém manutenção aos seus produtos é estabelecido em contrato, correspondendo a aproximadamente 6 anos. Este prazo corresponde a aproximadamente duas versões a frente. Após a expiração de versão, são mantidos os serviços de suporte e helpdesk para identificar problemas e tirar dúvidas. Para os clientes que não conseguem se planejar para o projeto de upgrade, eles podem utilizar a garantia estendida, quando disponível. 
Pela figura, é possível perceber que a versão 10 terá seu suporte encerrado ao mercado aproximadamente quando a versão 12 for lançada. Ao descrever os produtos em desenvolvimento, procuramos "abrir" a versão 11 para ilustrar que ela foi sofrendo evoluções ao longo do tempo. A primeira versão, 11, desenvolvida entre abril de 2009 e março de 2010, envolveu as etapas de planejamento, desenvolvimento e garantia da qualidade - quality assurance (QA), ou seja, testes e homologação. Após o lançamento, esta versão começa a sofrer updates e patches. O próximo lançamento, por não contemplar alterações tão significativas que justificassem uma nova versão, consistiu na release 11.5. Para cada release, executa-se o mesmo procedimento de roadmap de uma nova versão. Depois de lançada, a release sofre também evoluções, porém, de menor porte, que são os updates bimestrais, ou os patches emergenciais para correção de eventuais falhas do sistema.

Dentre as principais fontes de informação, foram destacados os altos executivos da empresa, os clientes / usuários, concorrentes, fornecedores, parceiros devido à necessidade de integração dos sistemas da TOTVS com sistemas de terceiros, governo devido à necessidade de adaptação legal, e o mercado internacional, uma vez que a TOTVS possui uma estratégia de internacionalização bastante forte. Também foram destacados com alto grau de importância a Internet/newsletters, feiras e eventos de negócios, provedores de informação e empresas de pesquisa, jornais/revistas impressas, associações e comitês setoriais, bem como universidades. Sobre este último aspecto, a TOTVS possui um programa de iniciação científica e convênio com algumas universidades.

Os principais objetivos do roadmap consistem em: identificar tecnologias importantes, planejar/definir processos internos para garantia da qualidade, e análise cruzada entre roadmaps de diferentes unidades de negócio.

Dentre os componentes mais importantes do roadmap, foram destacados com relação a:

(a) Mercado: nesta categoria, foi destacado como muito importante a identificação de segmentos de mercado, identificar as tendências de mercado, identificar padrões da indústria, analisar ações governamentais e as necessidades dos consumidores nos Comitês dos Segmentos. A empresa realiza de forma contínua diversas atividades para análise de mercado, tal como participação em eventos de negócio dos segmentos que a 
empresa atende, envolvimento em comitês e reuniões em entidades de classe de diversos segmentos, e análise de relatórios da equipe interna de inteligência de mercado. O roadmap é aprovado ao se desenvolver o planejamento estratégico do segmento, elaborado pela vertical e aprovado posteriormente pelo conselho da empresa;

(b) Produto: uma vez que a empresa trabalha com o conceito de ciclo de vida de software, é muito importante no roadmap a definição da data de lançamento e expiração do produto. Em função destas datas, são disponibilizados serviços de atualizações de software, e após o término do suporte, é permitida também a opção do cliente contratar a garantia estendida. Outro aspecto importante é a definição dos atributos e características do produto. Cabe destacar que muitas das atividades realizadas para análise de mercado têm por objetivo também a análise do produto. Adicionalmente às atividades já mencionadas no item (a), a empresa também analisa relatórios e white papers de consultorias de mercado, bem como realiza pesquisa sobre produtos de mercado.

(c) Tecnologia: foi destacada a importância de se identificar o início e fim do desenvolvimento de tecnologias utilizadas pela empresa, bem como os roadmaps de fornecedores e parceiros críticos, uma vez que os produtos da TOTVS são integrados aos produtos de diversos parceiros focalizados em negócios específicos. A TOTVS possui plataforma própria de desenvolvimento para algumas linhas de produtos o que lhe confere certa independência com relação a fornecedores de tecnologia. Mesmo assim, as tecnologias de suporte ao TOTVS Platform e de conectividade com banco de dados são monitoradas de forma contínua. Também monitora tecnologias utilizadas em algumas soluções específicas, como o .NET, adotado na linha de produtos RM, e Progress (banco de dados e ferramenta de desenvolvimento), adotado na linha de produtos Datasul.

(d) outros aspectos analisados no roadmap: Também foram destacados como importantes a análise sobre a estratégia de negócios da empresa, bem como a definição de planos de ação. Este último, em geral realizado após a aprovação do roadmap, envolve o acompanhamento da execução dos projetos de desenvolvimento. 
As barreiras mais importantes são a dificuldade de identificar as características do produto importantes para o futuro e gerenciar mudanças após o roadmap ser aprovado. Muitas vezes há alterações de ordem legal, alterações negociadas com novos clientes na aquisição do produto, ou mesmo o desenvolvimento compartilhado que consiste no cliente pagar uma parte do custo de desenvolvimento. Nestas situações, funcionalidades não previstas no roadmap original precisam ser incorporadas no produto, o que gera a necessidade de muitas vezes deixar de desenvolver outras funcionalidades também importantes, porém com menor prioridade, e que inicialmente tinham sido acordadas para a versão. Também foram destacados como importantes o comprometimento dos executivos, justamente devido a esta necessidade de negociação com clientes, a dificuldade de manter o roadmap atualizado e a dificuldade de se chegar a um acordo sobre as prioridades.

Dentre os benefícios mais importantes foram citados que o roadmap permite ligar a estratégia a planos de produto e tecnologia, a possibilidade de ter planos de tecnologia corporativos, uma visão de longo prazo ligando produto e tecnologia, a melhoria do planejamento do investimento, e a melhoria do planejamento sobre as prioridades da empresa. Também foi destacado como importante o fato de estimular o aprendizado interfuncional, a transferência de conhecimento entre parceiros e a criação de uma visão compartilhada das próximas implementações.

O processo de elaboração de roadmaps na TOTVS compreende:

1) Captação das sugestões: esta captação ocorre de forma contínua por meio de diversas fontes tais como os executivos da empresa, clientes, equipe comercial, equipe de arquitetos de soluções e equipe de implementação, entre outros. Estas sugestões são canalizadas para as diretorias do respectivo segmento de mercado.

2) Definição dos chamados IRM's (itens de roadmap). A empresa possui um software de apoio para cadastro e análise das diferentes demandas de evolução dos seus produtos. É realizada uma priorização que leva em consideração diversos fatores relacionados a retorno potencial em geração de negócios e risco. A empresa estruturou uma ferramenta para decisão ponderando-se estes diversos fatores, a fim de classificar quais os IRM que 
possuem alto retorno potencial e baixo risco. A ferramenta é flexível para permitir que os gestores do segmento mudem a classificação, pois eventualmente um item é classificado como pouco prioritário pelos fatores adotados, mas o executivo tem uma percepção e uma opinião diferente.

3) Para os itens selecionados, é feita uma estimativa de horas. A equipe técnica do segmento é responsável por estimar as horas necessárias para desenvolvimento de cada uma das funcionalidades priorizadas.

4) Com base na análise das prioridades, da estimativa de horas e da capacidade produtiva disponível, é definida uma proposta de roadmap que é apresentada ao VP de Sistemas e Segmentos para aprovação. Depois de aprovado, o VP de Sistemas e Segmentos apresenta o roadmap para o conselho executivo, apenas a título informativo. Os itens a serem desenvolvidos são cadastrados nos sistemas de controle de roadmap e projetos da empresa.

Após a definição final do roadmap, dá-se início ao desenvolvimento efetivo dos IRM de acordo com a metodologia de desenvolvimento da empresa. Esta fase tem duração aproximada de 9 meses. Após o encerramento da codificação, a empresa inicia a fase de testes e de desenvolvimento de conteúdos de conhecimento tais como documentação, e-learning (a empresa providencia treinamento à distância sobre as funcionalidades do sistema), kit presencial, roadshow (as novas versões são devidamente apresentadas aos clientes atuais e a potenciais clientes) e capacitação especialista (para que a equipe de implementação e suporte consiga atuar de forma efetiva com a nova versão). Esta fase tem duração de 3 meses, totalizando um período de 12 meses desde a aprovação do roadmap até o lançamento do produto no mercado.

Atualmente, está em andamento um novo modelo de suavização de versão de uma das linhas de produto da TOTVS, com o objetivo de encurtar o lançamento de inovação para os clientes. A ideia por trás deste modelo é lançar pequenos pacotes de inovação dentro de updates bimestrais de fácil instalação, sem a necessidade de contratar uma equipe de implantação para realizar o processo de upgrade de versão. 
O roadmap é comunicado internamente por meio de diversos canais, tais como a rede social corporativa nas comunidades dos segmentos, e-mail de comunicação corporativa, eventos anuais da área de atendimento e relacionamento, reuniões específicas do segmento, home page da TOTVS, portal do cliente, entre outros.

Externamente, o roadmap é comunicado por meio da rede social corporativa da empresa nas comunidades dos segmentos para clientes, eventos como o Universo TOTVS e os Ciclos TOTVS, portal de clientes, no site TOTVS News, além da Academia Virtual com e-learning das novas funcionalidades.

Finalizada a explanação individual, passamos à análise cruzada entre os casos e discussão dos resultados. 


\section{DISCUSSÃO}

\subsection{Influência do Porte da Empresa Sobre a Atividade de Elaboração de Roadmaps Tecnológicos}

\subsubsection{Comparação das Características Encontradas nos Casos}

Conforme discutido na seção de metodologia, adotou-se nesta tese uma escala Likert para avaliar a importância de 5 elementos do roadmap: objetivos, fontes de informação, conteúdo, barreiras/dificuldades, e benefícios. O objetivo do uso da escala Likert não foi a análise estatística, mas o de identificar os aspectos mais ou menos relevantes de uma forma que fosse possível comparar os casos. Desta forma, foi possível evidenciar aspectos que possuem uma alta relevância em todas as empresas, e aqueles que eventualmente são relevantes apenas para alguns casos.

Na tabela 1, relacionamos os objetivos levantados na revisão de literatura, e as notas atribuídas de 0 a 7 pelas empresas KEY (Keyword), COI (Coinfo), OPU (Opus), KIM (Kiman), BEM (Bematech), e TOT (TOTVS), além da Média e Desvio Padrão. A ordem de disposição das empresas reflete o porte, das menores (KEY) e (COI) para as maiores (BEM) e (TOT). Quesitos que receberam as notas mais altas (6 ou 7) foram pintados de cinza com letra em negrito. Os itens estão relacionados em ordem decrescente de Média. Este mesmo padrão foi aplicado nas demais tabelas também. Na tabela 1, é possível verificar que independente do porte da empresa, "Identificar oportunidades e ameaças tecnológicas" foi o objetivo que recebeu maior pontuação, seguido do "Planejamento de produto" e "Identificar tecnologias importantes". Estes três objetivos são importantes em empresas de diferentes portes. Já o objetivo de "Melhorar a comunicação externa (com clientes/parceiros)", que recebeu uma baixa pontuação para as empresas de pequeno porte, recebeu uma alta pontuação em empresas de médio e grande porte. O objetivo de "Análise cruzada de roadmaps entre diferentes unidades de negócio" recebeu nota 0 em empresas de pequeno e médio porte, e uma alta importância nas empresas de grande porte. 
Tabela 1 - Objetivos do roadmap - comparação entre as empresas

\begin{tabular}{|l|c|c|c|c|c|c|c|c|}
\hline \multicolumn{1}{|c|}{ Objetivos } & KEY & COI & OPU & KIM & BEM & TOT & Média & $\begin{array}{c}\text { Desv. } \\
\text { Pad. }\end{array}$ \\
\hline $\begin{array}{l}\text { Identificar oportunidades e ameaças } \\
\text { tecnológicas }\end{array}$ & $\mathbf{7}$ & 5 & 5 & $\mathbf{6}$ & $\mathbf{6}$ & $\mathbf{7}$ & $\mathbf{6 , 0 0}$ & 0,89 \\
\hline Planejamento de produto & $\mathbf{7}$ & 5 & 5 & $\mathbf{6}$ & 5 & $\mathbf{7}$ & 5,83 & 0,98 \\
\hline Identificar tecnologias importantes & $\mathbf{7}$ & 4 & 5 & 5 & $\mathbf{7}$ & $\mathbf{7}$ & 5,83 & 1,33 \\
\hline $\begin{array}{l}\text { Melhorar a comunicação externa } \\
\text { (com clientes/parceiros) }\end{array}$ & 3 & 2 & $\mathbf{7}$ & $\mathbf{6}$ & $\mathbf{6}$ & $\mathbf{7}$ & 5,17 & 2,14 \\
\hline Planejamento futuro a longo prazo & 5 & 3 & 4 & 4 & 4 & $\mathbf{7}$ & 4,50 & 1,38 \\
\hline Planejar capacitação de funcionários & 4 & 5 & 5 & 2 & 3 & $\mathbf{7}$ & 4,33 & 1,75 \\
\hline $\begin{array}{l}\text { Integração entre áreas/funç̃̃es } \\
\text { produto-tecnologia-mercado) }\end{array}$ & 5 & $\mathbf{7}$ & 0 & 5 & 3 & $\mathbf{6}$ & 4,33 & 2,50 \\
\hline Planejar/definir processos & 0 & $\mathbf{6}$ & 4 & 3 & 3 & $\mathbf{7}$ & 3,83 & 2,48 \\
\hline $\begin{array}{l}\text { Integração com processos de } \\
\text { qualidade }\end{array}$ & 0 & 4 & 4 & 4 & 4 & $\mathbf{7}$ & 3,83 & 2,23 \\
\hline $\begin{array}{l}\text { Persuadir alta gestão sobre } \\
\text { importância dos projetos }\end{array}$ & 5 & 4 & 0 & 4 & 4 & 5 & 3,67 & 1,86 \\
\hline Treinamento de novos funcionários & 0 & 4 & 5 & 1 & 3 & $\mathbf{7}$ & 3,33 & 2,58 \\
\hline Melhorar a comunicação interna & 2 & 2 & 0 & 2 & 4 & $\mathbf{7}$ & 2,83 & 2,40 \\
\hline $\begin{array}{l}\text { Análise cruzada de roadmaps entre } \\
\text { diferentes unidades de negócio }\end{array}$ & 0 & 0 & 0 & 0 & $\mathbf{6}$ & $\mathbf{7}$ & 2,17 & 3,37 \\
\hline
\end{tabular}

Na tabela 2, relacionamos para as mesmas empresas pesquisadas as notas atribuídas para as diversas fontes de informação para o roadmap. Os "Clientes / usuários" e os "Altos executivos das empresas" possuem uma alta relevância tanto para pequenas, médias ou grandes empresas. As duas empresas grandes pesquisadas, adicionalmente, utilizam-se de uma variedade muito maior de outras fontes de informação, tais como "Concorrentes", "Jornais e revistas", "Internet", "Feiras e eventos", "Provedores de informação" e "Associações / comitês setoriais". 
Tabela 2 - Fontes de informação - comparação entre as empresas

\begin{tabular}{|l|c|c|c|c|c|c|c|c|}
\hline \multicolumn{1}{|c|}{ Fonte de Informação } & KEY & COI & OPU & KIM & BEM & TOT & Média & $\begin{array}{c}\text { Desv. } \\
\text { Pad. }\end{array}$ \\
\hline Clientes / usuários & $\mathbf{6}$ & $\mathbf{7}$ & $\mathbf{7}$ & $\mathbf{6}$ & $\mathbf{7}$ & $\mathbf{7}$ & $\mathbf{6 , 6 7}$ & 0,52 \\
\hline Altos executivos da empresa & $\mathbf{7}$ & $\mathbf{7}$ & $\mathbf{6}$ & $\mathbf{6}$ & 5 & $\mathbf{7}$ & $\mathbf{6 , 3 3}$ & 0,82 \\
\hline $\begin{array}{l}\text { Funcionários (exceto executivos) da } \\
\text { área de TI }\end{array}$ & 5 & $\mathbf{7}$ & 5 & 4 & 3 & $\mathbf{7}$ & 5,17 & 1,60 \\
\hline Fornecedores & 4 & 3 & $\mathbf{6}$ & 5 & 5 & $\mathbf{7}$ & 5,00 & 1,41 \\
\hline Concorrentes & 5 & 0 & 5 & 4 & $\mathbf{7}$ & $\mathbf{7}$ & 4,67 & 2,58 \\
\hline Internet & 5 & 1 & 5 & 3 & $\mathbf{7}$ & $\mathbf{7}$ & 4,67 & 2,34 \\
\hline Governo & 0 & 2 & 0 & $\mathbf{6}$ & $\mathbf{7}$ & $\mathbf{7}$ & 3,67 & 3,39 \\
\hline Feiras/eventos de negócios & 1 & 0 & 2 & 5 & $\mathbf{6}$ & $\mathbf{7}$ & 3,50 & 2,88 \\
\hline Associações / Comitês setoriais & 0 & 0 & 4 & 4 & $\mathbf{7}$ & $\mathbf{6}$ & 3,50 & 2,95 \\
\hline $\begin{array}{l}\text { Provedores de informações / } \\
\text { empresas de pesquisas }\end{array}$ & 4 & 1 & 0 & 1 & $\mathbf{6}$ & $\mathbf{7}$ & 3,17 & 2,93 \\
\hline Jornais/revistas impressas & 1 & 0 & 2 & 2 & $\mathbf{6}$ & $\mathbf{6}$ & 2,83 & 2,56 \\
\hline $\begin{array}{l}\text { Publicações acadêmicas / } \\
\text { conferências científicas }\end{array}$ & 2 & 0 & 4 & 3 & 5 & 2 & 2,67 & 1,75 \\
\hline Funcionários de outras áreas & 0 & 0 & 2 & 2 & 4 & 5 & 2,17 & 2,04 \\
\hline $\begin{array}{l}\text { Funcionários (exceto executivos) da } \\
\text { área de marketing }\end{array}$ & 0 & 0 & $\mathbf{6}$ & 0 & 4 & 2 & 2,00 & 2,53 \\
\hline Universidades & 0 & 0 & 0 & 2 & 4 & $\mathbf{6}$ & 2,00 & 2,53 \\
\hline Patentes/registros de software & 0 & 0 & 0 & 1 & $\mathbf{6}$ & 3 & 1,67 & 2,42 \\
\hline Relatórios do mercado de capitais & 0 & 0 & 0 & 2 & 5 & 3 & 1,67 & 2,07 \\
\hline
\end{tabular}

Na tabela 3 apresentamos as notas atribuídas pelas empresas para a importância dos diversos componentes do roadmap. Independente do porte, são componentes importantes a "Análise das tendências de mercado" e das "Necessidades dos clientes". As "Ações governamentais e regulatórias" são importantes para grandes empresas, cujos softwares atendem a processos empresariais que possuem alto nível de regulação. As duas grandes empresas pesquisadas atribuem altas notas também para a "Identificação dos segmentos de mercado", para a definição da "Data de lançamento e retirada do produto do mercado", para a identificação do "Início e fim do desenvolvimento das tecnologias" utilizadas bem como o "Roadmap de 
fornecedores e parceiros críticos". Adicionalmente, as duas grandes empresas pesquisadas também atribuem alta importância para a definição dos "Planos de ação" que irão aproveitar as funcionalidades criadas na nova versão.

Tabela 3 - Componentes do roadmap - comparação entre as empresas

\begin{tabular}{|c|c|c|c|c|c|c|c|c|}
\hline Componente & KEY & $\mathrm{COI}$ & OPU & KIM & BEM & TOT & Média & $\begin{array}{l}\text { Desv. } \\
\text { Pad. }\end{array}$ \\
\hline \multicolumn{9}{|c|}{ Aspectos sobre Mercado } \\
\hline Necessidades dos clientes & 7 & 7 & 7 & 6 & 5 & 7 & 6,50 & 0,84 \\
\hline Tendências de mercado & 6 & 6 & 5 & 6 & 6 & 7 & 6,00 & 0,63 \\
\hline Identificação de Segmentos de mercado & 0 & 6 & 4 & 3 & 7 & 7 & 4,50 & 2,74 \\
\hline Padrões da indústria & 6 & 6 & 0 & 4 & 3 & 7 & 4,33 & 2,58 \\
\hline Ações governamentais/ regulatórias & 0 & 3 & 0 & 7 & 7 & 7 & 4,00 & 3,46 \\
\hline Análise dos Competidores & 0 & 4 & 0 & 4 & 6 & 5 & 3,17 & 2,56 \\
\hline \multicolumn{9}{|c|}{ Aspectos sobre Produto } \\
\hline Atributos/características do produto & 7 & 5 & 6 & 4 & 5 & 7 & 5,67 & 1,21 \\
\hline Início e término do desenv. de produtos & 3 & 5 & 7 & 5 & 5 & 5 & 5,00 & 1,26 \\
\hline $\begin{array}{l}\text { Data de lançamento e retirada do produto } \\
\text { do mercado }\end{array}$ & 3 & 4 & 0 & 5 & 6 & 7 & 4,17 & 2,48 \\
\hline \multicolumn{9}{|c|}{ Aspectos sobre Tecnologia } \\
\hline $\begin{array}{l}\text { Início e término da disponibilidade da } \\
\text { tecnologia no mercado }\end{array}$ & 4 & 4 & 6 & 5 & 5 & 4 & 4,67 & 0,82 \\
\hline $\begin{array}{l}\text { Pontos de decisão sobre tecnologias } \\
\text { alternativas }\end{array}$ & 3 & 4 & 6 & 4 & 6 & 4 & 4,50 & 1,22 \\
\hline Início e fim do desenvolv. da tecnologia & 3 & 5 & 0 & 6 & 6 & 6 & 4,33 & 2,42 \\
\hline Roadmaps de fornec./parceiros críticos & 0 & 5 & 5 & 3 & 6 & 6 & 4,17 & 2,32 \\
\hline Custo futuro da tecnologia utilizada & 0 & 5 & 0 & 5 & 5 & 4 & 3,17 & 2,48 \\
\hline \multicolumn{9}{|c|}{ Outros Aspectos } \\
\hline Plano de ação & 0 & 0 & 4 & 3 & 6 & 6 & 3,17 & 2,71 \\
\hline Análise estratégia de negócios da empresa & 0 & 0 & 0 & 7 & 4 & 6 & 2,83 & 3,25 \\
\hline Análise de Riscos & 0 & 0 & 0 & 2 & 6 & 0 & 1,33 & 2,42 \\
\hline
\end{tabular}


$\mathrm{Na}$ tabela 4, apresentamos as notas atribuídas pelas empresas pesquisadas para as barreiras e dificuldades encontradas na elaboração do roadmap. Dentre os 5 elementos pesquisados por meio da escala Likert (objetivos, fontes de informação, componentes, barreiras/dificuldades e benefícios), este foi o único que não apresentou um item que na média obtivesse uma avaliação muito alta ou um padrão comum dos elementos mais importantes para grandes empresas. Mesmo assim, podemos verificar que as três barreiras mais importantes, pela nota média, são "Manter o roadmap atualizado", "Dificuldade de identificar as funcionalidades do produto importantes para o futuro" e "Chegar a um acordo sobre as prioridades". Por outro lado, analisando a nota média, é possível verificar que algumas barreiras identificadas pela literatura apresentam uma baixa importância para as empresas pesquisadas, tais como "Vazamento de informação" e "Obtenção das informações".

Tabela 4 - Barreiras / dificuldades do roadmap - comparação entre as empresas

\begin{tabular}{|c|c|c|c|c|c|c|c|c|}
\hline Barreira / Dificuldade & KEY & $\mathrm{COI}$ & OPU & KIM & BEM & TOT & Média & $\begin{array}{l}\text { Desv. } \\
\text { Pad. }\end{array}$ \\
\hline Manter o roadmap atualizado & 7 & 3 & 1 & 6 & 4 & 6 & 4,50 & 2,26 \\
\hline $\begin{array}{l}\text { Dificuldade de identificar as funcionalid. do } \\
\text { produto importantes para o futuro }\end{array}$ & 2 & 6 & 4 & 5 & 3 & 7 & 4,50 & 1,87 \\
\hline Chegar a um acordo sobre prioridades & 3 & 4 & 6 & 2 & 5 & 6 & 4,33 & 1,63 \\
\hline Dificuldade de colocar em prática o roadmap & 5 & 4 & 1 & 3 & 7 & 4 & 4,00 & 2,00 \\
\hline Comprometimento dos executivos & 3 & 6 & 1 & 4 & 3 & 6 & 3,83 & 1,94 \\
\hline Cultura da empresa & 3 & 6 & 2 & 6 & 1 & 4 & 3,67 & 2,07 \\
\hline Falta de visão de futuro & 0 & 4 & 5 & 5 & 2 & 5 & 3,50 & 2,07 \\
\hline $\begin{array}{l}\text { Gerenciar mudanças após o roadmap ser } \\
\text { aprovado }\end{array}$ & 0 & 3 & 6 & 2 & 2 & 7 & 3,33 & 2,66 \\
\hline Subestimar o esforço para fazer o roadmap & 1 & 4 & 1 & 5 & 3 & 5 & 3,17 & 1,83 \\
\hline Dificuldade de prever a evolução tecnológica & 2 & 5 & 4 & 2 & 2 & 4 & 3,17 & 1,33 \\
\hline Dificuldade de obtenção das informações & 0 & 3 & 0 & 4 & 4 & 5 & 2,67 & 2,16 \\
\hline Vazamento de informação & 0 & 3 & 1 & 2 & 4 & 2 & 2,00 & 1,41 \\
\hline
\end{tabular}


A tabela 5 apresenta as notas atribuídas pelas empresas aos diferentes benefícios do roadmap. Neste aspecto, destacam-se com uma alta nota média os benefícios de "Ligar a estratégia a planos de produto e tecnologia" e "Melhorar o planejamento sobre as prioridades da empresa", que possui maiores notas principalmente entre as médias e grandes empresas. "Estabelecer uma visão compartilhada das próximas implementações" também foi um benefício apontado como muito importante para as médias e grandes empresas. Três benefícios foram apontados como muito importantes apenas pelas duas grandes empresas: "Estímulo ao aprendizado interfuncional", "Melhoria do planejamento do investimento", e a "Transferência de conhecimento na cadeia de suprimentos".

Tabela 5 - Benefícios do roadmap - comparação entre as empresas

\begin{tabular}{|c|c|c|c|c|c|c|c|c|}
\hline Benefício & KEY & $\mathrm{COI}$ & OPU & KIM & BEM & TOT & Média & $\begin{array}{l}\text { Desv. } \\
\text { Pad. }\end{array}$ \\
\hline $\begin{array}{l}\text { Ligar a estratégia a planos de produto e } \\
\text { tecnologia }\end{array}$ & 7 & 6 & 6 & 3 & 7 & 7 & 6,00 & 1,55 \\
\hline $\begin{array}{l}\text { Melhorar o planejamento sobre prioridades } \\
\text { da empresa }\end{array}$ & 5 & 5 & 6 & 7 & 6 & 7 & 6,00 & 0,89 \\
\hline $\begin{array}{l}\text { Construção de visão de longo prazo ligando } \\
\text { produto e tecnologia }\end{array}$ & 5 & 5 & 5 & 4 & 5 & 7 & 5,17 & 0,98 \\
\hline $\begin{array}{l}\text { Visão compartilhada das próximas } \\
\text { implementações }\end{array}$ & 2 & 4 & 7 & 6 & 6 & 6 & 5,17 & 1,83 \\
\hline Melhoria do planejamento do investimento & 0 & 5 & 6 & 5 & 7 & 7 & 5,00 & 2,61 \\
\hline $\begin{array}{l}\text { Reuso de tecnologia / reduzir duplicidades } \\
\text { de esforços }\end{array}$ & 4 & 3 & 6 & 6 & 7 & 4 & 5,00 & 1,55 \\
\hline Melhoria do time-to-market & 3 & 5 & 4 & 5 & 6 & 4 & 4,50 & 1,05 \\
\hline Estímulo ao aprendizado interfuncional & 0 & 4 & 6 & 2 & 6 & 6 & 4,00 & 2,53 \\
\hline Possibilitar planos de tecnol. corporativos & 0 & 0 & 6 & 2 & 5 & 7 & 3,33 & 3,08 \\
\hline Melhora da comunicação & 3 & 3 & 1 & 3 & 6 & 4 & 3,33 & 1,63 \\
\hline Melhor gestão de riscos & 2 & 1 & 4 & 4 & 5 & 4 & 3,33 & 1,51 \\
\hline $\begin{array}{l}\text { Transferência de conhecimento na Cadeia } \\
\text { de Suprimentos }\end{array}$ & 0 & 1 & 0 & 0 & 6 & 6 & 2,17 & 2,99 \\
\hline
\end{tabular}


As informações mais relevantes das cinco tabelas previamente discutidas foram sintetizadas na figura 21, que destaca os aspectos mais relevantes comuns a todas as empresas, e aqueles mais relevantes apenas para as grandes empresas. Os dados não permitiram identificar características que tivessem alta importância apenas para pequenas ou médias empresas. Cabe observar que como não houve consenso entre as empresas sobre as barreiras, na figura são apresentadas as três barreiras com maior nota média atribuída pelas empresas pesquisadas.

\begin{tabular}{|c|c|c|}
\hline \multicolumn{3}{|c|}{$\begin{array}{ll}\text { FONTES DE INFORMAÇÃO } & \\
\text { Concorrentes; } & \text { Feiras e eventos de negócios; } \\
\text { Jornais e Revistas; } & \text { Provedores de informação; } \\
\text { Internet; } & \text { Governo; } \\
& \text { Associações e Comitês Setoriais. }\end{array}$} \\
\hline $\begin{array}{l}\text { OBJETIVOS } \\
\text { Identificar } \\
\text { Oportunidades } \\
\text { e Ameaças } \\
\text { Tecnológicas; } \\
\text { - Planejamento } \\
\text { de produto; } \\
\text { - Identificar } \\
\text { tecnologias } \\
\text { importantes; } \\
\text { - Melhorar a } \\
\text { comunicação } \\
\text { externa; } \\
\text { Análise cruzada } \\
\text { de roadmaps }\end{array}$ & $\begin{array}{l}\text { COMPONENTES } \\
\text { - } \quad \text { Tendências de mercado; } \\
\text { - } \quad \text { Necessidades de clientes; } \\
\text { - } \quad \text { Ações governamentais; Identificação } \\
\text { de segmentos de mercado } \\
\text { - } \quad \text { Data de lançam. e retirada do produto; } \\
\text { - Início e fim do desenv. da tecnologia; } \\
\text { - } \quad \text { Roadmap de fornecedores/parceiros; } \\
\text { - Plano de ação } \\
\end{array}$ & 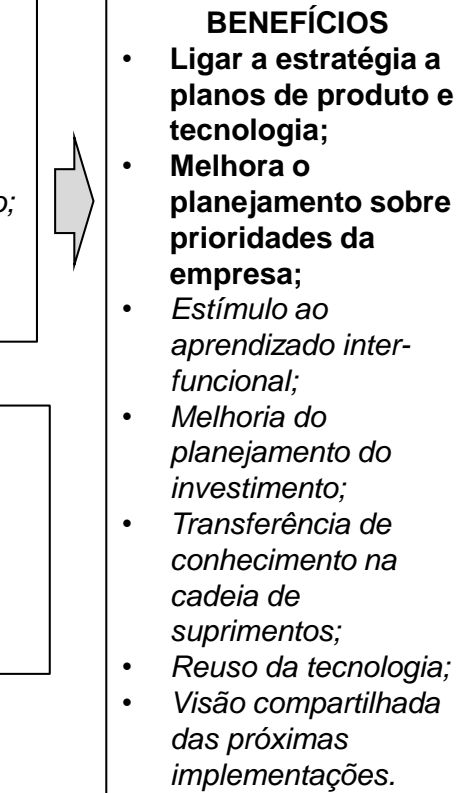 \\
\hline
\end{tabular}

Figura 21 - Características da elaboração do roadmap em empresas de software

O quadro 19 apresenta uma comparação entre as características encontradas nos casos estudados nesta tese.

A partir da análise dos dados coletados nas entrevistas, foi possível estabelecer duas importantes conclusões sobre como o porte da empresa influencia a atividade de elaboração de roadmaps:

a) Complexidade das interações internas e externas; 
b) Organização do processo de elaboração do roadmap;

Estes dois aspectos são discutidos nos próximos tópicos. 
Quadro 19 - Quadro comparativo dos casos estudados

\begin{tabular}{|c|c|c|c|c|c|c|c|c|c|c|}
\hline 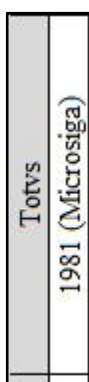 & 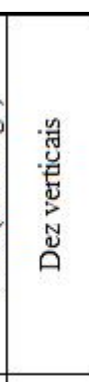 & 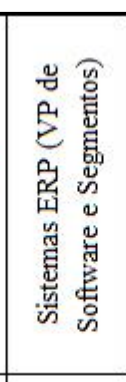 & 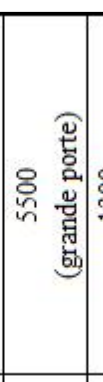 & 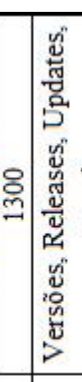 & 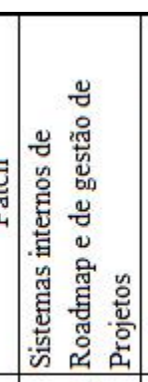 & 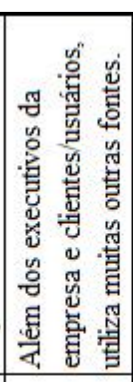 & 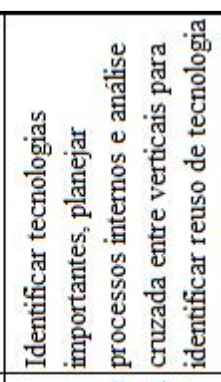 & 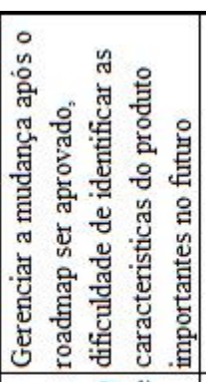 & 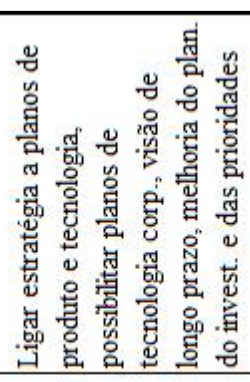 & 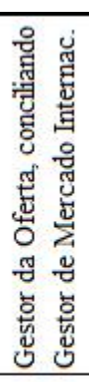 \\
\hline & 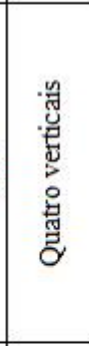 & 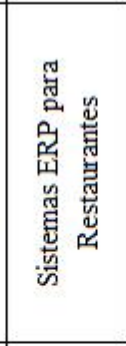 & 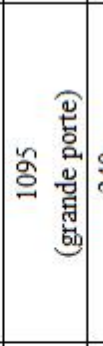 & 원 & 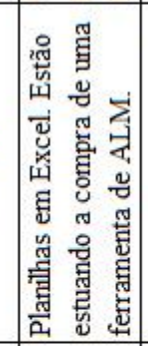 & 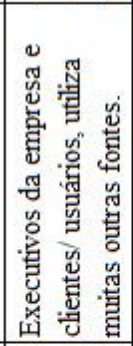 & 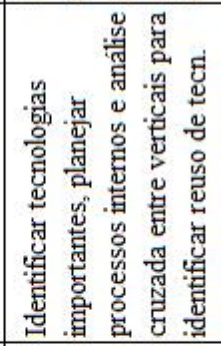 & 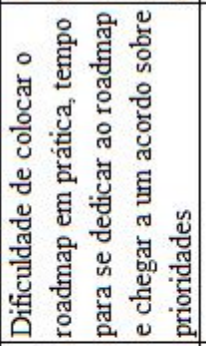 & 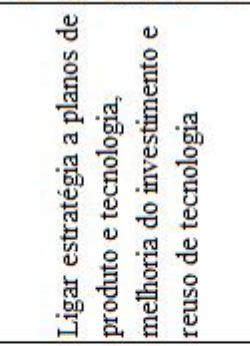 & \\
\hline & 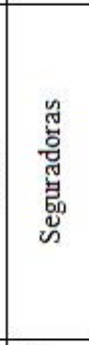 & 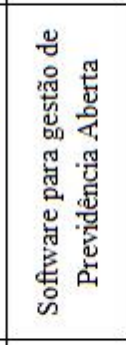 & 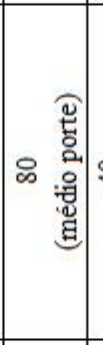 & 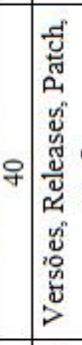 & 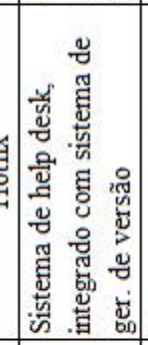 & 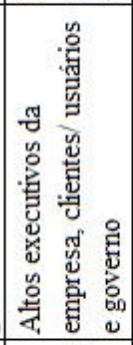 & 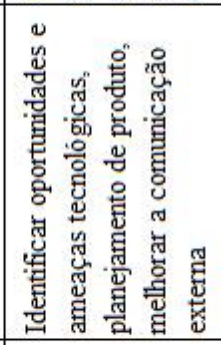 & 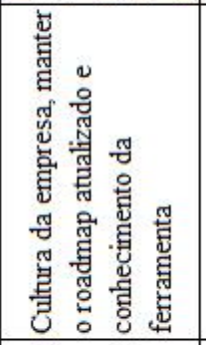 & 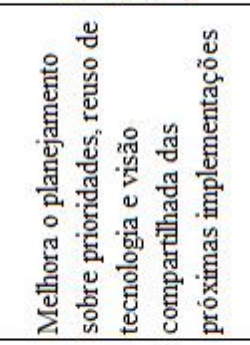 & 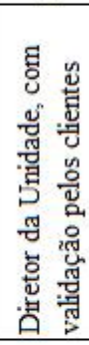 \\
\hline$\stackrel{0}{2}$ & 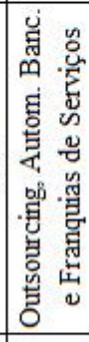 & 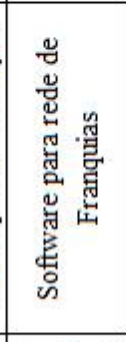 & 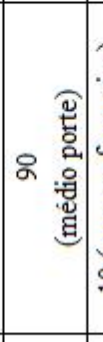 & 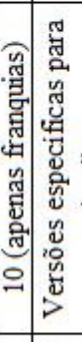 & 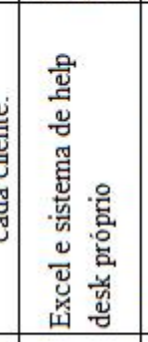 & 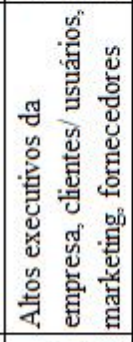 & 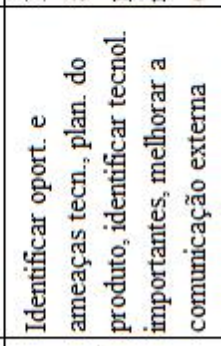 & 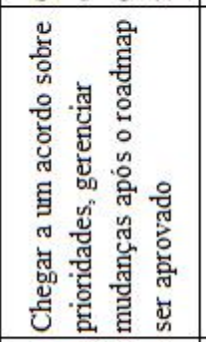 & 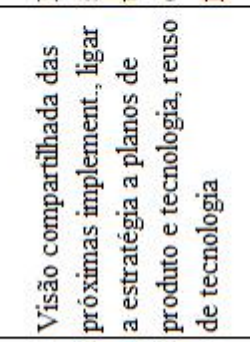 & 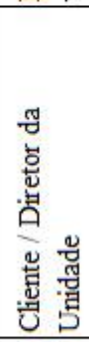 \\
\hline 㩄 & 息 & 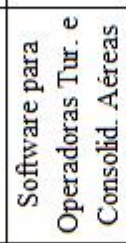 & 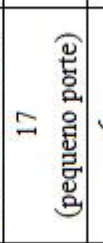 & 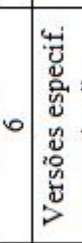 & 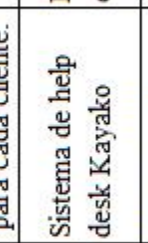 & 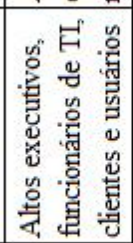 & $\circ$ & 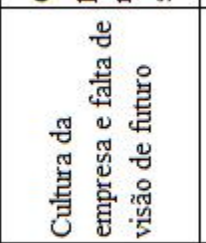 & 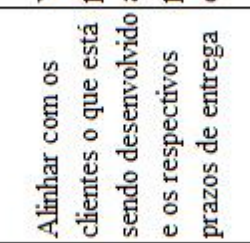 & \\
\hline & 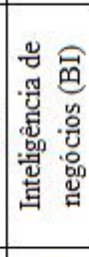 & 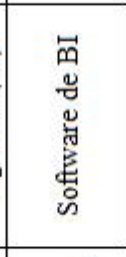 & 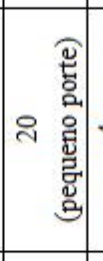 & + & 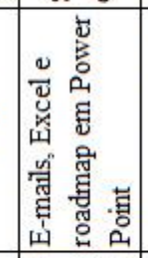 & 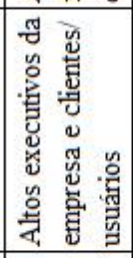 & 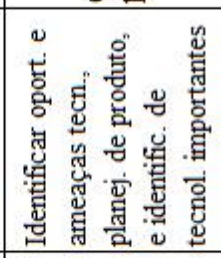 & 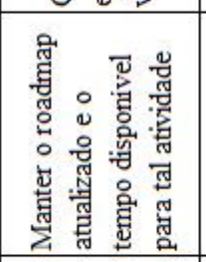 & 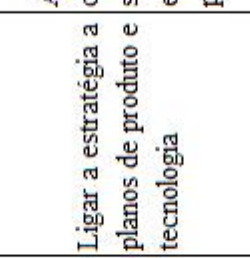 & to \\
\hline $\mid \begin{array}{c}\text { 点 } \\
\text { บ } \\
0\end{array}$ & 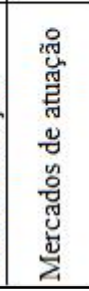 & 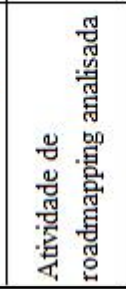 & 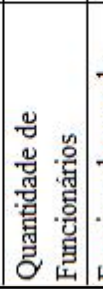 & 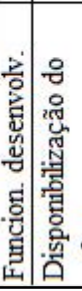 & 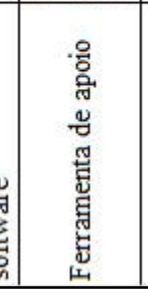 & 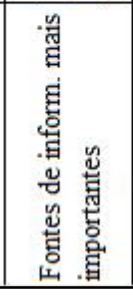 & 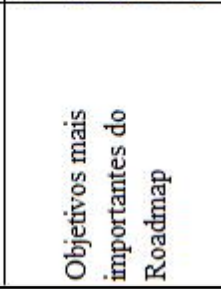 & $\begin{array}{l}\text { 离 } \\
\text { 恖 }\end{array}$ & . & \\
\hline
\end{tabular}




\subsubsection{Complexidade das Interações Internas e Externas}

A pesquisa de Suomalainen et al (2011) identificou os importantes stakeholders da atividade de elaboração de roadmaps em empresas de software. Porém, ele não torna explícito como interagem estes interessados no processo, nem como estas interações variam em empresas de diferentes portes. Nesta pesquisa, foi possível identificar que, à medida que aumenta o tamanho da empresa, aumenta também a complexidade das interações tanto internas quanto externas. A figura 22 explicita as interações existentes nas empresas Coinfo, Keyword e Opus.
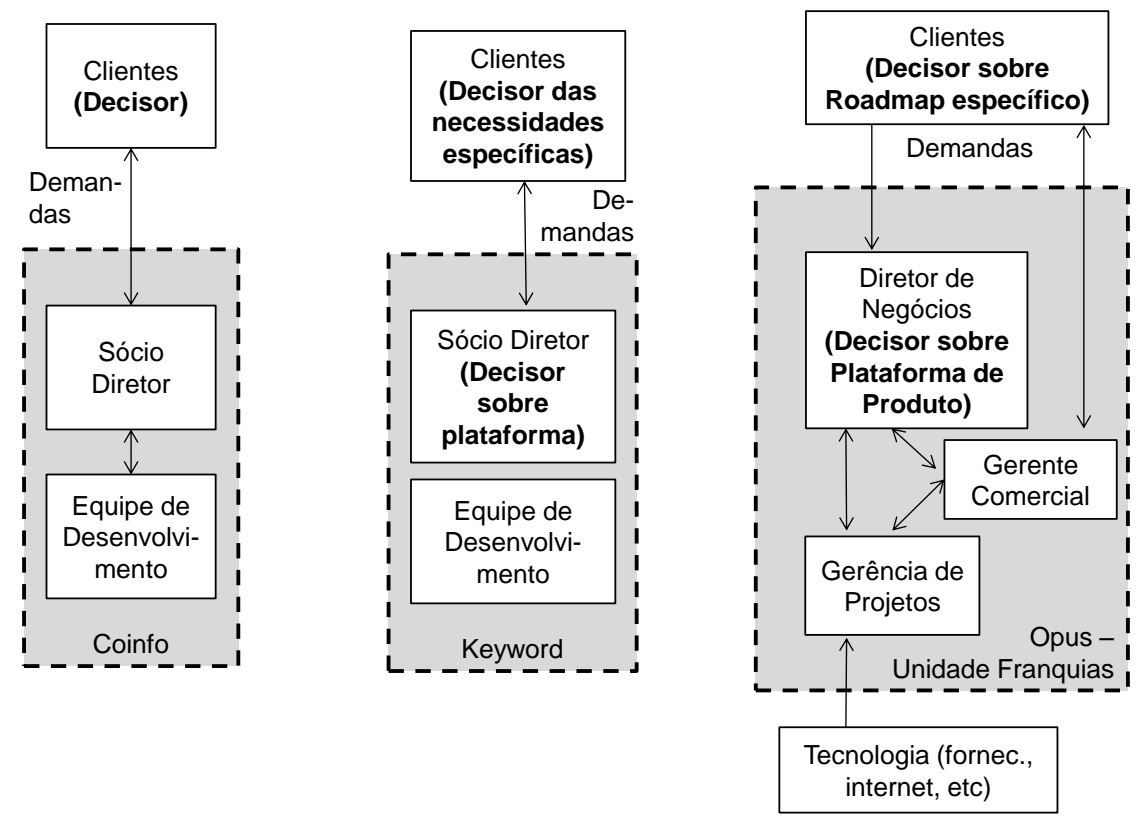

Figura 22 - Interações para elaboração de roadmaps na Coinfo, Keyword e Opus

Na Keyword, o Sócio-Diretor é também o principal desenvolvedor, e ele é quem decide a evolução da plataforma, baseado principalmente no que é identificado como necessidade para os clientes que a empresa pretende atingir. Em cada implementação, mudanças no software são necessárias, algumas envolvendo codificação e outras apenas configuração, e em geral estas mudanças são definidas pelos próprios clientes. A empresa Coinfo, apesar de atuar com produto, acaba evoluindo o software de cada cliente de forma individualizada. Conforme já foi discutido, a origem é a mesma e portanto as diferentes versões particulares de cada cliente possuem um núcleo comum. O cliente é quem decide pela evolução do sistema, aprovando os seus desenvolvimentos específicos. A Opus, mesmo tendo um porte maior que a Coinfo, adota uma estratégia muito semelhante para seus produtos. Desta forma, cada cliente possui 
sua própria instalação e decide quais as funcionalidades que deseja implementar. As demandas dos clientes são inseridas em um sistema, e a gerência comercial, junto com o Diretor de Negócios, procura estabelecer com o cliente qual a prioridade de acordo com as horas contratadas para evolução do sistema. Porém, existem algumas funcionalidades que são agregadas à plataforma do produto e são disponibilizadas para todos os clientes. O volume destas melhorias é pequeno, e em geral tem por objetivo melhorar a abordagem para conquistar novos clientes ou fidelizar os já existentes. A decisão sobre plataforma tecnológica em geral é feita pelo Diretor de Negócios, mas com grande interação da Gerência de Projetos, que é quem monitora as tecnologias e procura identificar aquelas mais adequadas para seus produtos.

Desta forma, em todas estas três empresas é possível perceber uma baixa interação da empresa com o ambiente externo, bem como poucas interações internas para se definir e elaborar o roadmap. A evolução tecnológica da plataforma do produto não é sistemática. No caso da Coinfo a tecnologia é a mesma adotada desde os primeiros clientes. Na Opus, existem clientes utilizando a plataforma das primeiras versões da solução, e outros clientes, em geral maiores e mais relevantes, para os quais a solução foi convertida para plataformas mais modernas de desenvolvimento. Já a Keyword procura periodicamente evoluir sua plataforma de produto, mas não obriga os clientes a migrarem de versão. A última versão da solução, desenvolvida em plataforma Web, ocorreu em 2010, e por enquanto não há previsão de realização de grandes evoluções na plataforma ou no produto.

Na figura 23, são representadas as interações da Kiman. É possível perceber que há um maior número de fontes externas de informação, aparecendo pela primeira vez o governo, também presente na Bematech e TOTVS. Isto se deve em parte pela característica dos setores de atuação destas empresas, altamente regulados. No caso da Kiman, o setor de previdência, da Bematech, PDVs, e no caso da TOTVS, por abranger processos fiscais e de emissão de nota fiscal, entre outros processos que precisam atender a várias exigências legais. Pode-se argumentar que o porte da empresa não teria, portanto, influência sobre este aspecto. Mas fica o questionamento se justamente a alta influência do governo em alguns setores, bem como a necessidade constante de adaptação das soluções, não gera uma seleção entre as empresas de software concorrentes, propiciando que apenas as médias e grandes empresas, com processos mais organizados de elaboração de roadmaps, permaneçam fornecendo software para estes 
setores. A tese não permite elucidar este ponto, mas é um questionamento para futuras pesquisas.

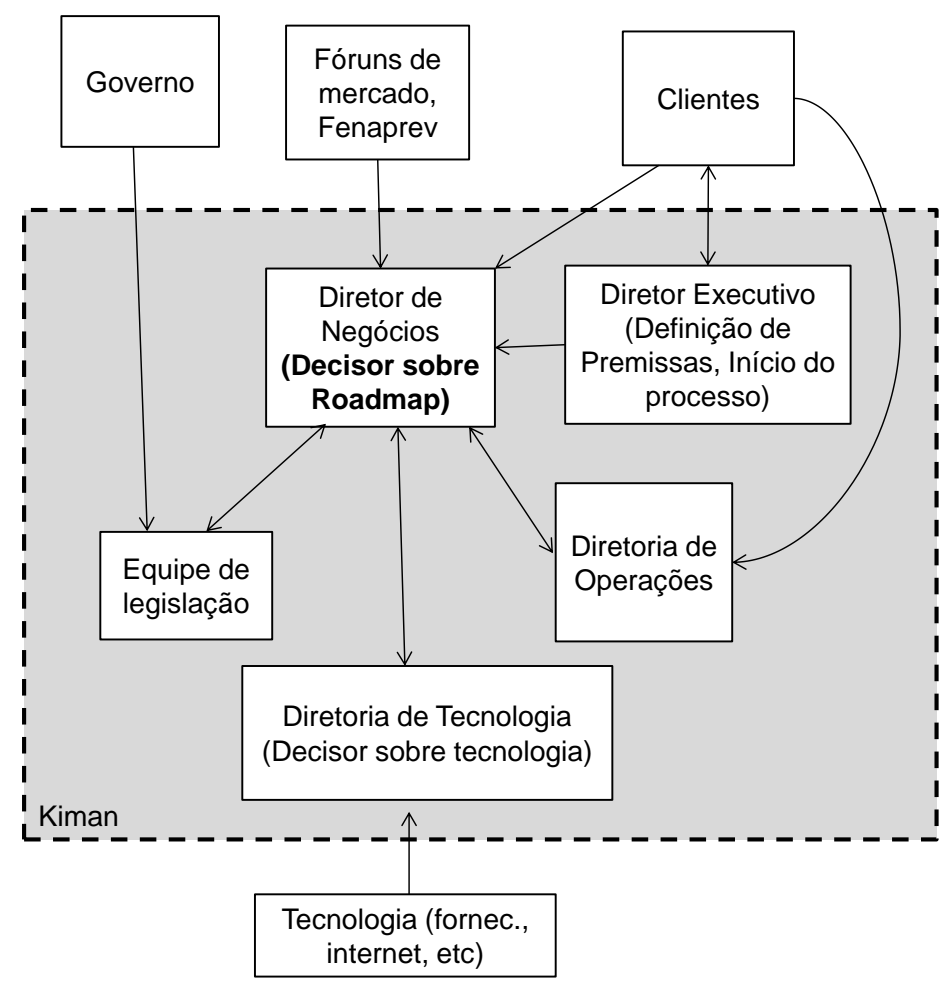

Figura 23 - Interações para elaboração de roadmaps na Kiman

Do ponto de vista interno, também há um número maior de interações. No caso da Kiman, o roadmap é centralizado na Diretoria de Negócios, sob a qual está subordinada uma área que monitora as mudanças na legislação. Também é envolvida a equipe de operações que está em constante contato com os clientes. O desenvolvimento do software em si é realizado pela Diretoria de Tecnologia que, conforme comentamos, possui cerca de 40 funcionários na área de desenvolvimento.

A figura 24 retrata as interações existentes para elaboração do roadmap na Bematech. Diferente da Kiman, que possui uma estrutura organizacional funcional, a Bematech possui uma estrutura matricial. Cada vertical cuida especificamente do seu segmento de atuação, captas as necessidades e prioriza o roadmap. Todavia, o desenvolvimento é realizado por um setor técnico específico para desenvolvimento de software. 


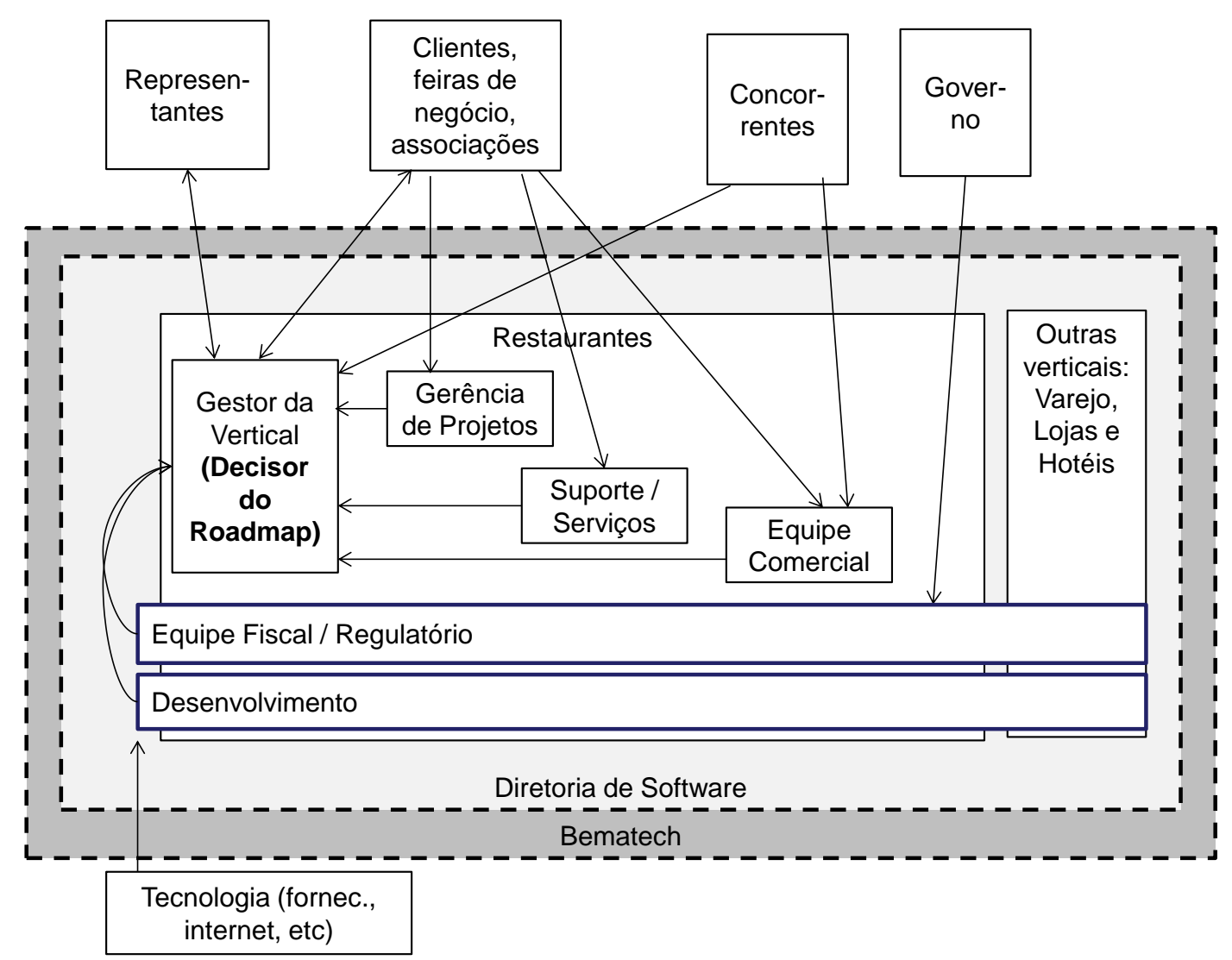

Figura 24 - Interações para elaboração de roadmaps na Bematech

A Bematech também possui uma área específica para monitorar as mudanças na legislação. Possui também uma equipe comercial e representantes, os quais estão em contato direto com os clientes finais e prospecções, trazendo grande partes das necessidades de evolução do software. A gerência de projetos e o suporte também são um ponto de contato importante da Bematech com seus clientes correntes, propiciando a obtenção de informações importantes para evolução de seus produtos.

Porém, da mesma forma que a Kiman, ainda existe uma grande centralização das decisões sobre o roadmap por parte de um executivo, no caso o Gestor da Vertical. Ele é quem capta as inúmeras informações e demandas, priorizando-as para que a equipe de desenvolvimento implemente as novas funcionalidades ou correções no software. 


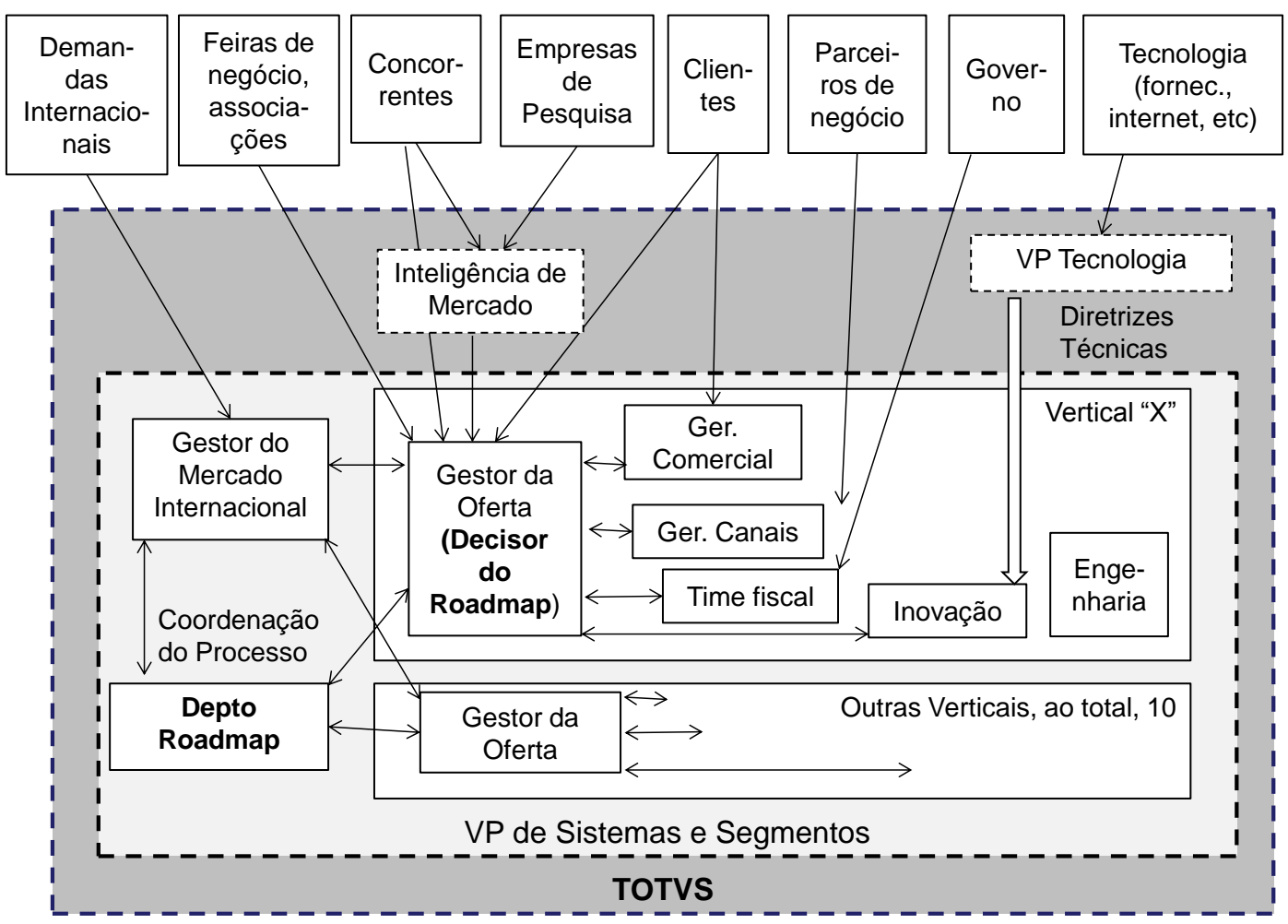

Figura 25 - Interações para elaboração do roadmap na TOTVS

A figura 25 exemplifica as interações do processo de elaboração de roadmap existentes na TOTVS. É possível perceber uma complexidade muito maior que a existente nas demais empresas. A TOTVS foi a única empresa dentre as pesquisadas que possui um departamento de roadmap. Também foi a única que possui um gestor de mercado internacional, cuja responsabilidade é interagir com representantes e clientes em diversos países, priorizando as necessidades e negociando-as para inclusão no roadmap nas verticais respectivas. Possui uma área de inteligência de mercado, responsável por analisar concorrência e relatórios de empresas de pesquisa especializadas em TI. Cada vertical possui um Gestor de Oferta, também chamado de Evangelizador, responsável por interagir com os diversos atores a fim de priorizar as necessidades do roadmap. A área de inovação cuida especificamente do desenvolvimento destas novas funcionalidades, seguindo diretrizes técnicas sobre padrões e plataforma de desenvolvimento estabelecidas pela VP de tecnologia.

\subsubsection{Organização do Processo}


A análise dos processos de roadmap das empresas estudas nesta tese oferecem oportunidade para enriquecer a literatura existente. Segundo Suomalainen et al (2011), as principais etapas seriam de captura de características, análise, priorização, validação e acordo sobre o roadmap, finalizando com a gestão de mudança.

Primeiramente, a pesquisa revelou que as empresas menores não possuem processos estruturados para elaboração de roadmaps. A criação de novas versões do produto ocorre de uma forma não sistemática, quando os executivos percebem que há necessidade de evoluir o produto. A Coinfo e a Opus possuem versões específicas para cada cliente. Em ambas, o processo é muito semelhante, pois identificam, em seu portfólio, o cliente existente que mais se assemelha a um novo cliente entrante, fazendo uma replicação do código, que passa então a evoluir de forma independente de acordo com a necessidade do cliente. A Keyword possui um código único, mas a criação de novas versões, e portanto a elaboração de novos roadmaps não é sistemática, sendo que grande parte de seu trabalho é a adaptação da ferramenta base para atender a necessidades específicas dos clientes existentes. Já a Kiman, Bematech e TOTVS possuem um processo de elaboração de roadmap mais sistemático, os quais serão detalhados a seguir.

A figura 26 ilustra o processo da Bematech. Diferente do que é exposto por Suomalainen et al (2011), a Bematech, não tem uma atividade bem delimitada com início e término para captura de informações e tão pouco fecha seu escopo ao início do desenvolvimento de uma versão. A captura de requisitos é feita de forma contínua ao longo do tempo. Ao iniciar um novo ciclo de desenvolvimento, é estabelecida uma visão macro do que se pretende agregar de novidade na solução, assim como o início e término do desenvolvimento, com uma meta para lançamento. Conforme já foi discutido anteriormente, a Bematech adota a metodologia de desenvolvimento Scrum, com sprints mensais. Cerca de duas semanas antes do início da nova sprint, o Gestor da Vertical estabelece a prioridade do que deverá ser implementado no referido ciclo. A área de desenvolvimento estima as horas e delimita as funcionalidades que consegue desenvolver no período, tendo em vista sua restrição de homens-hora para desenvolvimento. A cada sprint, a área de desenvolvimento faz os testes. Isto é feito sucessivas vezes, até o término final da versão, que então passa por testes integrados para garantia da qualidade. Ao ser finalizada, antes de ser disponibilizada para os clientes, a nova versão precisa ser homologada junto à Secretaria da Fazenda de cada Estado brasileiro. 
Muitas vezes, a empresa dá início ao planejamento de uma nova versão, mesmo antes de terminar a homologação da versão anterior.

Responsável pelas atividades:

Horizontal de Desenvolvimento

Gestor da Vertical

_. Área Regulatória / Fiscal

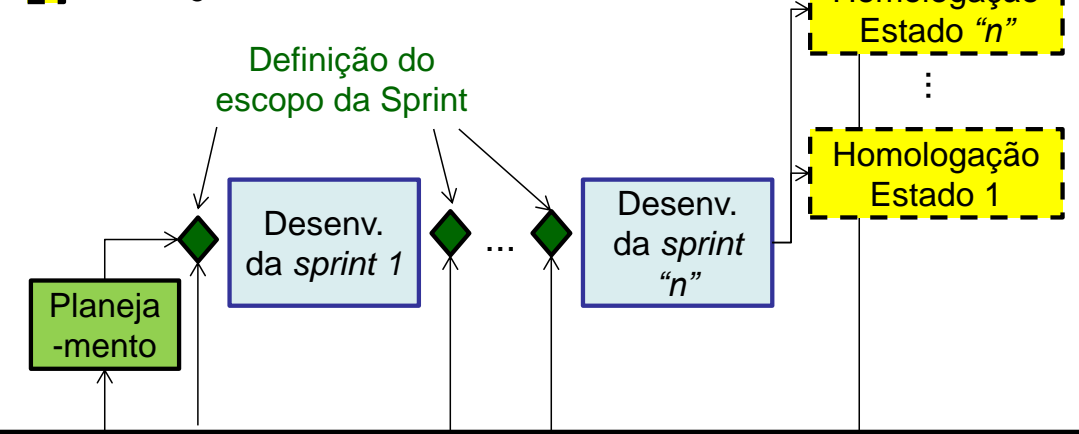

Processos de Monitoramento Contínuo e Captura de Idéias para o Roadmap Formação de visão sobre o futuro das soluções oferecidas pela empresa

Figura 26 - Processo de elaboracão de roadmans na Bematech

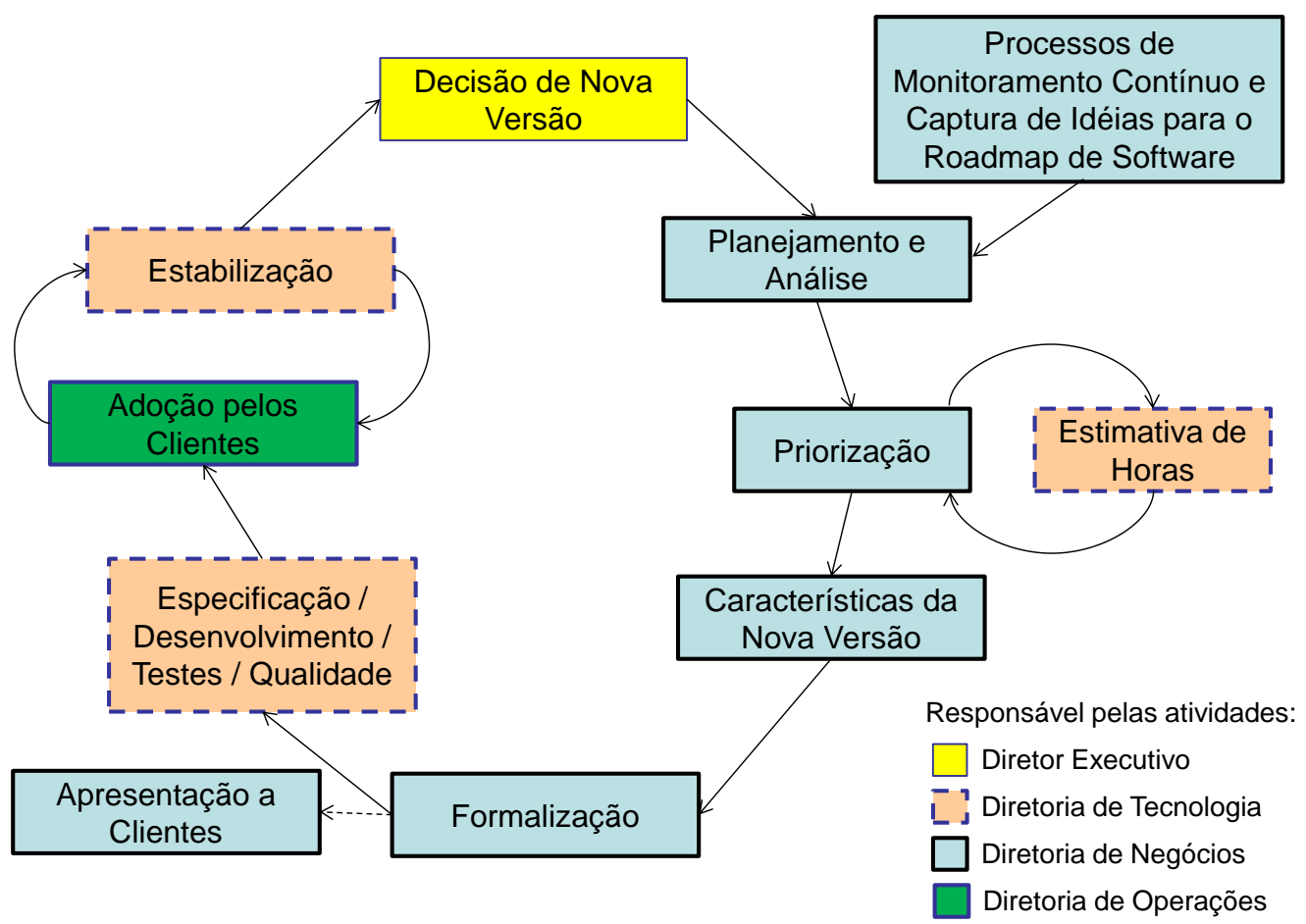

Figura 27 - Processo de elaboração de roadmap na Kiman 
A figura 27 ilustra o processo de elaboração de roadmap na Kiman. O processo tem início com a decisão, do Diretor Executivo, de se iniciar uma nova versão. Ele fornece diretrizes gerais, tais como a plataforma tecnológica a ser usada e uma meta de data para lançamento da versão. Esta decisão pode ser retardada por diversos motivos, sendo o principal a adoção da versão anterior por todos os clientes e sua estabilização. O processo de captura de necessidades dos clientes, bem como necessidades legais ocorre de forma contínua. $\mathrm{Na}$ Kiman, a validação e acordo sobre o roadmap consiste na decisão sobre as características da nova versão, determinada em grande parte pela já mencionada conta de "trás para frente" sobre as funcionalidades que podem ser incluídas, dada a restrição da data prevista para lançamento e horas disponíveis para desenvolvimento. Desta forma, dado o volume de recursos existentes e as horas restantes disponíveis, estabelece-se um corte nas características da nova versão. Há então uma formalização do que será incluído, e isto é divulgado amplamente para os clientes existentes. Dentre todas as empresas pesquisadas, a Kiman é a única que realiza esta divulgação externa. Algumas empresas comentaram não fazer isto para não gerar expectativa que eventualmente pode não ser cumprida. No caso da Kiman, ela assegura que as funcionalidades serão incluídas, mesmo que seja necessário decidir por um atraso na entrega da versão, ou pela alocação de mais profissionais que o inicialmente previsto. Como contrapartida, a vantagem é que novas solicitações dos clientes são postergadas para a nova versão em desenvolvimento, a não ser que o cliente arque com um custo de replicação para que a solicitação seja implementada tanto na versão atual quanto na nova. A área de tecnologia procede então com o desenvolvimento e os testes para garantia da qualidade, seguindo-se um processo ativo, por parte da Diretoria de Operações, para que os clientes adotem a nova versão. Não encontramos na literatura qualquer referência à importância do processo de adoção pelos clientes, no qual a empresa precisa atuar de forma ativa para estimular a adoção da nova versão, bem como à estabilização que compreende, no caso da Kiman, ao desenvolvimento de releases, patches e hotfix conforme já foi explicado. Estas duas etapas consistem em um pequeno ciclo dentro do ciclo maior de elaboração de roadmaps, que é decisivo para a empresa tomar a decisão de iniciar um novo ciclo e partir para o planejamento de uma nova versão. 


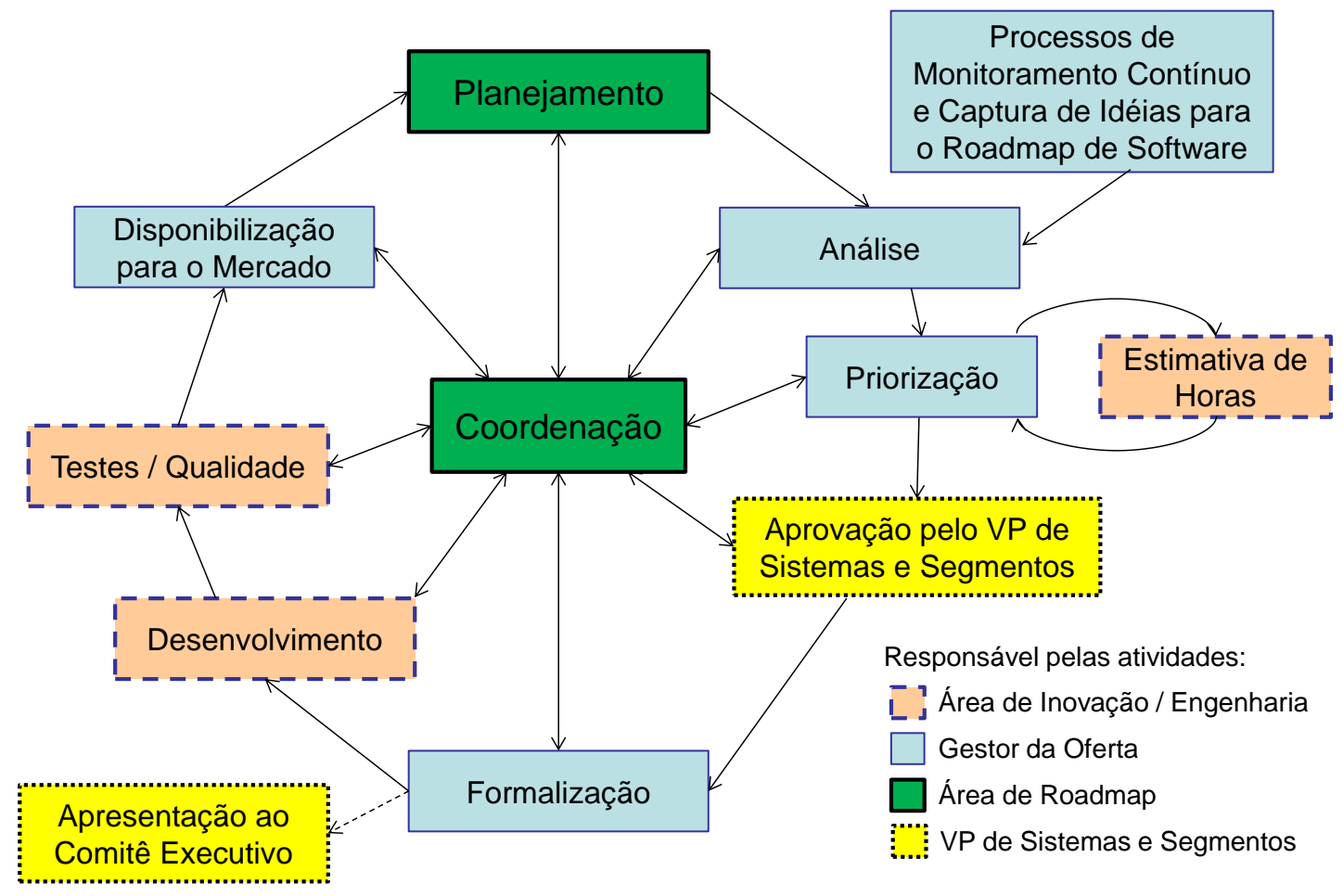

Figura 28 - Processo de elaboração de roadmap da TOTVS

A TOTVS também possui um processo de elaboração de roadmap que é melhor representado por um ciclo (figura 28). Porém, existem algumas diferenças importantes com relação ao processo da Kiman. Primeiramente, há uma área de roadmap que coordena o processo e é responsável por realizar o planejamento. O ciclo é contínuo, não sendo relevante uma decisão do diretor para iniciá-lo. O monitoramento das necessidades e novas funcionalidades também é contínuo. Cada uma das 10 verticais então organizam a lista dos chamados IRM (itens de roadmap) que desejam implementar na solução. O Gestor da Oferta, juntamente com o Gestor da Inovação, estimam as horas e estabelecem um corte dos IRM que podem ser desenvolvidos dado o prazo para lançamento da versão frente aos recursos disponíveis. Esta priorização é apresentada ao VP de Software e Segmentos para aprovação, seguindo-se então a formalização do roadmap, que depois é apresentado ao Comitê Executivo da TOTVS. A área de inovação é responsável pelo desenvolvimento e a engenharia pelos testes e garantia da qualidade. Uma série de atividades são feitas ao fim do desenvolvimento, o que inclui a produção de material de treinamento, manuais on-line, vídeos de treinamento, entre outros. Ao fim do processo, a nova versão é disponibilizada ao mercado. 
Os casos analisados sugerem que tamanho da empresa está co-relacionado com a estruturação da atividade de elaboração de roadmap. Não é possível dizer se um causa ou outro, porque tanto o crescimento da empresa pode exigir uma maior estruturação da atividade, quanto uma boa gestão de roadmap pode alavancar o crescimento da empresa. Porém, a literatura trata o tamanho da empresa sem uma métrica específica. Os casos analisados nesta tese sugerem que no setor de software não é o tamanho da empresa medido pelo número total de funcionários que importa, mas sim o número de pessoas envolvidas com desenvolvimento. A Kiman é menor que a Opus em número total de funcionários, mas possui mais desenvolvedores relacionados à aplicação estudada. Pode-se dizer que a Bematech foge à regra, pois apesar de ser a segunda maior, não possui ainda um processo tão estruturado quanto o da Kiman. Em parte, isto é devido à herança, pois ela "herdou" processos de empresas compradas, além de ser uma empresa oriunda do setor de hardware. Assim sendo, tanto a estrutura quanto os processos da área de software estão em transformação. Porém, seu tamanho e necessidade de expansão, aliado à necessidade de coordenar a demanda de muitos clientes, está fazendo com que a Bematech estruture rapidamente seu processo de roadmap.

A atividade de elaboração de roadmaps em geral não é representada na literatura por meio de ciclos, mas de etapas sequenciais (PHAAL et al, 2004; SUOMALAINEN et al, 2011). Em empresas de software, o ciclo de elaboração de roadmaps é uma importante atividade de inteligência tecnológica (esta sim representada como ciclo pela literatura), pois é quando a empresa cria sentido a partir das várias informações captadas de forma contínua e define o que será incluído ou não na próxima versão de seus produtos, tanto em termos de tecnologia quanto funcionalidades. Ao término de uma elaboração de roadmap, em geral sucede-se uma fase de análise/acompanhamento/estabilização, que permite a empresa um aprendizado e uma avaliação, antes de dar início ao próximo ciclo.

\subsection{Particularidades da Elaboração de Roadmap no Setor de Software}

Os casos analisados permitem identificar algumas particularidades importantes da elaboração de roadmap no setor de software, as quais são discutidas a seguir. 


\subsubsection{Foco no Curto Prazo}

Um dos primeiros aspectos que nos surpreendeu na pesquisa é o fato das empresas estudadas não estabelecerem um roadmap para um prazo superior a um ano. Também não planejam versões futuras que vão além da próxima versão imediata. Diversas referências da literatura tratam o roadmap como uma ferramenta para planejamento a longo prazo, o que pode envolver 5 ou até mais anos a frente (PHAAL, et al 2004; GROENVELD, 1997). Os dados coletados sugerem que isto não significa que as empresas não estejam atentas e preocupadas com a evolução futura dos produtos. Elas constantemente monitoram e tentam constituir uma visão de futuro a longo prazo, mas que, porém, não são traduzidas para o roadmap. Três possíveis explicações para este fenômeno são:

a) Rapidez da evolução tecnológica: todas as empresas acompanham a evolução tecnológica, mas devido à sua imprevisibilidade e ao rápido ritmo de inovação, parece que as empresas não se preocupam em fazer previsões sistemáticas sobre o futuro. No momento de planejamento da nova versão é que a empresa efetivamente avalia aquilo que, para o momento, é mais importante tendo em vista a aceitação pelo mercado e a disponibilidade de recursos para desenvolvimento.

b) Necessidade de mercado: um software dificilmente atende todas as necessidades dos clientes. Cada cliente novo aparece com necessidades não previstas. Para conquistar mercado, ou não perder clientes, as empresas negociam continuamente mudanças em seu software. Por isso, o roadmap precisa organizar estas solicitações negociadas, e eventualmente na capacidade que sobrar, desenvolver funcionalidades que a empresa acredita que possa gerar negócios ou facilitar as vendas futuras. Isso foi muito evidente nas pequenas e médias empresas. A única exceção parece ser a TOTVS que possui um volume significativo de horas dedicadas para inovação.

c) Constantes mudanças na legislação: um outro aspecto que impacta o custo das empresas de software é o volume de horas necessárias para implementar mudanças exigidas pela legislação. No caso da Bematech, foi citado que eles planejam dedicar um volume de recursos exclusivos para o roadmap regulatório, ou seja, as novas implementações que visam atender às mudanças de legislação. 
Nas empresas pesquisadas, o roadmap não contribui para a identificação de tecnologias de ruptura ou decisão de adoção de tais tecnologias. Em geral o roadmap é condicionado pela plataforma de desenvolvimento que a empresa adotou inicialmente. Esta descoberta tem respaldo nos argumentos de dependência de caminho (path dependency) e herança da RBV, e é um fator que pode restringir a capacidade dinâmica da empresa (BARNEY, 1991; DIERICKX; COOL, 1997). Os executivos até acompanham as novas tecnologias, mas o roadmap está muito ligado a uma rotina de identificar novas funcionalidades que possam ser agregadas e que permitam obter diferencial junto ao mercado (clientes e prospecções).

\subsubsection{Gestão de Códigos de Software}

Uma dimensão não tratada pela literatura é a quantidade de versões ativas de código dos softwares, mantida pela empresa. Diferente de produtos industriais, em que geralmente produtos físicos não continuam sofrendo alterações depois da introdução de novas versões, no caso de software, enquanto cada versão for utilizada por algum cliente, precisa de manutenção pelo menos para dar suporte à legislação e corrigir erros. Da mesma forma, o software de gestão precisa manter compatibilidade com as novas versões. Ou seja, não é um produto industrial que a empresa usuária pode simplesmente se desfazer e comprar outro (como um carro por exemplo). O cliente em geral quer extrair o máximo possível do investimento já realizado, e quer que a migração para novas versões gere o mínimo possível de risco e transtornos. Procuramos retratar alguns aspectos importantes sobre esta questão na figura 29.

No extremo esquerdo da figura, consta a empresa Coinfo que possui uma versão instalada para cada cliente. A evolução do produto é por meio de encomendas feitas pelos clientes, normalmente contratada na manutenção. Há uma dificuldade de ganho de escala, e também para migrar a plataforma tecnológica, já que a mudança teria que ser feita cliente a cliente.

Já a Keywrod possui muitas versões ativas, alguns clientes usando versões bastante antigas. A empresa tem dificuldade, portanto, em diluir custos com novos desenvolvimentos, e a plataforma fica inalterada por muitos anos. A empresa desenvolveu uma plataforma sobre a 
qual consegue desenvolver relatórios e visões para cada cliente, sem alterar o código. Assim, grande parte dos recursos trabalham em projetos específicos dos clientes.

\begin{tabular}{|c|c|c|c|c|}
\hline \multicolumn{2}{|r|}{$\begin{array}{c}\text { Customização } \\
\text { Total } \\
\text { (código replicado) }\end{array}$} & $\begin{array}{l}\text { Muitas } \\
\text { Versões } \\
\text { Ativas }\end{array}$ & $\begin{array}{l}\text { Poucas } \\
\text { Versões } \\
\text { Ativas }\end{array}$ & $\begin{array}{l}\text { Uma ou Duas } \\
\text { Versões de } \\
\text { Código }\end{array}$ \\
\hline Casos & Coinfo & Keyword & Totvs & $\begin{array}{c}\text { Kiman, } \\
\text { Bematech }\end{array}$ \\
\hline $\begin{array}{l}\text { Impactos } \\
\text { no } \\
\text { Roadmap }\end{array}$ & $\begin{array}{l}\text { Clientes } \\
\text { determinam } \\
\text { evolução dos } \\
\text { produtos } \\
\text { - Não há ganho } \\
\text { de escala } \\
\text { - Muito difícil } \\
\text { evoluir a } \\
\text { plataforma } \\
\text { tecnológica }\end{array}$ & $\begin{array}{l}\text { - Dificuldade de } \\
\text { diluir custos } \\
\text { de novos } \\
\text { desenvolvi- } \\
\text { mentos } \\
\text { - Plataforma } \\
\text { fica inalterada } \\
\text { e grande } \\
\text { parte dos } \\
\text { recursos } \\
\text { trabalham em } \\
\text { necessidades } \\
\text { específicas } \\
\text { dos clientes }\end{array}$ & $\begin{array}{l}\text { Conciliar demandas } \\
\text { de públicos } \\
\text { diferentes, tanto } \\
\text { internos quanto } \\
\text { externos } \\
\text { - Gerenciar mudanças } \\
\text { de código feitas em } \\
\text { versões anteriores e } \\
\text { garantir portabilidade } \\
\text { para novas versões } \\
\text { Desafio de integração } \\
\text { entre diferentes } \\
\text { softwares }\end{array}$ & $\begin{array}{l}\text { Desafio de criar uma } \\
\text { plataforma sobre a } \\
\text { qual clientes possam } \\
\text { parametrizar e } \\
\text { customizar sem } \\
\text { interferir no código } \\
\text { - } \text { Potencial de grande } \\
\text { ganho de escala } \\
\text { com poucos } \\
\text { recursos. No caso } \\
\text { da Kiman não é } \\
\text { observado devido ao } \\
\text { setor de Previdência } \\
\text { ter poucas empresas }\end{array}$ \\
\hline
\end{tabular}

Figura 29 - Versões ativas de código do software e impacto no roadmap

Se a empresa possuir diferentes softwares ou adotar diferentes plataformas, existe também a complexidade em se garantir a integração entre as soluções. Este é o caso da TOTVS que adquiriu várias empresas e consolidou os maiores fornecedores nacionais de software de gestão empresarial. $\mathrm{O}$ grande desafio é conciliar a demanda de públicos diferentes para que as funcionalidades sejam incluídas muitas vezes em versões que não são a última, aumentando o trabalho de replicação destas funcionalidades para as novas versões, juntamente com a complexidade de garantir a integração com outros produtos.

Já a Kiman e a Bematech possuem poucas versões ativas de código. Em geral duas e em alguns momentos da linha do tempo pode ser que todos os clientes estejam em uma única versão. O desafio é justamente garantir que a versão atenda à necessidade da maioria dos clientes, e desenvolver uma plataforma que permita parametrizar e customizar o sistema sem interferir no código. Há um grande potencial de ganho de escala, com poucos recursos. 
A Opus não foi citada na figura 29 porque mescla características da Coinfo (extremo esquerdo) com características de SAAS, que corresponde ao extremo direito na figura, que não é atingido nem pela Kiman, nem pela Bematech. A característica do extremo esquerdo é que cada cliente novo (uma rede de franquias) que ingressa recebe um código da aplicação que passa a evoluir de acordo com as demandas específicas. Este código portanto não pode ser aplicado a outra rede de franquias e isto limita a disponibilização de melhorias para toda a base de clientes. Porém, em alguns casos a rede possui centenas de franqueados. Como o sistema é operado pela Internet, no modelo SAAS, ele pode potencialmente e rapidamente adicionar até milhares de franqueados de uma mesma rede, sem necessidade de realizar novas instalações de seu produto. Estarão todos operando com um sistema atualizado, e com informações consolidadas pela matriz. Há portanto, neste sentido, um grande potencial para ganho de escala podendo ampliar muito rapidamente o número atendido de pontos de franquia.

\subsection{Proposta de Uma Metodologia Para Elaboração de Roadmap Tecnológico de Longo Prazo em Empresas de Software}

Conforme já foi discutido, as empresas pesquisadas elaboram roadmaps tecnológicos com prazos bem menores que os apontados por outros casos da literatura.

Por exemplo, Groenveld (1997) discute a elaboração de roadmaps na Philips, onde produtos de ciclo de vida curto abrangem um horizonte futuro de 3 a 4 anos (por exemplo, produtos de áudio portátil) e, produtos de ciclo de vida longo, possuem roadmaps que podem abranger até 10 anos (por exemplo, armazenamento ótico). Grossman (2004) explora a adoção de roadmap pelo Technology Management Group (TMG) da General Motors (GM), em que projetaram em 2000 um roadmap com horizonte de 10 anos.

Por este motivo, visando cobrir um gap entre a prática das empresas estudadas e o que é recomendado pela teoria, propomos neste tópico uma metodologia para elaboração de um roadmap tecnológico de longo prazo (RTLP) para empresas de software, com horizonte proposto de 4 anos ou mais. Foram consideradas para sua elaboração as metodologias 
discutidas na seção 2.5.5 da revisão de literatura, sobre processos para elaboração de roadmaps (GROENVELD, 1997; PHAAL et al, 2004; SILVEIRA JR., 2013; GERDSRI; KOCAOGLU, 2007; SUOMALAINEN et al; 2011).

O objetivo da metodologia proposta, ilustrada na figura 30, não é decidir detalhadamente cada funcionalidade a ser incluída nas próximas versões, mas sim ter uma visão macro das principais tecnologias a serem incorporadas no futuro. O roadmap detalhado de curto prazo, contendo as funcionalidades e as estimativas de horas, já é realizado em algumas das empresas pesquisadas e foi bastante discutido nas seções anteriores. Desta forma, nossa recomendação é que a empresa elabore o roadmap funcional, focado no curto prazo, adotando de forma complementar a metodologia proposta para planejar um RTLP. Este processo terá maior utilidade para empresas de grande porte, ou mesmo as de pequeno e médio portes que necessitem desenvolver uma visão de futuro mais apurada.

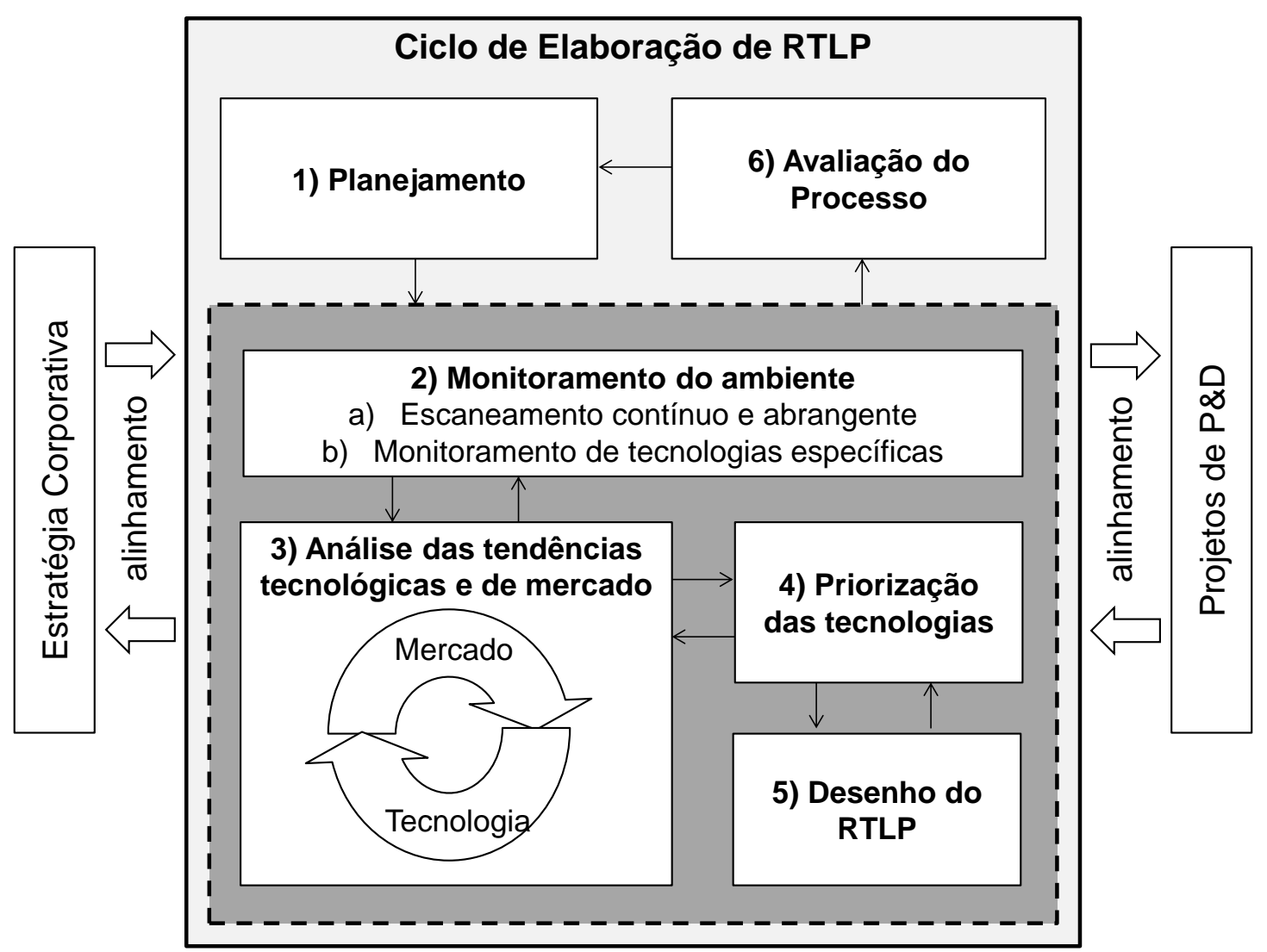

Figura 30 - Proposta de metodologia para elaboração de RTLP 
Entendemos que o RLTP deve ser realizado de forma cíclica e sistemática. Não pode ser uma atividade isolada, realizada uma única vez e depois esquecida pela organização. Manter "viva" a atividade de elaboração de roadmap e dar início à elaboração de roadmaps constituem importantes desafios apontados pela literatura (PHAAL et al, 2004).

A aplicação da metodologia aqui proposta para elaborar um RTLP não faz parte dos objetivos iniciais desta tese. A decisão por sua elaboração se deu após a análise dos casos, a fim de se cobrir uma lacuna existente entre os casos analisados e a literatura. Por este motivo é que esta metodologia de elaboração de RTLP não foi abordada anteriormente, no capitulo 3 que trata especificamente da metodologia da pesquisa. Infelizmente não foi possível aplicar esta metodologia em um dos casos estudados na tese. Nos próximos tópicos faremos uma discussão, de forma teórica, sobre as etapas propostas nesta metodologia.

\subsubsection{Planejamento do Processo de Elaboração de RLTP}

Juntamente com a avaliação do processo, o planejamento está destacado fora da área tracejada mais escura da figura porque são atividades de gestão do ciclo de elaboração de RLTP em si. A parte interna da área tracejada se refere a atividades relacionadas ao conteúdo do roadmap propriamente dito (etapas 2, 3, 4 e 5).

Entender a estratégia corporativa da empresa é importante para promover o alinhamento entre o RLTP e a estratégia. Cabe destacar que não é apenas a adaptação do RLTP à estratégia, pois muitas vezes a tecnologia desenvolvida no roadmap também pode gerar necessidade de ajustes na estratégia. Como será discutido posteriormente na fase de seleção das tecnologias, a empresa muitas vezes precisará definir critérios para a tomada de decisão. Estes critério devem estar alinhados com os objetivos estratégicos que a empresa almeja atingir. Parte-se da premissa que a empresa já possua uma estratégia corporativa, e sua formulação está fora do escopo desta metodologia. $\mathrm{O}$ alinhamento estratégico não está ligado diretamente na fase de planejamento, pois é necessário durante todo o processo de elaboração do RLTP. Inclusive, conforme comentado, durante a elaboração do RLTP podem ser identificadas tecnologias estratégicas que eventualmente podem gerar mudança na estratégia da empresa. Porém, na fase de planejamento deve ser feito um entendimento inicial sobre a estratégia corporativa da 
empresa, pois esta influenciará a escolha das tecnologias a serem monitoradas e os critérios de priorização, por exemplo.

Conforme comentado, é interessante que este ciclo se repita de forma planejada. Caso a empresa realize periodicamente uma revisão de sua estratégia, este pode ser o momento para dar início a este ciclo de elaboração de RTLP promovendo assim um melhor alinhamento entre a estratégia e o roadmap tecnológico da empresa. Ozaki et al (2012) analisaram o processo de formulação da estratégia tecnológica em duas empresas de telecomunicações. Uma das empresas, fornecedora de soluções de infraestrutura para operadoras de telecomunicações, faz semestralmente um workshop reunindo membros da equipe de tecnologia do mundo inteiro, para rever sua estratégia tecnológica e estabelecer sua visão para um horizonte de 5 anos a frente. Nesta empresa, faria sentido após cada um destes ciclos de revisão da estratégia tecnológica, revisar também seu RTLP. A outra empresa é uma operadora de telecomunicações, que faz anualmente o planejamento estratégico com foco no mercado, e que inclui o planejamento tecnológico apenas no sentido de identificar quais tecnologias irão suportar a estratégia da empresa. Neste caso, faz mais sentido planejar o RTLP anualmente, após o planejamento estratégico.

O planejamento compreende a identificação das etapas a serem cumpridas e a identificação e envolvimento dos recursos (humanos e materiais) necessários em cada etapa, uma vez que existem inúmeros stakeholders a serem atendidos (SUOMALAINEN et al, 2011). Muitas vezes, pode ser interessante envolver clientes, fornecedores, ou mesmo especialistas isentos para opinar sobre as potencialidades e riscos das tecnologias (SILVEIRA JR., 2013). Portanto, planejar o processo como um todo, bem como identificar os participantes em cada etapa é muito importante para que a atividade de elaboração do roadmap possa gerar os resultados esperados.

\subsubsection{Monitoramento do Ambiente}

Adotamos o termo "Monitoramento do Ambiente" apenas para não poluir a figura 30, mas é importante salientar que é um monitoramento específico em busca de oportunidades e ameaças tecnológicas. Na figura consta como etapa 2, mas esta atividade ocorre de forma 
contínua, inclusive após o término de um ciclo de elaboração de roadmap. Porém, informações coletadas precisam ser organizadas para a análise. Por este motivo esta atividade foi representada logo após o planejamento na figura.

Por monitoramento estamos entendendo aqui tanto a atividade de escaneamento, realizada de forma contínua e que envolve a busca menos direcionada de informações que possam representar oportunidades e ameaças tecnológicas, quanto o monitoramento direcionado, acompanhando o desenvolvimento de tecnologias estratégicas previamente identificadas por meio de projetos específicos (KERR et al, 2006; VASCONCELLOS; DINIZ, 2000).

O monitoramento deve estar alinhado com a estratégia corporativa da empresa (VASCONCELLOS; DINIZ, 2000; LICHTENTHALER, 2004), pois ela define em termos gerais a missão e os mercados em que a empresa irá atuar. Conforme já foi discutido, esta definição não é estática, uma vez que descobertas de novas tecnologias, até mesmo na fase de monitoramento, podem influenciar a estratégia da empresa. Porém, este alinhamento prévio é importante devido à inviabilidade de se monitorar um universo muito grande de tecnologias e mercados.

Neste sentido, recomenda-se que seja feito um monitoramento sistemático nos diversos ambientes em busca de tendências que possam representar oportunidades ou ameaças tecnológicas relacionadas à estratégia da empresa. Estas tendências poderiam ser captadas por diversas áreas e colaboradores e enviadas para uma área que pudesse desempenhar funções de inteligência tecnológica. Além da captação das informações oriundas de colaboradores internos, existem diversas outras fontes de informações, muitas já adotadas pelas grandes empresas estudadas nesta tese, tais como fornecedores de tecnologia, universidades e institutos de pesquisa.

Embora o roadmap seja de caráter tecnológico, o escaneamento deve abranger também outros ambientes que possam impactar a tecnologia, tais como o político, o econômico, o social, o de concorrência ou de clientes, conforme foi discutido na explicação do quadro 1, que tratou dos ambientes para escaneamento/monitoramento identificados na literatura. Muitas vezes o escaneamento não é realizado especificamente para a elaboração do roadmap, podendo ser uma atividade de inteligência relacionada ao marketing ou ao planejamento estratégico, mas 
que contribuirá fornecendo as informações relevantes para a atividade de elaboração de roadmaps.

Antes da elaboração do roadmap, portanto, é importante que a empresa tenha coletado informações que lhe permitam formar uma visão sobre o futuro. No setor automobilístico, muitas vezes esta visão é formada por meio da elaboração de carros conceito, ou seja, que incorporam uma visão de futuro sobre novas tecnologias, mas sem necessariamente ter o compromisso de lançamento comercial. A CNI (2013) relatou a experiência do lançamento do carro conceito MIO, da empresa FIAT. A metodologia envolveu 4 fases: Reflexão sobre o Futuro; Ideias para o Carro do Futuro; Desenho Coletivo do Carro do Futuro; e Design do Fiat Concept Car - FCC II. Por meio da Internet, fez pesquisas sobre o que os clientes e consumidores desejarão em um carro do futuro. Por meio de um time interdisciplinar envolvendo designers, engenheiros, antropólogos, sociólogos, e funcionários de diversas áreas, as informações sobre os desejos futuros foram interpretadas e transformadas em diversos conceitos incorporados no carro. É interessante observar que o ponto de partida não foi a tecnologia, mas sim a preocupação sobre como será a sociedade no futuro e qual o tipo de carro que ela irá desejar. Alguns dos conceitos tecnológicos identificados envolvem uma convergência muito forte com a área de software, tais como o "Infotainment", que permite integração de dispositivos para comunicação, mídia e navegação com comandos de voz e de toque, "Identidade eletrônica", que permite a conexão a redes sociais, "Head-up Display (HUD)", que permite projeção de informações no para-brisa, "Biometria a bordo", no qual a tecnologia libera o acesso ao automóvel e também reconhece o estado do motorista (por exemplo, quando está com sono). Apesar do carro conceito não ter pretensão de ser lançado comercialmente, projetos foram adicionados ao roadmap da FIAT para serem desenvolvidos (CNI, 2013).

A IBM, por sua vez, realiza anualmente um esforço para gerar o chamado Global Technology Outlook (GTO). O GTO é realizado sistematicamente desde 1982, envolve pessoas da IBM do mundo inteiro durante meses, e tem por objetivo identificar e avaliar as tendências tecnológicas que irão impactar a sociedade e os negócios ano a ano, até um horizonte de dez anos a frente (IBM RESEARCH, 2013; DILLENBERGER, 2011). Ao se estabelecer estas tendências, existe uma preocupação muito grande em se identificar como a sociedade está evoluindo. Muitas das tendências em TI adotadas largamente pelas empresas, bem como 
projetos de desenvolvimento de produtos da IBM, foram primeiramente identificadas no GTO. O principal objetivo não é acertar ano a ano as tecnologias que estarão no centro das atenções. Mais do que isso, o GTO fornece uma visão futura, um guia que permite às diversas áreas de IBM ajustarem seus produtos e serviços para atenderem a uma sociedade em mudança.

Durante a fase de monitoramento, a empresa pode também realizar uma auditoria tecnológica, a fim de se avaliar diversos aspectos da capacitação tecnológica da empresa frente aos concorrentes e ao mercado (VASCONCELLOS et al, 1990).

As empresas estudadas nesta tese já realizam um monitoramento contínuo do ambiente. Porém, ele é em geral informal (com exceção da TOTVS que possui um sistema para registro das idéias) e focado no curto prazo. Outro aspecto é que são misturados aspectos tecnológicos com as necessidades funcionais a serem agregadas no software.

Consideramos esta etapa de monitoramento uma contribuição à literatura existente sobre roadmap, pois em geral os artigos não mencionam a importância desta atividade de escaneamento e monitoramento. Uma possível explicação para a dificuldade de se iniciar e manter viva a atividade de elaboração de roadmaps apontada por Phaal et al (2004) pode ser justamente a falta de uma cultura orientada para o futuro, que estimule o monitoramento contínuo de oportunidades e ameaças tecnológicas. Levantar estas tendências somente no momento em que se vai planejar o roadmap pode, além de gerar um enorme esforço, fazer com que a empresa perca ou ignore muita informação relevante.

\subsubsection{Análise das Tendências Tecnológicas e de Mercado}

A etapa 3 consiste em identificar ameaças e oportunidades tecnológicas com base nas informações obtidas na etapa de monitoramento. Desta forma, entende-se que ao iniciar esta fase, a empresa já coletou e organizou informações relevantes sobre os diversos ambientes, já existindo portanto uma visão prévia sobre anseios dos potenciais clientes e da sociedade. Todavia, a figura 30 apresenta uma seta de retorno, pois durante a análise podem ser detectadas necessidades adicionais de informações, e que portanto gera a necessidade de 
retornar ao monitoramento. O processo como um todo é interativo, podendo haver idas e vindas, não sendo uma sequência rígida apenas de ida de uma atividade para outra.

Phaal et al (2004) propõe realizar três análises: análise de mercado, de tecnologia e de produto. Porém, não recomendamos adotar a mesma metodologia proposta por Phaal, que consiste em três workshops, um para tratar cada uma dessas análises. Um espaço de tempo maior pode ser necessário para o pleno entendimento destes três aspectos, podendo não ser viável concluir cada um em apenas um workshop. Como nosso objetivo é o longo prazo, consideramos que a análise de produto pode ser realizada depois. O produto é o meio de ligação entre o mercado almejado e a tecnologia escolhida, o que poderá ser feito de diversas formas (pela evolução de produtos existentes, pelo lançamento de novos produtos, por aquisições, etc.). Portanto, consideramos que a análise de quais produtos devam incluir quais tecnologias deva ser feito posteriormente, na elaboração do roadmap propriamente dito.

Nesta etapa, consideramos primordial a análise tanto do mercado quanto da tecnologia, o que não pode ser feita de forma sequencial. Na figura 30, representamos esta interação de forma circular, mas talvez a melhor representação fosse uma espiral, pois a análise irá abranger uma quantidade de detalhes cada vez maior a cada interação. Ela também é interativa com a etapa anterior de monitoramento, e com a etapa posterior de priorização. Assim, o fato de se partir para a próxima fase não significa que esta fase de análise tenha sido encerrada.

Nesta etapa, busca-se identificar também o momento em que as tecnologias estarão maduras, e/ou quando serão importantes para cada mercado específico que a empresa atua ou pretende atuar. Existem tecnologias que, mesmo maduras, são primeiro adotadas em um setor e depois em outros, e assim por diante.

Consideramos que a análise morfológica proposta por Silveira Jr. (2013) possa limitar o campo de visão de uma empresa de software, uma vez que ao decompor o produto nos seus principais componentes, considera-se a estrutura atual do produto. Por ser um setor extremamente dinâmico, muitas vezes as oportunidades, ou ameaças, surgem de tecnologias que fogem totalmente aos componentes atuais dos seus softwares. Apenas para citar um exemplo, se uma empresa como a Microsoft fizesse a análise morfológica do pacote Office, poderia encontrar componentes tais como "interface", "recursos de processamento de 
arquivos", entre outros, mas dificilmente incluiria a capacitação interna em gerenciamento de hardware e a infraestrutura de TI. Com a ascensão da computação em nuvem, a Microsoft precisa desenvolver também a competência de gerenciamento de hardware e infraestrutura para que possa prover suas soluções por meio da Internet.

Com base nos diversos autores que tratam sobre processo de elaboração de roadmaps (GROENVELD, 1997; PHAAL et al, 2004; SILVEIRA JR., 2013; GERDSRI; KOCAOGLU, 2007; SUOMALAINEN et al; 2011), propomos as seguintes atividades para a fase de análise:

a) Identificar os mercados: ou seja, os segmentos para os quais a empresa deseja fazer as análises. Por exemplo, a Coinfo poderia desejar fazer a análise para o setor de turismo, e incluir ainda um novo segmento em que não atua, mas tem interesse em explorar. Dentro do setor de turismo, poderia ser ainda mais específica, optando por analisar apenas consolidadoras aéreas e operadoras turísticas, ou ainda incluir agências de viagens em sua análise de mercado.

b) Selecionar as tendências tecnológicas que serão foco de análise em cada mercado: a empresa deverá selecionar, dentre as várias tecnologias acompanhadas sistematicamente ou captadas no monitoramento contínuo, as que deseja incluir nas análises.

c) Realizar uma Pesquisa Delphi Sobre Tendências Tecnológicas: além de Silveira Jr. (2013), Kanama et al (2004) também defende que a pesquisa Delphi é uma importante ferramenta na elaboração de roadmaps tecnológicos. A pesquisa Delphi também pode ser uma ferramenta de coleta de informações na fase de monitoramento. Porém, nesta fase de análise consideramos ela essencial, pois permitirá à empresa identificar, com base nas tendências monitoradas, qual o prazo de maturação das oportunidades e ameaças mais relevantes.

A pesquisa Delphi envolve os seguintes passos:

I. Identificar especialistas a participarem da pesquisa em cada segmento: uma possível lista de especialistas são os gerentes de TI das empresas clientes 
ou mesmo de não clientes. Podem ser incluídos consultores de tecnologia. Alguns especialistas de outros setores também poderiam ser convidados a responder a pesquisa, pois podem trazer uma nova luz sobre o tema, e a partir da aplicação da tecnologia no seu setor de especialidade, inferir como ela poderia ser usada no setor que é foco da pesquisa. Um aspecto importante é procurar evitar viéses na amostra (WRIGHT; GIOVINAZZO, 2000).

II. Elaborar o questionário: neste aspecto é importante citar a tecnologia e também oferecer uma explicação sobre ela. Por mais que sejam especialistas, eventualmente nem todo respondente conhece a tecnologia objeto da questão, ou pode até conhecê-la por outro nome. O questionário deverá permitir à empresa entender a visão dos especialistas sobre o prazo de maturação da tecnologia, quando ela será importante e seus riscos (KANAMA et al, 2004). Pode-se também perguntar, para cada tecnologia, aplicações que os respondentes vislumbrem como sendo importantes.

III. Aplicar o questionário: a aplicação do questionário é interativa (WRIGHT; GIOVINAZZO, 2000; KANAMA et al, 2004). Ou seja, pode-se repetir em " $n$ " rodadas. Na primeira rodada, pede-se para os respondentes opinarem sobre as questões apresentadas. Depois, tabula-se o questionário, eliminam-se questões em que foi obtido consenso e analisa-se a necessidade de inclusão de novas questões. Aplica-se uma segunda rodada, e repete-se o ciclo até que se obtenha consenso satisfatório nas respostas.

IV. Elaboração do relatório final: após a obtenção do consenso, elabora-se um relatório final consolidando os resultados da pesquisa.

d) Analisar a Evolução das Tecnologias: a pesquisa Delphi é um importante insumo para esta análise. Porém, a empresa precisa coletar evidências e analisar se as informações obtidas pelo Delphi realmente estão condizentes. Um outro aspecto importante é a identificação de riscos e ameaças (ALBRIGHT; KAPPEL, 2003). A pesquisa Delphi pode apontar, por exemplo, que uma determinada tecnologia será muito importante já daqui a um ano. Mas ela pode não considerar ameaças que muitas vezes são externas à tecnologia. Por exemplo, a adoção da computação em nuvem pode ser impactada negativamente pela percepção de falta de segurança desencadeada por notícias sobre 
espionagem, ou mesmo por novas legislações que obriguem as empresas a instalarem seus centros de dados no próprio país em que irá oferecer o serviço. Isto pode aumentar os custos e, até mesmo, inviabilizar a oferta do serviço.

e) Analisar o Potencial de Mercado das Tecnologias: a pesquisa Delphi pode fornecer diversas ideias sobre aplicações e potencial uso das tecnologias, mas que deverão ser complementadas com possíveis projeções sobre sua adoção pelo mercado. Projeções mercadológicas, sobre crescimento de mercado, ou até mesmo previsões sobre a evolução dos hábitos do consumidor podem ser necessárias para esta análise. Eventualmente a tecnologia pode estar disponível, mas pode não ser viável por falta de cultura ou por barreiras sociais à sua adoção. Como é proposto por diversos autores, a análise de mercado é um importante componente do roadmap (PHAAL et al, 2004; GROENVELD, 1997). As tecnologias que, ao final da avaliação não apresentarem potencial relevante de mercado, podem ser descartadas, de forma a simplificar o número de tecnologias que serão objetivo de priorização na próxima fase.

De posse destas análises, pode-se proceder ao passo seguinte.

\subsubsection{Priorização das Tendências Tecnológicas}

Após a análise tecnológica e de mercado, segue-se a priorização das tendências tecnológicas. Esta fase pode também exigir novas análises, fazendo com que o ciclo retorne para a fase anterior.

Dentre as empresas pesquisadas nesta tese, a que possui um método mais estruturado para a decisão de prioridades é a TOTVS, que avalia cada item do roadmap segundo vários critérios sobre potencial de geração de receitas e risco. Em outras empresas, o principal critério é que seja uma demanda legal ou uma demanda comum a vários clientes (por exemplo, na Kiman e Bematech), sendo também ponderado o risco. 
Em nossa revisão bibliográfica, encontramos apenas duas referências que discutiam a seleção de tecnologias para elaboração do roadmap, que foram os estudos de Silveira Jr. (2013) e Gerdsri e Kocaoglu (2007).

Gerdsri e Kocaoglu (2007) argumentam que a aplicação do método AHP puro, no sentido de comparar par a par as alternativas, é extremamente trabalhosa em cenários de rápida mudança. Isto porque a qualquer evolução nos parâmetros tecnológicos, é necessário realizar nova análise par a par sobre a preferência entre as tecnologias, para se chegar a uma nova priorização e refazer o roadmap. Gerdsri e Kocaoglu (2007) propõe então o TDE, já discutido anteriormente, que compara as métricas de desempenho e não as tecnologias em si. O modelo pode então ser alimentado facilmente com novos parâmetros conforme a tecnologia evolui. Contudo, o método proposto por Gerdsri e Kocaoglu (2007) se aplica bem para tomada de decisão entre tecnologias diferentes mas concorrentes entre si para uma mesma funcionalidade ou aplicação. Eles analisam especificamente 16 tecnologias concorrentes entre si para resfriamento de servidores. O método TDE não se aplica, portanto, ao nosso caso, que envolve tecnologias que podem servir para aplicações diferentes. Da mesma forma, a limitação da aplicação do AHP tradicional fica evidente, pois é inviável, a cada mudança tecnológica, fazer nova comparação par a par entre as tecnologias.

Silveira Jr. (2013), conforme já foi discutido, propõe a aplicação de um método semelhante ao SMART (EDWARDS, 1977), no qual se identificam critérios, pesos e, para cada tecnologia, atribui-se uma nota para cada critério. A somatória da multiplicação da nota de cada critério pelo seu peso constitui a percepção de utilidade do avaliador sobre a tecnologia.

Nesta tese, consideramos que o método SMART seja mais adequado por evitar a necessidade de refazer o modelo, com avaliações par a par a cada mudança tecnológica, da forma como é necessário no AHP. Eventualmente, em uma mudança pontual nos parâmetros de desempenho ou risco, apenas a tecnologia específica poderia ser reavaliada pelo método SMART. O método já foi discutido na revisão de literatura e compreende, sucintamente, os seguintes passos:

a) Identificar as entidades: que corresponde à identificação das tecnologias a serem avaliadas. 
b) Identificar as dimensões: que corresponde aos critérios que são importantes, tendo em vista os objetivos estratégicos. Não há como elaborar aqui uma lista pré-determinada de critérios, porque cada empresa possui seus objetivos particulares. Uma empresa que tenha por objetivo estratégico conquistar o mercado internacional terá critérios diferentes daquela que possui como objetivo estratégico melhorar a competitividade de seu software no mercado local, por exemplo.

c) Identificar os pesos das dimensões: seguindo recomendação de Edwards (1977), neste passo identifica-se primeiramente a dimensão de menor importância, à qual é atribuído peso 10. Em seguida, identifica-se a dimensão com a segunda menor importância, sendo avaliado o quanto ela é mais importante em relação à primeira. Se for $20 \%$ mais importante, receberia peso 12, por exemplo. Este processo se repete para todas as dimensões. Depois, pode-se padronizar o peso para uma escala decimal, dividindo-se cada peso pela somatória dos pesos.

d) Avaliação das entidades em relação às dimensões. Seguindo recomendação de Edwards (1977), as alternativas podem ser avaliadas em uma escala de 0 a 100, na qual 100 corresponde a uma situação em que a entidade tem total importância segundo a dimensão avaliada.

e) Ponderação das notas: cada nota atribuída seria multiplicada pelo peso da dimensão.

f) Calculo das prioridades finais: a somatória final das notas ponderadas, para cada entidade, forneceria sua pontuação total, em uma escala de 0 a 100.

Esta metodologia possui a limitação já apontada por Salo et al (2003) de se avaliar hoje tecnologias que estarão maduras com prazos diferentes, à luz da importância percebida no momento da avaliação. Porém, a metodologia proposta possui uma vantagem. Após a priorização, suponha que uma tecnologia $X$, disponível daqui a 4 anos, seja mais importante que a $\mathrm{Y}$, disponível daqui a 3 anos, e que ambas sejam independentes. Assumindo que não haja alteração nas avaliações de importância, caso ocorra uma mudança tecnológica que 
antecipe a tecnologia $\mathrm{X}$, ficará evidente para a empresa que ela deverá incorporar primeiro a tecnologia X e, portanto, alterar seu roadmap.

\subsubsection{Desenho do Roadmap Tecnológico de Longo Prazo}

A partir da identificação das tecnologias prioritárias, a empresa pode desenhar o RLTP, associando as tecnologias que seriam embarcadas em cada futura versão do produto, considerando o tempo aproximado de cada lançamento de versão.

Este roadmap não tem pretensão de fazer o detalhamento de cada funcionalidade a ser incluída nas versões, atividade esta que as empresas entrevistadas de grande porte já realizam com bom nível de estruturação. A cada nova versão, a empresa poderia proceder com o ciclo detalhado de roadmap.

Consideramos que este seja o momento adequado para se avaliar os produtos da empresa. Isto porque ao se desenhar os mercados almejados na parte superior do roadmap, e as tecnologias prioritárias da empresa na camada inferior, ela poderá reavaliar os produtos na camada intermediária para analisar se é melhor incorporar a tecnologia em um produto existente, ou mesmo criar novos produtos com o objetivo de oferecer a tecnologia para atingir os novos mercados.

Assim sendo, um importante aspecto deste roadmap é que ele não deve necessariamente se restringir às soluções ofertadas pela empresa no momento de sua elaboração. Algumas tecnologias poderão ser oferecidas em novas propostas de produtos.

A fim de exemplificar o resultado final da metodologia proposta, foi elaborado o roadmap da figura 31, que retrata um cenário fictício. Neste roadmap estão representadas 4 tecnologias (M, K, L e N), nesta ordem de prioridade, mas cujo prazo para poderem ser utilizadas é de 3, 1, 2 e 5 anos respectivamente. A empresa possui hoje um Software A para o Mercado X, mas pretende explorar a tecnologia L, por meio de um novo produto, o Software B, visando atingir primeiro o Mercado $\mathrm{Y}$ e depois o $\mathrm{Z}$. A vantagem desta forma de visualização é tornar visualmente claro que, em um cenário em que a Tecnologia $\mathrm{M}$ se antecipe e fique disponível 
no ano 2, ela terá prioridade em relação à tecnologia L. Na figura 31 representamos apenas os 4 primeiros anos de forma separada, e o que for previsto para cinco ou mais anos é agrupado ao final.

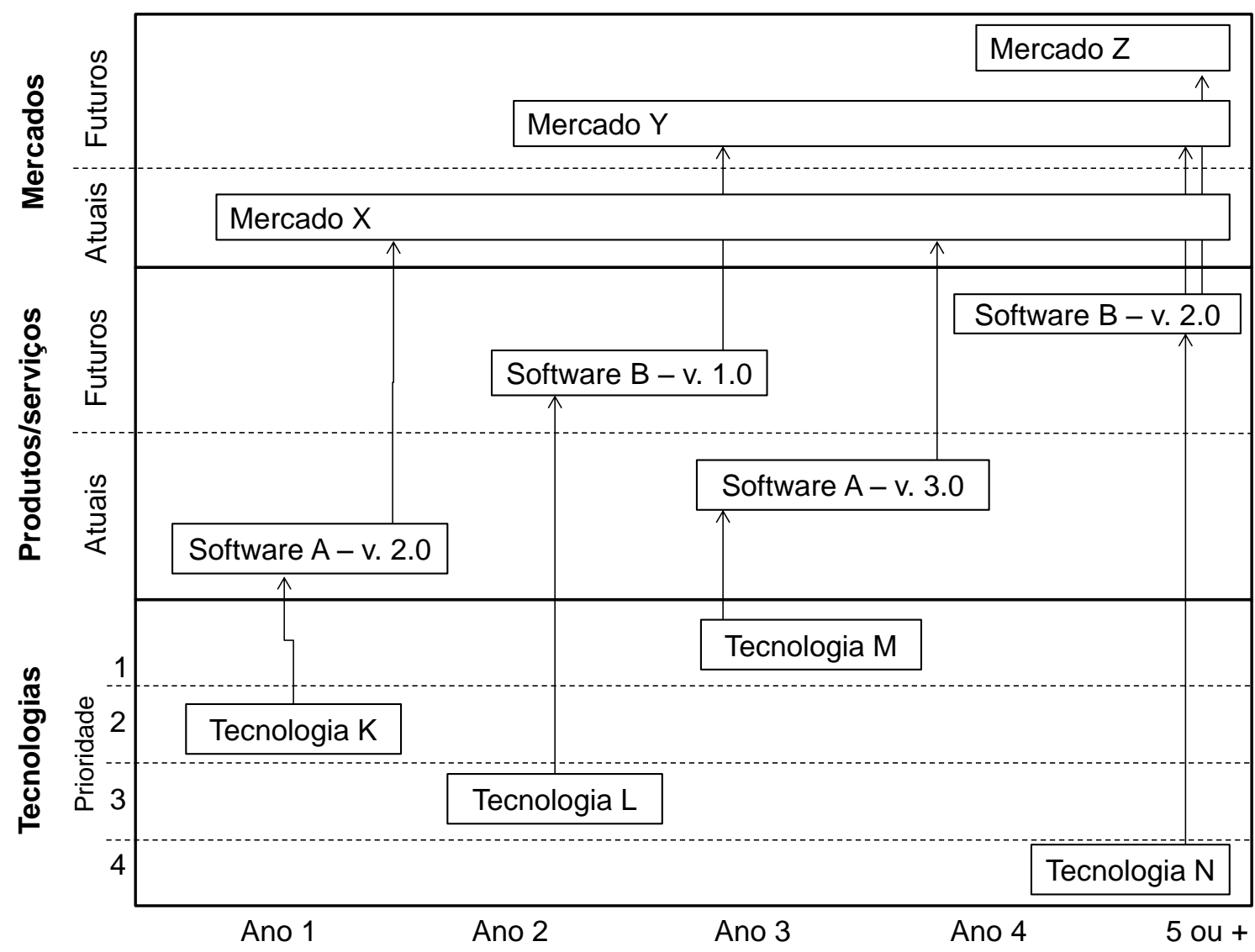

Figura 31 - Formato final de roadmap tecnológico de longo prazo para software

Conforme discutimos, empresas como IBM elaboram visões para até 10 anos a frente (IBM RESEARCH, 2013). O GTO da IBM, porém, não é um roadmap, mas uma visão dos temas tecnológicos que serão predominantes nos próximos anos. Consideramos que seja inviável ampliar tanto o horizonte do roadmap de uma empresa de software dada a velocidade com que as mudanças não antecipadas acontecem. Isto não significa que a indústria não deva estar atenta às mudanças de longo prazo em curso. Por exemplo, Dillenberger (2011) discute o futuro da TI com base no GTO da IBM. Um dos aspectos ressaltados é que saímos de uma era de aprendizagem estática para uma de aprendizagem dinâmica, e estamos caminhando no longo prazo (em torno de 2025) para uma nova era de sistemas de aprendizagem autônoma, inspirado nos sistemas biológicos e em processos cognitivos. Uma vez mapeadas e identificadas, as tecnologias relacionadas a esta tendência devem constar do radar de uma 
empresa de software de gestão. Porém, seria muito prematuro já adicioná-las ao raodmap. A realização sistemática da atividade de elaboração de RTLP permitirá à empresa identificar, com antecipação, quando e como as tecnologias cognitivas poderão ser incorporadas nos seus softwares de gestão. Eventualmente fornecedores de plataformas de desenvolvimento poderão fazê-lo, facilitando portanto a adoção desta tecnologia, tal como ocorreu com a Kiman no caso do uso de banco de dados em memória flash, em que esta funcionalidade foi proporcionada pela plataforma Oracle.

Este roadmap não tem objetivo de ser divulgado externamente, para não gerar expectativas e para não revelar os investimentos estratégicos que a empresa está fazendo em uma ou outra tecnologia. É uma ferramenta que permite vislumbrar e comunicar internamente qual a visão de futuro da empresa em termos de tecnologia, produtos e mercado.

\subsubsection{Avaliação do Processo}

Outro aspecto importante da gestão do ciclo de RLTP é a avaliação do processo e dos resultados. Envolve estabelecer métricas e realizar a avaliação em dois níveis. Um nível mais detalhado envolve avaliar o processo seguido em um ciclo específico de RLTP. Possíveis métricas neste nível podem incluir o custo e o prazo, por exemplo, para avaliar se o RLTP foi elaborado no orçamento e tempo previstos. O segundo nível, mais abrangente e estratégico, envolve avaliar se as previsões do RLTP, em termos de tecnologia, produto e mercado, estão sendo atingidas no longo prazo. Uma possível métrica poderia estar associada ao quanto as previsões do RLTP se concretizaram em termos das tecnologias previstas, no prazo previsto, por exemplo. São métricas que devem ser avaliadas com cuidado, pois não acertar a tecnologia e o prazo não significa necessariamente que o processo falhou ou que ele não trouxe resultados. A empresa pode eventualmente ter desenvolvido tecnologias correlatas, dependentes daquelas cuja previsão não foi acertada, mas que foram bem sucedidas. Não encontramos artigos que fizessem referência específica à avaliação dos resultados do roadmap, sendo este um potencial campo para futuras pesquisas. A avaliação pode fornecer importantes subsídios para o planejamento do próximo ciclo, permitindo assim aprimorar o processo como um todo. 
Após a elaboração do roadmap, projetos de pesquisa e/ou desenvolvimento de tecnologia podem ser necessários, porém, este alinhamento entre roadmap e a carteira de projetos da empresa está fora do escopo desta metodologia.

Infelizmente não foi possível aplicar esta metodologia nas empresas pesquisadas nesta tese, sendo esta uma possibilidade para pesquisas futuras. A seguir, passamos às considerações finais. 


\section{CONSIDERAÇÕES FINAIS}

O setor de software é muito dinâmico. Para se manterem competitivas, as empresas deste setor precisam desenvolver capacidades dinâmicas (TEECE et al, 1997) para se transformarem e incorporarem novas tecnologias. A própria evolução das plataformas computacionais obriga as empresas a incorporarem novas tecnologias, sob o risco de ficarem obsoletas. Porém, não basta apenas mudar, é necessário desenvolver uma maior consciência sobre o futuro para saber em que direção a mudança tecnológica deve ser conduzida (OZAKI et al, 2013). Para tanto, as empresas desenvolvem capacidades de inteligência tecnológica (LICHTENTHALER, 2003; NORLING et al, 2000; VASCONCELLOS et al, 2007) para monitorar continuamente o ambiente em busca de oportunidades e ameaças. Neste contexto, o roadmap tecnológico (PHAAL et al, 2004; GROENVELD, 1997; ALBRIGHT; KAPPEL, 2003) é uma importante ferramenta, não apenas pelo mapa final em si, mas por todo o processo que leva a empresa a escolher entre diferentes rotas tecnológicas a serem seguidas.

Neste estudo, procuramos investigar como empresas brasileiras de software realizam a atividade de elaboração de roadmaps tecnológicos. Por meio de seis estudos de caso em profundidade, foi possível coletar evidências para tecer três principais contribuições inéditas e de grande importância para a academia e para praticantes.

\section{a) Identificação das principais características da atividade de elaboração de roadmaps} tecnológicos em empresas brasileiras de software. Com base na revisão de literatura foram identificadas cinco dimensões importantes na atividade elaboração de roadmaps: objetivos, fontes de informação, processo/conteúdo, barreiras/dificuldades e benefícios. Nas empresas pesquisadas, de maneira geral, os principais objetivos estão associados a identificação de oportunidades e ameaças tecnológicas, por meio da identificação de tecnologias importantes, e a melhoria da comunicação externa com clientes e parceiros. As principais fontes de informação são os clientes e usuários, além dos altos executivos da empresa. O processo, bem como as barreiras encontradas são muito distintas entre os casos, sendo que este estudo não pode apresentar evidências sobre um padrão para elaboração de roadmap ou sobre barreiras mais recorrentes. Ambos os aspectos foram discutidos ao se analisar cada um dos estudos de caso de forma individual. Por fim, o principal benefício do roadmap consiste em ligar a estratégia a planos de produto e 
tecnologia. Cabe destacar que grande parte dos estudos sobre roadmap tecnológico são descrições sobre como uma ou mais empresas elaboram seus roadmaps. Sem um referencial comum, os autores acabam não olhando necessariamente os mesmos aspectos, o que dificulta em muito a comparação dos estudos. Assim sendo, o próprio modelo conceitual adotado nesta tese também constitui uma contribuição importante que poderá auxiliar futuras pesquisas na área.

b) Identificar como o porte da empresa influencia as características da atividade de elaboração de roadmaps. Penrose (1959) já salientava que os serviços prestados pelos recursos, em particular os de caráter gerencial, poderiam limitar o crescimento da firma. Nesta tese, a escolha da amostra se deu justamente para investigar como a atividade de elaboração de roadmaps varia entre empresas de diferentes portes. Novamente, o modelo conceitual adotado se mostrou muito útil pois permitiu tal comparação de forma bastante clara. A primeira diferença foi encontrada nos objetivos, pois as médias e grandes empresas possuem uma maior preocupação com a melhoria da comunicação externa (clientes/parceiros), além da preocupação das grandes empresas em permitir a análise cruzada entre os roadmaps de diferentes unidades de negócio. Enquanto nas pequenas e médias empresas, as duas principais fontes de informação são os altos executivos e os clientes/usuários, as empresas grandes atribuem alta importância para um número muito maior de fontes. O processo, conforme já foi comentado, é muito diferente entre as empresas, mas quanto maior o porte da empresa, maior a complexidade deste processo em termos de organização e interação entre diferentes agentes. Não foi possível identificar barreiras específicas para empresas de pequeno, médio ou grande porte, porém, a metodologia adotada permitiu identificar barreiras que, na média das avaliações, são mais relevantes. Por fim, empresas maiores possuem uma maior percepção de benefícios do que as pequenas ou médias empresas.

c) Particularidades do setor de software na atividade de elaboração de roadmaps. Foi possível identificar importantes particularidades do setor de software. A complexidade da atividade de elaboração de roadmaps, nas empresas pesquisadas está associada ao porte considerando não o número total de funcionários, mas o número de funcionários ligados a desenvolvimento. Uma empresa industrial geralmente tem poucos funcionários de P\&D em relação ao total de funcionários. Porém, como esta pesquisa evidencia, uma empresa 
de software tem uma quantidade muito grande de funcionários ligados a desenvolvimento. Em médias e pequenas pode chegar a quase $50 \%$ do total de funcionários (caso da Kiman), ou mesmo nas grandes empresas é superior a $20 \%$ do total de funcionários (caso da TOTVS e Bematech). O foco da atividade está concentrado no curto prazo (um ano ou menos e lançamento da próxima versão). Por fim, a gestão de códigos de software ativos é uma importante atividade nas empresas, que acaba trazendo importantes impactos tanto no roadmap, quanto posteriormente na possibilidade da empresa ganhar escala.

É muito intrigante o fato das empresas de software não se preocuparem em fazer um roadmap tecnológico de longo prazo. Neste sentido, tecemos algumas considerações:

- O roadmap em software contempla poucos aspectos de tecnologia de software relativamente às novas funcionalidades de negócio. A maior parte da discussão na elaboração dos roadmaps tecnológicos nas empresas de software recai sobre as funcionalidades de negócio que serão entregues na próxima versão. A principal tecnologia entregue pelo software de gestão muitas vezes são processos automatizados, implementados com as mesmas tecnologias de desenvolvimento já usadas nas versões anteriores. Outro fato é que a incorporação de tecnologias específicas muitas vezes exige menos horas de trabalho em relação ao total de horas necessárias nas novas funcionalidades de negócio.

- Muitas vezes a empresa não tem domínio sobre a evolução da tecnologia, que acontece de forma abrupta, e muitas vezes não antecipada. Muitas empresas de software adotam plataformas tecnológicas fornecidas pelas grandes empresas do setor como Microsoft, Oracle e IBM. Do ponto de vista de dispositivos, a empresa de software geralmente não consegue direcionar a evolução, que acontece de forma muito abrupta, exigindo apenas que ela se adapte permitindo que o software incorpore inovações tecnológicas ou possa ser executado em aparelhos antes inexistentes. Foi assim com tablets e smartphones, por exemplo. Nenhuma das empresas pesquisadas atuou no direcionamento destas tecnologias. Porém, uma vez que estas tecnologias móveis passaram a ser adotadas em larga escala pelos clientes, as empresas de software tiveram que se adaptar para que, pelo menos algumas funcionalidades, pudessem ser executadas nos novos aparelhos. 
- Plataformas de desenvolvimento. A mudança de plataforma de desenvolvimento exige um grande esforço da empresa de software. Porém, estas mudanças são deixadas no radar e a empresa não se preocupa em planejar estas migrações de plataforma a longo prazo (por exemplo, definir que será feita uma mudança para plataforma Y daqui a 2 anos, para a $\mathrm{Z}$ daqui a 5 anos e assim por diante). Em parte isto se deve justamente porque, conforme discutido no item anterior, a maioria das empresas não possuem domínio sobre a evolução das tecnologias de plataforma. Assim sendo, a mudança em algumas empresas vai sendo postergada, tanto devido ao alto investimento exigido, quanto para minimizar impactos nos clientes provocados por mudanças de plataforma. Muitas vezes a empresa vai postergando e toma a decisão de migração somente no momento em que se torna um problema crítico, por exemplo por gerar incompatibilidade com equipamentos ou com o ambiente operacional de grande parte dos clientes, ou até porque o fornecedor irá suspender o suporte à plataforma.

Neste cenário, fica uma questão: desenvolver um roadmap de longo prazo traz mesmo maior competitividade para a empresa de software? Esta é uma pergunta que infelizmente não pode ser respondida nesta tese, podendo ser objeto de pesquisas futuras. Mesmo assim, visando eliminar este gap entre a prática verificada nos casos e a literatura sobre roadmaps, foi proposta uma metodologia para elaboração de roadmaps tecnológicos de longo prazo para empresas de software.

\subsection{Limitações do Estudo}

Yin (2003) discute quatro aspectos importantes para julgar a qualidade do desenho da pesquisa em estudos de caso, sendo que um dos aspectos (validade interna) é aplicável somente para estudos causais, não sendo este o caso. Assim sendo, para nossos objetivos, foram tomadas precauções quanto a:

- Validade de construto: corresponde a estabelecer medidas operacionais corretas para os conceitos que são estudados. Foram adotadas nesta tese as três sugestões fornecidas por Yin (2003): uso de múltiplas fontes de evidência, estabelecer uma cadeia de evidências, e pedir para informantes-chave revisarem o estudo de caso. 
- Validade externa: corresponde ao estabelecimento do domínio ao qual os resultados poderão ser generalizados. Não é pretensão generalizar os resultados deste estudo. Mesmo assim, foram adotadas duas sugestões fornecidas por Yin (2003): usar a teoria para embasar proposições que guiarão o estudo, e utilizar a lógica de replicação entre os casos que serão estudados.

- Confiabilidade: demonstração de que o estudo pode ser repetido, com os mesmos resultados. Com este objetivo, foram adotadas duas sugestões fornecidas por Yin (2003): um protocolo de estudo de caso, bem como um repositório de dados com todas as informações coletadas sobre os casos estudados.

Mesmo assim, este estudo possui algumas limitações. A primeira delas é decorrente do próprio método escolhido, que não permite a generalização estatística. Porém, como apontado por Yin (2003), os estudos de caso podem permitir a chamada generalização analítica, ou seja, identificar determinadas situações em que a teoria se aplicou e adaptá-las a cada caso novo específico. Estudos de caso também permitem a formulação ou revisão de teorias (EISENHARDT, 1989), servindo de base para estudos quantitativos posteriores.

A outra limitação é o fato deste estudo ser realizado somente com empresas do setor de software brasileiras. Assim sendo, não é possível estender as conclusões e as descobertas para outros setores, ou mesmo no próprio setor em empresas multinacionais ou localizadas em outros países. Porém, a escolha se deu justamente devido ao fato de ser um setor altamente dinâmico, e no qual as empresas, para se manterem competitivas e sobreviverem, precisam detectar ameaças e oportunidades tecnológicas com antecedência a fím de criar novas soluções ou mesmo reescrever suas soluções para novas plataformas.

O método do estudo de caso ainda é passível da crítica da subjetividade na interpretação dos dados e na falta de validade e confiabilidade dos resultados. A fim de reduzir estes efeitos, procuramos seguir as recomendações de Yin (2003) e Eisenhardt (1989), a fim de detalhar os procedimentos no protocolo de estudo de caso. Também foi solicitado a cada um dos respondentes principais a revisão do estudo de caso individual da empresa, a fim de se identificar eventuais incorreções. 
O próprio tempo disponível para realização da pesquisa nos impediu de entrevistar mais pessoas ampliando a visão sobre o processo de elaboração de roadmaps nas empresas pesquisadas. Eventualmente pessoas de outras áreas e/ou outros níveis hierárquicos poderiam adicionar aspectos que não puderam ser contemplados nesta tese.

\subsection{Sugestões para Estudos Futuros}

Esta tese abre possibilidade para diversos estudos futuros. Algumas destas possibilidades são discutidas a seguir.

- Compreender melhor o processo de elaboração de roadmaps em empresas multinacionais do setor de software, especialmente aquelas que competem desenvolvendo plataformas tecnológicas, tais como Microsoft, Oracle ou Google. Estas empresas possivelmente adotam processos diferentes de elaboração de roadmaps, e seu estudo permitiria agregar novos conhecimentos sobre o tema.

- Realizar uma pesquisa quantitativa, no setor de software ou mesmo em outros setores, adotando o modelo conceitual utilizado nesta tese. Conforme já foi discutido, o próprio modelo conceitual desta tese é uma das contribuições do estudo. A identificação das principais dimensões da atividade de elaboração de roadmaps e a aplicação do questionário com escala Likert nos estudos de caso permitiu verificar a viabilidade de sua aplicação. Identificar como é realizada a atividade de elaboração de roadmaps tecnológicos em outros setores pode trazer novas visões e complementar o conhecimento existente, contribuindo não apenas para a academia mas também para a prática, fornecendo idéias sobre como desenvolver roadmaps tecnológicos. Outra possibilidade é aplicar as mesmas dimensões para uma revisão crítica de literatura e/ou pesquisa empírica sobre outras técnicas de gestão. Por exemplo, empresas de software tem se preocupado recentemente em adotar novas metodologias de desenvolvimento, tal como o Scrum, conforme foi verificado em algumas empresas estudadas nesta tese. Aplicar as mesmas dimensões para estudar o uso do Scrum pelas empresas permitiria entender os objetivos que levam a esta adoção, fontes de informação, seu processo de aplicação, barreiras/dificuldades, bem como os benefícios obtidos. 
- Aplicar a metodologia proposta de elaboração de um RTLP a um caso real. Nesta tese, foi sugerida uma metodologia para elaboração de roadmaps de longo prazo visando cobrir uma lacuna entre a prática e a teoria. Esta metodologia, porém, não pôde ser aplicada a um caso real devido a limitações tanto de disponibilidade das empresas e dos entrevistados quanto de tempo para sua aplicação.

- Os estudos desta tese evidenciam que existe relação entre o porte da empresa e a complexidade da atividade de elaboração de roadmaps em termos de organização e interação entre os agentes envolvidos. Porém, uma questão que fica em aberto é o quanto a maturidade da empresa na elaboração de roadmaps limita o seu crescimento. Novos estudos podem elucidar melhor esta questão, fornecendo importantes contribuições para empresas que estejam em trajetória de crescimento.

- Conforme foi comentado na seção em que discutimos o RTLP, não encontramos referências específicas tratando a avaliação dos resultados do roadmap. Entender se estes processos são avaliados, como são avaliados, ou mesmo pesquisas que permitam propor métodos para sua avaliação, poderão contribuir tanto para a academia quanto para a prática empresarial.

Desta forma, espera-se que esta tese possa servir de base para novas pesquisas que possam aprofundar o conhecimento sobre a atividade de elaboração de roadmaps tecnológicos. 


\section{REFERÊNCIAS}

ACEDO, F.; BARROSO, C.; GALAN, J. The resource-based theory: dissemination and main trends. Strategic Management Journal, v 27, p. 621-636, 2006.

ALBRIGHT, Richard; KAPPEL, Thomas. Technology roadmapping: Roadmapping the corporation. Research Technology Management, v. 46, n. 2, p. 31-59, 2003.

ALEGRE, Joaquín; LAPIEDRA, Rafael; CHIVA, Ricardo. A measurement scale for product innovation performance. European Journal of Innovation Management, v. 9, p. 333-346, 2006.

ALMEIDA Fernando C., ONUSIC, Luciana M; LESCA, Humbert. Criação de sentido e criatividade no monitoramento estratégico do ambiente. Revista de Administração da Universidade de São Paulo, v. 42, n. 4, p. 405-413, 2007.

AMIT, Raphael; SCHOEMAKER, Paul. Strategic Assets and Organizational Rent. Strategic Management Journal, v. 14, n. 1, p. 33-46, 1993.

ANDERSON, Philip; TUSHMAN, Michael. Technological Discontinuities and Dominant Designs: A Cyclical Model of Technological Change. Administrative Science Quarterly, v. 35, p. 604-633, 1990.

ANSOFF, H. Igor. Managing Strategic Surprise by Response to Weak Signals. California Management Review, v. 28, n. 2, p. $21-33,1975$.

ARCHIBUGI, D., PIANTA, M. Measuring Technological Change Through Patents and Innovation Surveys. Technovation 16, p. 451-468, 1996.

ASHTON, W. B.; KINZEY, B. R.; GUNN, M. E. A structured approach for monitoring science and technology developments. International Journal of Technology Management, v. 6, p. 91-111, 1991.

BARDIN, Laurence. Análise de Conteúdo. São Paulo: Edições 70, 2011.

BARKER, Derek; SMITH, David. Technology Foresight Using Roadmaps. Long Range Planning, v. 28, n. 2, p. 21-28, 1995.

BARNEY, Jay. Firm resources and sustained competitive advantage. Journal of Management, v. 7, n. 1, p. 99-120, 1991.

BENLIAN, A.; HESS, T.; BUXMANN, P. Drivers of SaaS adoption - an empirical study of different application types. Business \& Information Systems Engineerning. v. 5, p. 357369, 2009.

BERNHARDT, D.C. I want it fast, factual, actionable - Tailoring Competitive Intelligence to Executives’ Needs. Long Range Planning, v. 27, n. 1, p. 12-24, 1994. 
BOSE, Ranjit. Competitive intelligence process and tools for intelligence analysis. Industrial Management \& Data Systems, v. 108, n. 4, p. 510-528, 2008.

BRESNAHAN, Timothy; GREENSTEIN, Shane. Technological Competition and The Structure of The Computer Industry. The Journal of Industrial Economics, v. 47, p. 1-40, 1999.

BRIGHT, James. Evaluating Signals of Technological Change. Harvard Business Review, v. 48, n. 1, p. $62-70,1970$.

BROCKHOFF, Klaus. Competitor Technology Intelligence in German Companies. Industrial Marketing Management, 20, p. 91-98, 1991.

BRYNJOLFSSON, Erik; KEMERER, Chris. Network externalities in microcomputer software: An econometric analysis of the spreadsheet market. Management Science, v. 42, p. 1627-1647, 1996.

CARMEL, Erran. Cycle Time in Package Software Firms. Journal of Product Innovation Management, v. 12, p. 110-123, 1995.

American hegemony in packaged software trade and the culture of software. The Information Society, v. 13, p. 125-142, 1997.

CARVALHO, M. M.; FLEURY, A.; LOPES, A. P. An overview of the literature on technology roadmapping (TRM): Contributions and trends. Technological Forecasting \& Social Change, v. 80, p. 1418-1437, 2013.

CASSIOLATO, José E.; BAPTISTA, Margarida A. C. The effects of the Brazilian liberalisation of the IT industry on technological capabilities of local firms. Information Technology for Development, v. 7, p. 53-73, 1996.

CASTELlACCI, F. Technological Paradigms, Regimes and Trajectories: Manufacturing and Service Industries in a New Taxonomy of Sectoral Patterns of Innovation. Research Policy, 37, p. 978-994, 2008.

CHESBROUGH, H. The Era of Open Innovation. MIT Sloan Management Review. Boston: MIT, spring, p. 35-41, 2003.

Open Innovation: A New Paradigm for Understanding Industrial Innovation. In: Chesbrough, H.; Vanhaverbeke, W.; West, J. Open Innovation - Researching a New Paradigm. Oxford University Press, p. 1-12, 2006.

CHESBROUGH, H.; ROSENBLOOM, R. The role of the business model in capturing value from innovation: evidence from Xerox Corporation's technology. Industrial and Corporate Change, v. 11, n. 3, p. 529-555, 2002;

CHRISTENSEN, Clayton. The Innovator's Dilemma: When New Technologies Cause Great Firms to Fail. Boston: Harvard Business School Press, 1997. 
CLARK, Kim; WHEELWRIGHT, Steven. Managing New Product And Process Development. New York: Free Press, 1993.

COHEN, Wesley; LEVINTHAL, Daniel. Absorptive Capacity: A New Perspective on Learning and Innnovation. Administrative Science Quarterly, v. 35, n. 1, p. 128-152, 1990.

CNI - CONFEDERAÇÃO NACIONAL DA INDÚSTRIA. Inovação em cadeias de valor de grandes empresas: 22 casos. Brasília: CNI - IEL, 2013.

COOPER, R. G. Stage-Gate Systems: A New Tool for Managing New Products. Business Horizons, v. 33, n. 3, p. 44-54, 1990.

Perspective: The Stage-Gates Idea-to-Launch Process - Update, What's New, and NexGen Systems. The Journal of Product Innovation Management. 25, p. 213-232, 2008.

CUSUMANO, Michael. The Business of Software. New York: Free Press, 2004.

CUSUMANO, Michael; GAWER, Annabelle. The Elements of Platform Leadership. MIT Sloan Management Review, v. 43, n. 3, p. 51-58, 2002.

DAFT, R.; SORMUNEN, J.; PARKS, D. Chief Executive Scanning, Environmental Characteristics, And Company Performance: An Emprirical Study. Strategic Management Journal, v. 9, p. 123-139, 1988.

DAFT, Richard; WEICK, Karl. Toward a Model of Organizations as Interpretation Systems. Academy of Management Review, 1984, vol. 9, n. 2, p. 284-293.

DAVENPORT, Thomas. Process Innovation: reengineering work through information technology. Boston: Harvard Business School Press, 1993.

DIERICKX, Ingemar; COOL K. Asset stock accumulation and sustainability of competitive advantage. Management Science, v. 35, n. 12, p. 1504-1511, 1989.

DILLENBERGER, D. E. et al. Frontiers of information technology. IBM Journal Research \& Development, v. 55, n. 5, p. 1-13, 2011.

DISHMAN, Paul L.; CALOF, Jonathan L. Competitive intelligence: a multiphasic precedent to marketing strategy. European Journal of Marketing, v. 42, n. 7, p. 766 - 785, 2008.

DOLLINGER, Marc J. Environmental boundary spanning and information processing effects on organizational performance. Academy of Management Journal, 27, p. 351-368, 1984.

DREW, Stephen. Building technology foresight: using scenarios to embrace innovation. European Journal of Innovation Management, v. 9, n. 3, p. 241-257, 2006.

DUL, J.; HAK, Tony. Case Study Methodology in Business Research. Oxford: Elsevier, 2008. 
EDWARDS, Ward. How to use multiattribute utility measurement for social decisionmaking. IEEE Transactions on Systems, Man, and Cybernetics, Vol. 7, No. 5, p. 326-340, 1977.

EISENHARDT, Kathleen. Building Theories From Case Study Research. The Academy of Management Review, v. 14, n. 4, p. 532-550, 1989.

EISENHARDT, K.; MARTIN, J. Dynamic capabilities: what are they? Strategic Management Journal, v. 21, p.1105-1121, 2000.

ELBANNA, Said. Strategic decision-making: Process perspectives. International Journal of Management Reviews, v. 8, n. 1, p. 1-20, 2006.

EVANS, David S.; HAGIU, Andrei; SCHMALENSEE, Richard. A Survey of the Economic Role of Software Platforms in Computer-based Industries. CESifo Economic Studies, v. 51, p. 189-224, 2005.

FONSECA, F.; OZAKI, A.; WRIGHT, J. T. C. Técnicas de Avaliação e Previsão Tecnológica Adotadas por Empresas do Setor de TI no Brasil. In : XIV Congreso LatinoIberoamericano de Gestión Tecnológica. Anais eletrônicos... Lima: Altec, 2011.

FLEURY, André Leme; HUNT, Francis; SPINOLA, Mauro; PROBERT, David. Customizing the Technology Roadmapping Technique for Software Companies. Anais... Picmet, p. 1528$1538,2006$.

GERDSRI, N.; ASSAKUL, P.; VATANANAN, R. An activity guideline for technology roadmapping implementation. Technology Analysis \& Strategic Management, v. 22, n. 2, p. 229-242, 2010.

GERDSRI, Nathasit; KOCAOGLU, Dundar. Applying the Analytic Hierarchy Process (AHP) to build a strategic framework for technology roadmapping. Mathematical and Computer Modelling, v. 46, p. 1071-1080, 2007.

GOUVEA, Raul. The transnationalization of Brazil's software industry. Transnational Corporations, v. 16, n. 1, p. 145-164, 2007.

GRANT, Robert. Prospering in Dynamically-Competitive Environments: Organizational Capability as Knowledge Integration. Organization Science, v. 7, p. 375-387, 1996.

GROENVELD, Pieter. Roadmapping integrates business and technology. Research Technology Management, v. 40, n. 5, p. 48-55, 1997.

GROSSMAN, David. Putting Technology on the Road. Research Technology Management, March-April, p. 41-46, 2004.

HERRING, Jan. Key Intelligence Topics: A Process to Identify and Define Intelligence Needs. Competitive Intelligence Review, v. 10, n. 2, p. 4-14, 1999. 
HELFAT, Constance; WINTER, Nelson. Untangling Dynamic and Operational Capabilities: Strategy for the (N)ever-changing World. Strategic Management Journal, v. 32, p. 12431250, 2011.

HOBBS, B. F.; MEIER, P. M. Multicriteria Methods for Resource Planning: An Experimental Comparison. IEEE Transactions on Power Systems, v. 9, n. 4, p. 1811-1817, 1994.

HOWARD, Ronald. Decision Analysis: Practice and Promise. Management Science, v. 34, n. 6, p. 679-695, 1988.

IBGE. PINTEC - Pesquisa de Inovação Tecnológica. Rio de Janeiro: Instituto Brasileiro de Geografia e Estatística. Disponível em http://www.pintec.ibge.gov.br). Último acesso em 01/07/2011, 2010.

IBM Research. Global Technology Outlook 2013. IBM, 2013. Disponível em: http://www.zurich.ibm.com/pdf/isl/infoportal/Global_Technology_Outlook_2013.pdf Último acesso em 08/01/2014.

JENNINGS, Daniel F.; LUMPKIN, James R. Insights Between Environmental Scanning Activities and Porter's Generic Strategies: An Empirical Analysis. Journal of Management, 18, p. 791-803, 1992.

JONKER, Jan; PENNINK, Bartjan. The Essence of Research Methodology. Berlin: Springer, 2010.

JUHARI, Ariff S.; STEPHENS, Derek. Tracing the origins of competitive intelligence throughout history. Journal of Compettitie Intelligence and Management,v. 3, n. 4, p. 6182, 2006.

KANAMA, D.; KONDO, A.; YOKOO, Y. Development of technology foresight: integration of technology roadmapping and the Delphi method. International Journal of Technology Intelligence and Planning, v. 4, n. 2, p. 184-200, 2008.

KAPPEL, Thomas. Perspectives on roadmaps: how organizations talk about the future. The Journal of Product Innovation Management, v. 18, p. 39-50, 2001.

KEENEY, Ralph. Making Better Decision Makers. Decision Analysis, v. 1, n. 4, p. 193-204, 2004.

KERLINGER, Fred N. Metodologia da pesquisa em ciências sociais: um tratamento conceitual. São Paulo: EPU, 1980.

KERR, C.I.V.; MORTARA, L.; PHAAL, R.; PROBERT, D.R. A Conceptual Model for Technology Intelligence. Internatinal Journal of Technology Intelligence and Planning, v. 2, n. 1, 2006.

KOGUT, Bruce; ZANDER, Udo. Knowledge of the Firm, Combinative Capabilities, and the Replication of Technology. Organizational Science, v. 3, n. 3, p. 383-397, 1992. 
KOSTOFF, Ronald; BOYLAN, Robert; SIMONS, Gene. Disruptive Technology Roadmaps. Technological Forecast \& Social Change, v. 71, 2004.

KRIPPENDORFF, Klaus. Content analysis: na introduction to its methodology. Thousand Oaks: Sage, 2004.

LAURSEN, Keld; SALTER, Ammon. Open for Innovation: The Role of Openness in Explaining Innovation Performance Among U.K. Manufacturing Firms. Strategic Management Journal, v. 27, p. 131-150, 2006.

LICHTENTHALER, Eckhard. Third Generation Management of Technology Intelligence Processes. R\&D Management, Oxford, v. 33, n. 4, p. 361-375, 2003.

Technology intelligence process in leading European and North American multinationals. R\&D Management, Oxford, v. 34, p. 121-135, 2004.

MEYER, Marc; SELIGER, Robert. Product Platforms in Software Development. MIT Sloan Management Review, v. 40, p. 61-74, 1998.

MINTZBERG, H; RAISINGHANI, D.; THÉORÊT, A. The Structure of "Unstructured" Decision Processes. Administrative Science Quarterly, v. 21, p. 246-275, 1976.

MONTONI, Mariano A.; ROCHA, Ana R.; WEBER, Kival C. MPS.BR: A Successful Program For Software Process Improvement in Brazil. Software Process Improvement and Practice, v. 14, p. 289-300, 2009.

NELSON, R. ; WINTER, S. An evolutionary theory of economic change. Cambridge: Harvard University Press, 1982.

NEMOTO, Miriam; VASCONCELLOS, Eduardo; NELSON, Reed. The Adoption of New Technology: Conceptual Model and Application. Journal of Technology Management \& Innovation, v. 5, n. 4, p. 95-107, 2010.

NONAKA, Ikujiro; TAKEUCHI, Hirotaka. Criação de Conhecimento na Empresa. Rio de Janeiro: Elsevier, 1997.

NORLING, Parry et al. Putting competitive Technology Intelligence to Work. Research Technology Management, v. 43, n. 5, p. 23-28, 2000.

OECD - ORGANISATION FOR ECONOMIC CO-OPERATION AND DEVELOPMENT. Oslo Manual - Guidelines for Collecting and Interpreting Innovation Data. Paris: OECD, 2005.

OZAKI, Adalton; DEL REY, Alexandre; ALMEIDA, Fernando C. de. Radar de monitoramento tecnológico: uma ferramenta de interpretação de sinais fracos para identificação de surpresas estratégicas. Future Studies Research Journal, v. 3, n. 1, p. 84110, 2011. 
OZAKI, Adalton; FONSECA, Fernando; WRIGHT, James T. C. Prospecção tecnológica e consciência sobre o futuro: um estudo sob a ótica das capacidades dinâmicas utilizando modelagem de equações estruturais. Revista de Administração e Inovação, v. 10, p. 98-118, 2013.

OZAKI, Adalton; MELO JR., Augusto C. B. de; SBRAGIA, Roberto, VASCONCELLOS, Eduardo P. G. Technological Innovation Strategy: A Case Study in Brazilian Subsidiaries of MNCs. Revista Globalización, Competitividad y Gobernabilidad, v. 6, n. 3, 2012.

PATEL, Pari; PAVITT, Keith. The Technological Competencies of the World's Largest Firms: complex and path-dependent, but no much variety. Research Policy, 13, p. 343-373, 1997.

PHAAL, R.; FARRUKH, C. J. P.; PROBERT, D. R. Technology roadmapping - A planning framework for evolution and revolution. Technological Forecasting and Social Change, v. 71, p. 5-26, 2004.

PHAAL, R.; FARRUKH, C. J. P.; PROBERT, D. R. Strategic Roadmapping: A Workshopbased Approach for Identifying and Exploring Strategic Issues and Opportunities. Engineering Management Journal, v. 19, n. 1, p.3-12, 2007.

PENROSE, Edith. The Theory of the Growth of the Firm. London: Basil Blackwell Publisher, 1959.

PETRICK, Irene J.; ECHOLS, Ann E. Technology roadmapping in review: A tool for making sustainable new product development decisions. Technological Forecasting \& Social Change, v. 71, p. 81-100, 2004.

PRAHALAD, C. K.; HAMEL, G. The Core Competence of the Corporation. Harvard Business Review, 68, 3, p. 79-91, 1990.

PORTER, Michael. Competitive Strategy. New York: Free Press, 1980.

PORTER, A. L.; CUNNINGHAM, S. W.; BANKS, J.; ROPER, A. T.; MASON, T. W.; ROSSINI, F. A. Forecasting and Management of Technology. New Jersey: John Wiley \& Sons, 2011.

PRESCOTT, John. Introduction: Competitive Intelligence - Lessons from the Trenches. In: PRESCOTT, John e MILLER, Sthephen (Org). Proven Strategies in Competitive Intelligence - Lessons from the Trenches. New York: John Wiley \& Sons, p. 1-20, 2001.

PRESSMAN, Roger S. Software Engineering - A Practitioner's Approach. New York: McGraw Hill, 2005.

PROBERT, David; RADNOR, Michael. Technology roadmapping: Frontierexperience from industry-academia consortia. Research Technology Management, v. 46, n. 2, p. 27-59, 2003. 
ROHRBECK, René. Corporate Foresight - Towards a Maturity Model for the Future Orientation of a Firm. Berlim: Springer, 2011.

ROUSSELL, P.A.; SAAD, K.N.; ERICSON, T.J. Third Generation R\&D: Managing the Link to Corporate Strategy. Boston, MA: Harvard Business School Press, 1991.

SAATY, Thomas L. How to make a decision: The Analytic Hierarchy Process. European Journal of Operational Research, v. 48, p. 9-26, 1990.

SAAYMAN, A.; PIENAAR, J.; PELSMACKER, P.; VIVIERS, W.; CUYVERS, L.; MULLER, M.L.; JEGERS, M. Competitive intelligence: construct exploration, validation and equivalence. Aslib Proceedings: New Information Perspectives, v. 60, n. 4, p.383-411, 2008.

SÄÄKSJÄRVI, Markku; LASSILA, Aki; NORDSTRÖM, Henry. Evaluating the software as a service business model: from CPU time-sharing to online innovation sharing. IADIS International Conference e-Society, p. 177-186, 2005.

SALO, Ahti; GUSTAFSSON, Tommi; RAMANATHAN, Ramakrishnan. Multicriteria Methods for Technology Foresight. Journal of Forecasting, v. 22, p. 235-255, 2003.

SAWYER, S. Packaged software: implications of the differences from custom approaches to software development. European Journal of Information Systems, v. 9, p. 47-58, 2000.

SCHOEMAKER, Paul. Scenario Planning: A Tool for Strategic Thinking. MIT Sloan Management Review, v. 36, n. 2, p. 25-40, 1995.

SCHUMPETER, J. The Theory of Economic Development. Oxford University Press, New York, 1961.

SCHUH, Günther; GRAWATSCH, Markus. Triz-based Technology Intelligence. In: International Conference on Management of Technology, 13., 2004. Anais eletrônicos... Washington: IAMOT, 2004.

SCHWABER, Ken; SUTHERLAND, Jeff. The Scrum Guide. Scrum.org, 2013. Disponível em: https://www.scrum.org/Portals/0/Documents/Scrum\%20Guides/2013/Scrum-Guide.pdf. Último acesso em: 09/03/2014.

SELlTIZ, Claire; JAHODA; DEUTSCH; COOK. Método de Pesquisa nas Relações Sociais. São Paulo, EPU, 1974.

SILVEIRA JR., L. A. B. Aplicação de técnicas de previsão tecnológica visando reduzir o peso de amortecedores. São Paulo, 2013. Dissertação (Mestrado em Administração) Programa de Pós-Graduação em Administração, Departamento de Administração, Faculdade de Economia, Administração e Contabilidade da Universidade de São Paulo.

SMITH, Bradford; MANN, Susan. Innovation and Intellectual Property Protection in the Software Industry: An Emerging Role for Patents? The University of Chicago Law Review, v. 71, p. 241-264, 2004. 
SOFTEX - Associação para Promoção da Excelência do Software Brasileiro. Software e Serviços de TI: A Indústria brasileira em perspectiva. Campinas: SOFTEX, 2009.

SOUZA, C. A. de; ZWICKER, R. Sistemas ERP: Conceituação, Ciclo de Vida e Estudos de Casos Comparados. In: Souza, C. A. de; Saccol, A. (coordenação). Sistema ERP no Brasil. São Paulo: Editora Atlas, 2003.

SUBRAMANIAN, Ram; FERNANDES, Nirmala; HARPER, Earl. Environmental scanning in U.S. companies: Their nature and their relationship to performance. Management International Review, 33, P. 271-286, 1993.

SUOMALAINEN, Tanja; SALO, Outi; ABRAHAMSSON, Pekka; SIMILÄ, Jouni. Software product roadmapping in a volatile business environment. The Journal of Systems and Software, v. 84, p. 958-975, 2011.

TEECE, David. Explicating Dynamic Capabilities: The Nature and Microfoundations of (Sustainable) Enterprise Performance. Strategic Management Journal, v. 28, p. 1319-1350, 2007.

TEECE, David; PISANO, Gary; SHUEN, Amy. Dynamic Capabilities and Strategic Management. Strategic Management Journal, v. 18, n. 7, p. 509-533, 1997.

THOMAS, James B.; CLARK, Shawn M.;GIOIA, Dennis A. Strategic sensemaking and organizational performance: Linkages among scanning, interpretation, action and outcomes. Academy of Management Journal, 36, p. 239-270, 1993.

TIDD, J.; BESSANT, J.; PAVITT, K. Managing Innovation - Integrating Technological, Market and Organizational Change. John Wiley \& Sons, Chichester, 2005.

VASCONCELLOS, Eduardo; DINIZ, J. H. Inteligência Tecnológica: Modelo Conceitual e Aplicação. In: Simpósio de Gestão da Inovação Tecnológica, 21, 2000, São Paulo. Anais eletrônicos... São Paulo: PGT-USP, 2000.

VASCONCELLOS, Eduardo; MONTEROSSI, J. O.; BRUNO, Marcos A. C. Identification of Technological Threats and Opportunities: Conceptual Framework and Application an Autoparts Company. In: International Conference on Management of Technology, 16., 2007, Florida. Anais eletrônicos... Florida: IAMOT, 2007.

VASCONCELLOS, Eduardo; WAACK, Roberto da S.; PEREIRA, Ronan de F. Auditoria Tecnológica da Empresa: um estudo de caso. Revista de Administração, v. 25, n. 1, p. 3240, 1990.

VON HIPPEL, Eric; VON KROGH, Georg. Open Source Software and the "PrivateCollective” Innovation Model: Issues for Organization Science. Organization Science, v. 14, p. 209-223, 2003.

VOUK, M. A. Cloud computing - issues, research and implementations. Journal of Computing and Information Technology. v.16, n, 4, p. 235-246, 2008. 
WEICK. Carl. Sensemaking in Organizations. London: Sage, 1995.

WERNERFELT, Birger. A Resource-based View of the Firm. Strategic Management Journal, v. 5, p. 171-180, 1984.

WHALEN, Philip. J. Strategic and technology planning on a roadmapping foundation. Research Technology Management, v. 50, n. 3, p. 40-51, 2007.

WRIGHT, J.T.C.; GIOVINAZZO, R.A. Delphi - uma ferramenta de apoio ao planejamento prospectivo. Caderno de Pesquisas em Administração, v. 1, p. 54-65, 2000.

WRIGHT, J. T. C.; SPERS, R. G. O país no futuro: aspectos metodológicos e cenários. Estudos Avançados, v. 20, n. 56, p. 13-28, 2006.

YIN, R. K. Case Study Research. Design and Methods. California, Sage Publications, 2003.

ZOTT, C.; AMIT, R. Business Model Design: An Activity System Perspective. Long Rage Planning, v. 43, p. 216-226, 2010. 


\section{ANEXO A - ROTEIRO DE ENTREVISTA}

\section{DADOS DO RESPONDENTE}

a) Nome do Respondente

b) E-mail

c) Telefone

d) Nível hierárquico

e) Área

\section{QUESTÕES GERAIS SOBRE A EMPRESA}

a) Nome da Empresa

b) Ano de Fundação

c) Número Funcionários

\section{QUESTÕES SOBRE ROADMAP DE PRODUTO}

1. Quais os maiores desafios que a empresa enfrenta com relação à evolução de seus produtos?

2. Quais as maiores oportunidades e ameaças tecnológicas para a empresa atualmente?

3. A empresa realiza atividades de roadmap? Apenas para produto ou para tecnologias gerais que serão utilizadas também?

4. Quantos roadmaps vigentes a empresa possui? Para quais produtos?

5. Com que periodicidade o Roadmap é atualizado ou elaborado?

6. Qual o horizonte de tempo utilizado na elaboração dos Roadmaps? 
7. Avalie o grau de importância das seguintes fontes de informação para a empresa na elaboração do Roadmap:

\begin{tabular}{|l|l|l|l|l|l|l|l|l|}
\multicolumn{1}{c}{} & \multicolumn{1}{c}{$\begin{array}{l}\text { Pouco } \\
\text { Importante }\end{array}$} \\
\hline \multicolumn{1}{|c|}{ Fonte de Informação } & $0 *$ & 1 & 2 & 3 & 4 & 5 & 6 & 7 \\
\hline Altos executivos da empresa & & & & & & & & \\
\hline $\begin{array}{l}\text { Funcionários (exceto executivos) } \\
\text { da área de TI }\end{array}$ & & & & & & & & \\
\hline $\begin{array}{l}\text { Funcionários (exceto executivos) } \\
\text { da área de marketing }\end{array}$ & & & & & & & & \\
\hline Funcionários de outras áreas & & & & & & & & \\
\hline Clientes / usuários & & & & & & & & \\
\hline Concorrentes acadêmicas & & & & & & & & \\
\hline Fornecedores & & & & & & & & \\
\hline $\begin{array}{l}\text { Publicações } \\
\text { conferências científicas }\end{array}$ & & & & & & & & \\
\hline Jornais/revistas impressas & & & & & & & & \\
\hline Internet / Newsletters & & & & & & & & \\
\hline Patentes/registros de software & & & & & & & \\
\hline Feiras/eventos de negócios & & & & & & & \\
\hline Universidades informações / & & & & & & & & \\
\hline $\begin{array}{l}\text { Provedores de } \\
\text { empresas de pesquisas }\end{array}$ & & & & & & & \\
\hline Relatórios do mercado de capitais & & & & & & & & \\
\hline $\begin{array}{l}\text { Governo (legislação, estudos } \\
\text { setoriais) }\end{array}$ & & & & & & & \\
\hline Associações / Comitês setoriais & & & & & & & & \\
\hline$*$ o zero indica que a fonte de informação não é utilizada pela empresa & & \\
\hline
\end{tabular}

Caso existam outras fontes de informação, por favor indique abaixo:

\begin{tabular}{|c|c|c|c|c|c|c|c|}
\multicolumn{1}{c}{} & \multicolumn{3}{l}{$\begin{array}{l}\text { Pouco } \\
\text { Importante }\end{array}$} \\
\hline Fonte de Informação & 1 & 2 & 3 & 4 & 5 & 6 & 7 \\
\hline & & & & & & & \\
\hline & & & & & & & \\
\hline & & & & & & & \\
\hline & & & & & & & \\
\hline
\end{tabular}


8. Tendo em vista os objetivos do Roadmap (e de seu processo de elaboração), avalie a importância dos itens abaixo:

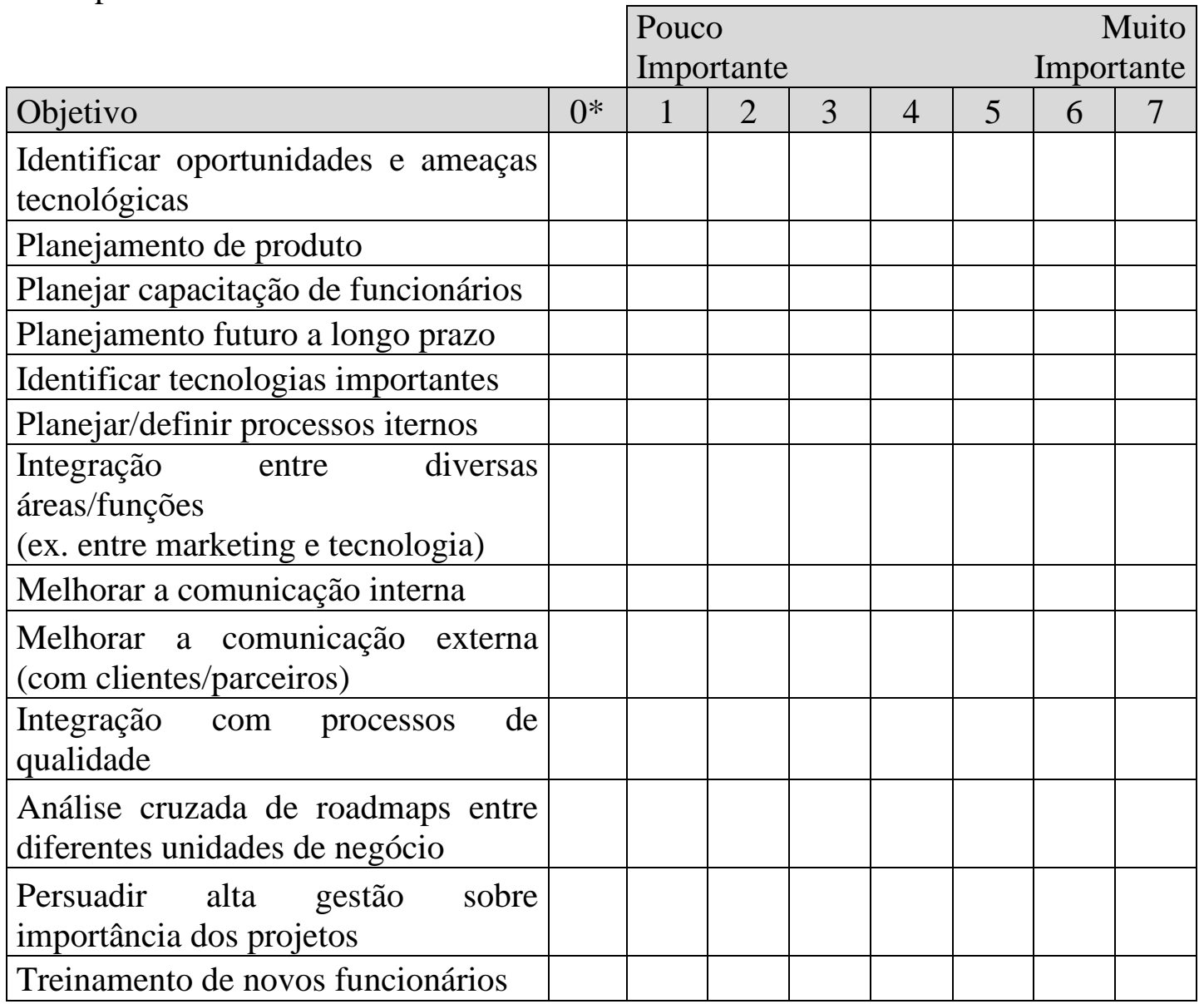

* o zero indica que o item não é um dos objetivos do Roadmap

Caso existam outros objetivos, por favor indique abaixo:

\begin{tabular}{|l|l|l|l|l|l|l|l|}
\cline { 2 - 9 } \multicolumn{1}{c|}{} & \multicolumn{9}{l}{$\begin{array}{l}\text { Muco } \\
\text { Importante }\end{array}$} \\
\hline Objetivo & 1 & 2 & 3 & 4 & 5 & 6 & 7 \\
\hline & & & & & & & \\
\hline & & & & & & & \\
\hline & & & & & & & \\
\hline
\end{tabular}


9. Assinale qual das figuras abaixo mais se aproxima do modelo de Roadmap adotado pela empresa

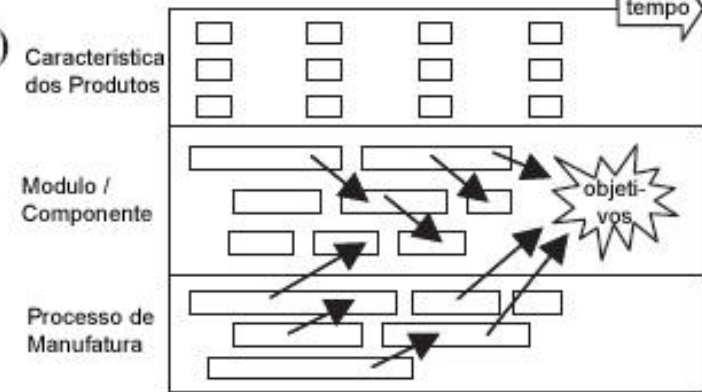

c)

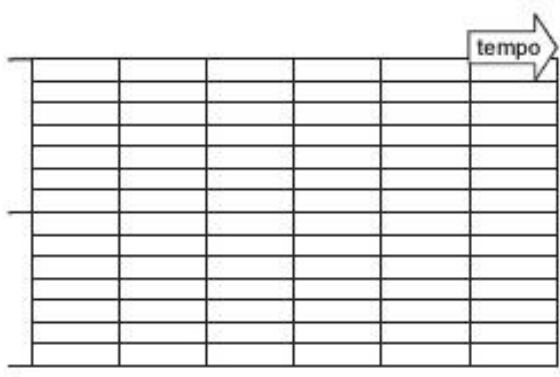

e)

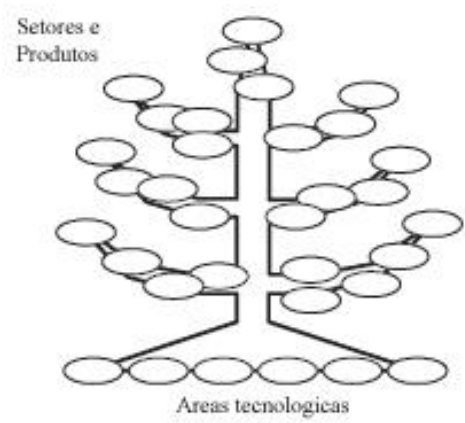

b)

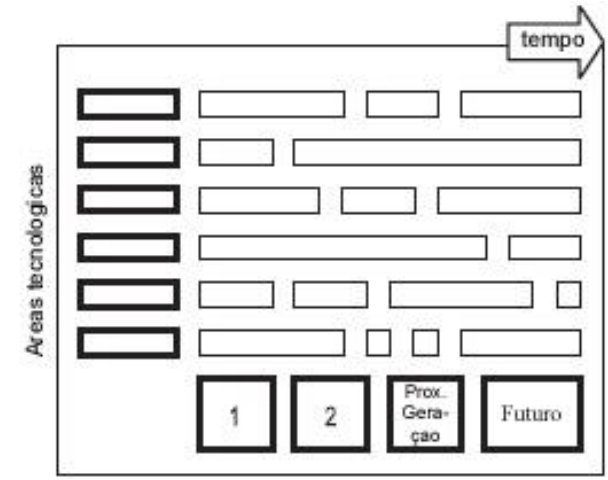

d)

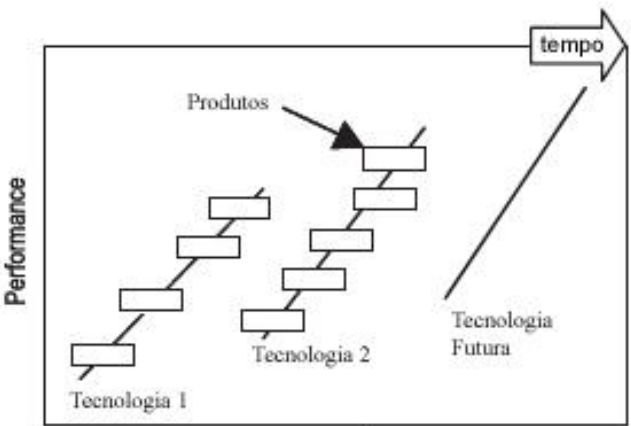

f)

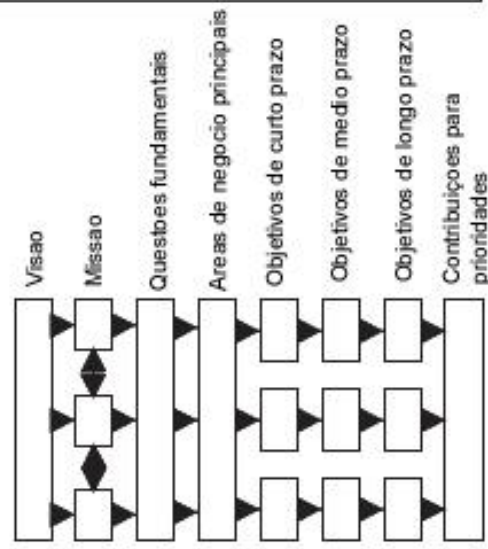

10. É possível fornecer uma amostra do roadmap da empresa? 
11. Assinale o grau de importância dos componentes abaixo no Roadmap adotado pela empresa (por componente, entende-se que o item faz parte do Roadmap, seja no gráfico ou em um documento anexo explicativo):

\begin{tabular}{|c|c|c|c|c|c|c|c|c|}
\hline & & & & & & & Imp & $\begin{array}{l}\text { Iuito } \\
\text { tante }\end{array}$ \\
\hline Componente & $0 *$ & 1 & 2 & 3 & 4 & 5 & 6 & 7 \\
\hline Aspectos so & ore $\mathrm{N}$ & Ierca & & & & & & \\
\hline Identificação de Segmentos de mercado & & & & & & & & \\
\hline Análise dos Competidores & & & & & & & & \\
\hline Tendências de mercado & & & & & & & & \\
\hline Padrões da indústria & & & & & & & & \\
\hline Ações governamentais/regulatórias & & & & & & & & \\
\hline Necessidades dos consumidores & & & & & & & & \\
\hline Outros (quais): & & & & & & & & \\
\hline & & & & & & & & \\
\hline Aspectos so & hre F & rodu & & & & & & \\
\hline $\begin{array}{l}\text { Início e término do desenvolvimento de } \\
\text { produtos }\end{array}$ & Uic & 100 & & & & & & \\
\hline $\begin{array}{l}\text { Data de lançamento e retirada do produto do } \\
\text { mercado }\end{array}$ & & & & & & & & \\
\hline Atributos/características do produto & & & & & & & & \\
\hline Outros (quais): & & & & & & & & \\
\hline & & & & & & & & \\
\hline Aspectos sob & e Te & cnols & & & & & & \\
\hline Custo futuro da(s) tecnologia(s) utilizada(s) & & & & & & & & \\
\hline $\begin{array}{lllll}\text { Início e fim do desenvolvimento } & \text { da } \\
\text { tecnologia } & & & & \\
\end{array}$ & & & & & & & & \\
\hline $\begin{array}{llll}\begin{array}{l}\text { Pontos de } \\
\text { alternativas }\end{array} & \text { decisão } & \text { sobre tecnologias } \\
\end{array}$ & & & & & & & & \\
\hline $\begin{array}{l}\text { Início e término da disponibilidade da } \\
\text { tecnologia no mercado }\end{array}$ & & & & & & & & \\
\hline Roadmaps de fornecedores/parceiros críticos & & & & & & & & \\
\hline Outros (quais): & & & & & & & & \\
\hline & & & & & & & & \\
\hline & & & & & & & & \\
\hline Outros & ispec & tos & & & & & & \\
\hline $\begin{array}{l}\text { Análise sobre a estratégia de negócios da } \\
\text { empresa }\end{array}$ & & & & & & & & \\
\hline Plano de ação & & & & & & & & \\
\hline Análise de Riscos & & & & & & & & \\
\hline Outros (quais): & & & & & & & & \\
\hline & & & & & & & & \\
\hline
\end{tabular}

* o zero indica que o item não é um dos componentes do Roadmap 
12. Assinale o grau de relevância das barreiras/dificuldades abaixo na elaboração do Roadmap:

\begin{tabular}{|c|c|c|c|c|c|c|c|c|}
\hline \multirow{2}{*}{ Barreira / Dificuldade } & \multirow[b]{2}{*}{$0 *$} & \multicolumn{5}{|c|}{$\begin{array}{l}\text { Pouco } \\
\text { Relevante }\end{array}$} & \multicolumn{2}{|c|}{$\begin{array}{r}\text { Muito } \\
\text { Relevante }\end{array}$} \\
\hline & & 1 & 2 & 3 & 4 & 5 & 6 & 7 \\
\hline Cultura da empresa & & & & & & & & \\
\hline Desconhecimento da ferramenta & & & & & & & & \\
\hline Comprometimento dos executivos & & & & & & & & \\
\hline Subestimar o esforço para fazer o roadmap & & & & & & & & \\
\hline $\begin{array}{l}\text { Tempo disponível para se dedicar ao } \\
\text { roadmap }\end{array}$ & & & & & & & & \\
\hline Vazamento de informação & & & & & & & & \\
\hline Falta de visão de futuro & & & & & & & & \\
\hline Dificuldade de obtenção das informações & & & & & & & & \\
\hline Manter o Roadmap atualizado & & & & & & & & \\
\hline $\begin{array}{l}\text { Dificuldade de colocar em prática o } \\
\text { roadmap }\end{array}$ & & & & & & & & \\
\hline Chegar a um acordo sobre prioridades & & & & & & & & \\
\hline $\begin{array}{l}\text { Gerenciar mudanças após o roadmap ser } \\
\text { aprovado }\end{array}$ & & & & & & & & \\
\hline $\begin{array}{|llll|}\begin{array}{l}\text { Dificuldade de prever a evolução } \\
\text { tecnológica }\end{array} & & \\
\end{array}$ & & & & & & & & \\
\hline $\begin{array}{l}\text { Dificuldade de identificar as características } \\
\text { do produto importantes para o futuro }\end{array}$ & & & & & & & & \\
\hline
\end{tabular}

* o zero indica que o item não é uma barreira / dificuldade do Roadmap

Caso existam outras barreiras/dificuldades na elaboração do Roadmap, indique abaixo:

\begin{tabular}{|c|c|c|c|c|c|c|c|}
\cline { 2 - 9 } \multicolumn{1}{c|}{} & \multicolumn{9}{l}{ Pouco Importante } & \multicolumn{5}{c|}{ Muito Importante } \\
\hline Barreira/Dificuldade & 1 & 2 & 3 & 4 & 5 & 6 & 7 \\
\hline & & & & & & & \\
\hline & & & & & & & \\
\hline & & & & & & & \\
\hline & & & & & & & \\
\hline
\end{tabular}


13. Assinale o grau de importância dos benefícios abaixo com a adoção de Roadmap pela empresa:

\begin{tabular}{|l|l|l|l|l|l|l|l|l|}
\cline { 2 - 7 } \multicolumn{2}{c}{} & \multicolumn{1}{l}{$\begin{array}{l}\text { Pouco } \\
\text { Importante }\end{array}$} \\
\hline \multicolumn{1}{|c|}{ Benefício } & 0 * & 1 & 2 & 3 & 4 & 5 & 6 & 7 \\
\hline $\begin{array}{l}\text { Ligar a estratégia a planos de } \\
\text { produto e tecnologia }\end{array}$ & & & & & & & \\
\hline $\begin{array}{l}\text { Possibilitar planos de tecnologia } \\
\text { corporativos }\end{array}$ & & & & & & & & \\
\hline $\begin{array}{l}\text { Construção de visão de longo prazo } \\
\text { ligando produto e tecnologia }\end{array}$ & & & & & & & & \\
\hline $\begin{array}{l}\text { Estímulo ao aprendizado inter- } \\
\text { funcional }\end{array}$ & & & & & & & & \\
\hline Melhora da comunicação & & & & & & & & \\
\hline Melhoria do time-to-market & & & & & & & & \\
\hline $\begin{array}{l}\text { Melhoria do planejamento do } \\
\text { investimento }\end{array}$ & & & & & & & \\
\hline $\begin{array}{l}\text { Melhora o planejamento sobre } \\
\text { prioridades da empresa }\end{array}$ & & & & & & & & \\
\hline $\begin{array}{l}\text { Transferência de conhecimento na } \\
\text { Cadeia de Suprimentos }\end{array}$ & & & & & & & & \\
\hline Melhor Gestão de Riscos & & & & & & & & \\
\hline $\begin{array}{l}\text { Reuso de tecnologia / reduzir } \\
\text { duplicidades de esforços }\end{array}$ & & & & & & & \\
\hline $\begin{array}{l}\text { Visão compartilhada das próximas } \\
\text { implementações }\end{array}$ & & & & & & & & \\
\hline
\end{tabular}

* o zero indica que o item não é um benefício do Roadmap

Caso existam outros benefícios do Roadmap, indique abaixo:

\begin{tabular}{|c|c|c|c|c|c|c|c|}
\cline { 2 - 9 } \multicolumn{1}{c|}{} & \multicolumn{9}{c}{ Pouco Importante } & \multicolumn{6}{c|}{ Muito Importante } \\
\hline & 1 & 2 & 3 & 4 & 5 & 6 & 7 \\
\hline Benefício & & & & & & & \\
\hline & & & & & & & \\
\hline & & & & & & & \\
\hline & & & & & & & \\
\hline
\end{tabular}

14. O roadmap é planejado apenas tendo em vista o Brasil, ou existe a preocupação com a internacionalização dos produtos? Quais os impactos da internacionalização sobre o roadmap?

15. Quais as etapas do processo de roadmap adotado pela empresa?

16. A empresa realiza uma etapa de planejamento para elaboração do roadmap? Quais as atividades e áreas responsáveis?

17. Quais as atividades executadas pela empresa para análise de mercado? (identificar as áreas responsáveis por cada atividade) 
18. Quais as atividades executadas pela empresa para análise de produtos? (identificar as áreas responsáveis por cada atividade)

19. Quais as atividades executadas pela empresa para análise de tecnologias? (identificar as áreas responsáveis por cada atividade)

20. Quais as tecnologias importantes analisadas ou monitoradas pela empresa e que podem gerar algum impacto no roadmap?

21. Como a empresa obtém as idéias sobre novas necessidades/funcionalidades em seus produtos?

22. Quais análises são realizadas pra avaliar as idéias geradas para o roadmap? (identificar as etapas de análise)

23. Como a empresa prioriza as idéias e define quais serão implementadas em cada versão de seus produtos?

24. Como a empresa valida a versão final dos roadmaps? Quem são os envolvidos? Quais as etapas?

25. Como o roadmap é comunicado internamente na empresa?

26. O roadmap é comunicado externamente?

Se sim, para quem (clientes, parceiros, etc) e como?

27. Como a empresa controla a numeração de versão dos produtos?

28. Que tipos diferentes de implementações a empresa utiliza? (versões, releases, patches, etc)

29. Como a empresa distribui as correções para os clientes?

30. Como a empresa controla as versões dos produtos instalados em cada cliente? 